RICARDO PATRICIO ÁLVAREZ BRICEÑO

\title{
PROJETO E ANÁLISE DE DISPOSITIVO DINÂMICO PARA O ESTUDO DAS VIBRAÇÕES INDUZIDAS POR ESCOAMENTOS BIFÁSICOS
}




\section{PROJETO E ANÁLISE DE DISPOSITIVO \\ DINÂMICO PARA O ESTUDO DAS \\ VIBRAÇÕES INDUZIDAS POR \\ ESCOAMENTOS BIFÁSICOS}

Dissertação apresentada à Escola de Engenharia de São Carlos da Universidade de São Paulo, como parte dos requisitos para a obtenção do Título de Mestre em Engenharia Mecânica

Área de Concentração:

Dinâmica das Máquinas e Sistemas

ORIENTADOR: Prof. Dr. Leopoldo P. R. de Oliveira

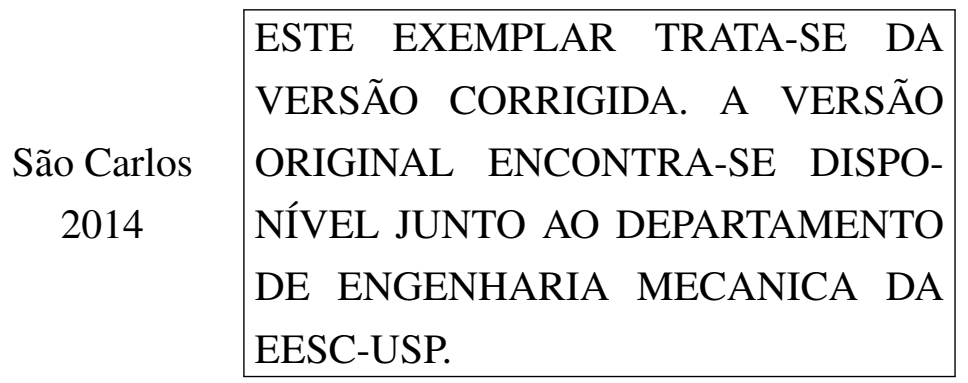


AUTORIZO A REPRODUÇÃO TOTAL OU PARCIAL DESTE TRABALHO, POR QUALQUER MEIO CONVENCIONAL OU ELETRÔNICO, PARA FINS DE ESTUDO E PESQUISA, DESDE QUE CITADA A FONTE.

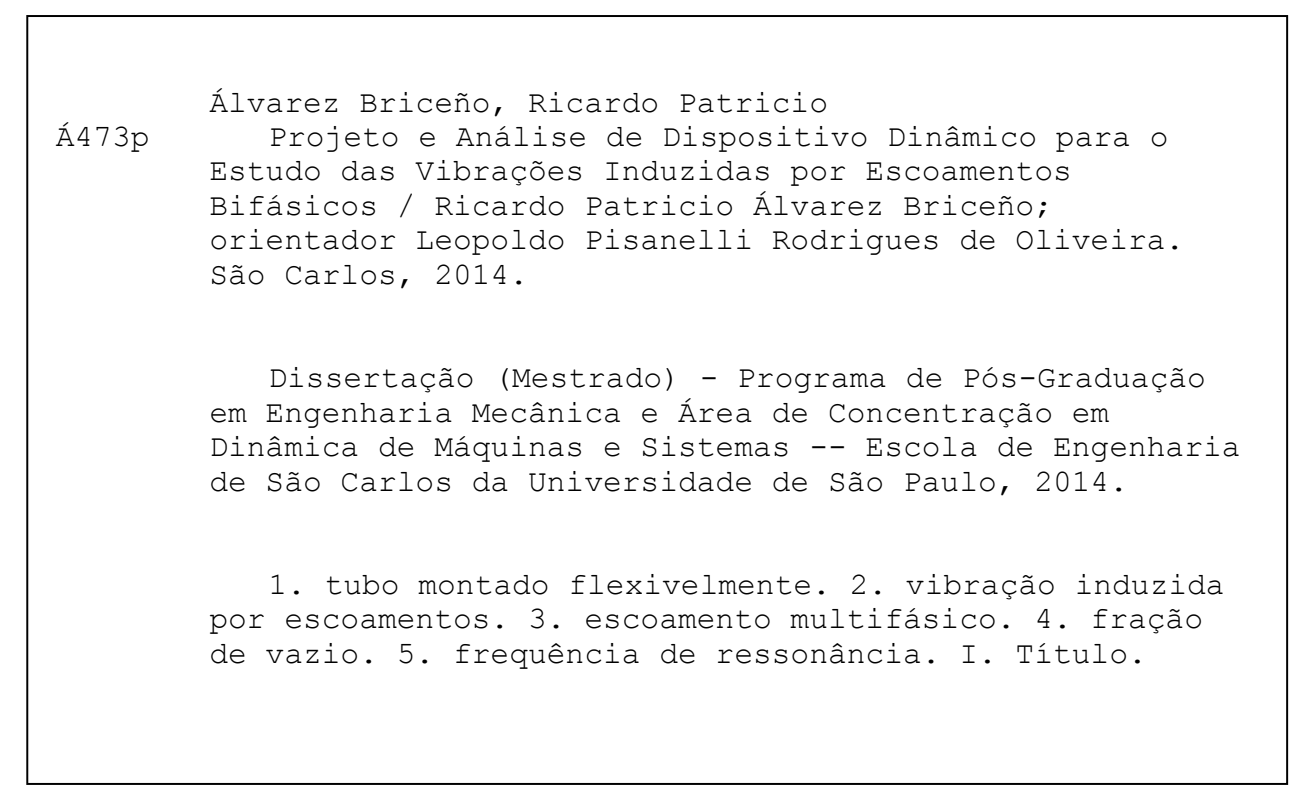


FOLHA DE JULGAMENTO

Candidato: Engenheiro RICARDO PATRICIO ALVAREZ BRICEÑO.

Título da dissertação: "Projeto e análise de dispositivo dinâmico para o estudo das vibrações induzidas por escoamentos bifásicos".

Data da defesa: 30/05/2014

\section{Comissão Julgadora:}

Prof. Dr. Leopoldo Pisanelli Rodrigues de Oliveira

(Orientador)

(Escola de Engenharia de São Carlos/EESC)

Prof. Titular José Elias Laier

(Escola de Engenharia de São Carlos/EESC)
Resultado:

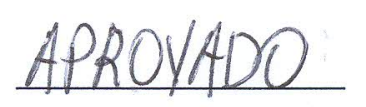

Prof. Dr. Paulo José Paupitz Gonçalves

(Universidade Estadual Paulista "Júlio de Mesquita Filho"/UNESP-Bauru)

APROUADO

Coordenador do Programa de Pós-Graduação em Engenheira Mecânica: Prof. Associado Marcelo Areias Trindade

Presidente da Comissão de Pós-Graduação:

Prof. Titular Denis Vinicius Coury 
Dedico esse trabalho a Deus e aos meus pais Ricardo e Anita, aos quais eu devo tudo. 
”Toda meta que se haya alcanzado jamás comenzó con apenas un solo paso. . y la creencia de que se podía alcanzar. Si la senda se torna difícil de transitar y parecería que nunca jamás llegarás al final... busca en lo profundo de tu corazón y hallarás una fortaleza que no sabías tener. Cree en ti... y recuerda que es posible que los sueños se tornen realidad" Jason Blume (Un regalo de mis queridos amigos el día que comenzó esta aventura.) 


\section{Agradecimentos}

Ao Prof. Dr. Leopoldo P. R. de Oliveira pela adequada orientação do presente trabalho, pela paciencia, pelo tempo brindado e pela confiança depositada em mim desde o primeiro dia.

À SENESCYT (Secretaría Nacional de Educación Superior, Ciencia, Tecnología e Innovación - Equador) e ao CNPq (Conselho Nacional de Desenvolvimento Científico e Tecnológico) pelo apoio financeiro brindado.

Ao projeto Universal do CNPq sob coordenação do Prof. Dr. Gherhardt Ribatski.

Aos professores do programa da Pós-Graduação em Engenharia Mecânica, pelos conhecimentos transmitidos nas aulas e fora de elas.

Aos funcionários do Laboratório da Dinâmica, especialmente ao Diego Antonietti e aos funcionários da oficina mecânica, os quais usinaram as peças da estrutura projetada nesse trabalho.

Ao Fabio Toshio Kanizawa, pela construção da bancada experimental, pela ajuda na realização dos testes apresentados nesse trabalho e pelas constantes sugestões feitas.

Aos meus caros amigos equatorianos, Diego e Juan, pelo carinho, pelo seu apoio incondicional, por cada experiência nova, por construir um pedaço de Equador em São Carlos e por ser meus irmãos nesta grande aventura.

À Camila, pelo seu carinho, paciência e bons momentos vividos.

À turma do Laboratório da Dinâmica, pela simplicidade, os conselhos e sugestões ao presente trabalho. Obrigado pela camaradagem...p por ser além de colegas uns bons amigos. "É NOIS!"

Aos meus pais Ricardo e Anita, exemplo de tenacidade e responsabilidade. Obrigado pelo seu apoio incondicional, por sempre acreditar em mim... nada disto seria possível sem a sua ajuda. À minha irmã Heysel, pelo seu apoio e a sua alegria. Obrigado família, porque sempre pude sentir seu carinho apesar da distância.

Aos meus caros amigos no Equador, por sempre ficar atrás de mim, pelo seu apoio, por nunca me deixar sozinho.

Ao Prof. Dr. Víctor Guerrero, quem tem muito a ver com tudo isto. Obrigado pelos seus conselhos, pelo seu bom exemplo e por criar a curiosidade da pos- graduação em mim. 


\section{Resumo}

\section{ÁLVAREZ BRICEÑO, R. P. Projeto e análise de dispositivo dinâmico para o estudo das}

vibrações induzidas por escoamentos bifásicos. 2014. 121 f. Dissertação (Mestrado) - Departamento de Engenharia Mecânica, Escola de Engenharia de São Carlos, Universidade de São Paulo, São Carlos, 2014.

As Vibrações Induzidas por Escoamentos (VIEs) são dos problemas dinâmicos mais importantes no projeto de trocadores de calor de tipo carcaça e tubos. Esta interação fluido - estrutura pode gerar vibrações de grande amplitude dos tubos ou partes internas do equipamento, o que pode provocar o impacto entre componentes e até falha por fadiga. Várias bancadas experimentais têm sido construídas para o estudo desta interação fluido - estrutura, no entanto, alguns mecanismos de vibração, principalmente aqueles relacionados com escoamentos bifásicos, não são completamente compreendidos. Portanto, neste trabalho, o projeto de uma estrutura dinâmica para o estudo das vibrações induzidas por escoamento bifásico é apresentado. Esta estrutura é composta por um sistema de fios de aço tensionados que permitem que a primeira frequência de ressonância do tubo seja sintonizada. O tubo instrumentado foi instalado numa seção de testes de tubos rígidos em configuração triangular normal com uma razão de passo transversal e diâmetro de 1,26. Os resultados experimentais foram contrastados com uma modelagem teórica desenvolvida para esta estrutura dinâmica. Pôde-se verificar que a primeira frequência de ressonância e seu fator de amortecimento coincidem com os valores estimados pelo modelo, enquanto que a segunda frequência de ressonância apresenta valor teórico 6,6\% maior do que o experimental. A seguir, um estudo experimental no ar foi desenvolvido para o reconhecimento dos modos de vibração e as frequências de ressonância da estrutura dinâmica. $\mathrm{O}$ fator de amortecimento no ar também foi estimado, o método de Kennedy - Pancu combinado com o algoritmo ERA foi usado para este fim. Assim que a primeira frequência de ressonância foi reconhecida e sintonizada, testes em escoamentos de água foram realizados. A influência da velocidade do escoamento monofásico de água na amplitude de vibração e nas características da Densidade Espectral (PSD) de aceleração foi analisada. Finalmente, testes em escoamento bifásico foram feitos, a sensibilidade do tubo ao escoamento bifásico fica evidente quando analisadas as amplitudes nas PSDs. Além disso, a influência da fração de vazio na amplitude de vibração e no fator de amortecimento foi revisada, no entanto, resultados de estudos anteriores não foram conferidos pelo alto amortecimento concentrado introduzido por alguns elementos 
construtivos utilizados.

Palavras-chave: tubo montado flexivelmente, vibração induzida por escoamentos, escoamento multifásico, fração de vazio, frequência de ressonância. 


\section{Abstract}

\section{ÁLVAREZ BRICEÑO, R. P. Design and Analysis of a Dynamic Structure for the Study of}

Multiphase Flow Induced Vibration. 2014. 121p. Dissertation (Master Degree) - Department of Mechanical Engineering, São Carlos School of Engineering, University of São Paulo, São Carlos, 2014.

Flow - Induced Vibration (FIV) is the most critical dynamic issue in the design of heat exchangers. This fluid - structure phenomenon may generate high amplitude vibration of tubes or structural parts, which may lead to impacts between internal components or even failure due to fatigue. Many test benches have been constructed to study this fluid - structure interactions, however, some vibration mechanisms, mostly those related to multiphase flow, are not yet fully understood. Therefore, in this work, the design of a dynamic structure for the study of multiphase flow induced vibration is presented. This structure is composed by a system of tensioned piano wires that allow the first natural frequency of the instrumented tube to be calibrated. The tube was installed in a rigid bundle configured in a normal triangular pattern with pitch-todiameter ratio of 1.26. Then, an experimental study in air environment was performed aiming at addressing the mode shapes and resonance frequencies of the dynamic structure. The damping ratio in air environment was also estimated, the Kennedy - Pancu method in combination with the Eigensystem Realization Algorithm have been used to that purpose. Experimental results in air were compared with a theoretical model. The first resonance frequency and its damping factor presented a good agreement with the model, while the second resonance frequency deviated some $6,6 \%$ from the predicted value. Tests in water and multiphase flow were also performed. The influence of water flow velocity on vibration amplitudes and on the Power Spectrum Densities (PSDs) has been analyzed. Finally, tests for two - phase water/air flow were carried out; the tube sensitivity to multiphase flow is evident when the vibration level in acceleration PSDs is by analyzed. Also, the influence of void fraction on vibration amplitude and damping ratio

have been addressed, however, previous studies could not be validated due to the high damping introduced by some constructive elements of the structure.

Keywords: flexible mounted tube, flow - induced vibration, multiphase flow, void fraction resonance frequency. 


\section{Sumário}

Lista de Figuras $\quad$ xi

Lista de Tabelas $\quad$ xvii

Lista de Símbolos $\quad$ xix

1 Introdução 1

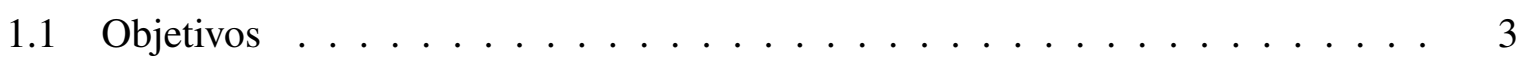

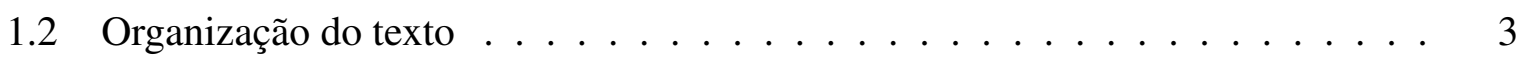

2 Vibrações induzidas por escoamento externo cruzado 5

2.1 Vibração induzida por desprendimento de vórtices . . . . . . . . . . . . . . 7

2.1.1 Desprendimento alternado de vórtices num cilindro estacionário em escoamento monofásico . . . . . . . . . . . . . 7

2.1.2 Sincronização acompanhada de desprendimento alternado de vórtices ou desprendimento simétrico de vórtices . . . . . . . . . . . . . . 11

2.1.3 Efeitos da vibração do cilindro no desprendimento de vórtices . . . . . 11

Correlação longitudinal da esteira e força dos vórtices . . . . . . . . . 11

Sincronização . . . . . . . . . . . . . . . . . . . 12

Padrão e simetria dos vórtices na esteira do tubo . . . . . . . . . . . 12

Força de arrasto sobre o cilindro . . . . . . . . . . . . . . . 13

2.1.4 Desprendimento de vórtices em bancos de cilindros . . . . . . . . . . . . 14

Escoamento uniforme . . . . . . . . . . . . . . . . . . . 14

Escoamento não uniforme . . . . . . . . . . . . . . . . . 15

2.1.5 Desprendimento de vórtices em escoamento bifásico . . . . . . . . . . 16

2.2 Vibração aleatória induzida pela turbulência do escoamento . . . . . . . . . . . 21

2.2.1 Vibração aleatória de um cilindro em escoamento monofásico . . . . . 21

2.2.2 Vibração aleatória induzida por escoamento monofásico num banco de

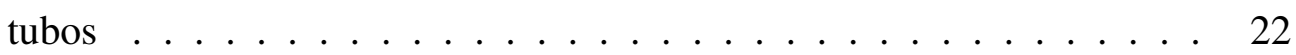

2.2.3 Vibração aleatória de um cilindro em escoamento bifásico . . . . . . . 23

2.3 Vibração induzida por escoamento oscilatório . . . . . . . . . . . . . . . . . . 24

2.3.1 Força inercial e força de arrasto . . . . . . . . . . . . . . . . . 24 
2.3.2 Movimento paralelo ao escoamento . . . . . . . . . . . . . 26

Equação de movimento do cilindro na direção paralela ao escoamento . 26

Soluções lineares . . . . . . . . . . . . . . . . . . . . . . . . 28

Resposta paralela de estruturas continuas . . . . . . . . . . . 31

2.3.3 Força transversal e resposta de um cilindro . . . . . . . . . . . . 32

2.4 Instabilidade fluido-elástica . . . . . . . . . . . . . . . . . . . 34

2.4.1 Descrição da instabilidade fluido-elástica . . . . . . . . . . . . . 34

2.4.2 Teoria da instabilidade fluido-elástica . . . . . . . . . . . . . 39

Mecanismo de deslocamento . . . . . . . . . . . . . . . . 40

Mecanismo de velocidade . . . . . . . . . . . . . . . . 42

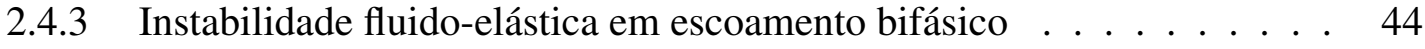

3 Projeto da estrutura dinâmica 49

3.1 Características gerais de uma bancada experimental para o estudo das VIE . . . 49

3.1 .1 Tipos e material dos tubos . . . . . . . . . . . . . . . . 49

3.1 .2 Configuração da bancada de tubos . . . . . . . . . . . . . 50

3.1.3 Parâmetros do escoamento . . . . . . . . . . . . . . . . 50

3.1.4 Suspensão dos tubos na seção de testes . . . . . . . . . . . . . . 53

3.2 Revisão das bancadas experimentais de estudos anteriores . . . . . . . . . . . 55

3.3 Características da seção de testes da bancada experimental . . . . . . . . . 63

3.4 Projeto da estrutura dinâmica . . . . . . . . . . . . . . . . . . 66

3.4.1 Antecedentes . . . . . . . . . . . . . . . 66

3.4 .2 Porta-acelerômetros . . . . . . . . . . . . . . . . 66

3.4.3 Tampa do porta-acelerômetros . . . . . . . . . . . . . 68

3.4.4 Sistema de tensionamento dos fios de aço . . . . . . . . . . . . 69

3.4 .5 Tubo . . . . . . . . . . . . . . . . . 74

3.4 .6 Vedação da estrutura dinâmica . . . . . . . . . . . . . . . . 74

3.4.7 Montagem da estrutura dinâmica . . . . . . . . . . . . . . 75

4 Modelagem da estrutura dinâmica $\quad 77$

5 Análise experimental da estrutura dinâmica $\quad 83$

5.1 Procedimento . . . . . . . . . . . . . . . . . . 83

5.2 Instrumentação . . . . . . . . . . . . . . . . . . . . 85

5.3 Resultados de testes dinâmicos no ar . . . . . . . . . . . . . . 85

5.3.1 Medições das Funções de Resposta em Frequência . . . . . . . . . . . . . . 85

5.3.2 Cálculo do amortecimento . . . . . . . . . . . . . . . . . . 89

5.3.3 Comparação com o modelo teórico . . . . . . . . . . . . . . . 91

5.4 Resultados de testes dinâmicos em escoamento monofásico de água e escoamento bifásico água - ar . . . . . . . . . . . . . . . . . . . . . 96 
5.4.1 Resposta do tubo . . . . . . . . . . . . . . . . . 96

Escoamento monofásico de água . . . . . . . . . . . . . . . . 96

Escoamento bifásico . . . . . . . . . . . . . . . . . . 99

5.4.2 Cálculo do amortecimento . . . . . . . . . . . . . . . . 111

6 Conclusões e sugestões para trabalhos futuros 115

6.1 Conclusões . . . . . . . . . . . . . . . . . . . . . 115

6.2 Sugestões para trabalhos futuros . . . . . . . . . . . . . 117

$\begin{array}{ll}\text { Referências Bibliográficas } & 119\end{array}$ 


\section{Lista de Figuras}

2.1 Vibração induzida por escoamento de ar sobre a ponte em TacomalEE.UU . . . 6

2.2 Caminho de vórtices de Karman . . . . . . . . . . . . . . . . . . 7

2.3 Variação do número de Strouhal para diferentes acabamentos superficiais. Tomado de Lienhard (1966) . . . . . . . . . . . . . . . . . 10

2.4 Número de Strouhal para diferentes seções transversais. Tomado de Blevins (1990) . . . . . . . . . . . . . . . . . . . . 11

2.5 Mecanismos de sincronização paralela e perpendicular ao escoamento. Tomado de Kaneko et al. (2008) . . . . . . . . . . . . . . . . . . . . . . . . . . . . . 12

2.6 Faixas de sincronização de desprendimento de vórtices com um cilindro oscilando transversalmente. Resultados experimentais tomados de Koopman (1967): $\square$ para $R e=100, \bullet$ para $R e=200, \triangle$ para $R e=300$. Resultados experimentais tomados de Stansby (1976): $\mathbf{\square}$ para $R e=3600$, o para $R e=9200$. . . . .

2.7 Faixas de sincronização sub-harmônicas para um cilindro. Tomado de Olinger e Sreenivasan (1988) f . . . . . . . . . . . . . . . . . . . . 13

2.8 Desprendimento de vórtices atrás de um cilindro transversalmente à direção principal do escoamento no ponto de ressonância, $R e=190$. Tomado de Griffin e Ramberg (1974) . . . . . . . . . . . . . . . . . . . . . . . . . 14

2.9 Mapa do número de Strouhal para bancos de cilindros em linha. Tomado de Kaneko et al. (2008) . . . . . . . . . . . . . . . . . . 15

2.10 Mapa do número de Strouhal para bancos de cilindros em configuração triangular. Tomado de Kaneko et al. (2008) . . . . . . . . . . . . . . . . . . . . 16

2.11 Deslocamento do tubo num banco quadrado normal em função da velocidade do escoamento entre tubos e fração de vazio. a) Direção paralela ao escoamento b) Direção perpendicular ao escoamento. Tomado de Chung e Chu (2006) . . .

2.12 Deslocamento do tubo num banco quadrado rotacionado em função da velocidade do escoamento entre tubos e fração de vazio até 50\%. a) Direção paralela ao escoamento e b) Direção perpendicular ao escoamento. Tomado de Chung e

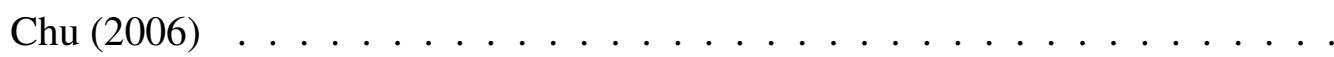


2.13 Deslocamento do tubo num banco quadrado rotacionado em função da velocidade do escoamento entre tubos e fração de vazio desde $60 \%$ até $95 \%$. a) Direção paralela ao escoamento e b) Direção perpendicular ao escoamento. Tomado de Chung e Chu (2006) . . . . . . . . . . . . . . . . . . . . . . . . . 20

2.14 Vibração induzida por escoamento bifásico para diferentes frações de vazio. Tomada de Kaneko et al. (2008)

2.15 Modelo mecânico de um cilindro dentro de um escoamento. Inspirado de Ble-

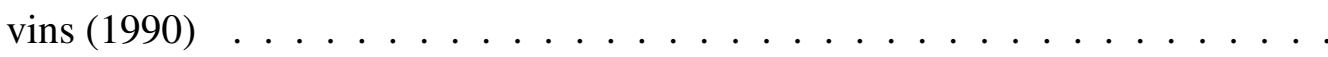

2.16 Componentes da força paralela do fluido sobre uma estrutura num escoamento oscilatório. Tomada de Blevins (1990)

2.17 Força paralela máxima sobre uma estrutura num escoamento oscilatório com uma componente principal $U_{o} \neq 0$. Tomada de Blevins (1990) . . . . . . . . .

2.18 Máxima resposta dinâmica paralela de uma estrutura de um grau de liberdade a um escoamento oscilatório. $C_{o}=C_{m}=1,5 ; \zeta_{s}=0 ; A=\pi d^{2} / 4$. Tomado de Blevins (1990) . . . . . . . . . . . . . . . . . .

2.19 Força transversal em função do tempo sobre um cilindro circular em escoamento oscilatório para vários números de Keulengan - Carpenter. Tomada de Obasaju et al. (1988) . . . . . . . . . . . . . . . . . . . . . . . . . 33

2.20 União de jatos na esteira do tubo. Tomado de Roberts (1966) . . . . . . . . . . 35

2.21 Vibração com órbita elíptica de um arranjo de tubos exposto a um escoamento. Tomado de Tanaka e Takahara (1981) . . . . . . . . . . . . . . . . . . . . . 35

2.22 Amplitude de vibração do tubo em função da velocidade do escoamento entre tubos. $\circ$ Todos os tubos livres e $\bullet$ Os tubos dos extremos fixos. $\left(m /\left(\rho d^{2}\right)=\right.$ 370). Tomado de Blevins (1990)

2.23 Resposta de arranjos de tubos a escoamento cruzado. a) Tubos de bronze em escoamento de água ((CHEN et al., 1978)) e b) Tubos de plástico em escoamento de $\operatorname{ar}(($ SOPER, 1983)) . . . . . . . . . . . . . . . . . . .

2.24 Velocidade crítica de instabilidade em escoamento monofásico. Tomado de Ble-

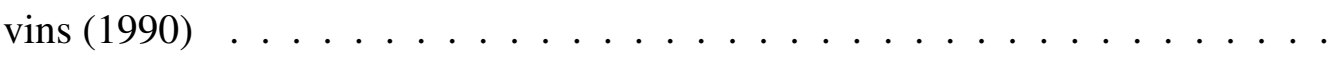

2.25 Modelo mecânico de fila de tubos (Amortecedores paralelos às molas não apresentados). Inspirado em Blevins (1990)

2.26 Resultados experimentais apresentados em Weaver e El-Kashlan (1981) para amortecimento dinâmico gerado por um fluido na direção transvversal ao escoamento num banco de tubos em configruação triangular rotacionada $P / d=1,37543$

2.27 Comparação entre valores teóricos e experimentais para instabilidade. Resultados tomados de Price e Paidoussis (1986) . . . . . . . . . . . . . . . . 
3.1 a) Tubo de superfície lisa tomado de http:Ilpt-made-in-china.comlco_cntoolpeaklproduct_ColdRoll-Precision-Stainless-Steel-Seamless-Tubes_essgnioog.html e b) tubo de superfície alhetada http:Ilwww.beca-engineering.com LowFin.html. . . . . . . . 50

3.2 Tipos de configurações de bancos de tubos. Baseado em Zukauskas e Ulinskas (1983). . . . . . . . . . . . . . . . . . 5 51

3.3 Mecanismo de suspensão de uma seção de testes para a análise das vibrações induzidas por escoamentos num túnel de vento. Tomado de Grover e Weaver (1978).

3.4 Suportes de tubos para testes de vibração. 1) Tubos de aço inoxidável, 2) suportes elásticos. Tomado de Tanaka et al. (2002)

3.5 Estrutura dinâmica proposta em Mureithi et al. (2005). 1) Tubos de aço inoxidável, 2) suportes elásticos. . . . . . . . . . . . . . . . . . 58

3.6 Estrutura dinâmica para montar o tubo na seção de testes. Tomado de Grover e Weaver (1978)． . . . . . . . . . . . . . . . . . . 59

3.7 Desenho esquemático do cilindro flexível e o seu sistema de montagem no túnel de vento. Tomado de Price et al. (1987). . . . . . . . . . . . . . . . . . . . . . 60

3.8 Desenho esquemático do cilindro flexível e o seu sistema de montagem no túnel de água. Tomado de Price et al. (1987). . . . . . . . . . . . . . . . . . . . . 61

3.9 Esquema de suspensão do tubo. Tomado de Mitra et al. (2009). . . . . . . . . . . 61

3.10 Esquema da estrutura dinâmica. Tomado de Khalifa et al. (2012). . . . . . . . . 62

3.11 Ilustração do circuito principal do aparato experimental. Tomado de Kanizawa

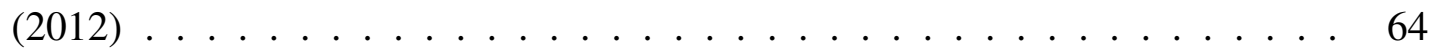

3.12 Diagrama esquemático da parede do banco de tubos. Tomado de Kanizawa (2012). 65

3.13 Detalhe das furações nas proximidades da posição destinada ao tubo flexível. Tomado de Kanizawa (2012) . . . . . . . . . . . . . . . . . . . . 65

3.14 Partes do porta-acelerômetros e seu funcionamento. . . . . . . . . . . . . . 67

3.15 Partes da tampa do porta-acelerômetros. . . . . . . . . . . . . . . . 69

3.16 Conjunto porta-acelerômetros e tampa. . . . . . . . . . . . . . . . . . 69

3.17 Sistema de tensionamento dos fios de aço . . . . . . . . . . . . . . 70

3.18 Relação entre os parâmetros $L$ e $T$ para diferentes frequências naturais do tubo instrumentado. . . . . . . . . . . . . . . . . 71

3.19 Tensões sobre os fios de aço: a) Sem escoamento e b) Sob um escoamento cruzado. 72

3.20 Vista posterior do conjunto formado pela placa e o bushing . . . . . . . . . 73

3.21 Estrutura instalada numa parede da seção de testes. . . . . . . . . . . . . . . . 74

4.1 Esquema da estrutura dinâmica no modo de vibração bouncing . . . . . . . . . 77

4.2 Esquema da estrutura dinâmica no modo de vibração bouncing . . . . . . . . . 78

4.3 Sistema de coordenadas $x_{c}-\theta$ e $x_{1}-x_{2} \ldots \ldots \ldots \ldots$ 
5.1 Diagrama da configuração para medição da FRF no ar. . . . . . . . . . . . . . 84

5.2 Configuração para medição de FRF do tubo montado na seção de testes. . . . . 84

5.3 Configuração para medição de resposta do tubo a escoamento monofásico de água e escoamento bifásico água-ar. . . . . . . . . . . . . . . . . 85

5.4 a) FRF de acelerância do tubo na direção $x$ e b) Função coerência. . . . . . . . . 86

5.5 a) FRF de acelerância do tubo na direção y e b) Função coerência. . . . . . . . . 87

5.6 a) FRF de acelerância do tubo na direção $x$ e b) Função coerência. . . . . . . . . 87

5.7 a) FRF de acelerância do tubo na direção y e b) Função coerência. . . . . . . . 88

5.8 Plano complexo ou de Argand da receptância do ponto 1 na coordenada $x$. . . 90

5.9 FRF de Nyquist para a posição $x_{1}$ manipulada através do ERA. . . . . . . . . . 92

5.10 FRF de receptância experimental de ponto direto vs. FRF teórica na coordenada $x .95$

5.11 FRF de receptância experimental de ponto direto vs. FRF teórica (atualizada) na direção $x \ldots \ldots \ldots \ldots$. . . . . . . . . . . . . . . . . . . . . . 96

5.12 PSD de aceleração em escoamento monofásico de água medida no ponto 1. a) Coordenada $x$ e b) coordenada $y \ldots \ldots$. . . . . . . . . . . 97

5.13 PSD suavizada de aceleração em escoamento monofásico de água medida no ponto 1. a) Coordenada $x$ e b) coordenada $y \ldots \ldots$. . . . . . . . . . 98

5.14 Testes realizados no presente trabalho localizados no mapa de padrões de escoamento bifásico proposto por Ulbrich e Mewes (1994). . . . . . . . . . . . 100

5.15 PSD de aceleração para escoamento bifásico com fração de vazio de 0,30 . Resposta medida no ponto 1. a) Coordenada $x$ e b) coordenada $y . \ldots$. . . . . . 101

5.16 PSD de aceleração para escoamento bifásico com fração de vazio de 0,40 . Resposta medida no ponto 1. a) Coordenada $x$ e b) coordenada $y$. . . . . . . . . 102

5.17 PSD de aceleração para escoamento bifásico com fração de vazio de 0,50 . Resposta medida no ponto 1. a) Coordenada $x$ e b) coordenada $y \ldots \ldots$. . . . . 103

5.18 PSD de aceleração para escoamento bifásico com fração de vazio de 0,60 . Resposta medida no ponto 1. a) Coordenada $x$ e b) coordenada $y$. . . . . . . . . 104

5.19 PSD de aceleração para escoamento bifásico com fração de vazio de 0,70 . Resposta medida no ponto 1. a) Coordenada $x$ e b) coordenada $y$. . . . . . . . 105

5.20 PSD de aceleração para escoamento bifásico com fração de vazio de 0,80 . Resposta medida no ponto 1 . a) Coordenada $x$ e b) coordenada $y$. . . . . . . . 106

5.21 PSD de aceleração para escoamento bifásico com fração de vazio de 0,90 . Resposta medida no ponto 1. a) Coordenada $x$ e b) coordenada $y$. . . . . . . . . 107

5.22 Variação da frequência de ressonância com a fração de vazio a) Coordenada $x$

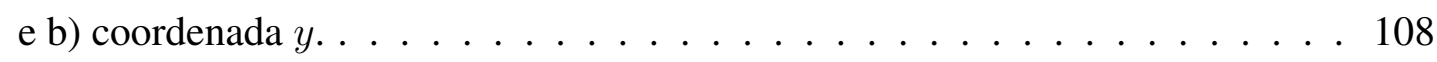

5.23 Valor RMS da aceleração em função da velocidade homogênea do escoamento para cada fração de vazio. a) Coordenada $x$ e b) coordenada $y$. . . . . . . . . 109

5.24 Valor RMS da aceleração em função da velocidade homogênea do escoamento para cada fração de vazio. a) Coordenada $x$ e b) coordenada $y$. . . . . . . . 110 
5.25 Exemplo de PSD suavizada a) Coordenada $x$ e b) Coordenada $y$. . . . . . . . . 112 5.26 Fator de amortecimento total médio em escoamento bifásico. Resultados comparados com os trabalhos Chung e Chu (2006) e Pettigrew et al. (1989) . . . . 112 


\section{Lista de Tabelas}

2.1 Mecanismos de VIEs. Tomado de Khushnood et al. (2004) . . . . . . . . . . . 6

2.2 Regime de desprendimento de vórtices. Baseado em Blevins (1990) . . . . . . 9

2.3 Valores de $C$ e $a$ para escoamento monofásico para intervalos do parâmetro massa de amortecimento. Tomado de Blevins (1984a) . . . . . . . . . . . . 39

2.4 Coeficientes de ajuste da curva da velocidade crítica para diferentes tipos de tubulações. Tomado de Blevins (1990) . . . . . . . . . . . . . . . . . . 39

5.1 Parâmetros de entrada para o cálculo das matrizes de estado. . . . . . . . . . 91

5.2 Pontos de meia potência, frequências de ressonância e fatores de amortecimento. 91

5.3 Valores dos parâmetros da modelagem . . . . . . . . . . . . . . . . . 91 


\section{Lista de Símbolos}

$A$ área transversal do duto, acelerância

$A_{g}$ área transversal ocupada pela fase gás

$A_{l}$ área transversal ocupada pela fase líquido

$A_{t r}$ projeção da área do tubo perpendicular à direção do escoamento

${ }_{r} A_{j k}$ constante modal

$a$ expoente do parâmetro massa - amortecimento do modelo de Connors

$C$ constante de instabilidade

$C_{a}$ coeficiente de massa adicionada

$C_{g}^{\prime}$ coeficiente adimensional de força de arrasto da fase gás

$C_{l}^{\prime}$ coeficiente adimensional de força de arrasto da fase líquida

$C_{m}$ coeficiente de inércia

$C_{D}$ coeficiente de arrasto

$C_{L}$ coeficiente de força transversal

$C^{\prime}$ coeficiente de força instável

d diâmetro do cilindro ou tubo

$d_{a c-0}$ distância entre a posição do acessório até o centro de inércia do tubo

$f$ frequência $[\mathrm{Hz}]$ (geral)

$f_{1}, f_{2}$ frequências de meia potência

$f_{o}$ frequência natural correspondente a um modo de vibração

$f_{n}$ frequência natural da estrutura dinâmica

$f_{r}$ frequência reduzida 
$f_{s}$ frequência de desprendimento de vórtices

$F_{D}$ força de arrasto dinâmico

$F_{I}$ força inercial

$F_{k}$ força aplicada no ponto $k$

$F_{L}$ força transversal ao tubo

$G_{F}$ densidade espectral de excitação turbulenta

$\tilde{g}_{i}(z)$ distribuição da força do escoamento ao longo do tubo

$H$ distância entre os pontos de fixação dos fios de aço

$H_{t}$ comprimento do tubo

$I_{0}$ momento de inércia da estrutura dinâmica com respeito ao centro de inércia do tubo

$I_{t 0}$ momento de inércia do tubo com respeito ao seu centro de inércia

$I_{a c}$ momento de inércia dos acessórios com respeito ao seu centro de inércia

$I_{a c 0}$ momento de inércia dos acessórios com respeito ao centro de inércia do tubo

$J_{i}$ joint acceptance

$k$ rigidez

$K c$ número de Keulegan - Carpenter

$K$ matriz rigidez

$K_{r}$ rigidez modal

$K_{\text {mola }}$ módulo de rigidez da mola

$L$ comprimento dos fios de aço

$m$ massa do conjunto tubo e acessórios (modelagem), massa do tubo por unidade de comprimento (revisão bibliográfica)

$m_{a c}$ massa do acessório

$m_{t}$ massa exclusivamente do tubo (modelagem)

$m_{g e q}$ massa efetiva da fase gás

$m_{l e q}$ massa efetiva da fase líquida 
$M$ matriz massa

$M_{r}$ massa modal

$R$ receptância

$R_{e}$ raio externo do tubo

$R_{i}$ raio interno do tubo

$S R$ fator de estabilidade

St número de Strouhal

$S_{i}$ velocidade efetiva

$S_{1}$ espaçamento transversal

$S_{2}$ espaçamento longitudinal

$T$ período (geral) [s], período de oscilação do escoamento, tensão nos fios de aço

$T_{C}$ matriz de transformação linear

$T_{s}$ período de desprendimento de vórtices

$U$ velocidade de escoamento (geral), velocidade entre tubos quando trata-se de banco de tubos

$U_{\infty}$ velocidade de escoamento livre

$U_{c}$ rit velocidade crítica de instabilidade

$U_{e}$ velocidade efetiva de escoamento (geral)

$U_{g}$ velocidade da fase gás

$U_{l}$ velocidade da fase líquida

$U_{m}$ amplitude de oscilação da velocidade do escoamento

$U_{o}$ amplitude de velocidade média do escoamento

$U_{r}$ velocidade reduzida

$U_{2 F}$ velocidade homogênea de escoamento bifásico

$X$ deslocamento do tubo no domínio da frequência

$x$ coordenada transversal à direção do escoamento (lift direction) 
$x_{1}$ deslocamento do extremo 1 do tubo (modelagem)

$x_{2}$ deslocamento do extremo 2 do tubo (modelagem)

$x_{c}$ deslocamento do centro de inércia do tubo

$x_{j}$ resposta medida no ponto $j$

$\Delta x$ deformação da mola

$Y_{i, r m s}$ valor RMS da resposta do cilindro

y coordenada paralela à direção do escoamento (drag direction)

$\alpha$ fração de vazio superficial, ângulo de inclinação dos fios de aço respeito à horizontal

$\alpha_{j, k}$ receptância teórica (excitação no ponto $k$, medida no ponto $j$ )

$\beta$ fração de vazio volumétrica

$\beta_{o}$ joint acceptance

$\delta$ decremento logarítmico

$\varepsilon$ rugosidade superficial característica

$\zeta$ fator de amortecimento

$\eta$ fator de perda por amortecimento histerético

$\eta_{e q}$ velocidade adimensional efetiva da fase gás

$\theta$ deslocamento angular do tubo respeito à horizontal

$\mu$ viscosidade cinemática

$\xi_{e q}$ velocidade adimensional efetiva da fase líquida

$\rho$ densidade do fluido

$\rho_{g}$ densidade da fase gás

$\rho_{l}$ densidade da fase líquida

$\rho_{2 F}$ densidade de escoamento bifásico

$\tau$ razão de passo transversal e diâmetro, defasagem

$\phi_{o}$ modo de vibração do tubo 
$\phi_{r}$ modo de vibração da estrutura dinâmica normalizado pela massa (modelagem)

$\Phi$ forma espectral adimensional ou densidade espectral padrão

$\chi$ fator de correção

$\psi$ vetor de modo de vibração (modelagem)

$\Psi$ matriz modal

$\omega$ frequência circular $[\mathrm{rad} / \mathrm{s}]$

$\omega_{r}$ frequência modal circular

$\omega_{n 1}$ primeira frequência natural circular da estrutura dinâmica 


\section{Capítulo 1}

\section{Introdução}

O trocador de calor de tipo casco e tubos, segundo Cengel (2003), talvez seja o trocador de calor mais comum nas aplicações industriais. Várias são as aplicações destes equipamentos que vão desde sistemas simples como condensadores e evaporadores de processo numa indústria de alimentos até instalações críticas como os geradores de vapor presentes numa central nuclear de geração de energia elétrica. Portanto, conhecer os detalhes do projeto deste tipo de equipamento é de grande utilidade.

$\mathrm{Na}$ procura de maior eficiência do trabalho destes trocadores de calor, cada vez maiores velocidades do escoamento são usadas para a refrigeração (escoamento externo, geralmente do lado do casco) e menor quantidade de material estrutural é instalado para o suporte dos tubos, trazendo consigo outros desafios para as equipes de projeto, entre eles o mais importante, a vibração induzida por escoamentos (VIE).

A VIE é o resultado da excitação que um escoamento exerce sobre uma estrutura (também conhecida como interação fluido-estrutura). Existem casos nos quais a resposta oscilatória da estrutura é de grande amplitude, sendo uma situação que deve ser evitada já que afeta de forma detrimental a vida útil destes sistemas. Por exemplo, três casos de falhas nos sistemas de refrigeração para reatores nucleares são narrados em Blevins (1979). Neles se pode verificar que a VIE não é exclusiva de um tamanho de reator, tipo de equipamento, ou fluido refrigerante; e que elas podem aparecer em qualquer seção onde exista interação fluido-estrutura.

Segundo Pettigrew e Taylor (2003), as forças de excitação induzidas por escoamento axial são relativamente pequenas em trocadores de calor, razão pela qual a vibração nas tubulações é governada pelo escoamento cruzado. Na revisão feita por Pettigrew et al. (1991), assim como na bibliografia em geral, é aceito que os principais mecanismos de vibração induzida por escoamento monofásico cruzado são: (i) instabilidade fluido-elástica, (ii) desprendimento alternado de vórtices, (iii) excitação por turbulência e (iv) ressonância acústica.

Os mesmos mecanismos de vibração se apresentam em tubulações sob a ação de escoamentos bifásicos, porém, as características destes mecanismos ainda não são bem conhecidas como no caso monofásico. Ressalta-se essa necessidade já que, segundo Noghrehkar et al. (1999), quase a metade dos equipamentos de troca de calor tipo casco e tubos apresenta escoamento bifásico (água-vapor) do lado do casco. 
Várias bancadas de testes têm sido construídas para o estudo dos mecanismos de VIE. Nelas tem-se estudado o efeito de diferentes fatores sobre a resposta dinâmica dos tubos, por exemplo, tem-se realizado testes para conhecer a influência do tipo de escoamento, da configuração geométrica do banco de cilindros, razão de passo transversal e diâmetro (pitch-to-diameter ratio), amortecimento mecânico nos tubos, interação fluido-elástica e fração de vazio (no caso de escoamento bifásico). Khushnood et al. (2004) apresenta uma extensa revisão sobre os estudos já realizados e as bancadas construídas para a pesquisa da vibração induzida por escoamentos bifásicos num trocador de calor.

A instalação dos tubos na seção de testes é um detalhe importante no projeto da bancada experimental. Segundo a informação disponível, existem três formatos de instalação dos tubos na seção de testes, esta pode ser: rígida (com engaste em cada extremo), em balanço (engaste num extremo) e flexível. A montagem do tipo flexível refere-se ao uso de uma estrutura dinâmica adicional para a instalação dos tubos, esta estrutura permite ao tubo ter uma menor rigidez do que se fosse instalado em balanço.

Geralmente os tubos instalados flexivelmente e em balanço são instrumentados para medir a resposta dinâmica e estudar o fenômeno vibratório desejado, enquanto que os tubos rígidos não são instrumentados e são usados para completar a tubulação do banco. No entanto, existem poucas exceções nas quais o tubo rígido é instrumentado, por exemplo, nos testes apresentados em Nakamura et al. (1995a) onde se faz um estudo do mecanismo de vibração aleatória.

Pode-se dizer que a escolha entre a montagem em balanço e a flexível não está diretamente ligada ao mecanismo de VIE estudado, senão com a versatilidade e complexidade da bancada, e as suposições do pesquisador. Uma mostra desse fato é que embora o uso de tubos flexíveis pareça uma tendência mais recente, ainda tem-se experimentado em bancadas com tubos em balanço. Este é o caso de Grover e Weaver (1978) e Pettigrew et al. (2001), os dois estudaram o mecanismo de instabilidade fluido-elástica; o primeiro com tubos flexíveis e o segundo com um tubo em balanço.

A instalação flexível dos tubos instrumentados apresenta a possibilidade de se calibrar a frequência natural do sistema formado pelo tubo e a estrutura dinâmica, o qual representa uma vantagem frente aos outros dois tipos de instalação citados. Uma configuração flexível amplamente usada é a estrutura dinâmica composta por dois fios de aço que suspendem o tubo na seção de testes. O princípio de funcionamento desta estrutura dinâmica é controlar a rigidez do tubo suspendido na seção de testes através da tensão nos fios de aço, dessa forma a frequência natural do sistema pode ser calibrada. Geralmente o sistema usado para esticar os fios é composto por um conjunto parafuso e porca, o qual com seu deslocamento relativo aplica ou retira a tensão do fio.

A possibilidade de controlar a frequência natural do tubo é uma vantagem já que mecanismos de VIE tais como a vibração por turbulência, sincronização do desprendimento de vórtices e a instabilidade fluido-elástica estão diretamente relacionados com a frequência natural de oscilação do tubo. Portanto, se a frequência natural puder ser sintonizada à quantidade de testes 
possíveis é maior aumentando a versatilidade da bancada experimental. Além disso, o funcionamento deste tipo de estrutura dinâmica será simples, composto por poucas peças e sua construção será de menor custo.

Este tipo de estrutura dinâmica tem sido usada para estudos em escoamento monofásico e bifásico. No caso de escoamento monofásico pode-se citar como referência as bancadas construídas em Grover e Weaver (1978), Price et al. (1987) e Khalifa et al. (2012). Para o estudo de escoamento bifásico pode-se citar as seções de testes construídas em Nakamura et al. (1995b) e Mitra et al. (2009).

Baseado no preâmbulo apresentado, o presente estudo é proposto, correspondendo ao projeto de uma estrutura dinâmica para a suspensão dos tubos numa seção de testes para a análise das vibrações induzidas por um escoamento vertical bifásico ar - água, a ser instalado numa bancada devodata ao estudo de VIE bifásicos, construída paralelamente ao desenvolvimento deste projeto. Para tanto, uma revisão prévia das estruturas dinâmicas já existentes será feita baseada na informação disponível na literatura. Além disso, previamente ao projeto da estrutura dinâmica, uma revisão dos principais mecanismos de VIE será feita para um melhor entendimento da problemática do projeto desse sistema.

\subsection{Objetivos}

- Projetar e construir uma estrutura dinâmica para a suspensão do tubo na seção de testes de forma que a sua primeira frequência de ressonância possa ser sintonizada.

- Identificar as frequências de ressonância e os modos de vibração do tubo instrumentado.

- Calcular o fator de amortecimento para os modos de vibração do tubo instrumentado em ambiente ar.

- Desenvolver um modelo mecânico teórico da estrutura dinâmica para contrastar os resultados experimentais obtidos.

- Verificar a influência da velocidade do escoamento monofásico de água na frequência de ressonância e a amplitude da resposta dinâmica do tubo instrumentado.

- Verificar a influência da fração de vazio do escoamento bifásico na frequência de ressonância e a amplitude da resposta dinâmica do tubo instrumentado.

- Calcular o fator de amortecimento para os modos de vibração do tubo em escoamento monofásico de água e escoamento bifásico. Verificar a influência da fração de vazio.

\subsection{Organização do texto}

A informação apresentada neste trabalho foi organizada da seguinte maneira:

- Capítulo 2: descrição dos mecanismos de vibração induzida por escoamentos e a importância relativa entre eles. 
- Capítulo 3: definição das características de uma bancada de testes e revisão das bancadas já projetadas para o estudo das VIE monofásicos e bifásicos. Seleção do tipo de estrutura dinâmica a projetar, seguido de ensaios para a verificação da funcionalidade. Finalmente, apresentação do projeto da estrutura dinâmica.

- Capítulo 4: desenvolvimento da modelagem dinâmica da estrutura.

- Capítulo 5: apresentação dos resultados experimentais e comparação com os valores teóricos estimados

- Capítulo 6: apresentação das conclusões do trabalho realizado. 


\section{Capítulo 2}

\section{Vibrações induzidas por escoamento externo cru- zado}

A vibração induzida por escoamento (VIE) externo cruzado é o problema dinâmico mais importante em vários campos da engenharia. Segundo Kaneko et al. (2008), os produtos industriais atingidos por este fenômeno podem-se classificar em três grupos: aeronaves, construções civis e equipamentos de uma planta industrial. A excitação gerada pelo vento nas asas de um avião é um exemplo da presença da VIE no primeiro grupo. Pontes e prédios expostos ao vento e plataformas offshore para exploração petrolífera expostas às ondas marítimas formam parte das aplicações do segundo grupo. Como exemplo da VIE atuando sobre estruturas civis podese citar o ocorrido com a ponte de Tacoma Narrows (ver Fig. 2.1) nos Estados Unidos no ano de 1940. Como exemplo do terceiro grupo se pode citar aos equipamentos de troca de calor tipo tubo e carcaça, nos quais um escoamento a alta velocidade bate um tubo que conduz outro fluido.

As estruturas podem ser excitadas por diferentes tipos de escoamento. Por exemplo, no caso das linhas de condução de energia elétrica, espera-se que a fonte de excitação seja o vento que bate sobre elas, que neste caso seria um escoamento monofásico de ar estável ou instável. No caso de uma plataforma petrolífera no meio do oceano, espera-se que a força das ondas que atuam sobre ela seja equivalente a um escoamento monofásico oscilatório, o qual excita a estrutura periodicamente. Nos dois exemplos o escoamento foi entendido como monofásico, porém, nem sempre é assim, escoamentos multifásicos excitam estruturas em várias aplicações industriais, entre elas, talvez os equipamentos mais representativos sejam os antes mencionados trocadores de calor de tubo e carcaça. É comum que nestes aparelhos se opere com escoamento bifásico líquido - gás do lado da carcaça. Os escoamentos bifásicos apresentam diferentes distribuições da fase líquida e gás em função da fração de vazio e da vazão mássica, isto gera uma excitação mais complexa do que no caso monofásico.

Após várias décadas de pesquisa se conhece que os principais mecanismos de vibração induzida por escoamentos são: vibração aleatória, vibração induzida por desprendimento de vórtices (Strouhal Periodicity), instabilidade fluido - elástica e resonância acústica (KHUSHNOOD et al., 2004). Na Tabela 2.1 se apresenta um resumo destes mecanismos de vibração e a sua importân- 


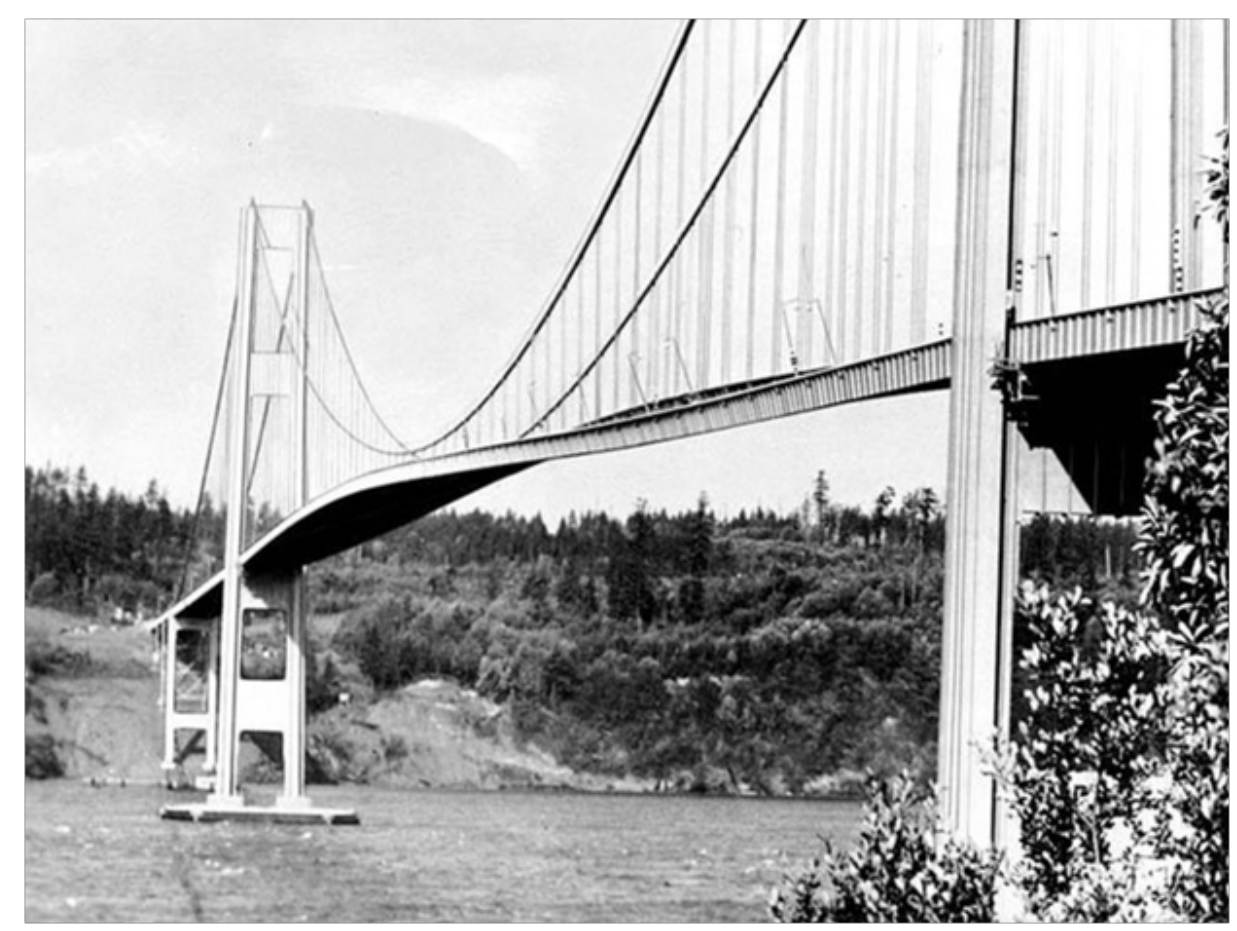

Figura 2.1: Vibração induzida por escoamento de ar sobre a ponte em TacomalEE.UU. Tomado de http: IVimeo.com $\ 14850219$

cia em diferentes tipos de escoamento.

Tabela 2.1: Mecanismos de VIEs. Tomado de Khushnood et al. (2004)

\begin{tabular}{|c|c|c|c|c|}
\hline Tipo de escoamento & $\begin{array}{l}\text { Instabilidade } \\
\text { fluido - elás- } \\
\text { tica }\end{array}$ & $\begin{array}{l}\text { Desprendimento } \\
\text { de vórtices }\end{array}$ & $\begin{array}{l}\text { Vibração alea- } \\
\text { tória }\end{array}$ & $\begin{array}{l}\text { Resonância } \\
\text { acústica }\end{array}$ \\
\hline \multicolumn{5}{|l|}{ Cilindro único } \\
\hline Líquido & $\mathrm{a}$ & $\mathrm{b}$ & $\mathrm{b}$ & $\mathrm{a}$ \\
\hline Gás & $\mathrm{a}$ & $\mathrm{c}$ & $\mathrm{c}$ & $\mathrm{a}$ \\
\hline Bifásico & $\mathrm{a}$ & $\mathrm{a}$ & $\mathrm{b}$ & $\mathrm{a}$ \\
\hline \multicolumn{5}{|l|}{ Banco de tubos } \\
\hline Líquido & $\mathrm{b}$ & $\mathrm{c}$ & $\mathrm{c}$ & $\mathrm{a}$ \\
\hline Gás & $\mathrm{b}$ & $\mathrm{a}$ & $\mathrm{c}$ & $\mathrm{b}$ \\
\hline Bifásico & $\mathrm{b}$ & $\mathrm{a}$ & $\mathrm{b}$ & $\mathrm{a}$ \\
\hline $\begin{array}{l}\text { a: Improvável } \\
\text { b: Possível } \\
\text { c: Mais importante }\end{array}$ & & & & \\
\hline
\end{tabular}

A seguir serão abordadas as características dos principais mecanismos de vibração induzida por escoamento externo cruzado a um cilindro e a um banco de tubos. Esse estudo servirá para entender em termos gerais o problema dinâmico que será analisado por meio da estrutura dinâmica projetada nesse trabalho. Será incluída uma revisão da excitação induzida por um 
escoamento oscilatório. A resonância acústica não será considerada no presente trabalho.

\subsection{Vibração induzida por desprendimento de vórtices}

\subsubsection{Desprendimento alternado de vórtices num cilindro estacionário em escoamento monofásico}

Segundo a descrição de Blevins (1990), conforme as partículas do fluido vão se aproximando à frente do contorno de um cilindro liso, estático, a pressão sobre elas aumenta já que o cilindro representa um obstáculo que gera uma zona de baixa velocidade no fluido. Aquela pressão impele duas camadas de fluido as quais escoam por cada um dos lados do perfil circular do cilindro. Para altos valores do número de Reynolds, $R e$, as camadas não conseguem chegar até a parte mais a jusante do cilindro, elas se desprendem perto do ponto de maior largura da seção transversal gerando assim duas camadas de cisalhamento atrás do cilindro. As camadas estão limitadas internamente pela esteira do cilindro, onde a velocidade é baixa, e externamente pelo fluido escoando livremente. Este gradiente de velocidades causa que as camadas de cisalhamento se enrolem umas às outras na zona da esteira do cilindro formando vários vórtices discretos de fluido. Desse jeito, na esteira do tubo, forma-se um arranjo de vórtices conhecido tipicamente como caminho de vórtices de Karman. Este mecanismo é apresentado na Fig. 2.2.

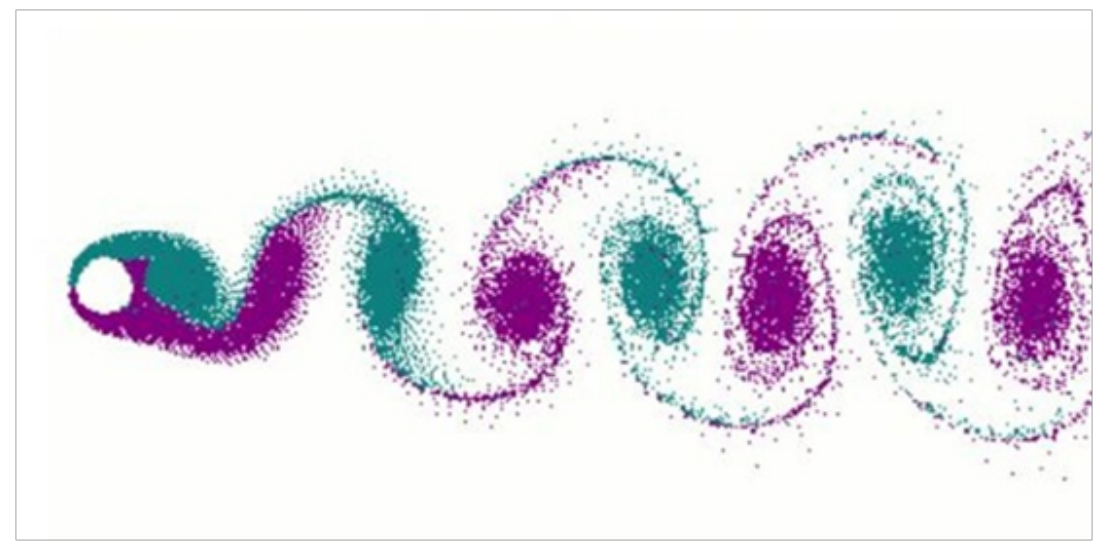

Figura 2.2: Caminho de vórtices de Karman. Tomado de http:Iltheourworld.comlwpcontent \Theaeolusacousticwindpavilion_3_www.theourworld.com_.jpg

O desprendimento de vórtices depende da velocidade do escoamento que passa externamente ao cilindro, por isso decidiu-se delimitar os regimes de desprendimento de vórtices baseado no número de Reynolds, o qual é uma função da velocidade do escoamento $U$ como se vê na Eq. 2.1.

$$
R e=\frac{\rho U d}{\mu}
$$

Nesta expressão aparece o diâmetro do cilindro, $d$, a viscosidade cinemática do fluido, $\mu$, e a densidade do fluido $\rho$. É importante mencionar que no caso de um único cilindro Re é calculado com a velocidade do escoamento livre $U_{\infty}$, a diferença do caso de bancos de cilindros, onde $R e$ 
é calculado com a velocidade efetiva entre cilindros $U$, a qual é maior do que a velocidade de escoamento livre.

Em Blevins (1990) se apresenta uma descrição das características do desprendimento de vórtices para diferentes faixas de $R e$. Os diferentes regimes são ilustrados graficamente na Tab. 2.2. No primeiro intervalo, para $R e<5$, não se observa desprendimento de vórtices, pelo contrário, as camadas de fluido que se separam no primeiro ponto de contato com o cilindro contornam todo o perímetro sem desprendimento de vórtices e sem uma esteira a jusante do cilindro. Esse comportamento muda para o seguinte intervalo, $5 \leq R e \leq 45$, onde o fluido se separa da parte posterior do cilindro e pares simétricos de vórtices aparecem na esteira. $\mathrm{O}$ comprimento desses vórtices aumenta linearmente com $R e$ chegando a ser aproximadamente o triplo do diâmetro do cilindro para $R e=45$. A camada de fluido no contorno do cilindro é laminar e o fluido é estável na esteira. Assim que o escoamento apresenta um Re maior, $45 \leq R e \leq 150$, o fluido na esteira passa a ser instável e um dos vórtices se desprende do contorno do cilindro. Forma-se uma esteira periódica laminar alternada de vórtices de sinais opostos conhecida como caminho de vórtices. No intervalo de $150 \leq R e \leq 300$ os vórtices que se desprendem do contorno do cilindro chegam a ser turbulentos, porém as camadas que escoam nos contornos do cilindro permanecem laminares. Para o intervalo $300 \leq R e \leq 1,5 \times 10^{5}$, também conhecido como intervalo subcrítico, as camadas laminares separam-se $80^{\circ}$ depois do ponto mais a montante do cilindro e o desprendimento de vórtices é periódico e mais forte. Depois aparece um intervalo de transição, $1,5 \times 10^{5} \leq R e \leq 3,5 \times 10^{6}$, no qual as camadas de fluido no contorno do cilindro chegam a ser turbulentas e o ponto de separação delas se desloca até $140^{\circ}$. Além disso, aparecem fenômenos como decrescimento do coeficiente de arrasto, $C_{D}$, até aproximadamente 0,3 (normalmente o valor de $C_{D}$ está ao redor de 0,6) e uma ampliação do espectro das frequências com as quais os vórtices se desprendem do tubo. Finalmente, para Re $>3,5 \times 10^{6}$, ou também conhecido como intervalo supercrítico, a característica geral mais importante é que a relação entre a separação entre vórtices e o diâmetro do cilindro é quase constante para a maioria de caminhos de vórtices. Características mais detalhadas sobre este intervalo podem ser achadas nos trabalhos citados no mesmo Blevins (1990).

Os vórtices desprendidos desde as fronteiras do cilindro interagem com este último excitandoo periodicamente nas direções perpendicular e transversal ao escoamento resultando no mecanismo de vibração conhecido como vibração induzida por desprendimento de vórtices (VIV). Como resultado dos trabalhos experimentais conseguiu-se definir uma expressão que permite estimar a frequência de desprendimento de vórtices predominante $f_{s}$ na direção transversal ao escoamento, esta se apresenta na Eq. 2.2:

$$
f_{s}=\frac{U S t}{d}
$$

onde $S t$ é o número de Strouhal. Este número representa uma proporção adimensional e constante entre a frequência dominante de desprendimento de vórtices, $f_{s}$, e a velocidade do esco- 
Tabela 2.2: Regime de desprendimento de vórtices. Baseado em Blevins (1990)

\begin{tabular}{ll|l|}
\hline & Intervalo & Características \\
Regime de escoamento não \\
separado
\end{tabular}

amento dividida para a largura do cilindro que neste caso é o diâmetro $d$. Deve-se mencionar que na Eq. $2.2 f_{s}$ está expresso em Hertz, pelo qual a velocidade $U$ deve ser expressa em unidades de comprimento por segundo e o diâmetro em unidades de comprimento coerentes com a velocidade.

As experiências de laboratório mostram que as oscilações transversais ao escoamento ocorrem na frequência dominante do desprendimento de vórtices $f_{s}$ e a oscilação na direção paralela ocorre ao dobro dessa frequência. Segundo Blevins (1990) essa é uma consequência da geometria do caminho de vórtices a jusante do cilindro.

Por cada oscilação do cilindro uma camada se desprende do lado de maior deslocamento transversal, assim a frequência de desprendimento de vórtices coincide com a frequência de deslocamento do cilindro. Em contrapartida, a oscilação paralela ao escoamento está relaci- 
onada com a variação de pressão gerada pelo caminho de vórtices que aparece na esteira do cilindro. Por cada oscilação do cilindro são gerados dois vórtices que excitam ele paralelamente duas vezes por oscilação transversal.

O número St é afetado pela turbulência do escoamento e a rugosidade da superfície do cilindro. Em Blevins (1990) afirma-se que uma turbulência de até aproximadamente $10 \%$ tem só pequenos efeitos sobre o mecanismo de vibração induzida por desprendimento de vórtices, embora segundo Torum e Anand (1985), Gartshore (1984), Fage e Warsap (1929), Barnett e Cermak (1974) apud Blevins (1990) possa provocar uma deslocação descendente dos regimes de desprendimento de vórtices. Por outro lado, com respeito à influência do acabamento superficial do cilindro, no mesmo Blevins (1990) se menciona que dentro do intervalo de transição $\left(2 \times 10^{5} \leq R e \leq 2 \times 10^{6}\right)$ cilindros lisos podem gerar uma esteira caótica e desorganizada, além de altos valores de $S t$, em quanto que os cilindros relativamente rugosos (rugosidade superficial $\varepsilon / d=3 \times 10^{-3}$ ou maior, onde $\varepsilon$ é rugosidade superficial característica) apresentam esteiras organizadas e periódicas com valores de $S t$ de 0,25. Isso é apresentado na Fig. 2.3, na qual se pode ver que $S t$ varia aproximadamente entre 0,1 e 0,3 para todo o domínio de $R e$ para um cilindro circular de superfície rugosa.

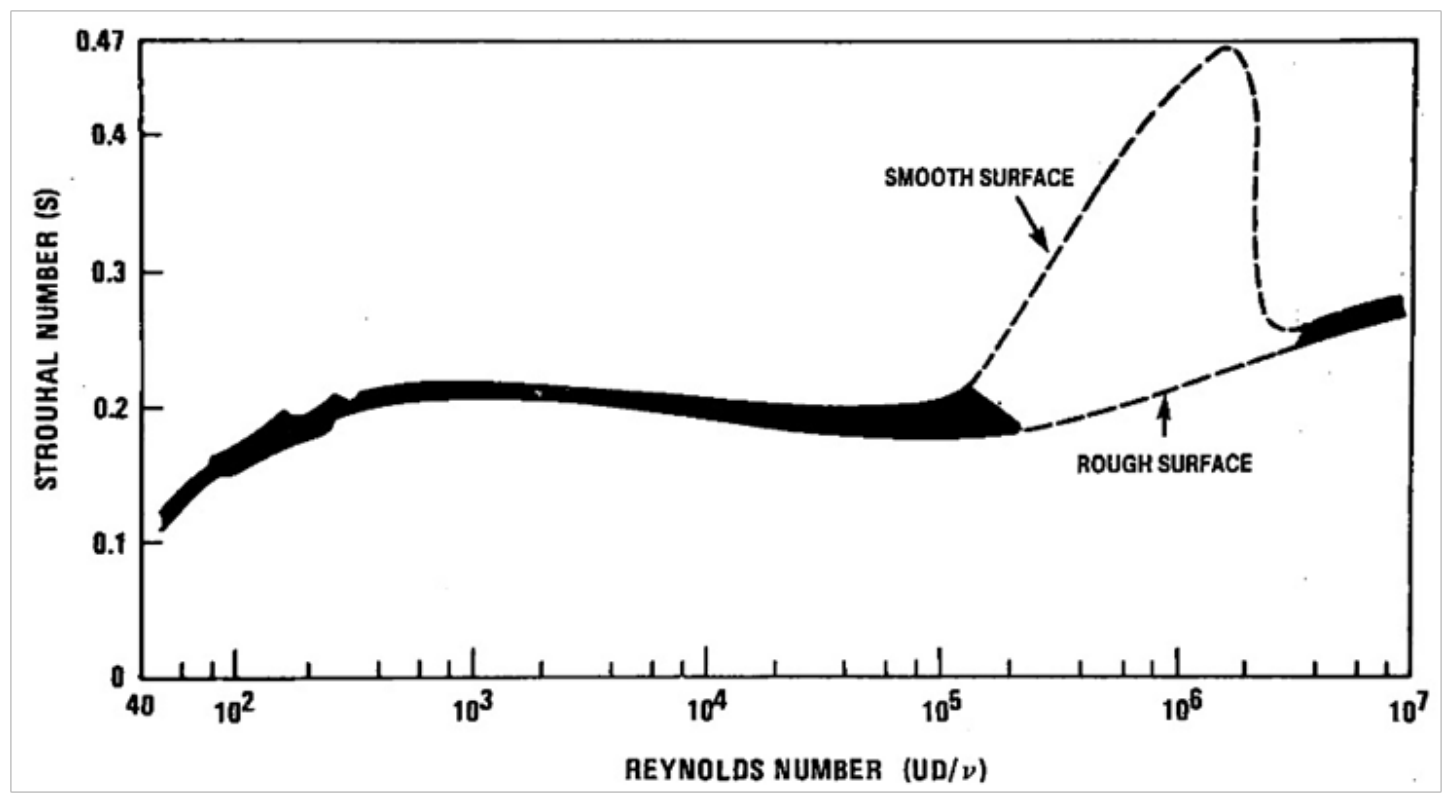

Figura 2.3: Variação do número de Strouhal para diferentes acabamentos superficiais. Tomado de Lienhard (1966)

Embora nesta seção se analisa a vibração induzida por vórtices em cilindros de seção circular é importante dizer que o valor de $S t$ não apresenta importantes variações para diferentes seções transversais. Em Blevins (1990) citam-se autores que sugeriram que é possível definir um valor universal de $S t$ só em função do comprimento que separa as camadas de cisalhamento que se desprendem da seção do corpo dentro do escoamento. Nesse caso, o termo $d$ na Eq. 2.2 estaria definido como o comprimento entre os pontos de desprendimento das camadas. Assim, o valor de $S t$ estaria ao redor de 0,2 para uma larga faixa de $R e$ sem importar a seção transversal 
do corpo, como aparece na Fig. 2.4.

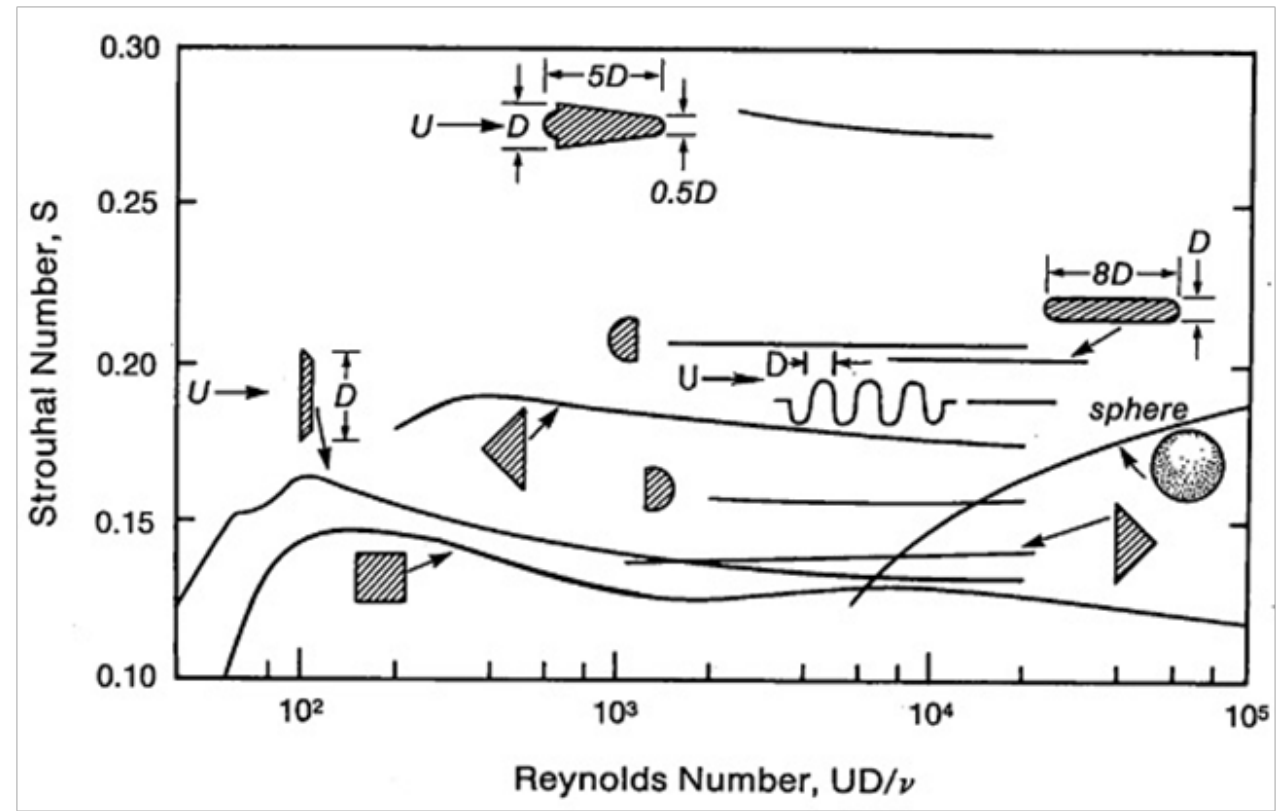

Figura 2.4: Número de Strouhal para diferentes seções transversais. Tomado de Blevins (1990)

\subsubsection{Sincronização acompanhada de desprendimento alternado de vórtices ou despren- dimento simétrico de vórtices}

Quando a frequência natural da estrutura $f_{n}$, neste caso do cilindro, e a frequência de desprendimento de vórtices estão muito próximas, esta última se sincroniza com a primeira gerando um fenômeno conhecido como lock-in. Segundo Kaneko et al. (2008), a sincronização pode ocorrer nas duas direções; paralela e perpendicular ao escoamento. O resultado da sincronização é o aumento da amplitude das oscilações da estrutura, o qual pode provocar falhas por fadiga e incluso desgaste por batimento se o cilindro forma parte de um arranjo.

Em certas circunstancias o lock-in na direção paralela está acompanhada de vórtices simétricos. Isto pode ocorrer a velocidades menores do que no caso de sincronização por vórtices alternados. Na Figura 2.5 se esquematizam os tipos de sincronização alternada e paralela para um cilindro. É importante mencionar que para escoamentos de fluidos de baixa densidade muitas vezes a sincronização paralela é suprimida.

\subsubsection{Efeitos da vibração do cilindro no desprendimento de vórtices}

A vibração transversal do cilindro com uma frequência igual ou perto de $f_{s}$ influi significativamente sobre a frequência de desprendimento dos vórtices. Os pontos apresentados em Blevins (1990) são resumidos a seguir.

\section{Correlação longitudinal da esteira e força dos vórtices}

A vibração do cilindro numa frequência similar à de desprendimento de vórtices organiza a esteira formada atrás dele. Isto faz que a correlação entre os vórtices ao longo do eixo lon- 


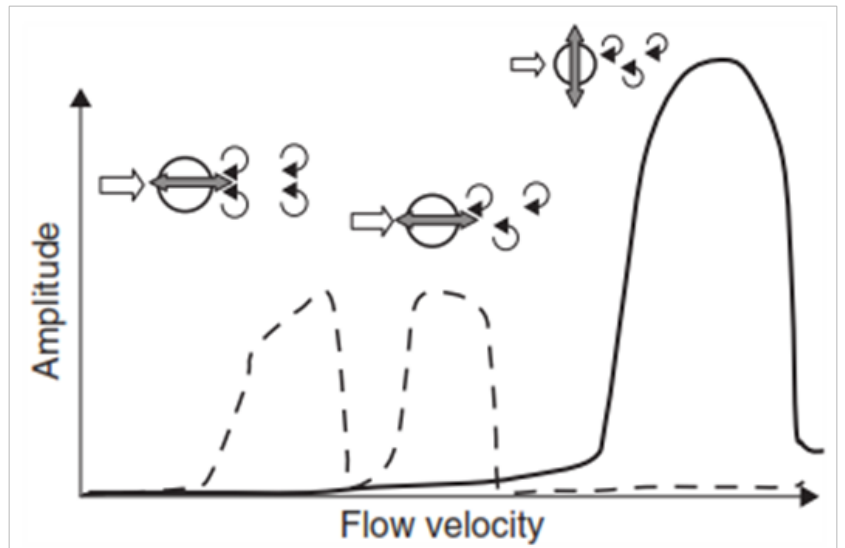

Figura 2.5: Mecanismos de sincronização paralela e perpendicular ao escoamento. Tomado de Kaneko et al. (2008)

gitudinal do cilindro aumente. Em Blevins (1990) se define à correlação como uma medida da tridimensionalidade da esteira, quanto maior é a correlação ao longo do eixo mais bidimensional é a esteira do cilindro. A correlação aumenta com a amplitude de vibração. Em Toebes (1969) se apresenta um estudo da velocidade, pressão e correlações na esteira turbulenta de um cilindro circular. Neste trabalho se mostra como a correlação entre vórtices ao longo do eixo aumenta com a amplitude de vibração do cilindro.

\section{Sincronização}

Quando a vibração transversal do cilindro é de grande amplitude, aumenta a capacidade do cilindro de sincronizar a frequência de desprendimento de vórtices. Neste caso, a vibração do cilindro passa a controlar o desprendimento dos vórtices. Como se pode ver na Fig. 2.6 para grandes amplitudes de vibração o deslocamento do cilindro pode governar o desprendimento de vórtices numa margem de $\pm 40 \%$ com respeito à frequência de desprendimento que ocorreria para um cilindro estático. É importante mencionar que a sincronização também pode ocorrer nas faixas das frequências sub-harmônicas de $f_{s}$ como se apresenta na Fig. 2.7. Em qualquer dessas bandas a frequência natural de desprendimento de vórtices é suprimida, aparecendo só a frequência de oscilação do cilindro como a frequência de desprendimento.

\section{Padrão e simetria dos vórtices na esteira do tubo}

A tendência normal é que os vórtices se desprendam no ponto de máxima amplitude de vibração do cilindro, mas esse padrão é alterado pela sua própria oscilação. Estudos citados em Blevins (1990) mencionam que quando a frequência de vibração do cilindro é levemente menor do que a frequência de desprendimento de vórtices então o vórtice se desprende do lado oposto ao de máximo deslocamento. Em contrapartida, quando a frequência de vibração do cilindro é levemente maior que a frequência de desprendimento de vórtices, então estes se desprendem do lado de máximo deslocamento do cilindro.

Quando a amplitude do deslocamento do cilindro chega a ser maior do que a metade do 


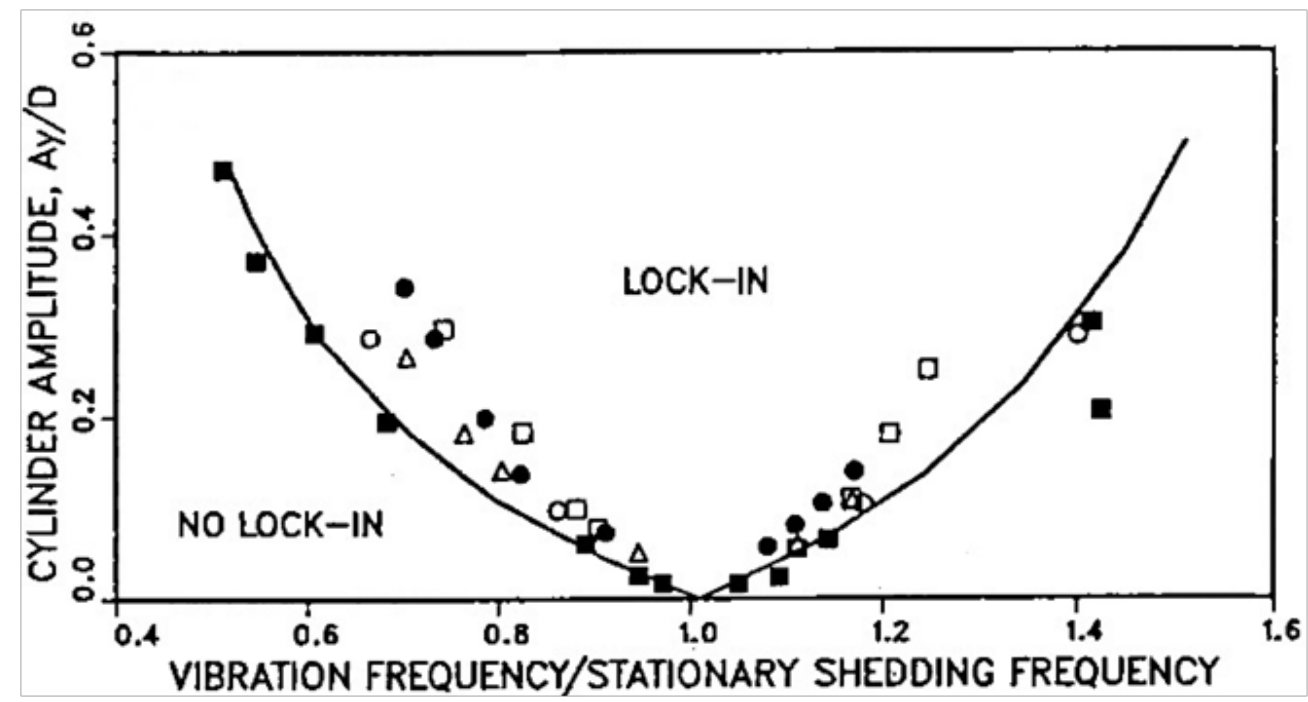

Figura 2.6: Faixas de sincronização de desprendimento de vórtices com um cilindro oscilando transversalmente. Resultados experimentais tomados de Koopman (1967): $\square$ para $R e=100, \bullet$ para $R e=200, \triangle$ para $R e=300$. Resultados experimentais tomados de Stansby (1976): $\mathbf{\square}$ para $R e=3600$, ० para $R e=9200$.

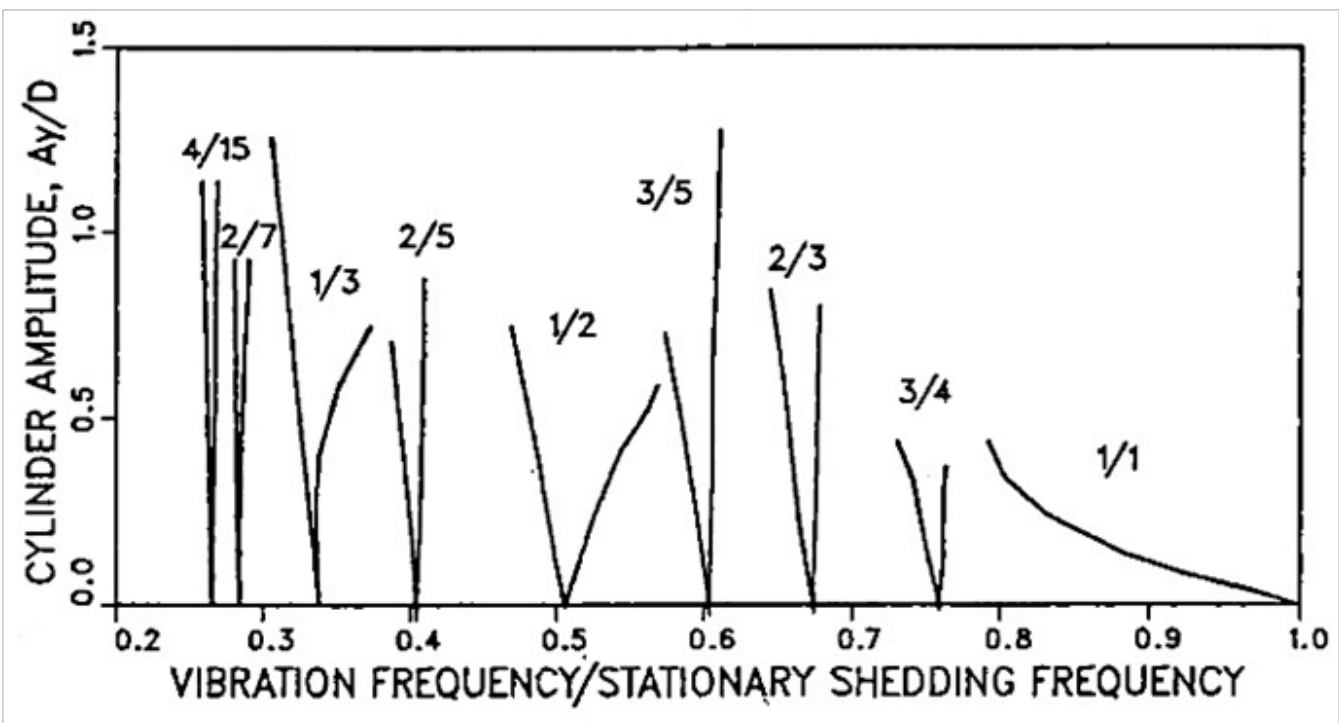

Figura 2.7: Faixas de sincronização sub-harmônicas para um cilindro. Tomado de Olinger e Sreenivasan (1988)

seu diâmetro, a simetria alternada dos vórtices é alterada, desprendendo-se assim mais de dois vórtices por ciclo de vibração. Na Figura 2.8, se apresentam os caminhos de vórtices gerados para tubos vibrando com diferentes amplitudes de vibração.

\section{Força de arrasto sobre o cilindro}

A força de arrasto $F_{D}$, que é a força que exerce o escoamento sobre o cilindro, é modificada pela sua própria vibração. Esta força é paralela ao escoamento e pode ser calculada com a Eq. 2.3: 


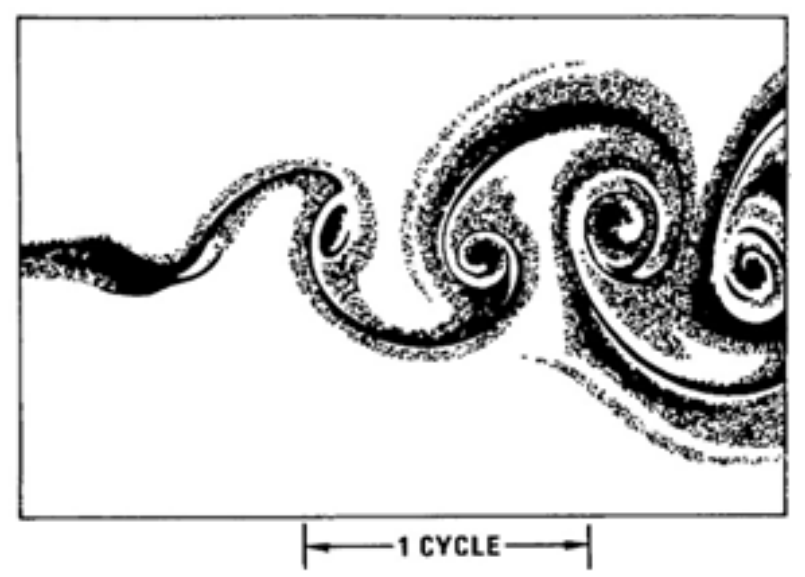

(a) Desprendimento de vórtices alternado estável, amplitude adimensional de vibração $A_{y} / d=0,5$

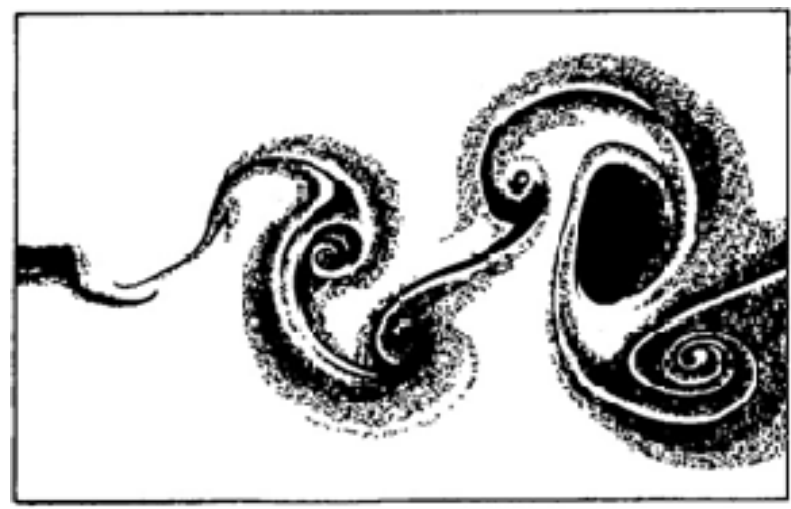

(b) Desprendimento de vórtices alternado instável, amplitude adimensional de vibração $A_{y} / d=1$

Figura 2.8: Desprendimento de vórtices atrás de um cilindro transversalmente à direção principal do escoamento no ponto de ressonância, $R e=190$. Tomado de Griffin e Ramberg (1974)

$$
F_{D}=\frac{1}{2} \rho U^{2} d C_{D}
$$

Quando a frequência de oscilação do cilindro entra em ressonância com a frequência de desprendimento de vórtices o valor do coeficiente de arrasto $C_{D}$ tende a aumentar. Blevins (1990) cita outros autores que apresentam expressões para calcular o valor de $C_{D}$ para um cilindro oscilando. $C_{D}$ pode ser estimado por meio de expressões obtidas experimentalmente pelo ajuste de curvas ou em correlações como as apresentadas por Vandiver (1983) e Skop et al. (1977).

\subsubsection{Desprendimento de vórtices em bancos de cilindros}

\section{Escoamento uniforme}

O número de Strouhal usa-se também para o estudo do desprendimento de vórtices por escoamento uniforme em bancos de cilindros, no entanto, neste caso, St não tem sido reportado como função de $R e$, senão como função da configuração do banco de cilindros e da separação entre eles. Em Fitzhugh (1973) apud Kaneko et al. (2008) publicam-se mapas para determinar 
St para um tubo dentro de um banco, os mapas se apresentam na Fig. 2.9 e na Fig. 2.10. Os números de Strouhal nestes mapas estão baseados no diâmetro do tubo e na velocidade média efetiva do escoamento. Segundo Blevins (1990), o número St obtido para bancos de tubos caracteriza o pico no espectro de turbulência do fluido dentro do banco.

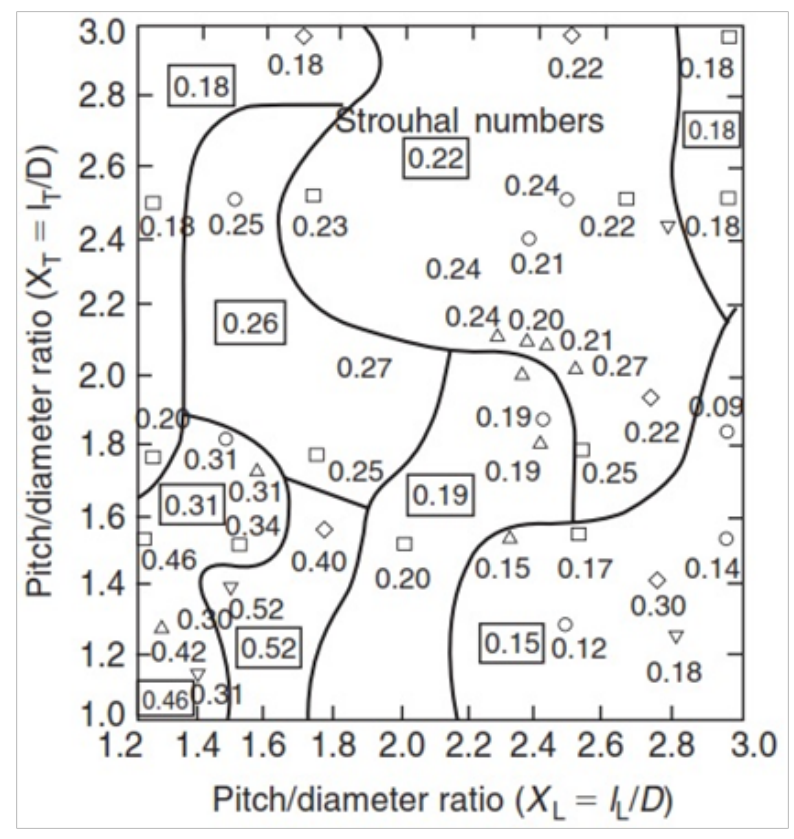

Figura 2.9: Mapa do número de Strouhal para bancos de cilindros em linha. Tomado de Kaneko et al. (2008)

Mediante os mapas das figs. 2.9 e 2.10 se projetam os parâmetros de operação dos bancos de tubos para evitar a sincronização entre o desprendimento de vórtices e a vibração transversal dos tubos, porém, deve-se lembrar que a sincronização também pode ocorrer na direção paralela ao escoamento. Devido às múltiplas considerações necessárias para o projeto de equipamentos com tubulações tem-se optado pela redação de manuais de procedimentos baseados na experiência de trabalhos desenvolvidos previamente, como por exemplo, o código ASME para a fabricação de tanques e caldeiras.

\section{Escoamento não uniforme}

Segundo o exposto por Kaneko et al. (2008), a frequência de desprendimento de vórtices em escoamento não uniforme também é estimada por meio da Eq. 2.2, no entanto, a diferença é que neste caso a frequência de desprendimento muda com a velocidade ao longo do eixo do cilindro. Quando a variação de velocidade é considerável então não se apresenta sincronização embora numa região do cilindro os vórtices estejam-se desprendendo numa frequência igual à frequência natural do cilindro.

Em caso de não existir experiência prévia neste regime de escoamento, este problema pode ser tratado por meio da discretização do campo de velocidades ao longo do eixo do cilindro na coordenada $z$. Para essa análise, o cilindro é dividido em $k$ intervalos, supondo uma resposta 


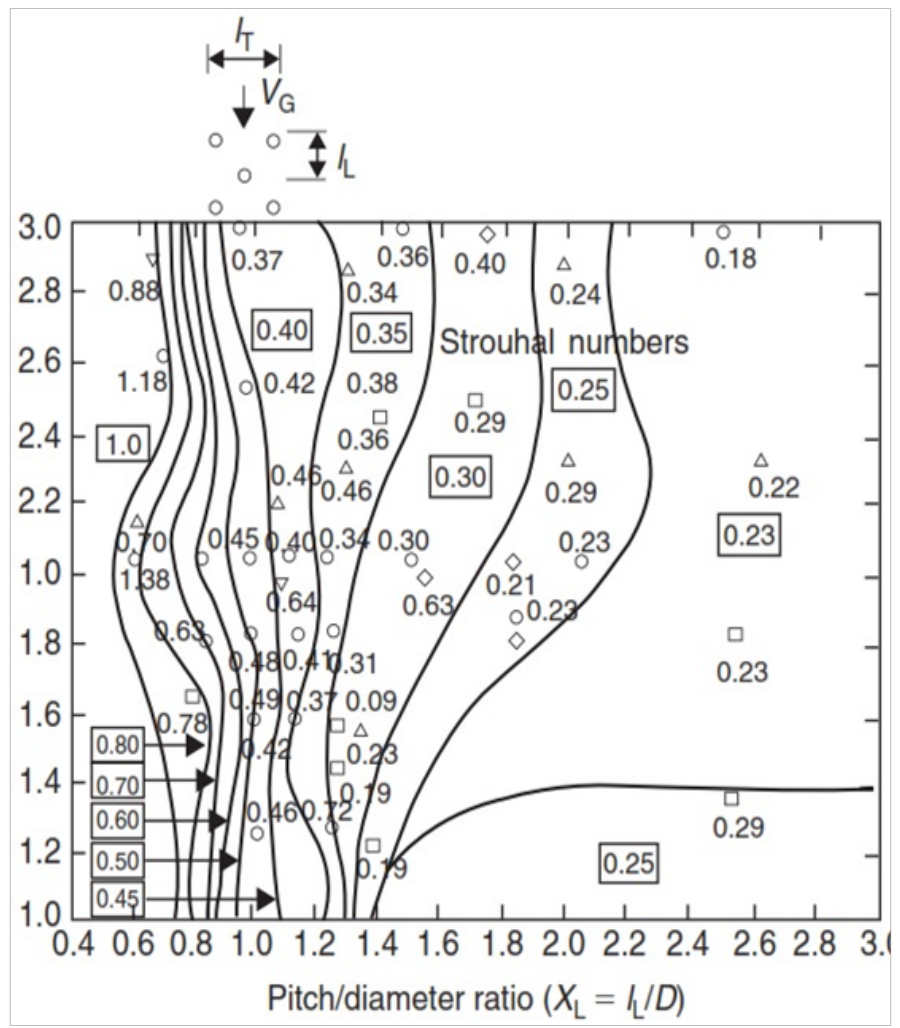

Figura 2.10: Mapa do número de Strouhal para bancos de cilindros em configuração triangular. Tomado de Kaneko et al. (2008)

linear do cilindro, a resposta pode ser calculada através da soma das componentes máximas da resposta $X_{d}^{k}$ devido à força $F_{k}$ em cada intervalo do cilindro como se vê na Eq. 2.4.

$$
X_{d}(x)=\sum_{k=1}^{k}{ }_{k} X_{d}(z)
$$

\subsubsection{Desprendimento de vórtices em escoamento bifásico}

A vibração de um corpo excitado por um escoamento bifásico depende do padrão de escoamento. O padrão do escoamento está caracterizado pela fração de vazio superficial $\alpha$ segundo como é apresentado em detalhe em Collier e Thome (1994). Segundo Kaneko et al. (2008), o desprendimento de vórtices num cilindro exposto a um escoamento bifásico não tem sido claramente observado na maioria dos padrões. Em estudos recopilados em Kaneko et al. (2008) reportou-se a formação de vórtices em escoamentos com uma fração de vazio até de $15 \%$. Além disso, menciona-se que a fração de vazio crítica (fração de vazio máxima para a qual se apresenta a geração de vórtices) depende da relação entre a média do tamanho da bolha e o diâmetro do cilindro, quanto menor for esta relação a fração de vazio crítica é maior.

Para estimar a frequência de desprendimento de vórtices num escoamento bifásico usa-se a mesma formulação que no caso monofásico, porém, a densidade do fluido e a velocidade do escoamento são expressas dependendo do modelo bifásico teórico assumido. Por exemplo, 
se o modelo homogêneo for usado, a densidade e a velocidade para o regime bifásico podem ser calculadas com a Eq. 2.5 e a Eq. 2.6 respectivamente, as quais foram tomadas de Collier e Thome (1994).

$$
\begin{gathered}
\rho_{2 F}=\rho_{g} \alpha+\rho_{l}(1-\alpha) \\
\bar{U}_{2 F}=j_{g}+j_{l}
\end{gathered}
$$

Nas equações 2.5 e 2.6 o subíndice $2 F$ corresponde ao escoamento bifásico, $l$ à fase líquida e $g$ à fase gás do escoamento. A letra $j$ é a velocidade superficial, a qual representa a velocidade do fluido como se ele escoasse como um monofásico através de toda a seção transversal.

Em bancos de tubos, a influência da fração de vazio sobre o desprendimento de vórtices ainda não tem sido compreendida totalmente. Em Kaneko et al. (2008) se menciona que embora resultados para altas frações de vazio não tenham sido reportados, deve-se considerar a possibilidade de desprendimento de vórtices quando o escoamento é quase um monofásico de gás, o qual pode corresponder a um padrão de escoamento névoa. Portanto, Kaneko et al. (2008) conclui que para escoamentos com frações de vazio entre $15 \%$ e $95 \%$ o desprendimento de vórtices pode ser considerado como desprezível.

Por outro lado, em Chung e Chu (2006) se apresenta um conjunto de testes para o estudo de VIE bifásicos desenvolvidos em bancos de tubos com configurações quadrado normal e quadrado rotacionado (ver seção 3.1.2), ambas com razão $\tau$ igual a 1,633. Os resultados indicam que o fenômeno de vibração induzida por desprendimento de vórtices não se apresenta num banco de tubos em configuração quadrado normal. No entanto, no banco em configuração quadrado rotacionado aparece o lock-in em escoamento bifásico até uma fração de vazio de $40 \%$. Como é esperado, o lock-in provoca a oscilação dos tubos com uma maior amplitude na direção perpendicular ao escoamento. Os gráficos que indicam a amplitude de vibração para diferentes frações de vazio e velocidades do escoamento na direção paralela e perpendicular ao escoamento se apresentam nas figs. 2.11, 2.12 e 2.13.

No mesmo artigo de Chung e Chu (2006) são citados outros trabalhos nos quais o fenômeno do lock-in não se apresentou em frações de vazio tão altas. Por exemplo, em Taylor et al. (1989) se menciona que para frações de vazio maiores a 15\% não se apresenta evidência de desprendimento de vórtices para um tubo num banco em configuração quadrada normal com razão $\tau$ igual a 1,47. O trabalho de Feenstra et al. (2003) também foi citado, nele se deduziu que uma pequena quantidade de vapor (fração de vazio igual a 5 - 10\%) é suficiente para romper o desprendimento de vórtices. Finalmente neste artigo se cita o trabalho de Chu et al. (2005), no qual se apresentam os resultados para um banco de tubos em configuração triangular paralelo com razão $\tau$ igual a 1,47 no qual também não se apresentou vibração por desprendimento de vórtices. Como conclusão se pode dizer que os efeitos causados pela presença de desprendimento de vórtices num banco de tubos em escoamento bifásico ainda não são bem conhecidos 


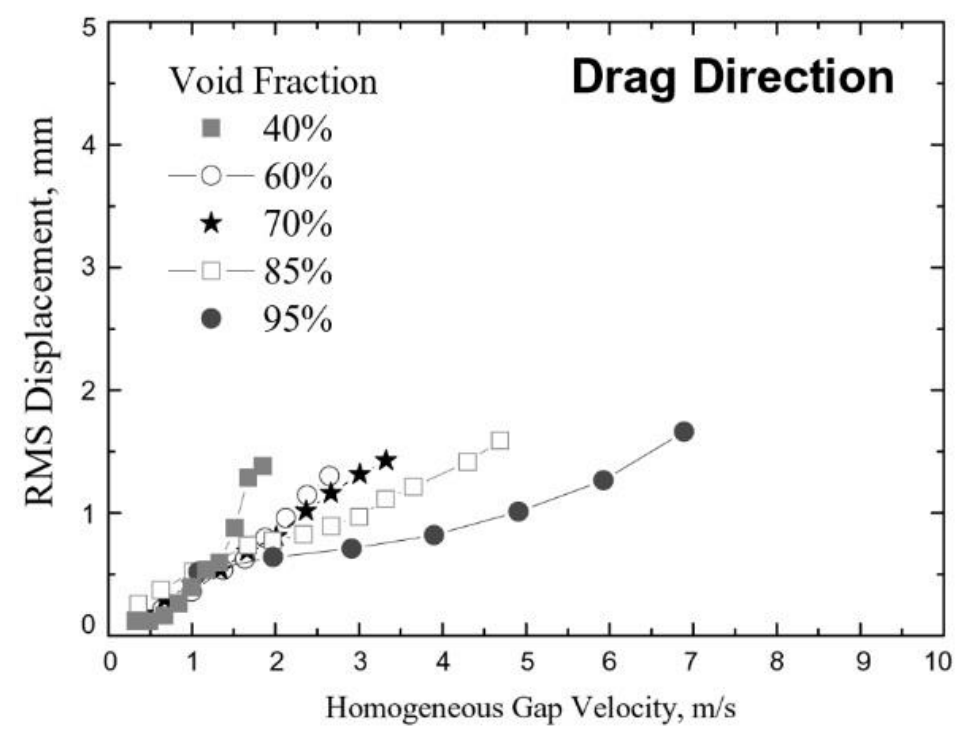

(a)

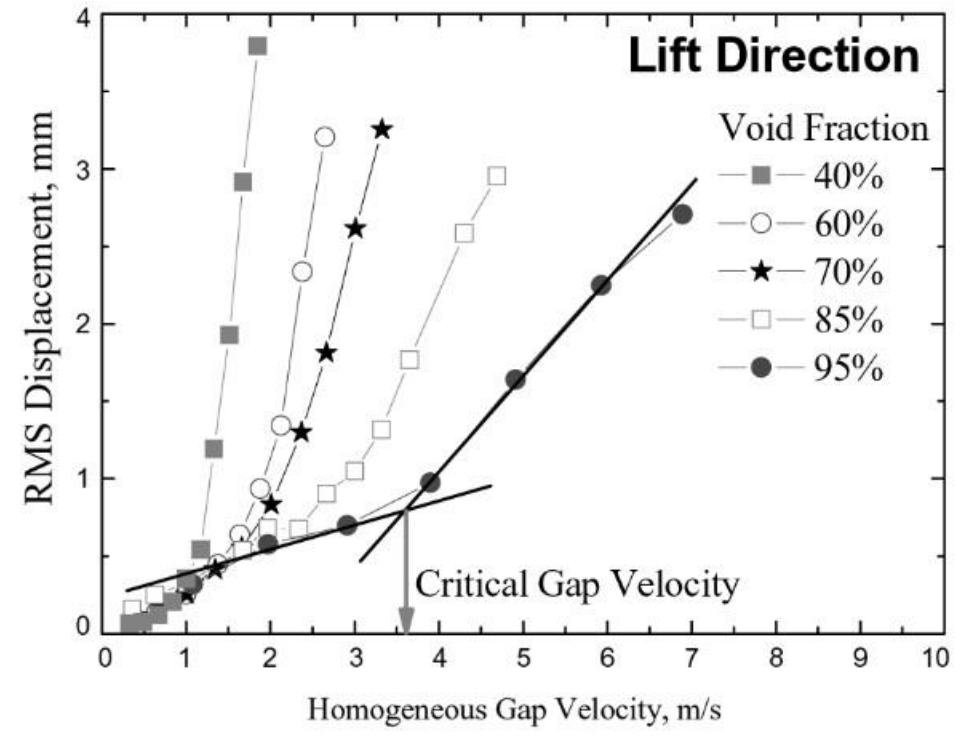

(b)

Figura 2.11: Deslocamento do tubo num banco quadrado normal em função da velocidade do escoamento entre tubos e fração de vazio. a) Direção paralela ao escoamento b) Direção perpendicular ao escoamento. Tomado de Chung e Chu (2006)

e mais testes precisam ser feitos. 


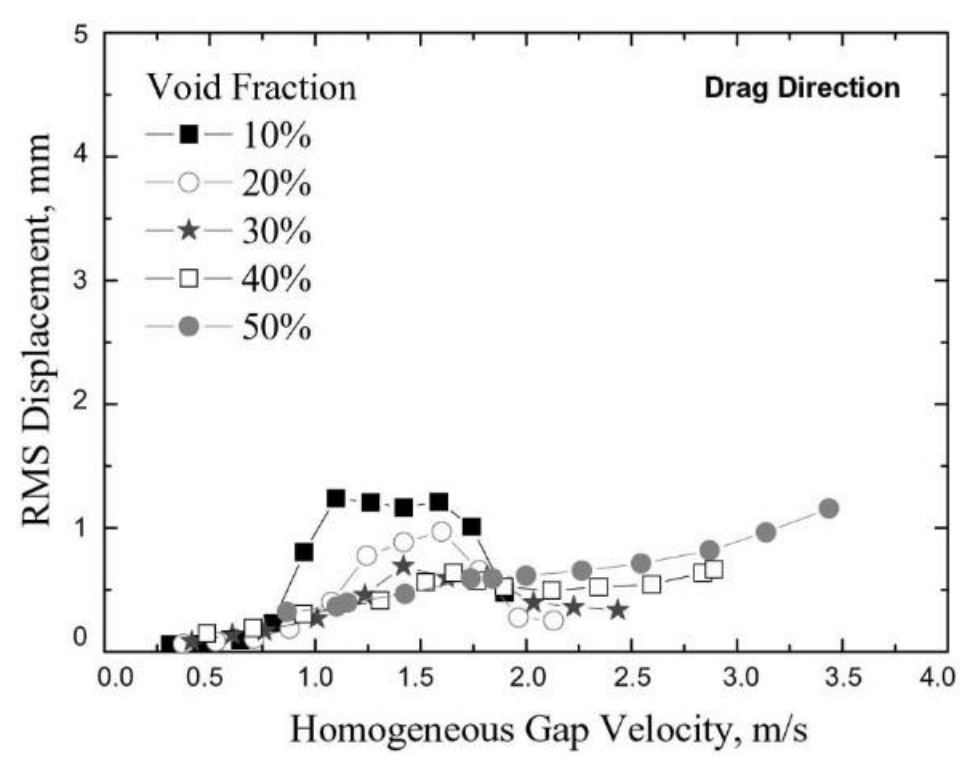

(a)

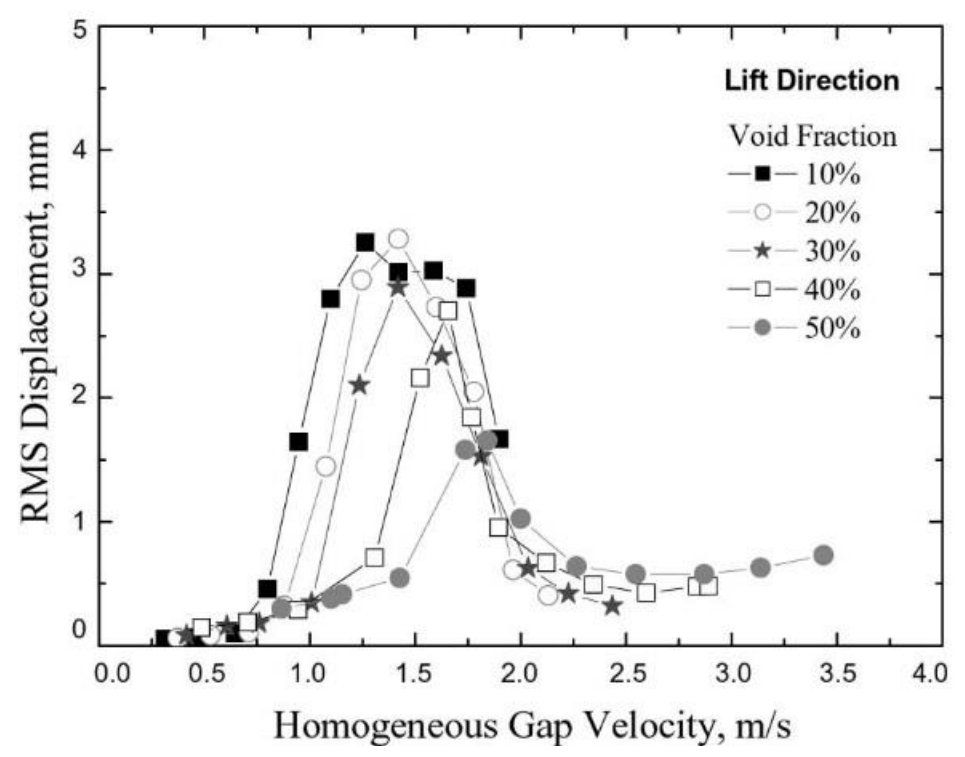

(b)

Figura 2.12: Deslocamento do tubo num banco quadrado rotacionado em função da velocidade do escoamento entre tubos e fração de vazio até 50\%. a) Direção paralela ao escoamento e b) Direção perpendicular ao escoamento. Tomado de Chung e Chu (2006) 


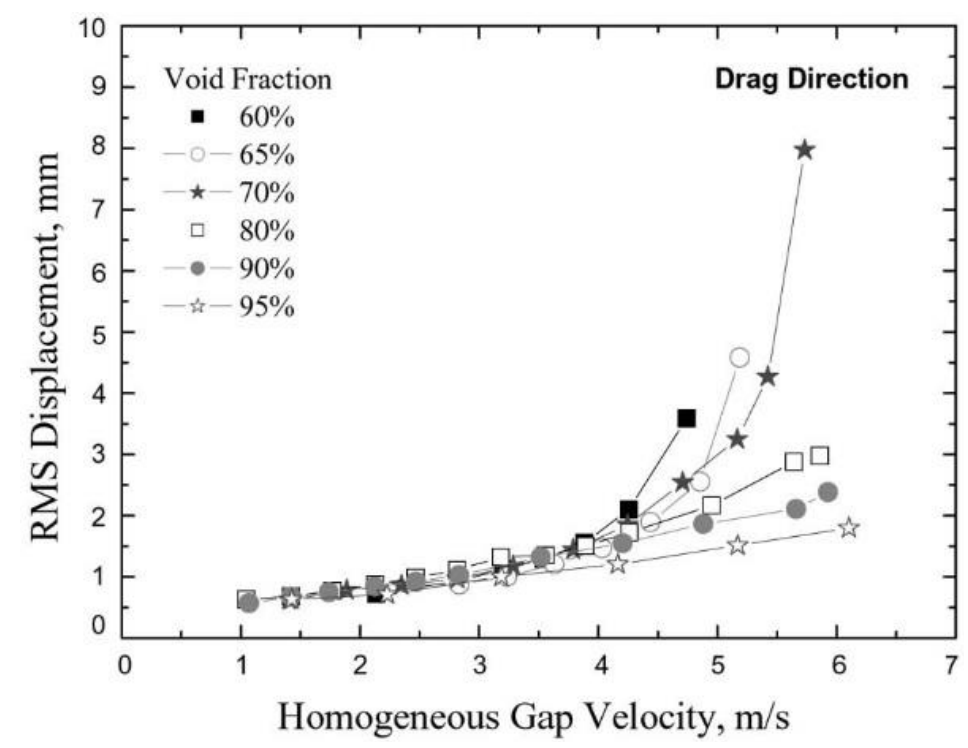

(a)

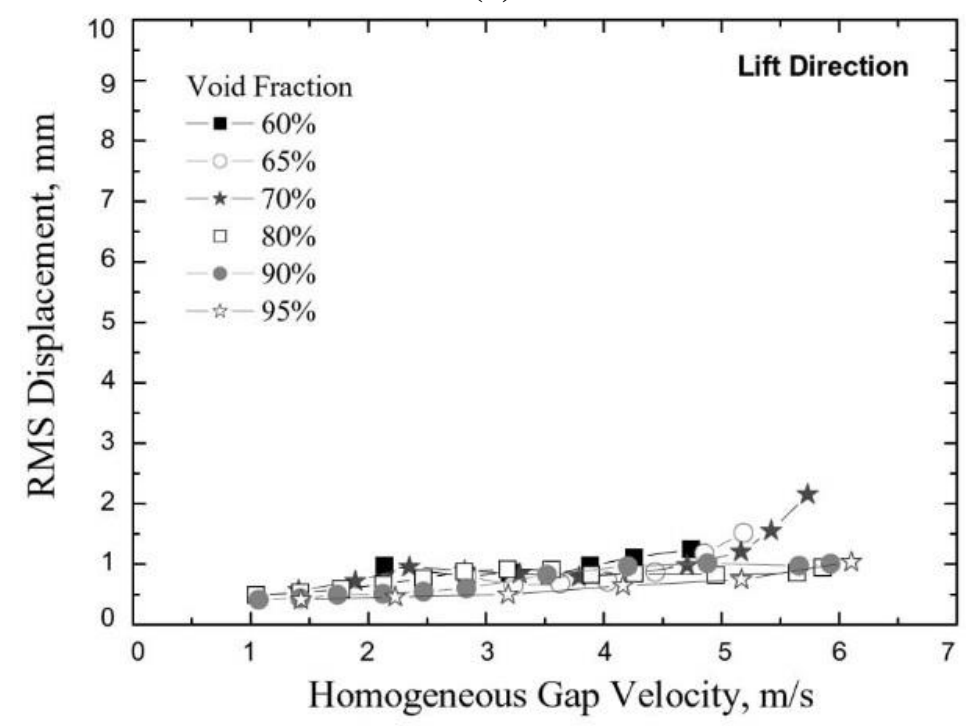

(b)

Figura 2.13: Deslocamento do tubo num banco quadrado rotacionado em função da velocidade do escoamento entre tubos e fração de vazio desde $60 \%$ até $95 \%$. a) Direção paralela ao escoamento e b) Direção perpendicular ao escoamento. Tomado de Chung e Chu (2006) 


\subsection{Vibração aleatória induzida pela turbulência do escoamento}

Como foi descrito na seção 2.1, um cilindro é inevitavelmente excitado pelo desprendimento de vórtices mesmo fora da faixa de sincronização. Aparte desse mecanismo, outra força dinâmica causada pela turbulência do escoamento sempre está presente. Se a frequência natural do cilindro estiver afastada da frequência de desprendimento, então o cilindro vai ser excitado pelas componentes presentes na faixa larga de excitação que estiverem perto da frequência natural do cilindro. A resposta do cilindro a esse tipo de carregamento é conhecida como vibração aleatória induzida pela turbulência do escoamento.

\subsubsection{Vibração aleatória de um cilindro em escoamento monofásico}

O escoamento turbulento excita aos elementos estruturais em várias frequências. A análise determinística para cada uma destas componentes na banda de frequências excitada pode ser pouco prática, portanto o estudo da excitação e a respectiva resposta do cilindro são feitos estatisticamente. Desta maneira o problema se reduz a lidar só com magnitudes médias no tempo ao invés que magnitudes instantâneas. Uma introdução às ferramentas estatísticas necessárias para o estudo da vibração aleatória é feita em Blevins (1990).

Existem manuais de construtores nos quais se tem desenvolvido expressões que permitem estimar a amplitude de vibração de um cilindro devido a um escoamento turbulento. Por exemplo, em Kaneko et al. (2008) se apresenta a Eq.2.7 tomada do manual da Sociedade Japonesa de Engenheiros Mecânicos (JSME), a qual permite estimar o valor rms da resposta vibratória de deslocamento do tubo $w(z)_{\text {mean }}$ :

$$
w(z)_{\text {mean }}^{2}=\frac{\beta_{0} G_{F}\left(f_{0}\right)}{64 \pi^{3} m^{2} f_{0}^{3} \zeta} \phi_{0}^{2}(z)
$$

onde $m$ é a massa do tubo por unidade de comprimento, $\zeta$ é o fator de amortecimento, $\phi_{0}^{2}$ é um modo de vibração do tubo e sua respectiva frequência $f_{0}$. O termo $\beta_{0}$ é uma medida da compatibilidade entre a distribuição da força ao longo do eixo axial do tubo e o seu modo de vibração, é conhecido como joint acceptance e está definido pela Eq. 2.8:

$$
\beta_{0}=\frac{\int_{0}^{L} \tilde{g}_{i}(z) \tilde{y}_{i}(z) d z}{\int_{0}^{L} \tilde{y}_{i}^{2}}
$$

onde $L$ é o comprimento do tubo, $\tilde{g}_{i}(z)$ é a forma da distribuição da força transversal ao longo do comprimento do tubo exposto ao escoamento, o qual está normalizado a um valor máximo de 1 . O termo $\tilde{y}_{i}(z)$ é o deslocamento do tubo na direção paralela ao escoamento. Pode-se ver da Eq.2.8 que o caso ideal é quando $\beta_{0}=1$, isto acontece quando a forma da distribuição da força é idêntica à forma do modo de oscilação, é dizer $\tilde{g}_{i}(z)=\tilde{y}_{i}(z)$. É importante mencionar que o termo $\beta_{0}$ foi recolhido de Blevins (1990) devido a que a nomenclatura de Kaneko et al. (2008) encontrava-se incompleta. 
O termo $G_{F}\left(f_{0}\right)$ representa à densidade espectral da excitação turbulenta exercida pelo escoamento por unidade de comprimento, esta é calculada para a frequência $f_{0}$ através da equação Eq.2.9:

$$
G(f)=\left(C^{\prime} \frac{1}{2} \rho U^{2} d\right)^{2} \Phi(f r) \frac{d}{U}
$$

onde $C^{\prime}$ é um coeficiente da força instável do fluido aproximadamente igual a 0,13 segundo Kaneko et al. (2008) e $f_{r}$ é a frequência reduzida adimensional que pode ser calculada com a Eq.2.10:

$$
f_{r}=\frac{f d}{U}
$$

A densidade espectral padrão $\Phi\left(f_{r}\right)$ pode ser calculada com a Eq.2.11, a qual recolhe uma grande quantidade de resultados experimentais.

$$
\Phi(f r)= \begin{cases}\frac{4}{\left(1+4 \pi^{2} f_{r}^{2}\right)}, & \text { se } U_{r} \leq 3,3 \text { e } f_{r} \geq 0,3 \\ \frac{7,979 \times 10^{-3}}{\left(f_{r}^{4}\right)}, & \text { se } 3,3 \leq U_{r} \leq 5 \text { e } 0,2 \leq f_{r} \leq 0,3 .\end{cases}
$$

O termo $U_{r}$ corresponde à velocidade reduzida adimensional calculada através da Eq.2.12:

$$
U_{r}=\frac{U}{f_{0} d}
$$

\subsubsection{Vibração aleatória induzida por escoamento monofásico num banco de tubos}

Quando o cilindro está montado num banco, como por exemplo, no caso de um trocador de calor, a vibração aleatória induzida pelo escoamento está composta de duas parcelas: a gerada pela própria turbulência do escoamento e a correspondente aos vórtices desprendidos pelos cilindros a montante. É importante poder estimar a amplitude de oscilação dos cilindros para estar em capacidade de projetar faixas seguras de operação do equipamento e assim evitar falhas seja por batimento entre cilindros ou por fadiga. Em Blevins (1990) se apresenta uma expressão para calcular a amplitude de vibração do cilindro no i-ésimo modo de vibração analisado e sua respectiva frequência natural $f_{i}$, esta equação está definida por:

$$
\frac{Y_{i, r m s}}{d}=\frac{1}{16 \pi^{3 / 2}} \frac{\rho d^{2}}{m}\left(\frac{U}{f_{i} d}\right)^{1,5} \frac{J_{i}}{\zeta^{1 / 2}}[\Phi]^{1 / 2} \overline{y_{l}}(z)
$$

onde:

$Y_{i, r m s}$ é o valor eficaz da amplitude da resposta do cilindro,

$\rho$ é a densidade do fluido,

$d$ é o diâmetro do cilindro,

$U$ é a velocidade do escoamento que atravessa o menor espaço entre cilindros,

$\bar{y}_{i}(z)$ é a forma do modo de vibração a qual é normalizada para ter um valor máximo de 1 e depende da posição no eixo axial do cilindro (coordenada $z$ ),

$\zeta$ é o fator de amortecimento. 
$J_{i}$ é uma medida da compatibilidade entre a distribuição da força ao longo do eixo axial do tubo e o seu modo de vibração, este é conhecido como joint acceptance e é calculado através da Eq.2.8. Se o escoamento estiver totalmente correlacionado com o deslocamento do tubo então $J_{i}$ é igual a 1 , em caso de correlação parcial $J_{i}$ pode ser calculado com a equação:

$$
J_{i}=\left(\frac{l_{c}}{L}\right)^{1 / 2}
$$

onde $L$ é o comprimento do cilindro. Blevins et al. (1981) achou que $l_{c}=6,8 d$, no entanto, Axisa et al. (1988) sugere $l_{c}=8 d$. A forma espectral adimensional $\Phi$ está em função da frequência reduzida $f_{r}$, os valores sugeridos por Axisa et al. (1988) se podem ver na Eq.2.15.

$$
\Phi(f d / U)= \begin{cases}4 \times 10^{-4}(f d / U)^{-0,5}, & \text { se } 0,01 \leq(f d / U) \leq 0,2 \\ 3 \times 10^{-6}(f d / U)^{-3,5}, & \text { se } 0,2 \leq(f d / U) \leq 3\end{cases}
$$

Com relação à natureza da vibração, Blevins (1990) baseado em outros autores sinala que as forças de arrasto e transversal têm a mesma frequência em arranjos com distâncias pequenas entre cilindros, o qual sugere que não se apresenta um desprendimento de vórtices regular, mas, em vez disso, aparecem vórtices individuais entre os cilindros do arranjo os quais afetam a vibração dos cilindros a jusante.

\subsubsection{Vibração aleatória de um cilindro em escoamento bifásico}

A força de excitação que um escoamento bifásico exerce sobre um cilindro é afetada pela fração de vazio, o qual é o parâmetro que caracteriza este tipo de escoamentos. Kaneko et al. (2008) descrevem alguns resultados experimentais onde mediram-se as forças flutuantes exercidas pelo fluido na direção paralela e transversal ao escoamento. Reportou-se que para altos valores de fração de vazio se apresenta um incremento na oscilação na direção paralela ao escoamento, ao contrario do que ocorre na direção transversal, na qual a oscilação diminui e a sincronização desaparece. $\mathrm{O}$ incremento das oscilações do cilindro com a fração de vazio se pode ver na Fig. 2.14, para altas frações de vazio a amplitude das vibrações paralelas ao escoamento aumenta se comparadas às que aparecem em escoamento monofásico, o qual é representado na Fig. 2.14 como fração de vazio zero. A vibração basicamente atribui-se à contínua variação da densidade dos fluidos que batem contra o cilindro. Além da presença de bolhas, com o aumento da fração de vazio, diminui a massa adicionada à estrutura e, consequentemente, há um aumento de aceleração. Nesta figura pode-se observar também que para escoamentos bifásicos não se apresenta lock-in, no entanto o apresentado nesta bancada não pode ser generalizado para todas as configurações. Nas figs. $2.12 \mathrm{a}$ e $2.12 \mathrm{~b}$ se pode ver a existência do lock-in em bancos de tubos em escoamento bifásico.

Segundo Kaneko et al. (2008), pouco tem sido publicado ao redor da vibração aleatória 


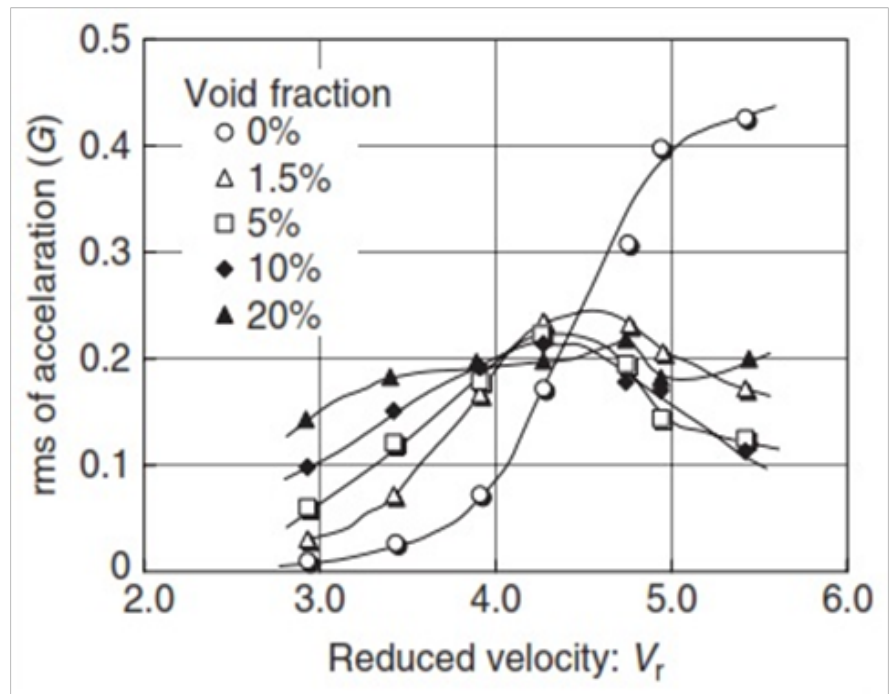

Figura 2.14: Vibração induzida por escoamento bifásico para diferentes frações de vazio. Tomada de Kaneko et al. (2008)

induzida por escoamento bifásico, portanto um método definido para o cálculo da amplitude de vibração neste caso não têm sido publicado ainda.

\subsection{Vibração induzida por escoamento oscilatório}

\subsubsection{Força inercial e força de arrasto}

Quando um cilindro circular é exposto a um escoamento oscilatório, como se vê na Fig. 2.15, o cilindro é excitado por uma força paralela ao escoamento a qual está composta por duas parcelas: a força inercial $F_{I}$ e a força de arrasto $F_{D}$. Em Blevins (1990) descreve-se que a força inercial tem duas componentes. A primeira delas se deve à força de empuxo que exerce o fluido sobre a estrutura imersa, a qual é igual à massa do fluido deslocada pela estrutura vezes a aceleração do escoamento. A segunda componente da força inercial corresponde à massa adicionada, a qual representa ao fluido que é arrastado por uma estrutura acelerada. A expressão para calcular a força inercial por unidade de comprimento se apresenta na Eq. 2.16,

$$
F_{I}=\rho A \dot{U}+C_{a} \rho A(\dot{U}-\ddot{x})
$$

onde $\rho$ é a densidade do fluido, $A$ é a área transversal do cilindro, $U(t)$ é a velocidade do escoamento, $x$ é o deslocamento do cilindro e $C_{a}$ é o coeficiente de massa adicionada o qual está tabelado também em Blevins (1984b).

Por outra parte, o arrasto dinâmico $F_{D}$ é a força que exerce o fluido sobre a estrutura devido à velocidade relativa entre eles. $F_{D}$ pode ser calculada mediante a Eq. 2.17.

$$
F_{D}=\frac{1}{2} \rho|U-\dot{x}| d C_{D}
$$

A soma de $F_{I}$ e $F_{D}$ é a força paralela total do escoamento sobre a estrutura. Se a estrutura 


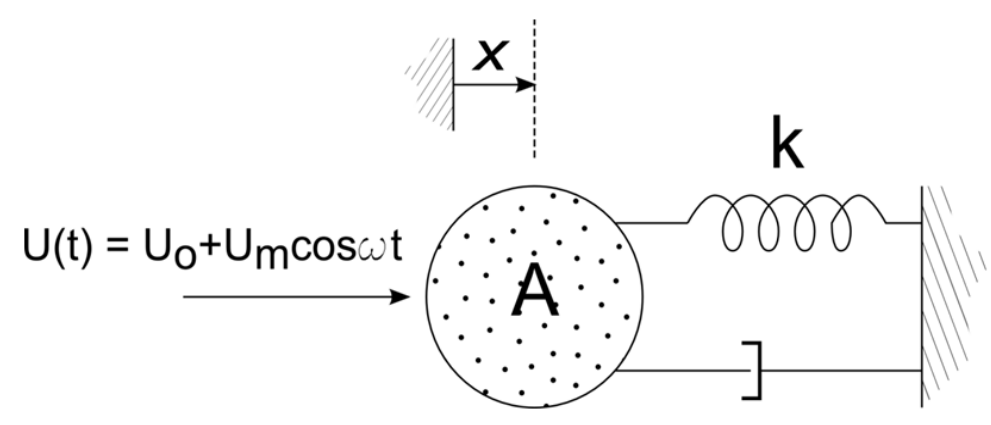

Figura 2.15: Modelo mecânico de um cilindro dentro de um escoamento. Inspirado de Blevins (1990)

for estática $(x=\dot{x}=\ddot{x}=0)$, então a força sobre ela pode ser calculada mediante a Eq. 2.18.

$$
F_{(x=0)}=\rho A C_{m} \dot{U}+\frac{1}{2} \rho|U| U d C_{D}
$$

onde o coeficiente de inércia $C_{m}$ está definido pela Eq. 2.19:

$$
C_{m}=1+C_{a}
$$

A velocidade $U(t)$ descrita nas equações corresponde à velocidade de um escoamento que oscila sinusoidalmente com frequência $\omega$. A velocidade pode ser expressa em função da amplitude de velocidade média constante do escoamento, $U_{o}$, e a amplitude de oscilação, $U_{m}$, como se apresenta na Eq. 2.20.

$$
U=U_{o}+U_{m} \cos (\omega t)
$$

Se as equações 2.20 e 2.18 são combinadas, se obtém uma expressão da força em função da velocidade e do tempo como se mostra na Eq. 2.21.

$$
F(t)=-\rho A C_{m} \omega U_{m} \operatorname{sen}(\omega t)+\frac{1}{2} \rho\left|U_{o}+U_{m} \cos (\omega t)\right|\left(U_{o}+U_{m} \cos (\omega t)\right) d C_{D}
$$

Se o escoamento é completamente oscilatório, significa dizer $U_{o}$ igual a zero, e analisam-se os valores máximos da função apresentada na Eq. 2.21, então a força máxima do escoamento sobre o cilindro pode ser calculado para duas condições:

$$
F(t)_{\text {max }}= \begin{cases}\rho A C_{m} U_{m} \omega, & \text { se } \frac{U_{m}}{\omega d} \leq \frac{C_{m} A}{C_{D} d^{2}} \\ \frac{1}{2} \rho U_{m}{ }^{2} d C_{D}+\frac{\rho A^{2} C_{m}^{2} \omega^{2}}{2 C_{D} d}, & \text { se } \frac{U_{m}}{\omega d} \geq \frac{C_{m} A}{C_{D} d^{2}} .\end{cases}
$$

Segundo o descrito em Blevins (1990), se $\left(U_{m} / \omega d\right) \leq 6$ então a força máxima se deve à componente inercial e os pontos de amplitude máxima ocorrem num ângulo de fase de $90^{\circ} \mathrm{e}$ $270^{\circ}$ como se vê na Fig. 2.16. Em contrapartida, se $\left(U_{m} / \omega d\right) \gg 6$ então a força máxima é 
dominada pela força de arrasto e os pontos de amplitude máxima ocorrem nos ângulos de fase de: $0^{\circ}, 180^{\circ}$ e $360^{\circ}$.
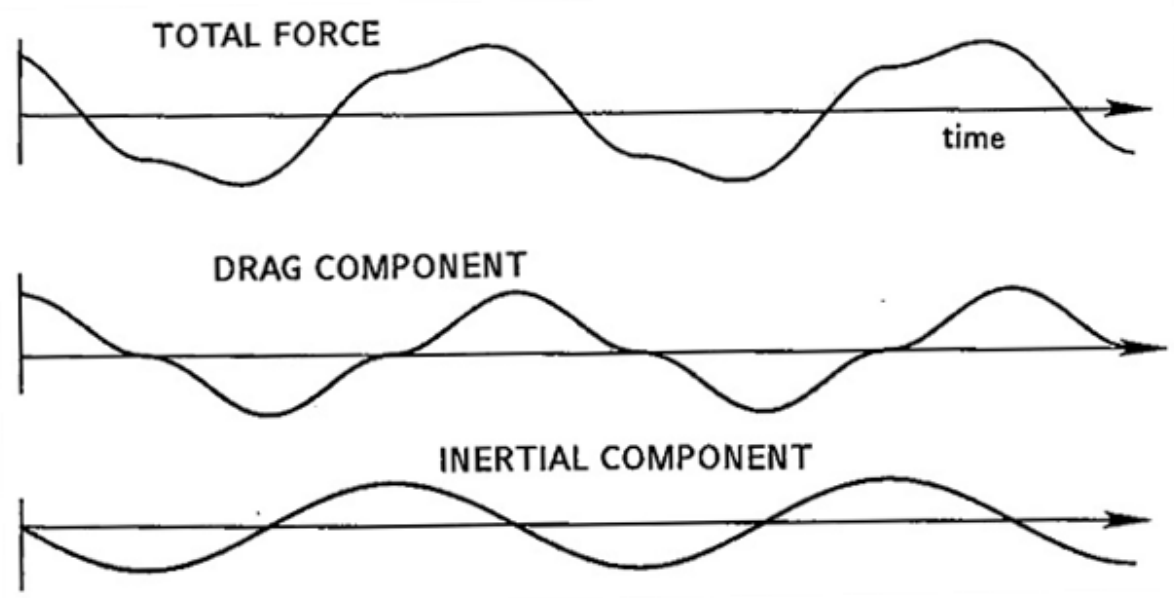

Figura 2.16: Componentes da força paralela do fluido sobre uma estrutura num escoamento oscilatório. Tomada de Blevins (1990)

Quando a velocidade média $U_{o}$ é diferente de zero, a força paralela máxima pode ser analisada através de uma expressão adimensionalisada para o valor máximo da componente inercial, como se apresenta na Eq. 2.23.

$$
F_{T}=\rho A C_{m} U_{m} \omega\left\{-\operatorname{sen}(\omega t)+\frac{U_{o}}{U_{m}} \frac{U_{o}}{\omega d} \frac{d^{2}}{2 A} \frac{C_{D}}{C_{m}} \times\left|1+\frac{U_{m}}{U_{o}} \cos (\omega t)\right|\left(1+\frac{U_{m}}{U_{o}} \cos (\omega t)\right)\right\}_{23}
$$

Uma análise do valor máximo do fator entre chaves no membro direito da Eq. 2.23 também é feito em Blevins (1990). Na Figura 2.17 se apresentam as curvas de valores máximos para diferentes proporções entre $U_{o}$ e $U_{m}$. Nessa figura se pode ver que para baixos valores de $U_{m} / f d$, a força máxima é dominada pela componente inercial, em quanto que para altos valores da mesma relação, a força é dominada pela força de arrasto.

\subsubsection{Movimento paralelo ao escoamento}

\section{Equação de movimento do cilindro na direção paralela ao escoamento}

Baseado na Fig. 2.15 se propõe a equação de movimento na direção paralela ao escoamento, essa é:

$$
\left(m \rho A C_{a}\right) \ddot{x}+2 m \zeta_{s} \omega_{n} \dot{x}+k x=\rho A C_{m} \dot{U}+\frac{1}{2} \rho|U-\dot{x}|(U-\dot{x}) d C_{D}
$$

Como é típico, do lado esquerdo da Eq. 2.24 se pode reconhecer aos parâmetros do sistema mecânico e do lado direito à força de excitação. A única diferença é que o termo da massa adicionada $\rho A C_{a} \ddot{x}$ tem sido inserido na parte esquerda da equação. O termo $x$ é o deslocamento 


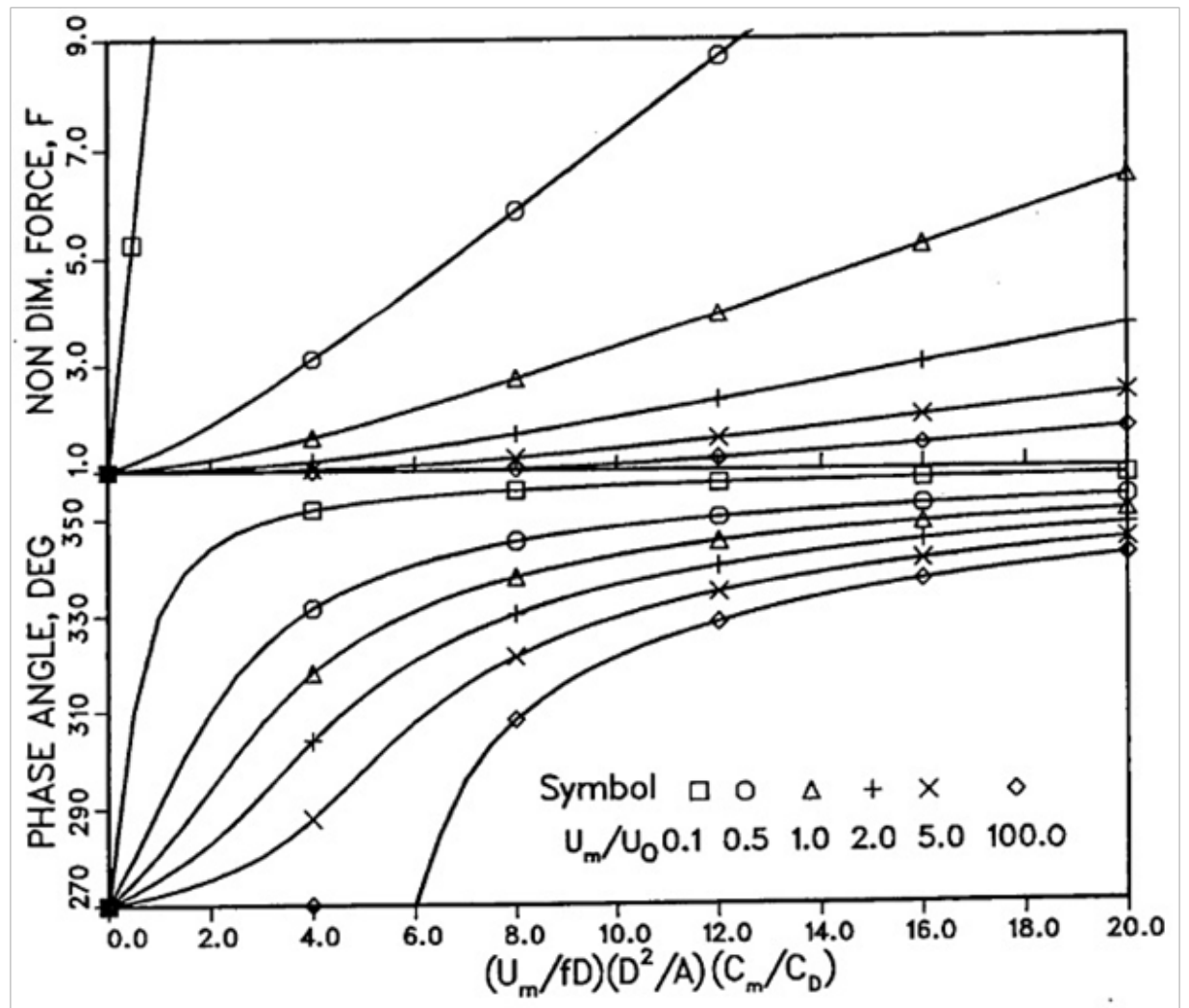

Figura 2.17: Força paralela máxima sobre uma estrutura num escoamento oscilatório com uma componente principal $U_{o} \neq 0$. Tomada de Blevins (1990)

da estrutura, $m$ é a massa do cilindro mais qualquer fluido que estiver escoando através dele, $k$ é a rigidez estrutural e $\zeta_{s}$ é o fator de amortecimento estrutural.

A equação 2.24 é do tipo não linear devido ao termo da força de arrasto. Segundo Blevins (1990), existem três alternativas pelas quais se pode resolver a Eq. 2.24, elas são: (i) solução numérica direta obtida através da integração no tempo, (ii) linearização da equação para aproximar uma solução de estado estacionário no domínio da frequência e (iii) solução estática obtida ao desprezar os termos $\ddot{x}$ e $\dot{x}$. Para a primeira alternativa de resolução citam-se alguns métodos de integração numérica, particularmente em Blevins (1990) se apresentam os resultados obtidos através do uso do método de Adams - Bashforth para um escoamento harmônico de frequência $\omega$.

Na Figura 2.18 se apresenta a resposta de duas estruturas calculada pelo método de AdamsBashforth ; a parte (a) corresponde a uma estrutura cuja massa é quase igual à massa de fluido que ela desloca (ou seja neutralmente flutuante) e a parte (b) é a de uma estrutura de massa dez vezes maior do que a massa de fluido que ela desloca, como por exemplo uma estrutura de aço submersa. Para o eixo vertical das figuras se usou a amplitude da resposta dinâmica normalizada pela resposta estática, a qual é entendida como o deslocamento provocado pela força máxima, calculada pela Eq. 2.22, sobre uma estrutura de rigidez $k$. No eixo horizontal a frequência foi 
normalizada pela frequência natural da estrutura $f_{n}$, a qual é calculada com a seguinte equação,

$$
f_{n}=\frac{\omega_{n}}{2 \pi}=\frac{1}{2 \pi}\left(\frac{k}{m_{t}}\right)^{1 / 2}
$$

onde $m_{t}$ é a massa $m$ da estrutura mais a massa adicionada do fluido como aparece na Eq. 2.24:

$$
m_{t}=m+\rho A C_{a}
$$

Como se vê nos resultados, para um fator de amortecimento estrutural $\zeta_{s}$ igual a zero nas duas estruturas, a resposta é maior para baixos valores do fator $U_{m} / f d$. Isso se deve ao fato de que neste caso a força do escoamento oscilatório é dominada pela componente inercial, a qual é independente do deslocamento estrutural, em quanto que para forças dominadas pela componente de arrasto, a força do escoamento é reduzida pelo movimento da estrutura.

Se a estrutura é rígida o suficiente, tal que a sua primeira frequência natural seja mais de cinco vezes maior do que a frequência de oscilação do escoamento, então a avaliação estática do deslocamento da estrutura permite ter uma boa aproximação do deslocamento real. Isso pode ser conferido nos resultados da Fig. 2.18, onde para baixas frequências a amplitude da resposta normalizada está ao redor de 1 .

\section{Soluções lineares}

A Equação 2.22 descreve o deslocamento do cilindro, esta apresenta um termo não linear, o qual corresponde à força de arrasto. Se for considerado que a velocidade da onda do escoamento é muito maior do que a velocidade da estrutura como geralmente acontece, então se pode simplificar o termo não linear da Eq. 2.22 da seguinte forma:

$$
|U-\dot{x}|(U-\dot{x})=|U-\dot{x}| U-|U-\dot{x}| \dot{x} \cong|U| U-|U| \dot{x} \approx|U| U
$$

A substituição da Eq. 2.27 permite linearizar a Eq. 2.24, cujo novo formato é apresentado na Eq. 2.28.

$$
m_{t} \ddot{x}+\left(2 m \zeta_{s} \omega_{n}+\frac{1}{2} \rho d C_{D}|U|\right) \dot{x}+k x=\rho A C_{m} \dot{U}+\frac{1}{2} \rho|U| U d C_{D}
$$

A Equação 2.28 é uma equação linear com coeficientes dependentes do tempo já que na parte esquerda aparece o termo $U(t)$. Para tratar essa dificuldade, a velocidade da onda do escoamento $U(t)$, definida pela Eq. 2.20, é expandida numa série de Fourier, da qual só se toma o primeiro termo, ou seja, só o valor da média. Assim $U$ não está mais em função do tempo. Com essa aproximação a Eq. 2.28 é expressa como:

$$
m_{t} \ddot{x}+\left(2 m_{t} \zeta_{t} \omega_{n}\right) \dot{x}+k x=\rho A C_{m} \dot{U}+\frac{1}{2} \rho|U| U d C_{D}
$$




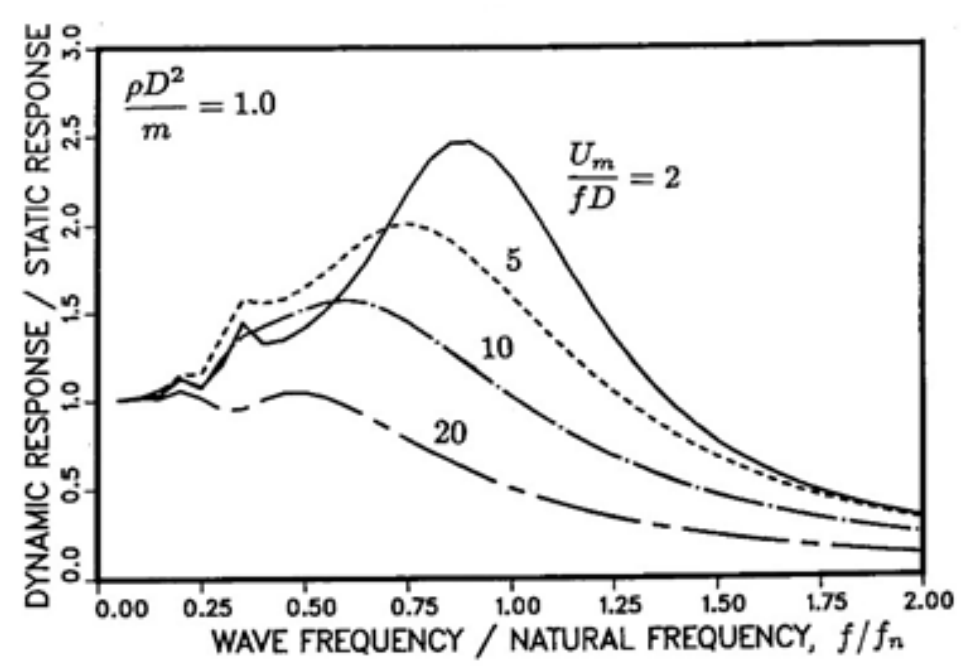

(a) Parâmetro $\rho d^{2} / m=1,0$

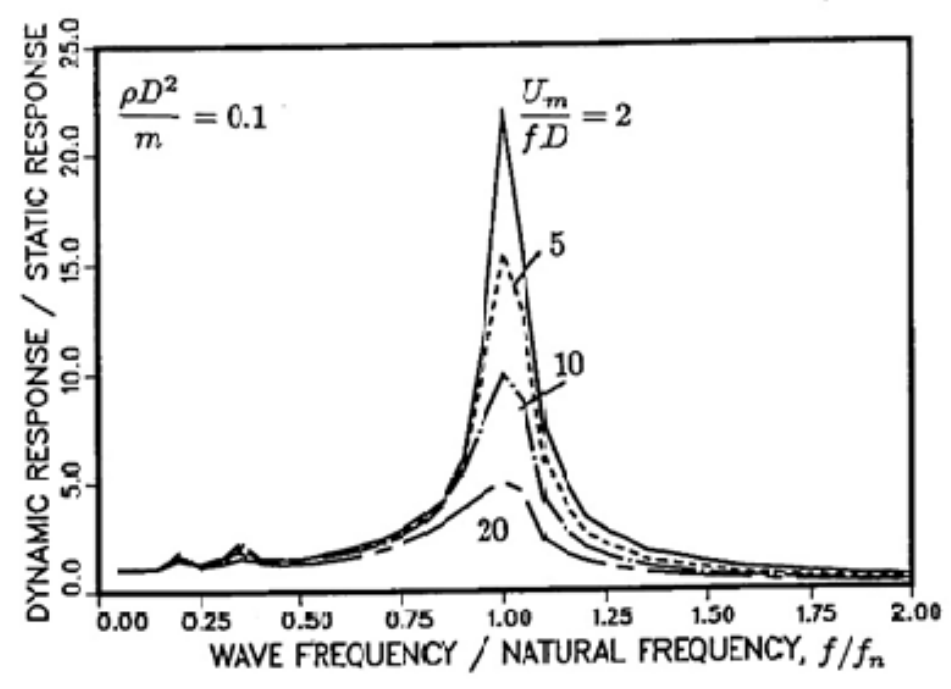

(b) Parâmetro $\rho d^{2} / m=0,1$

Figura 2.18: Máxima resposta dinâmica paralela de uma estrutura de um grau de liberdade a um escoamento oscilatório. $C_{o}=C_{m}=1,5 ; \zeta_{s}=0 ; A=\pi d^{2} / 4$. Tomado de Blevins (1990)

onde o fator de amortecimento total $\zeta_{t}$ é definido pela soma da parcela estrutural e a parcela do fluido.

$$
\zeta_{t}=\zeta_{s} \frac{m}{m_{t}}+\frac{C_{D}}{4} \frac{\rho d^{2}}{m_{t}} \frac{\overline{|U|}}{\omega_{n} d}
$$

Como se explicou acima, o termo $\overline{|U|}$ é o valor médio do valor absoluto da velocidade do escoamento oscilatório, o qual pode ser calculado como se apresenta na Eq.2.31.

$$
\overline{|U|}= \begin{cases}(2 / \pi) U_{m}, & \text { se } U=U_{m} \cos (\omega t) \\ U_{o}, & \text { se } U=U_{o}+U_{m} \cos (\omega t) \text { e } U_{o}>U_{m}\end{cases}
$$


Em Blevins (1990) a solução de estado estável para a Eq. 2.29 é estudada para dois casos: quando a velocidade $U(t)$ está composta pela parcela constante $U_{o}$ mais a parcela oscilatória $U_{m}$ e quando a velocidade só tem a parcela oscilatória. No primeiro caso, a resposta sob a suposição de estado estável na frequência de oscilação do escoamento e seus harmônicos pode ser calculada com a seguinte expressão:

$$
\frac{x(t)}{d}=b_{0}+a_{1} \operatorname{sen}(\omega t)+b_{1} \cos (\omega t)+a_{2} \operatorname{sen}(2 \omega t)+b_{2} \cos (2 \omega t)
$$

Os coeficientes estão definidos pelas seguintes expressões:

$$
\begin{aligned}
& b_{0}=\frac{\rho d^{2}}{2 m}\left(\frac{U_{o}^{2}+\frac{1}{2} U_{m}^{2}}{\omega^{2} d^{2}}\right) C_{D} \\
& a_{1}=\frac{\rho d^{2}}{m} \frac{U_{m}}{\omega_{n} d} \frac{\omega}{\omega_{n}}\left\{2 \zeta_{t} C_{D} \frac{U_{o}}{\omega d}-C_{m} \frac{A}{d^{2}}\left[1-\left(\frac{\omega}{\omega_{n}}\right)^{2}\right]\right\} M F_{1} \\
& b_{1}=\frac{\rho d^{2}}{m} \frac{U_{m}}{\omega_{n} d} \frac{\omega}{\omega_{n}}\left\{2 \zeta_{t} C_{m} \frac{A}{d^{2}}-\frac{U_{o}}{\omega d} C_{D}\left[1-\left(\frac{\omega}{\omega_{n}}\right)^{2}\right]\right\} M F_{1} \\
& a_{2}=\zeta_{t} \frac{\omega}{\omega_{n}} \frac{\rho d^{2}}{m}\left(\frac{U_{m}}{\omega_{n} d}\right)^{2} C_{D} M F_{2}
\end{aligned}
$$

onde $M F_{i}$ é fator de amplificação da resposta dinâmica definido por:

$$
\begin{aligned}
& M F_{i}=\left\{\left[1-\left(\frac{i \omega}{\omega_{n}}\right)^{2}\right]^{2}+\left(\frac{2 \zeta_{i} i \omega}{\omega_{n}}\right)^{2}\right\}^{-1} \\
& i=1,2, \ldots
\end{aligned}
$$

Neste caso a parcela constante da velocidade $U_{o}$ provoca o deslocamento estático da estrutura e amplifica a deformação gerada pelas componentes oscilatórias do escoamento. As ressonâncias na resposta dinâmica aparecem quando a frequência de oscilação do escoamento $\omega$ se iguala à frequência natural da estrutura $\omega_{n}$ e no caso de ressonância sub-harmônica, na qual $\omega$ coincide com a metade do valor $\omega_{n}\left(2 \omega=\omega_{n}\right)$.

Quando se trata de um escoamento composto unicamente por uma parcela oscilatória, o produto de velocidades na expressão da força de arrasto pode ser expandido por uma série de Fourier como se vê na Eq. 2.35.

$$
|U| U=U_{m}^{2}|\cos (\omega t)| \cos (\omega t)=\sum_{i=1,3,5 \ldots}^{\infty} c_{i} \cos (i \omega t)
$$

O coeficiente $c_{i}$ é calculado com a Eq. 2.36:

$$
\begin{aligned}
& c_{i}=\frac{8}{\pi i\left(4-i^{2}\right)} \operatorname{sen}\left(\frac{i \pi}{2}\right) \\
& c_{1}=0,8488 \\
& c_{3}=0,16977 \\
& c_{5}=0,02425
\end{aligned}
$$


A resposta, igual do que no caso anterior, é representada pela expansão numa série de Fourier:

$$
\frac{x(t)}{d}=\sum_{i=0}^{N}\left(a_{i} \operatorname{sen}(i \omega t)+b_{i} \cos (i \omega t)\right)
$$

onde os coeficientes $a_{i}$ e $b_{i}$ estão definidos por:

$$
\begin{aligned}
& b_{0}=0 \\
& a_{1}=\frac{\rho d^{2}}{m} \frac{U_{m}}{\omega_{n} d} \frac{\omega}{\omega_{n}}\left\{\left[1-\left(\frac{\omega}{\omega_{n}}\right)^{2}\right] \frac{A}{d^{2}} C_{m}+\zeta_{t} c_{1} C_{D} \frac{U_{m}}{\omega d}\right\} M F_{1} \\
& b_{1}=\frac{\rho d^{2}}{m} \frac{U_{m}}{\omega_{n} d} \frac{\omega}{\omega_{n}}\left\{c_{1}\left[1-\left(\frac{\omega}{\omega_{n}}\right)^{2}\right] \frac{U_{m}}{\omega d} \frac{C_{D}}{2}+2 \zeta_{t} C_{m} \frac{A}{d^{2}}\right\} M F_{1} \\
& a_{i}=\frac{\rho d^{2}}{m} \frac{i \omega}{\omega_{n}}\left(\frac{U_{m}}{\omega_{n} d}\right)^{2} \zeta_{t} c_{i} C_{D} M F_{i} \\
& i=3,5,7, \ldots \\
& b_{i}=\frac{\rho d^{2}}{m}\left[1-\left(\frac{i \omega}{\omega_{n}}\right)^{2}\right]\left(\frac{U_{m}}{\omega_{n} d}\right)^{2} \zeta_{t} c_{i} C_{D} M F_{i} \\
& i=3,5,7, \ldots \\
& a_{i}=b_{i}=0, i=2,4,6, \ldots
\end{aligned}
$$

Neste caso, quando o escoamento é claramente oscilatório, não há um valor do deslocamento médio estático da estrutura $\left(b_{0}=0\right)$. Quando a frequência da onda do escoamento $\omega$ se aproxima até a frequência natural da estrutura $\omega_{n}$ ou até um submúltiplo dessa frequência $\left[\omega=(1 / j) \omega_{n}, j=3,5, \ldots\right]$, a estrutura entra em ressonância com as componentes da força exercida pelo escoamento. Na Figura $2.18 \mathrm{~b}$ se pode ver a presença desses pequenos picos de ressonância nas frequências sub-harmônicas de $\left(\omega_{n} / 3\right)$ e $\left(\omega_{n} / 5\right)$.

\section{Resposta paralela de estruturas continuas}

A flexão dinâmica de vigas, cabos e varas num escoamento oscilatório é governada pela seguinte equação diferencial parcial:

$$
m \frac{\partial^{2} X(z, t)}{\partial t^{2}}+L[X(z, t)]=F
$$

onde $m$ é massa da estrutura por unidade de comprimento, $X(z, t)$ é o deslocamento na direção paralela ao escoamento, o qual está em função do tempo e da posição ao longo do eixo do corpo na coordenada $z . L[X(z, t)]$ é um operador autoadjunto linear que permite obter a relação força-deslocamento para cada elemento diferencial do corpo submerso no escoamento. Para estruturas relativamente pequenas, o operador $L[X(z, t)]$ é dominado pela rigidez à flexão.

Para a solução da Eq. 2.39 se introduz um conjunto de frequências naturais $\omega_{i}$ relacionadas com os modos de vibração não amortecidos $\widetilde{x}_{i(z)}$. Assim, a solução da Eq. 2.39 está composta pela soma dos deslocamentos modais proposta na Eq. 2.40,

$$
X(z, t)=\sum_{i=1}^{N} x_{i}(t) \widetilde{x}_{l}(z)
$$


Substituindo $X(z, t)$ na Eq. 2.39 e depois de integração ao longo do eixo $z$, se obtêm uma série de equações diferenciais ordinárias desacopladas que descrevem o movimento da estrutura excitada por um escoamento oscilatório de velocidade uniforme $U$ ao longo de $z$, como se vê na Eq. 2.41:

$$
m_{t} \ddot{x}_{i}+2 m_{t} \zeta_{t} \omega_{i} \dot{x}_{i}+m \omega_{i}^{2} x_{i}=\rho A C_{m} \dot{U} \beta_{i}+\frac{1}{2} \rho|U| U d C_{D} \beta_{i}
$$

A Eq.2.41 é do mesmo tipo do que a Eq. 2.28, no entanto, se pode notar a inclusão do termo $\beta_{i}$, o qual depende do tipo de elemento estrutural. Em Blevins (1990) se apresentam valores de $\beta_{i}$ para vários elementos estruturais.

\subsubsection{Força transversal e resposta de um cilindro}

Um cilindro circular exposto a um escoamento oscilatório gera desprendimento de vórtices, os quais produzem forças que excitam o tubo na direção perpendicular ao escoamento. Em Blevins (1990) tem-se usado o número de Keulegan - Carpenter para caracterizar os regimes de vibração perpendicular do cilindro. O número de Keulegan - Carpenter, $K c$, é calculado por meio da Eq. 2.42.

$$
K c=\frac{U_{m}}{f d}=\frac{2 \pi U_{m}}{\omega d}=\frac{U_{m} T}{d}
$$

Quando $K c>30$, o período de desprendimento de vórtices, $T_{s} \approx 5 d / U_{m}$, é uma pequena fração do período de oscilação do escoamento, $T=d K c / U_{m}$, e a formulação para desprendimento de vórtices apresentada na seção 2.1 pode ser usada. No entanto, quando $K c<30$ o desprendimento de vórtices interage fortemente com a oscilação do escoamento. Blevins (1990) faz uma recopilação de vários estudos e descreve os diferentes regimes de vibração transversal em função de valores de $K c$. Quando $K c<0,4$ o escoamento não se separa da parte posterior do cilindro e não se apresentam forças transversais. No seguinte regime definido no intervalo $0,4<K c<4$, vórtices simétricos se formam na esteira do cilindro, mas as forças transversais são mínimas. Isto muda para o regime $4<K c<8$, onde um dos vórtices é mais forte provocando assimetria e com isso a vibração do cilindro. A frequência dominante de vibração transversal $f_{s}$ é o dobro da frequência de oscilação do escoamento $f$. No seguinte regime, $8<K c<15$, os pares de vórtices se desprendem alternadamente na metade do ciclo de oscilação do escoamento. $f_{s}$ continua sendo o dobro de $f$. No regime $15<K c<22$, múltiplos pares de vórtices se desprendem do cilindro por cada ciclo de oscilação do escoamento. A frequência dominante de desprendimento de vórtices e força transversal $f_{s}$ é três vezes maior do que a frequência do escoamento $f$. Para o intervalo $15<K c<22, f_{s}$ chega a ser 4 vezes o valor de $f$. Finalmente, quando $K c>30$ se produz um estado quase estável de desprendimento de vórtices, onde $f_{s}$ é aproximadamente o múltiplo mais próximo de $f$ correspondente à relação de Strouhal: 


$$
\begin{aligned}
& \frac{f_{s}}{f}=2,3,4,5, \ldots=\text { um inteiro } \approx 0,2 K c \\
& \text { com: } \\
& f_{s} \approx 0,2 \frac{U_{m}}{d}
\end{aligned}
$$

Na Figura 2.19 se apresenta a oscilação da força transversal para diferentes valores de $K c$ dentro de um período de oscilação do escoamento. Como foi descrito nos parágrafos acima, em quanto o valor de $K c$ aumenta, a frequência da força também aumenta.

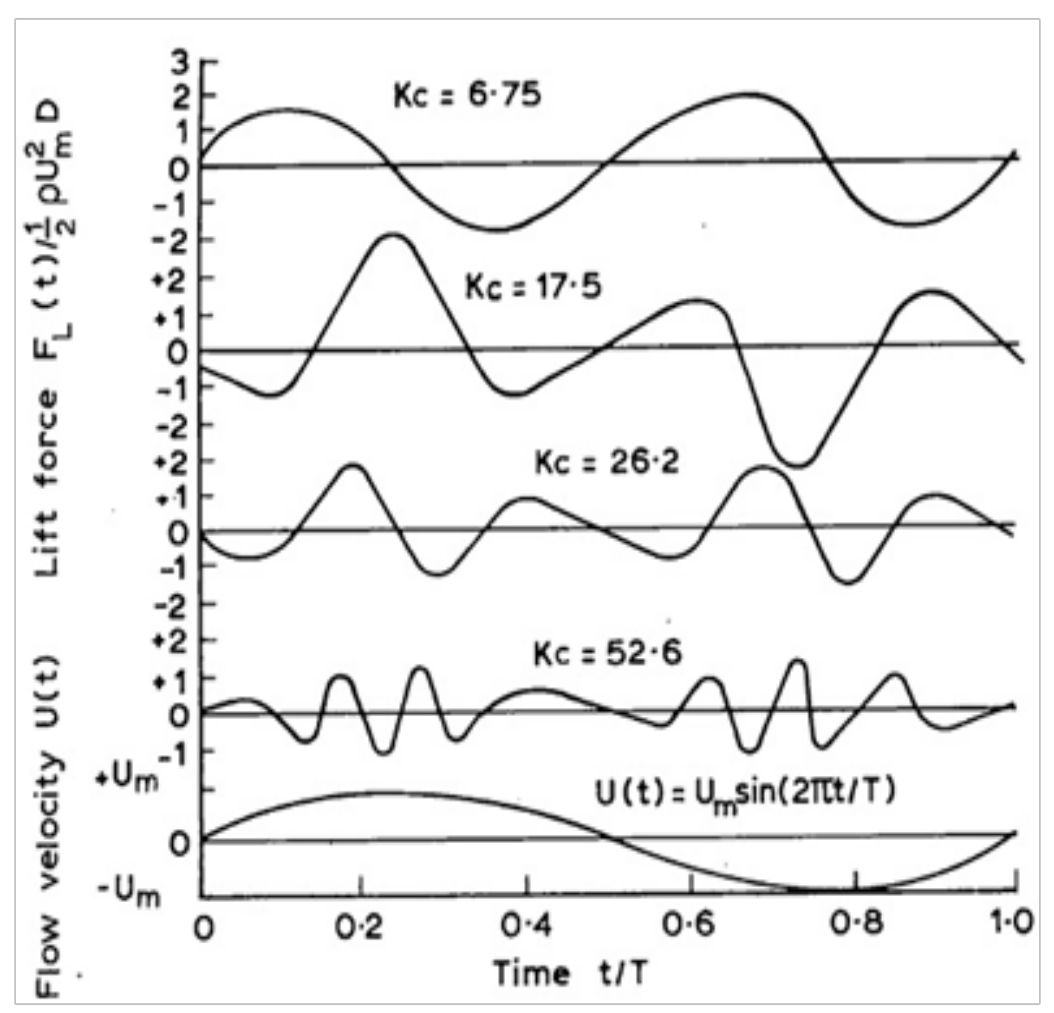

Figura 2.19: Força transversal em função do tempo sobre um cilindro circular em escoamento oscilatório para vários números de Keulengan - Carpenter. Tomada de Obasaju et al. (1988)

Bearman et al. (1984), Bearman e Hall (1987) e Graham (1987) propuseram o seguinte modelo para estimar a força transversal por unidade de comprimento sobre um cilindro circular num escoamento oscilatório de frequência harmônica:

$$
F_{L}(t)=\frac{1}{2} \rho U_{m}^{2} d C_{L} \cos (\phi) \operatorname{sen}^{2}(2 \pi f t)
$$

$C_{L}$ é o coeficiente da força transversal e $\phi$ é uma função do tempo representada por:

$$
\phi=0,2 K c[1-\cos (2 \pi f t)]+\psi
$$

onde $\psi$ é uma constante que dá a fase da força transversal quando $t=0$ e depende do histórico do escoamento. Blevins (1990) cita que para cilindros circulares o valor do coeficiente $C_{L}$ 
varia com outros fatores como o deslocamento do cilindro e a correlação do desprendimento de vórtices ao longo do cilindro.

Como resumo se pode dizer que no escoamento continuo e no oscilatório, o desprendimento de vórtices produz uma resposta ressonante, uma faixa de sintonização de frequência e uma amplitude de vibração auto-limitada de ao redor de 2 ou 3 diâmetros. As principais diferenças que se podem citar são que, no escoamento oscilatório a frequência de desprendimento se sintoniza a si mesma a um inteiro múltiplo da frequência de oscilação do escoamento e que devido a que a frequência de desprendimento pode variar dentro de um ciclo de oscilação do escoamento então ressonâncias podem ser formadas ou destruídas dentro desse lapso de tempo.

\subsection{Instabilidade fluido-elástica}

\subsubsection{Descrição da instabilidade fluido-elástica}

Os tubos que fazem parte de um banco instalado dentro de um aparelho de troca de calor são inevitavelmente excitados quando são expostos a um escoamento cruzado. Experimentalmente tem-se observado que após uma velocidade crítica do escoamento, $U_{\text {crit }}$, os tubos começam a vibrar com amplitudes maiores às normais, as quais praticamente são só limitadas pelo batimento contra outros tubos ou estruturas adjacentes. Esse mecanismo de vibração é conhecido como instabilidade fluido-elástica e pode provocar o colapso do aparelho em poucas horas. É importante mencionar que a instabilidade fluido-elástica não se apresenta quando o escoamento bate um único cilindro, senão quando ele pertence a um arranjo.

A instabilidade fluido-elástica foi explicada por Connors no ano 1969 como um fenômeno no qual o banco de tubos é capaz de se autoexcitar absorvendo a energia do fluido que passa através dele. Esta energia é maior do que a dissipada pelo amortecimento do fluido gerando assim vibrações de cada vez maior amplitude. Os dois primeiros modelos publicados para explicar a instabilidade fluido-elástica foram os desenvolvidos por Roberts (1966) e Connors (1970). Roberts observou que os jatos de fluido formados a jusante de uma fila de tubos se juntam. A união desses jatos se produz ao tempo que o cilindro se desloca para frente e para trás, como se vê na Fig. 2.20. Este mecanismo induz mudanças na força de arrasto que atua sobre os cilindros alternados atrás da primeira fileira de cilindros. Roberts observou que aqueles cilindros respondiam a aquelas forças vibrando com grandes amplitudes quando a velocidade do escoamento supera uma velocidade crítica. Aquela instabilidade foi atribuída à defasagem entre o deslocamento do tubo e a força desestabilizadora exercida pelo fluido, sendo chamada de Time Lag Mechanism.

Outro modelo foi proposto por Connors (1970). Ele, para estudar este fenômeno, fez testes numa fila de tubos suspensos por fios de aço num túnel de vento. Ele considerou a instabilidade fluido-elástica como resultado do deslocamento induzido por forças do fluido geradas pela interação entre tubos adjacentes, os quais vibram em órbitas elípticas sincronizadas como se vê na Fig. 2.21. Connors apresenta à instabilidade como produto da interação provocada pelo deslocamento relativo entre tubos adjacentes e portanto o modelo tomou o nome de Displa- 


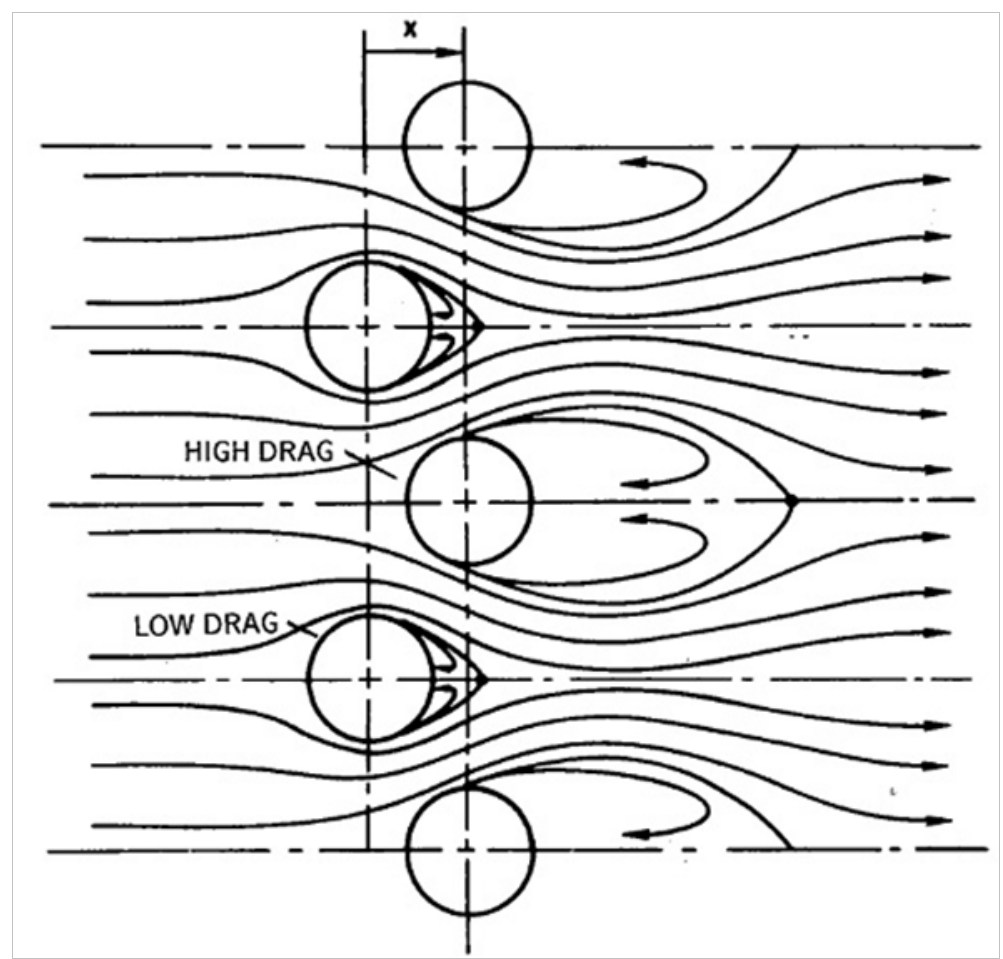

Figura 2.20: União de jatos na esteira do tubo. Tomado de Roberts (1966)

cement Mechanism. Uma consequência deste modelo é que numa bancada de tubos rígidos e um único tubo flexível a instabilidade não deveria aparecer. Isso foi conferido por Price et al. (1987) num banco de tubos de distribuição quadrada e razão $\tau$ igual a 2,12. No entanto, Weaver e Yeung (1983) reportaram instabilidade fluido-elástica numa seção de testes com um único tubo montado elasticamente num banco de tubos de distribuição quadrada e razão $\tau$ igual a 1,5. Este fato sugere, segundo Blevins (1990), que o modelo proposto por Connors e o proposto por Roberts podem estar operando ao mesmo tempo, e que a instabilidade fluido-elástica não pode ser explicada por um único modelo simples.

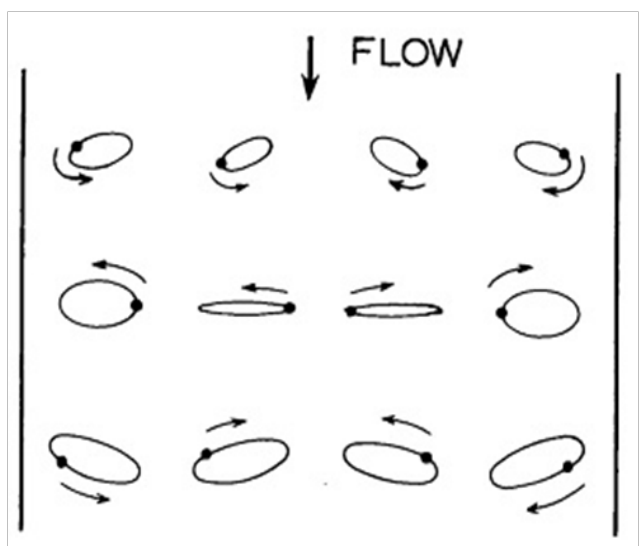

Figura 2.21: Vibração com órbita elíptica de um arranjo de tubos exposto a um escoamento. Tomado de Tanaka e Takahara (1981) 
Quando um banco de tubos entra na instabilidade a amplitude das oscilações aumenta rapidamente com a velocidade do escoamento. Segundo Blevins (1990), a amplitude de oscilação de um tubo num banco pode ser expressa como $U^{n}$, onde $n=4$ após a entrada à instabilidade, comparado com $n=1,5$, que é o valor aproximado do expoente antes de ultrapassar a velocidade crítica (ver Fig. 2.21) e os tubos oscilam nas suas próprias frequências naturais e modos de vibração. Alguns estudos citados em Blevins (1990) reportaram que é possível retardar a velocidade de entrada à instabilidade mediante a desintonização das frequências naturais dos tubos dentro do arranjo, no entanto, isso não ocorreu em todos os testes e em ocasiões a velocidade crítica se manteve. Frequentemente a entrada à instabilidade é mais gradual num arranjo com tubos com diferentes frequências naturais como se pode ver na Fig. 2.23, onde se apresenta uma amplitude de vibração adimensionalizada em função da velocidade reduzida do escoamento entre tubos para dois tipos diferentes de tubulação.

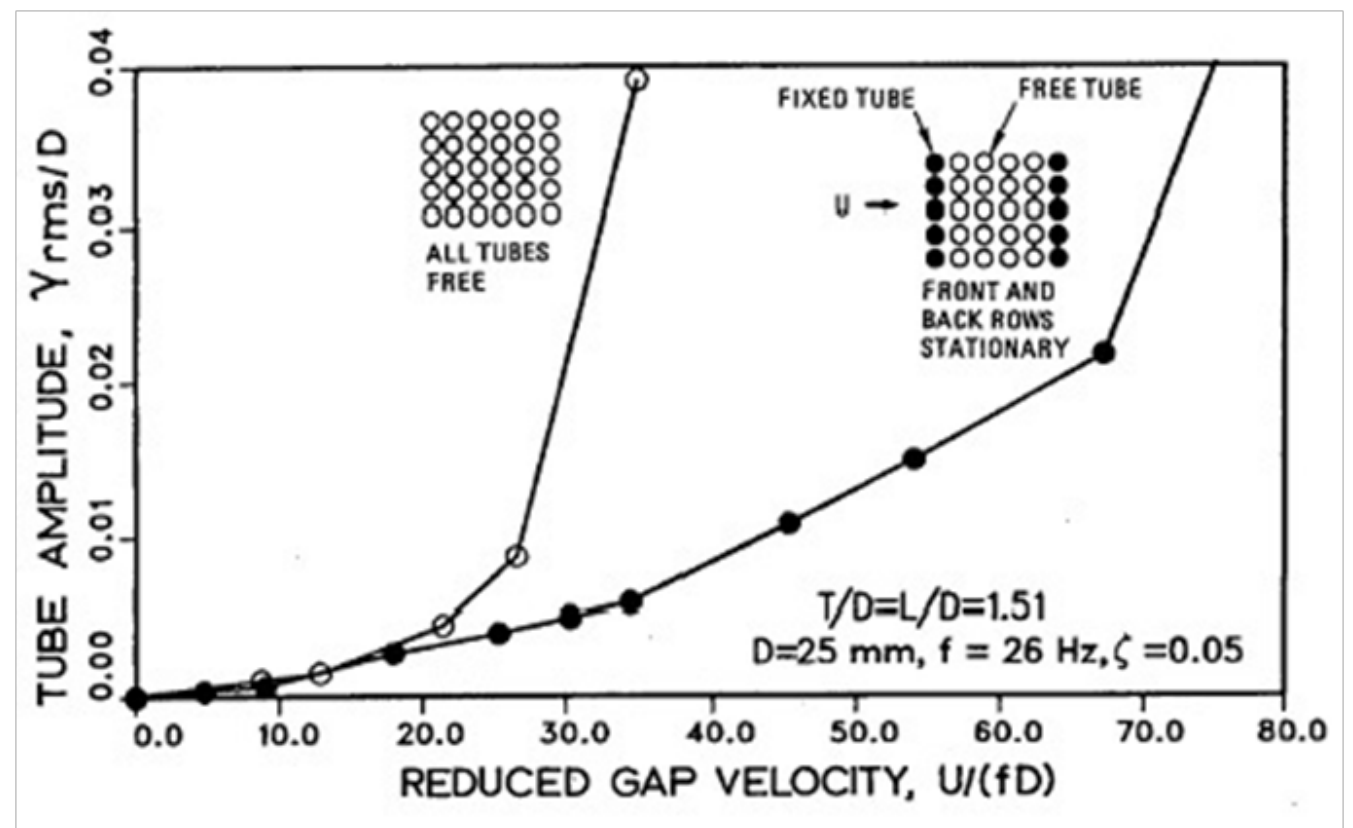

Figura 2.22: Amplitude de vibração do tubo em função da velocidade do escoamento entre tubos. $\circ$ Todos os tubos livres e $\bullet$ Os tubos dos extremos fixos. $\left(m /\left(\rho d^{2}\right)=370\right)$. Tomado de Blevins (1990)

A instabilidade fluido-elástica ocorre tanto em escoamentos de líquido como gás. Segundo a informação apresentada em Blevins (1990), nos dois casos a instabilidade fluido-elástica se manifesta como vibrações de grande amplitude, no entanto, uma diferença notável é que quando o escoamento é líquido o lock-in correspondente ao desprendimento de vórtices se apresenta perto da velocidade crítica de instabilidade. Em escoamento gasoso, geralmente a velocidade de entrada à instabilidade esta afastada da velocidade do lock-in como se vê na Fig. 2.23.

Como se pode ver na Fig. 2.23, o incremento da amplitude de oscilação devido à instabilidade é súbito. Por essa razão para as equipes de projeto de equipamentos formados por tubulações é extremamente importante poder estimar a velocidade crítica de entrada à instabili- 


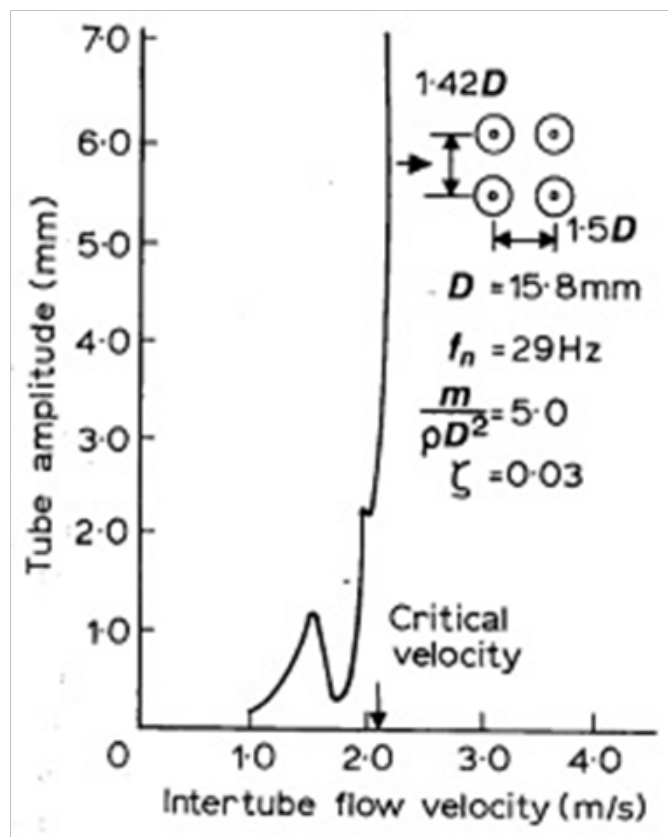

(a)

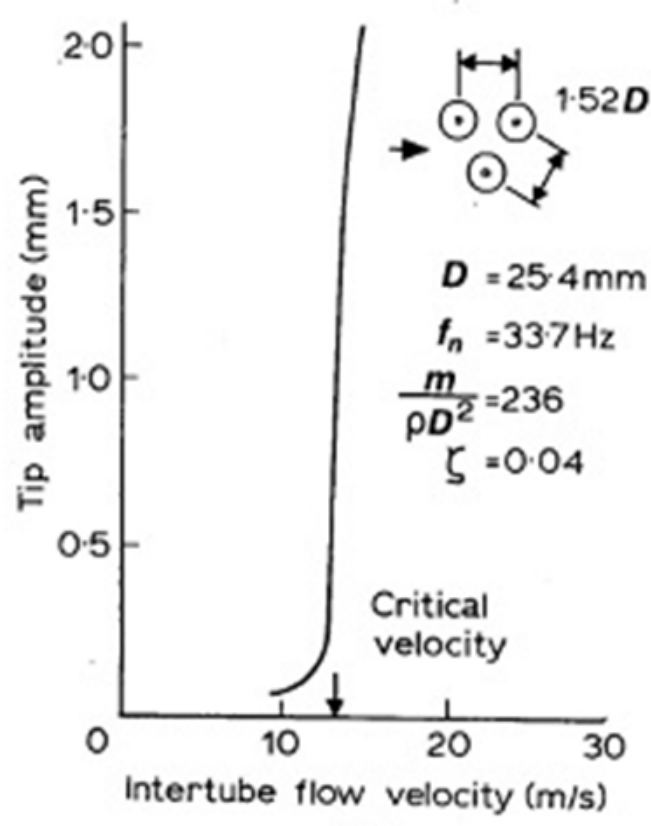

(b)

Figura 2.23: Resposta de arranjos de tubos a escoamento cruzado. a) Tubos de bronze em escoamento de água ((CHEN et al., 1978)) e b) Tubos de plástico em escoamento de ar ((SOPER, 1983))

dade. Um método disponível para essa estimação é através da análise adimensional. Em Blevins (1990) cita-se que a velocidade crítica de instabilidade pode ser expressa em função da velocidade reduzida $\left(U / f_{n} d\right)$, a razão de massa $\left(m / \rho d^{2}\right)$, o fator de amortecimento $\zeta$, a razão de passo transversal e diâmetro $\tau$ e configuração do arranjo, o número de Reynolds $R e$ e a turbulência do escoamento a montante do banco de tubos. No entanto, não existem dados experimentais que confirmem claramente a influência de $R e$, nível de turbulência e configuração do arranjo na velocidade crítica. Desse jeito, uma expressão com formato mais simples é apresentada na Eq. 2.46:

$$
\frac{U_{c r i t}}{f_{n} d}=C\left[\frac{m(2 \pi \zeta)}{\rho d^{2}}\right]^{a}
$$

onde:

$d$ é o diâmetro externo do tubo,

$f_{n}$ é a frequência natural do tubo expressada em Hertz, geralmente o primeiro modo de vibração do tubo já que é o primeiro em ser excitado,

$m$ é a massa por unidade de comprimento do tubo, incluindo o fluido interno,

$U_{c r i t}$ é a velocidade média através do menor espaço entre tubos no arranjo. Esse valor corresponde ao valor crítico de entrada à instabilidade do sistema,

$\zeta$ é o fator de amortecimento, que segundo Blevins (1990) frequentemente está na faixa entre 0,01 e 0,03 . No entanto, quando a vibração é de grande amplitude pode chegar até 0,05 . Se o tubo não estiver apoiado em nenhuma parte do seu comprimento $\zeta$ pode cair até 0,001 ; 
$\rho$ é a densidade do fluido escoando. Se for um escoamento bifásico líquido - gás, a expressão do modelo homogêneo pode ser usada.

O conjunto $(2 \pi \zeta)$ é igual a $\delta$, o qual no campo de estudo das vibrações é conhecido como decremento logarítmico. O coeficiente $C$ e o expoente $a$ se obtêm por ajuste de curvas de resultados experimentais. Na Figura 2.24 se apresentam 170 pontos correspondentes às medições de velocidade crítica para vários tipos de configurações com razões $\tau$ entre 1,1 e 2,0 para testes com escoamento monofásico de água e ar. A linha pontilhada corresponde ao coeficiente $C_{m e d}$, que é o coeficiente da curva obtida através da média dos valores de velocidade crítica medida, e a curva sólida representa ao coeficiente $C_{90 \%}$, o qual representa um limite inferior estatístico. Acima da linha sólida estão o 90\% das medições. Na discussão proposta por Blevins (1990) se destaca a dispersão das medições em torno do parâmetro $m(2 \pi \zeta) / \rho d^{2} \approx 0,7$; o qual sugere que dois diferentes mecanismos de instabilidade podem estar operando nessa região. Por essa razão, nesta fonte bibliográfica a curva foi ajustada em dois intervalos, acima e embaixo de $m(2 \pi \zeta) / \rho d^{2} \approx 0,7$; como se vê na Tab. 2.3.

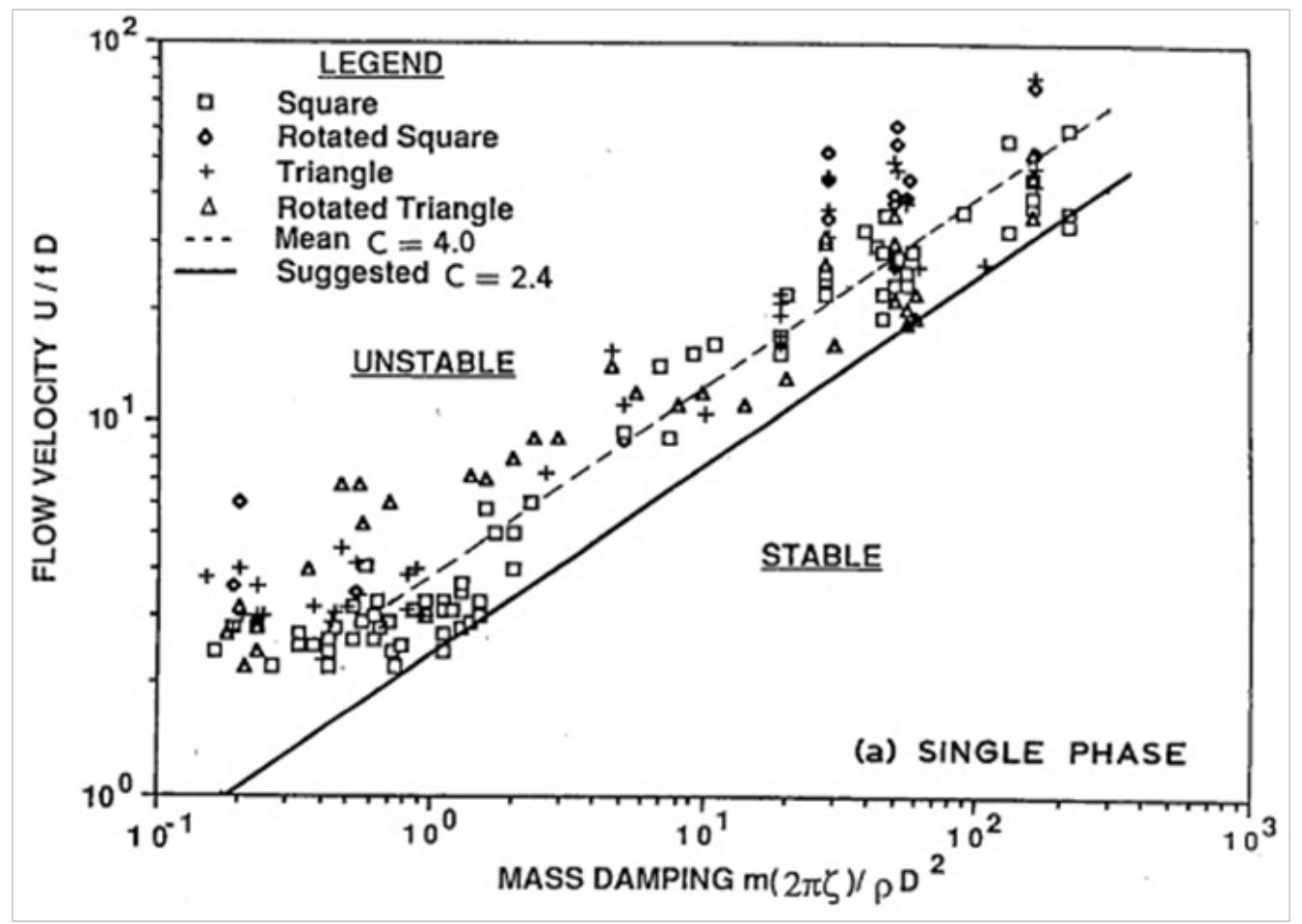

Figura 2.24: Velocidade crítica de instabilidade em escoamento monofásico. Tomado de Blevins (1990)

Estudos experimentais em Pettigrew e Taylor (1991) têm mostrado que o valor de $a$ é tipicamente igual a 0,5 tal como se apresenta na Tab. 2.3. Baseado em Blevins (1990), para o intervalo $m(2 \pi \zeta) / \rho d^{2}>0,7$; existem as suficientes medições para calcular valores de $C_{m e d} \mathrm{e}$ $C_{90 \%}$ para diferentes configurações de banco de tubos. Esses valores se apresentam na Tab. 2.4.

O valor do coeficiente $C_{90 \%}$ é 2,4 para todas as configurações de bancos de tubos. O có- 
Tabela 2.3: Valores de $C$ e $a$ para escoamento monofásico para intervalos do parâmetro massa de amortecimento. Tomado de Blevins (1984a)

\begin{tabular}{|c|c|c|c|}
\hline Parâmetro massa de amortecimento & $C_{\text {med }}$ & $C_{90 \%}$ & a \\
\hline$m(2 \pi \zeta) / \rho d^{2}<0,7$ & 3,9 & 2,7 & 0,21 \\
\hline$m(2 \pi \zeta) / \rho d^{2}>0,7$ & 4,0 & 2,4 & 0,5 \\
\hline
\end{tabular}

Tabela 2.4: Coeficientes de ajuste da curva da velocidade crítica para diferentes tipos de tubulações. Tomado de Blevins (1990)

\begin{tabular}{|c|c|c|c|c|c|c|}
\hline$C$ & Triangular & $\begin{array}{l}\text { Triangular } \\
\text { rotacionado }\end{array}$ & $\begin{array}{l}\text { Quadrado } \\
\text { rotacionado }\end{array}$ & Quadrado & $\begin{array}{l}\text { Todas as confi- } \\
\text { gurações }\end{array}$ & $\begin{array}{l}\text { Filas de } \\
\text { tubos }\end{array}$ \\
\hline$C_{\text {med }}$ & 4,5 & 4,0 & 5,8 & 3,4 & 4,0 & 9,5 \\
\hline$C_{90 \%}$ & 2,8 & 2,3 & 3,5 & 2,4 & 2,4 & 6,4 \\
\hline
\end{tabular}

digo ASME para a fabricação de caldeiras e recipientes a pressão, seção 3, sugere o uso deste valor para o projeto de aparelhos com tubulações. Para um arranjo de uma única fila com $m(2 \pi \zeta) / \rho d^{2}>5$, os dados experimentais sugerem usar $C_{90 \%}=6,4$.

\subsubsection{Teoria da instabilidade fluido-elástica}

A descrição do mecanismo de instabilidade fluido-elástica requer de modelos teóricos precisos que permitam descrever a ação das forças do fluido sobre o banco de testes. No entanto, esse problema não tem sido completamente resolvido, ou seja, um modelo teórico que descreva uma fronteira completa entre o regime estável e instável não tem sido estabelecido até hoje. É essa a razão pela qual nenhum dos modelos desenvolvidos consegue prever a instabilidade num banco de tubos sem antes ter rodado testes nele. Apesar disso, em caso de não existir resultados experimentais prévios, uma boa aproximação da fronteira de instabilidade pode ser obtida através dos resultados experimentais apresentados na Fig. 2.24.

O modelo chamado mecanismo de deslocamento (Displacement Mechanism) para instabilidade fluido-elástica foi proposto na década dos anos 70. A hipótese que usa o modelo é que a força fluido-elástica tem uma relação linear com o deslocamento do tubo, justificando assim seu nome. Neste modelo dois coeficientes da força devem ser definidos experimentalmente já que eles dependem da configuração do banco de tubos. No entanto, devido à dispersão apresentada quando o parâmetro massa - amortecimento é aproximadamente igual a 0,7; presumiu-se a existência de outro mecanismo de instabilidade atuando neste mesmo range de valores do parâmetro mencionado. Após uns anos, na década dos anos 80, foi estabelecida a existência de outro mecanismo atuando paralelamente ao modelo de deslocamento, o qual foi denominado como mecanismo de velocidade. Segundo Blevins (1990), em termos aproximados, a instabilidade em $m(2 \pi \zeta) / \rho d^{2}>0,7$ pode ser associado com o modelo do mecanismo de deslocamento 
e para $m(2 \pi \zeta) / \rho d^{2}<0,7$ a instabilidade está relacionada com o fenômeno de defasagem entre a força do fluido e deslocamento dos tubos, amortecimento negativo, ou talvez desprendimento de vórtices.

\section{Mecanismo de deslocamento}

A distribuição do fluido que atravessa um banco de tubos depende diretamente do deslocamento relativo entre cada um deles. Quando um tubo se desloca levemente numa fila do arranjo se produz uma mudança na distribuição do fluido tal que a força estável que exerce o fluido sobre os tubos muda também. Para modelar a variação da força gerada pelo deslocamento relativo entre tubos se considera um sistema mecânico como o proposto na Fig. 2.25. Neste sistema se representa três tubos adjacentes do arranjo, definidos como $j-1, j$ e $j+1$, os quais podem se deslocar nas direções paralela e perpendicular à direção do escoamento $\left(x_{j}, y_{j}\right)$. Ao igual do que em outros sistemas, a rigidez de cada estrutura é representada como uma mola.

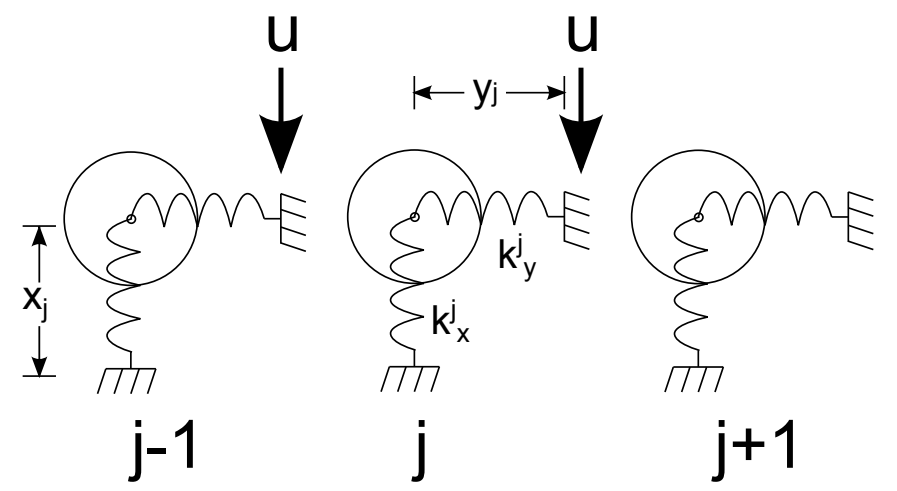

Figura 2.25: Modelo mecânico de fila de tubos (Amortecedores paralelos às molas não apresentados). Inspirado em Blevins (1990)

A mudança na força do fluido exercida sobre os tubos por unidade de comprimento pode ser expressa como:

$$
\begin{aligned}
& F_{x}^{j}=\frac{\rho U^{2}}{4} g_{x}\left(x_{j+1}-x_{j}, x_{j}-x_{j-1}, y_{j+1}-y_{j}, y_{j}-y_{j-1}\right) \\
& F_{y}^{j}=\frac{\rho U^{2}}{4} g_{y}\left(x_{j+1}-x_{j}, x_{j}-x_{j-1}, y_{j+1}-y_{j}, y_{j}-y_{j-1}\right)
\end{aligned}
$$

onde as funções $g_{x}$ e $g_{y}$ tem unidades de 1/comprimento e expressam a variação da força do fluido sobre um tubo devido a deslocamento de tubos adjacentes. Expressões teóricas para as funções $g_{x}$ e $g_{y}$ têm sido desenvolvidas por Balsa (1977), Lever e Weaver (1982), Paidoussis et al. (1984) e experimentalmente medidas por Connors (1970), Tanaka e Takahara (1981), Hara (1989) e Price e Valerio (1989).

As expressões mostradas na Eq. 2.47 devem ser combinadas com a condição de simetria da força do fluido expressa como: 


$$
\begin{gathered}
\frac{\partial g_{x, y}}{\partial\left(x_{j}-x_{j-1}\right)_{x=y=0}}=\mp \frac{\partial g_{x, y}}{\partial\left(x_{j+1}-x_{j}\right)_{x=y=0}}=K_{x, y} \\
\frac{\partial g_{x, y}}{\partial\left(y_{j}-y_{j-1}\right)_{x=y=0}}= \pm \frac{\partial g_{x, y}}{\partial\left(y_{j+1}-y_{j}\right)_{x=y=0}}=C_{x, y}
\end{gathered}
$$

Os subíndices apresentados em $g_{x, y}, K_{x, y}, C_{x, y}$ se referrem a cada expressão representa duas equações, a primeira para as componentes de $x$, e a segunda para os componentes de $y$. Expressões para as forças em $x$ e $y$ podem ser obtidas a partir de combinar a Eq. 2.47 com a Eq. 2.48 e supondo que a força do fluido varia suavemente com o deslocamento do tubo de forma que $g_{x}$ e $g_{y}$ podem ser representados só pelos seus componentes lineares. Uma vez definidas as forças, estas podem ser colocadas do lado direito das equações de balance dinâmico para o tubo $j$ em cada uma das coordenadas como se vê na Eq. 2.49.

$$
\begin{aligned}
& m \ddot{x}_{j}+2 m \zeta_{x}^{j} \omega_{x}^{j} \dot{x}_{j}+k_{x}^{j} x_{j}=\frac{1}{4} \rho U^{2}\left[K_{x}\left(-x_{j+1}-x_{j-1}+2 x_{j}\right)\right]+C_{x}\left(y_{j+1}-y_{j-1}\right) \\
& m \ddot{y}_{j}+2 m \zeta_{y}^{j} \omega_{y}^{j} \dot{y}_{j}+k_{y}^{j} x_{j}=\frac{1}{4} \rho U^{2}\left[C_{y}\left(-y_{j+1}-y_{j-1}+2 y_{j}\right)\right]+K_{y}\left(x_{j+1}-x_{j-1}\right)
\end{aligned}
$$

onde $m$ é a massa do tubo por unidade de comprimento, a qual já inclui a massa adicionada pelo fluido. $\omega_{x}^{j}$ e $\omega_{y}^{j}$ são as frequências naturais circulares do tubo. O amortecimento está representado pelos fatores $\zeta_{x}^{j}$ e $\zeta_{y}^{j}$, os quais incluem a componente do estrutural mais o amortecimento exercido pelo fluido.

Com ajuda de várias hipóteses simplificadoras descritas em Blevins (1990), as equações do movimento para o tubo $j$ na coordenada paralela ao escoamento e para o tubo $j+1$ na coordenada perpendicular ao escoamento podem ser expressas como aparece na Eq. 2.50.

$$
\begin{aligned}
& m \ddot{x}_{j}+2 m \zeta_{x}^{j} \omega_{x}^{j} k_{x}^{j} \dot{x}_{j}=\frac{1}{2} \rho U^{2} C_{x} y_{j+1} \\
& m \ddot{y}_{j+1}+2 m \zeta_{y}^{j+1} \omega_{y}^{j+1} \dot{y}_{j+1}+k_{y}^{j+1} y_{j+1}=-\frac{1}{2} \rho U^{2} K_{y} x_{j}
\end{aligned}
$$

Com estas expressões, e depois da analise descrita em Blevins (1990), a expressão para o cálculo da velocidade crítica é expressa como:

$$
\frac{U_{\text {crit }}}{\left(f_{x} f_{y}\right)^{1 / 2} d}=\frac{2^{3 / 2} \pi}{\left(C_{x} K_{y}\right)^{1 / 4}}\left(\frac{m}{\rho d^{2}}\right)^{1 / 2}\left[\left(1-\frac{f_{x}}{f_{y}}\right)^{2}+4 \zeta^{2}\right]^{1 / 4}
$$

$\mathrm{Na}$ Equação 2.51 o amortecimento é representado por $\zeta$ e é considerado igual nas duas direções. Além disso, nesta equação aparecem as frequências naturais $f_{x}$ e $f_{y}$, as quais correspondem à oscilação de dois tubos adjacentes em duas direções diferentes. A Equação 2.51 prediz que a velocidade crítica de entrada na instabilidade aumenta com o amortecimento e com a desintonização das frequências naturais dos tubos que conformam o banco. Os dois efeitos tem sido vistos experimentalmente. Se as frequências naturais dos tubos são iguais então a 
Eq. 2.51 fica mais simples ainda, tal como foi proposta em Connors (1970):

$$
\frac{U_{c r i t}}{f_{n} d}=C\left(\frac{m(2 \pi \zeta)}{\rho d^{2}}\right)^{1 / 2}
$$

onde,

$$
C=\frac{2(2 \pi)^{1 / 2}}{\left(C_{x} K_{y}\right)^{1 / 4}}
$$

e o conjunto $C_{x} K_{y}{ }^{1 / 4}$ é medido experimentalmente para cada tipo de banco de tubos.

A Equação 2.51 prediz que diferenças na frequência natural dos tubos aumenta a velocidade crítica de entrada na instabilidade. Além disso, o modelo de mecanismo de deslocamento gera a predição de que se um único tubo flexível, rodeado de tubos rígidos, será sempre estável. No entanto, testes mostram que a desintonização dos tubos nem sempre consegue aumentar a velocidade crítica e que tem ocasiões nas quais um único tubo flexível entra em instabilidade apesar de estar rodeado de tubos rígidos. Segundo Blevins (1990), em fluidos densos como água, o expoente do parâmetro $m(2 \pi \zeta) / \rho d^{2}$ é menor do que $1 / 2$, ele menciona que um valor de 0,2 permite um melhor ajuste dos resultados experimentais.

\section{Mecanismo de velocidade}

O mecanismo de deslocamento está baseado em que o fluido responde de forma instantânea ao deslocamento do tubo. No entanto, entre a força do fluido e o deslocamento do tubo se apresenta uma defasagem, a qual é curta, mas é finita. Aquele intervalo de tempo, definido como $\tau$, tem sido modelado por alguns pesquisadores. As expressões para essa defasagem $\tau$ apresentadas em Blevins (1990) são:

$$
\tau= \begin{cases}\frac{10 d}{U}, & \text { Roberts (1966) } \\ \frac{P}{U}, & \text { Lever e Weaver (1982) } \\ \frac{d}{U}, & \text { Price e Paidoussis (1986) }\end{cases}
$$

Os resultados experimentais reportados por Roberts correspondem ao tempo para a ativação dos jatos atrás dos tubos. Neste modelo, $U$ é a velocidade do escoamento antes de entrar no banco de tubos. Nos modelos de Lever e Weaver (1982) e Price e Paidoussis (1986) $\tau$ é a defasagem entre o deslocamento dos tubos e a força exercida pelo fluido e $U$ é a velocidade do escoamento entre os tubos.

Outro fenômeno não considerado no mecanismo de deslocamento é o amortecimento gerado pelo fluido. Esse fenômeno é descrito por Blevins (1990) como uma componente de força que surge no fluido quando a velocidade relativa entre o tubo e o fluido aumenta. Expressões para estimar o amortecimento gerado pelo arrasto do fluido são apresentadas na Eq.2.55. 


$$
\begin{aligned}
& 2 \pi \zeta_{x}=\frac{C_{D}}{2} \frac{\rho d^{2}}{m} \frac{U}{f d} \\
& 2 \pi \zeta_{y}=\frac{C_{D}}{4} \frac{\rho d^{2}}{m} \frac{U}{f d}
\end{aligned}
$$

Nestas expressões $C_{D}$ é o coeficiente de força de arrasto, $\zeta_{x}$ e $\zeta_{y}$ são os fatores de amortecimento nas direções $x$ e $y$. A Figura 2.26 mostra o amortecimento transversal ao deslocamento induzido pelo arrasto do fluido. Usou-se um valor de $C_{D}$ igual a 0,8 baseado no modelo de carga prevista através de testes num banco de tubos. Como se pode ver, o modelo teórico prediz satisfatoriamente o amortecimento até uma velocidade do escoamento de $2 \mathrm{~m} / \mathrm{s}$. Neste ponto o valor do amortecimento diminui bruscamente e chega a ser negativo ao tempo que o banco de tubos chega a ser instável. Isto, segundo Blevins (1990), sugere que possivelmente a defasagem entre o deslocamento do tubo e a força do fluido gera um efeito de amortecimento negativo no sistema.

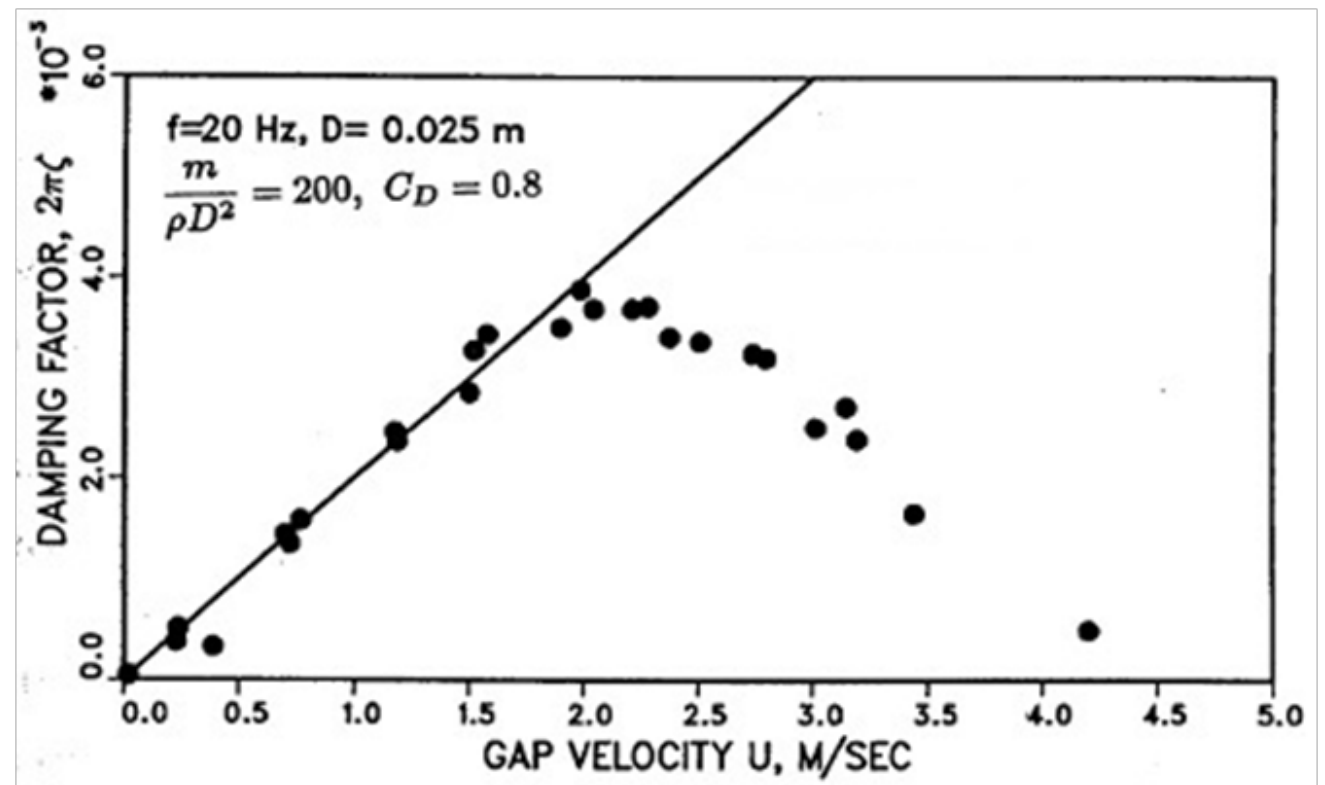

Figura 2.26: Resultados experimentais apresentados em Weaver e El-Kashlan (1981) para amortecimento dinâmico gerado por um fluido na direção transvversal ao escoamento num banco de tubos em configruação triangular rotacionada $P / d=1,375$

O fenômeno de instabilidade gerado pelo amortecimento negativo pode ser examinado se a Eq.2.49 é expressa para um único tubo flexível rodeado de tubos estáticos, é dizer $x_{j+1}=$ $x_{j-1}=y_{j+1}=y_{j-1}=0$. A equação de equilíbrio dinâmico na coordenada $y$ está definida por:

$$
m \ddot{y}+2 m \zeta_{y} \omega_{y} \dot{y}+k_{y} y=\frac{1}{2} \rho U^{2} C_{y} y
$$

Neste ponto Blevins (1990) menciona que a Eq.2.56 é estável para pequenas forças do fluido já que essas forças atuam em fase com o deslocamento do tubo e, além disso, são pequenas em relação à rigidez estrutural $k_{y} y$. No entanto, se a defasagem $\tau$ é considerada como é proposta neste modelo, a força do fluido terá uma componente em fase com a velocidade, e esta compo- 
nente pode ser desestabilizadora.

Se a oscilação do tubo é harmônica então o deslocamento e a velocidade podem ser expressos como:

$$
\begin{aligned}
& y=A_{y} \operatorname{sen}(\omega t) \\
& \dot{y}=A_{y} \omega \cos (\omega t)
\end{aligned}
$$

e a expressão da força do fluido fica como a Eq.2.56:

$$
F_{y}=\frac{1}{2} \rho U^{2} C_{y} A_{y} \operatorname{sen}(\omega t)
$$

Se a força atuar em fase com a velocidade, $F_{y}$ pode ser expressa como:

$$
F_{y}=\frac{1}{2} \rho U^{2} C_{y}\left[y \cos (\omega \tau)-\frac{1}{\omega} \dot{y} \operatorname{sen}(\omega \tau)\right]
$$

Se for usada a aproximação do valor de $\tau$ sugerida por Price e Paidoussis (1986) e se for considerado só o termo da força que está em fase com a velocidade, então a equação de equilíbrio dinâmico para o tubo fica:

$$
m \ddot{y}_{j}+\left[2 m \zeta_{y}^{j} \omega_{y}^{j}+\frac{1}{2} \rho U^{2} C_{y} \frac{1}{\omega_{j}} \frac{d}{U} \operatorname{sen}\left(\omega_{j}\right)\right] \dot{y}_{j}+k_{j} y_{j}=0
$$

A Equação 2.60 pode apresentar uma instabilidade quando o coeficiente da velocidade $\dot{y}_{j}$ é igual ou menor do que zero, caracterizando uma força de amortecimento negativa, ou seja que introduz energia no sistema ao invés de dissipála. Se só esse termo for igualado a zero, a instabilidade pode ser expressa em função da velocidade reduzida como aparece na Eq. 2.61.

$$
\frac{U^{2}}{\omega_{j}^{2} d^{2}} \operatorname{sen}\left(\frac{\omega_{j} d}{U}\right)=\frac{-4 m \zeta_{y}}{C_{y} \rho d^{2}}
$$

Pela característica periódica da função seno, a Eq.2.61 prevê um regime instável em múltiplos intervalos nos quais $C_{y}$ seja negativo (BLEVINS, 1990). Price e Paidoussis (1986) acharam que $C_{y}$ é negativo para vários intervalos. Na Figura 2.27 se apresenta esta teoria para um único cilindro flexível em comparação com resultados experimentais obtidos para bancos com todos os tubos flexíveis.

\subsubsection{Instabilidade fluido-elástica em escoamento bifásico}

Em termos gerais a vibração fluido-elástica é o resultado da combinação dos efeitos da força de arrasto, a vibração aleatória induzida pela turbulência do escoamento e a retroalimentação da excitação causada pelas interações entre o tubo e o fluido (SASAKAWA et al., 2005). Todos os autores revisados coincidem em que a instabilidade fluido-elástica também aparece também em escoamento multifásico.

Aparentemente o mesmo modelo proposto por Connors pode ser usado para estimar a velocidade crítica de entrada à instabilidade, no entanto, nestes casos os parâmetros da Eq. 2.46 


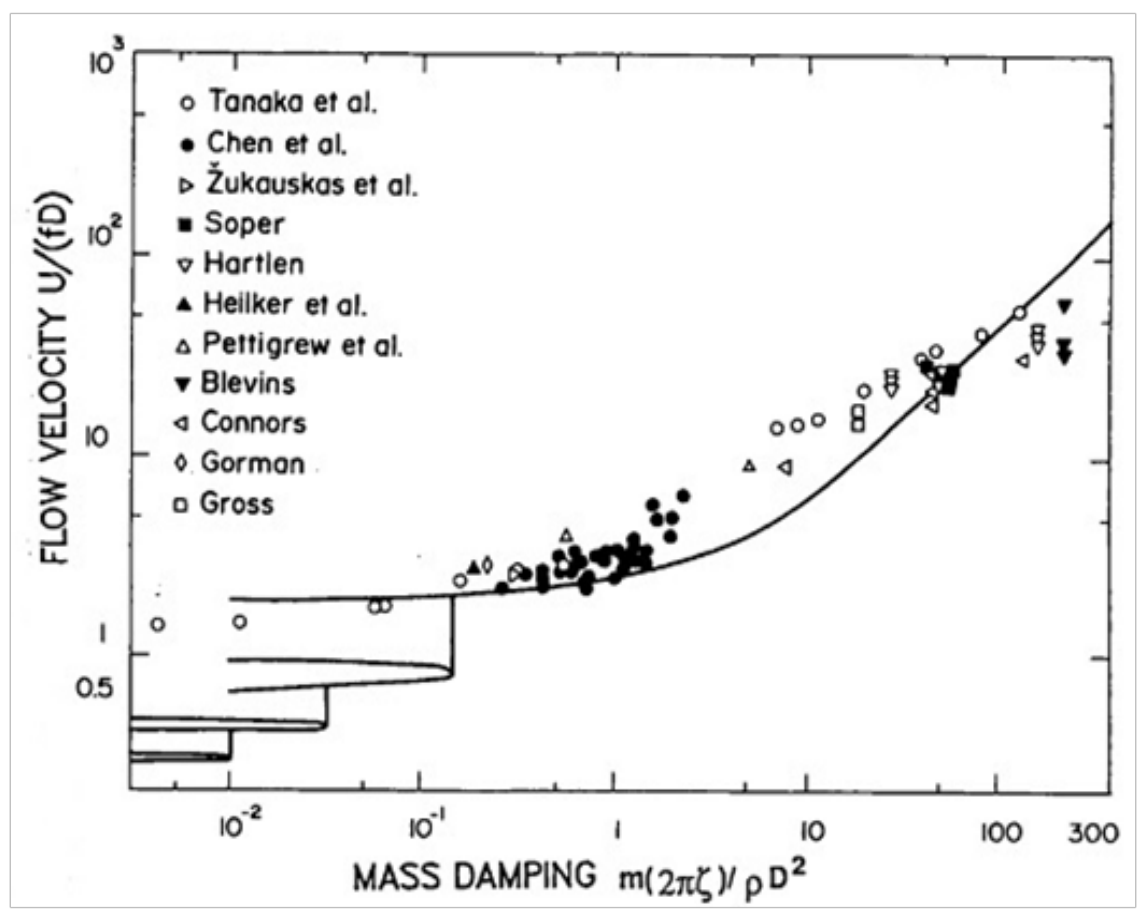

Figura 2.27: Comparação entre valores teóricos e experimentais para instabilidade. Resultados tomados de Price e Paidoussis (1986).

como a frequência natural do tubo e a densidade do fluido devem ser calculados para o caso bifásico. A constante de instabilidade, $C$, e o expoente do parâmetro adimensional massa amortecimento, $a$, são obtidos por ajuste de curvas. Depois, a velocidade crítica $U_{c r i t}$ pode ser estimada através do modelo homogêneo.

Em Sasakawa et al. (2005) também se menciona que o mesmo modelo de Connors pode ser usado para estimar a velocidade crítica de instabilidade. Neste trabalho é adicionado o critério do fator de estabilidade $S R$ (acrônimo de Stability Ratio) definido como a razão entre a velocidade efetiva do escoamento $U_{e}$ e a velocidade crítica $U_{\text {crit }}$ :

$$
S R=\frac{U_{e}}{U_{c r i t}}
$$

portanto o comportamento instável aparece quando $S R$ é maior do que 1 . A velocidade efetiva do escoamento pode ser calculada através da expressão sugerida em Kaneko et al. (2008):

$$
U_{e}=\left[\frac{\int_{0}^{L} \frac{\rho(z)}{\rho_{\text {avg }}} U^{2}(z) \phi^{2}(z) d z}{\int_{0}^{L} \frac{m(z)}{m_{\text {avg }}} \phi^{2}(z) d z}\right]^{0,5}
$$

onde se pode ver que se a densidade média do fluido $\rho_{a v g}$ e a massa média do tubo $m_{\text {avg }}$ ao longo do eixo axial do tubo são usadas então a velocidade efetiva é igual à velocidade do escoamento entre tubos.

Em aplicações industriais tais como o projeto de plantas e trocadores de calor o fator de 
estabilidade de projeto $S R_{d e s}$ é usado em vez do fator $S R$ :

$$
S R_{d e s}=(1-\chi) S R
$$

onde $\chi$ neste caso é um fator de correção. $\mathrm{O}$ uso deste tipo de fatores ainda mostra o desconhecimento dos fenômenos relacionados com a entrada ao regime instável.

Para o uso do modelo de Sasakawa et al. (2005) os parâmetros como a frequência natural do tubo, a constante de instabilidade, a massa do tubo, o fator de amortecimento e a densidade do escoamento devem ser avaliados nas condições de operação do equipamento. Quando este modelo é aplicado a um escoamento bifásico, frequentemente o modelo homogêneo é assumido. No entanto, os casos de altas frações de vazio incorporam fortes componentes intermitentes e oscilatórias assim o modelo homogêneo não apresenta uns bons resultados nestes regimes. Nos casos de alta fração de vazio melhores resultados são obtidos ao considerar a estrutura do fluido como uma função do tempo (SASAKAWA et al., 2005).

Deve-se notar que o critério de Connors falha em explicar completamente o mecanismo de instabilidade fluido-elástica devido a que em escoamento bifásico a fração de vazio e o padrão de escoamento, os quais não são representados no modelo, afetam à instabilidade. Várias pesquisas experimentais em sistemas bifásicos têm sido desenvolvidas, a maioria delas usando misturas água-ar devido a que a geração de um escoamento bifásico água-vapor aumenta o custo e a complexidade da bancada. Porém, a razão de tensões superficiais no sistema água - vapor é diferente do caso água - ar e portanto as mesmas condições experimentais não são reproduzidas. Como alternativa têm-se desenvolvido testes em sistemas bifásicos de Freon 134a cujas caraterísticas físicas são mais semelhantes ao sistema água - vapor.

Pettigrew et al. (2002) apresentou um estudo do amortecimento dos tubos em escoamento bifásico água - ar, Freon 22 e Freon 134a. Ele menciona que os valores de amortecimento obtidos são semelhantes apesar da diferença existente entre as propriedades físicas dos fluidos. Este fato marca a necessidade de um melhor entendimento da influência dos parâmetros que caracterizam as fases do escoamento bifásico, como por exemplo, o efeito da tensão superficial no amortecimento.

A influência dos parâmetros geomêtricos da tubulação na instabilidade fluido-elástica em sistemas bifásicos também têm sido estudada. Em Pettigrew et al. (1985) e Pettigrew et al. (1989) se realizaram testes em tubulações com configuração quadrado rotacionado, triangular normal e triangular paralela de tubos em cantilever com razão $\tau$ igual a 1,47 e 1,32. Os resultados destes experimentos sugerem um valor de 4,0 para a constante de instabilidade $C$. Além disso, os autores encontraram que a razão $\tau$ afeta à constante de instabilidade, este efeito foi mais pronunciado em escoamento bifásico e foi atribuído ao acoplamento hidrodinâmico que aumenta quando o espaço entre tubos é menor (MITRA et al., 2009).

Em Khushnood et al. (2004) se faz uma revisão do fenômeno de instabilidade fluido-elástica em escoamento bifásico. Neste artigo se menciona que o modelo proposto por Connors (1970) 
é aceito como útil para o projeto de tubulações, embora parâmetros como a constante de instabilidade $C$ e o expoente do parâmetro adimensional massa - amortecimento $a$ é modificado e discutido em vários trabalhos. Segundo Khushnood et al. (2004), a distribuição do fluido e a sua velocidade pode ser estimada através da equação proposta por Connors (1978):

$$
\frac{U_{\text {crit }}}{f_{i} d}=C\left[\frac{m_{0} \delta_{i}}{\rho_{0} d^{2} S_{i}}\right]^{1 / 2}
$$

onde $S_{i}$ é o homôlogo da expressão da velocidade efetiva apresentado em Sasakawa et al. (2005):

$$
S_{i}=\frac{\int_{0}^{L}\left(\rho(z) / \rho_{0}\right) \psi(z)^{2} \phi_{i}(z)^{2} d z}{\int_{0}^{L}\left(m(z) / m_{0}\right) \phi_{i}(z)^{2} d z}
$$

sendo $L$ o comprimento do tubo exposto ao escoamento cruzado, $\psi(z)$ é a distribuição do escoamento, $\phi(z)$ é o modo de vibração correspondente, $\rho(z)$ é a densidade do escoamento e $m(z)$ é a massa do tubo; estas propriedades são avaliadas em função da posição no eixo axial do tubo z. O parâmetro $m_{0}$ é a média da massa do tubo e $\rho_{0}$ é a média da densidade do escoamento ao longo do eixo do tubo.

A Equação 2.65 é derivada teoricamente da hipóteses que a instabilidade fluido-elástica tem uma relação linear com o deslocamento do tubo, o qual implica ao mencionado mecanismo de deslocamento (CHEN, 1987). No entanto, na década de 1980 foi estabelecido que o mecanismo de instabilidade fluido-elástica não está limitado ao mecanismo de deslocamento senão também conta com a participação do mecanismo de velocidade. Portanto a Eq.2.66 não pode ser aplicada em todos os casos, o qual é verdade mesmo sendo um escoamento monofásico (KHUSHNOOD et al., 2004). Em Nakamura et al. (1997) e Nakamura et al. (2000) sugiriu-se um novo método para calcular o limite de instabilidade em escoamento bifásico. Este método está baseado no aspecto físico do fenômeno. Segundo estes estudos, o limite de instabilidade para escoamento bifásico através do modelo bifásico homogêneo pode ser estimado com a Eq.2.67

$$
\xi_{e q}^{2}+\beta \mu \eta_{e q}^{2}=1+\beta \mu
$$

onde $\mu$ está definido como a razão de massas efetivas entre a fase gás e a fase líquida por unidade de comprimento do tubo:

$$
\mu=\frac{m_{g e q}}{m_{l e q}}
$$

Os termos $\xi_{e q}$ e $\eta_{e q}$ são as velocidades adimensionais efetivas (ou velocidade adimensional do escoamento que passa pelo menor espaço entre tubos) da fase líquida e da fase gás respectivamente. $\beta$ é um parâmetro adimensional definido por:

$$
\beta=\left(\frac{\bar{\alpha}}{1-\bar{\alpha}}\right) \gamma
$$


Na Equação 2.69 र é a média temporal da fração de vazio $\alpha$ e $\gamma$ é um parâmetro adimensional definido como:

$$
\gamma=\left(\frac{C_{g}^{\prime}}{C_{l}^{\prime}}\right)\left(\frac{\rho_{g}}{\rho_{l}}\right)\left(\frac{U_{c g}}{U_{c l}}\right)^{2}
$$

onde $C_{l}^{\prime}$ e $C_{g}^{\prime}$ são os coeficientes adimensionais da força de arrasto sobre o tubo, $U_{c l}$ e $U_{c g}$ são as velocidades críticas para as fases do escoamento bifásico. Os subíndices $l$ e $g$ correspondem às fases líquida e gás. 


\section{Capítulo 3}

\section{Projeto da estrutura dinâmica}

O objetivo desse capítulo é realizar a revisão do estado da arte que permita projetar e construir uma estrutura dinâmica para o estudo da vibração induzida por escoamentos. Portanto nesse capítulo se detalham os parâmetros que caracterizam uma bancada experimental para o estudo da VIE. Sobre este conhecimento se apresentarão as bancadas experimentais mais representativas já usadas em trabalhos anteriores e posteriormente se escolherá a estrutura dinâmica mais apropriada para instalar o tubo instrumentado na seção de testes paralelamente construída no NETeF. Após a seleção do tipo de estrutura dinâmica, se apresenta o projeto detalhado dos componentes e da montagem em CAD.

\subsection{Características gerais de uma bancada experimental para o estudo das VIE}

Vários modelos de bancada têm sido usados até hoje. Em geral, se pode dizer que uma bancada de testes é composta por: (i) um sistema de circulação de fluido, (ii) a seção de testes ou tubulação, (iii) os instrumentos de medição e (iv) o sistema de aquisição de dados. Para o presente trabalho, as características geométricas da seção de testes são de especial importância, já que disso dependerá o espaço disponível para a instalação da estrutura dinâmica. Segundo a informação revisada na bibliografia e, apesar das diferenças entre bancadas, se pode dizer que os parâmetros que caracterizam uma seção de testes são os seguintes:

a. Tipo e material dos tubos

b. Configuração da bancada de tubos, razão de passo transversal e diâmetro $(\tau)$

c. Geometria dos tubos

d. Parâmetros do escoamento

e. Suspensão dos tubos

\subsubsection{Tipos e material dos tubos}

Os tubos utilizados para a construção dos trocadores de calor e das bancadas de testes que os representam podem ser de dois tipos: (i) tubos de superfície externa cilíndrica lisa e (ii) tubos 
com superfície externa alhetada. O design com superfície alhetada facilita a transferência de calor entre fluidos, no entanto, eles são mais caros, por isso é que a maioria das bancadas são projetadas com tubos de superfície lisa. Os tipos de tubos são ilustrados na Fig. 3.1. O material usado para a fabricação dos tubos pode variar, a tendência geral é usar aço inoxidável já que são partes que estão expostas permanentemente a fluidos. O material dos tubos também pode ser ligas de cobre, níquel e ferro.

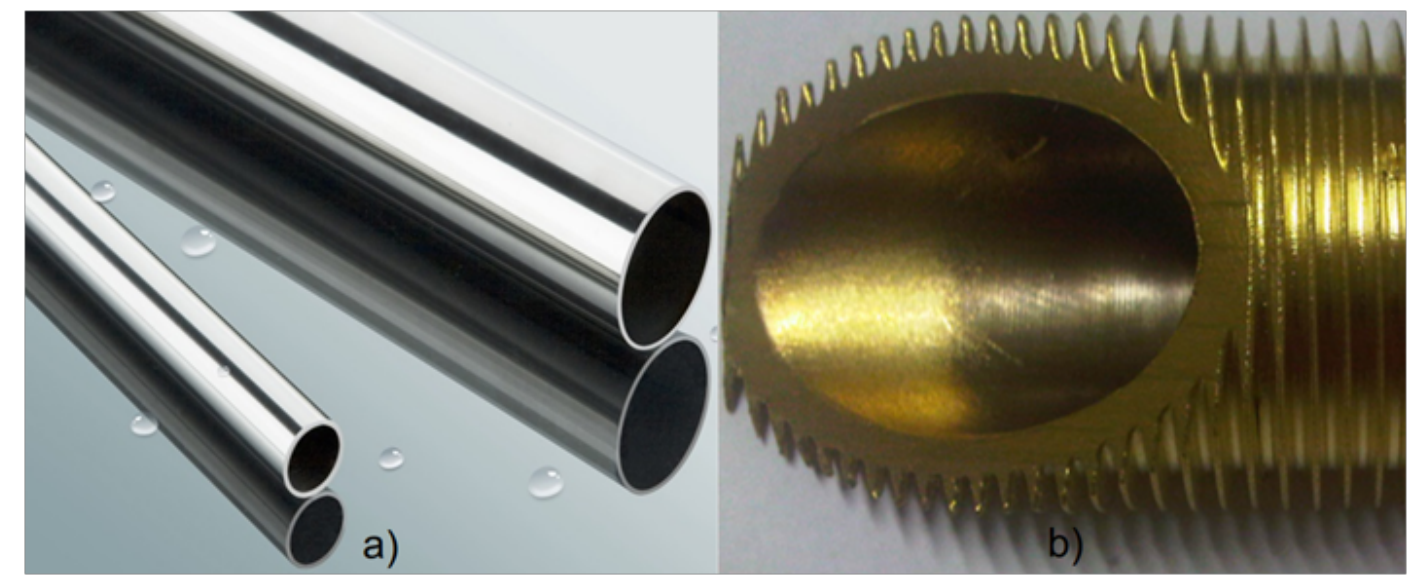

Figura 3.1: a) Tubo de superfície lisa tomado de http:Ipt-made-inchina.comlco_cntoolpeaklproduct_Cold-Roll-Precision-Stainless-Steel-SeamlessTubes_essgnioog.html e b) tubo de superfície alhetada http:Ilwww.becaengineering.com \LowFin.html.

A geometria dos tubos está definida pelo diâmetro, comprimento e espessura da parede. Embora em muitas das aplicações industriais os aparelhos usem tubos dobrados em formato de $\mathrm{U}$, a maioria das bancadas experimentais estão conformadas por tubos retos que atravessam a seção de testes.

\subsubsection{Configuração da bancada de tubos}

Como se vê na Fig. 3.2 os tubos da seção de testes podem ser instalados segundo diferentes configurações. Baseado na distribuição geométrica dos tubos a razão de passo transversal e diâmetro está definida como $\tau$,

$$
\tau=\frac{S_{1}}{d}
$$

onde $d$ é o diâmetro externo do tubo e $S_{1}$ é o passo transversal entre tubos. Esta razão serve para quantificar o espaço entre tubos que tem o escoamento para passar através da seção de testes. Na bibliografia este parâmetro é mencionado como pitch-to-diameter ratio, ele é adimensional e permite comparar diferentes configurações e seções de testes.

\subsubsection{Parâmetros do escoamento}

A resposta dinâmica dos tubos está influenciada diretamente pelos parâmetros que caracterizam um escoamento. Os principais parâmetros são: 


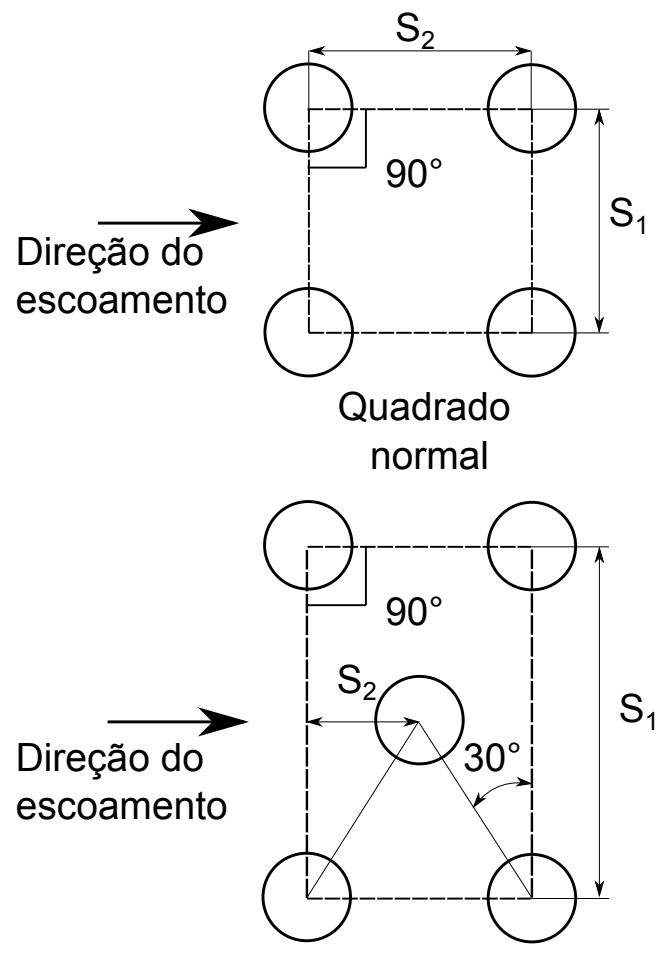

Triangular rotacionado

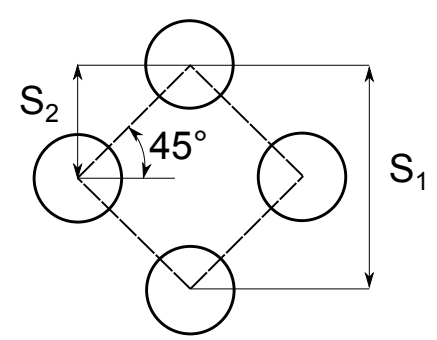

Quadrado rotacionado

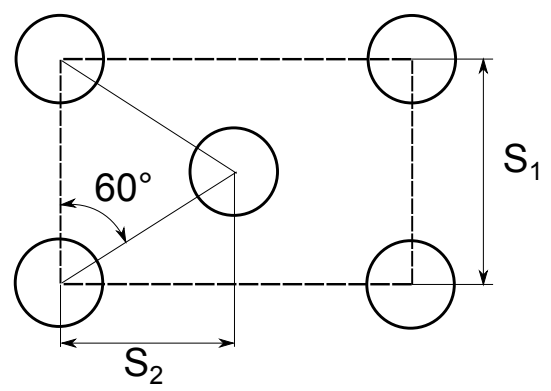

Triangular normal

Figura 3.2: Tipos de configurações de bancos de tubos. Baseado em Zukauskas e Ulinskas (1983).

- Tipo de escoamento: o escoamento na bancada de testes pode ser monofásico ou bifásico. Em caso de ser monofásico, este pode ser líquido ou gás. O escoamento bifásico está caracterizado pela fração de vazio superficial $\alpha$, a qual é uma medida da quantidade da seção transversal ocupada pela fase gás $A_{g}$ e pela fase líquida $A_{l}$ dentro do duto pelo qual o escoamento bifásico é conduzido e cuja seção transversal é representada pela letra $A$. A fração de vazio superficial é calculada através das Eq.3.2:

$$
\alpha=\frac{A_{g}}{A}
$$

lembrando que a soma das seções transversais ocupadas pelo líquido e pelo gás deve ser igual a seção transversal total do duto e portanto a Eq.3.3 se deve cumprir.

$$
(1-\alpha)=\frac{A_{l}}{A}
$$

A fração de vazio controla a geometria ou topologia do escoamento, no entanto, além da fração de vazio, o desenvolvimento de um padrão de escoamento depende de condições como a pressão, vazão, fluxo de calor e geometria do canal (COLLIER; THOME, 1994). Como foi descrito no Capítulo 2, a fração de vazio afeta diretamente a excitação sobre os tubos de uma bancada. Devido à complexidade da interação das variáveis do escoamento 
bifásico com a tubulação, a vibração induzida por eles não tem sido bem compreendido ainda. Informação sobre as características de cada padrão de escoamento podem ser encontradas em Kanizawa (2012).

A vazão mássica do escoamento bifásico $W$ está definida pela soma da vazão mássica da fase líquida $W_{l}$ e da fase gás $W_{g}$. Do mesmo jeito, a vazão volumétrica do escoamento bifásico $Q$ corresponde à soma das vazões volumétricas da fase líquida $Q_{l}$ e da fase gás $Q_{g}$. A velocidade média de cada fase é representada pela letra $U$ com seu respectivo subescrito segundo a fase que representa. A velocidade de cada fase pode ser calculada a partir das vazões mássica e volumétrica com as eqs.3.4 e 3.5

$$
\begin{gathered}
U_{g}=\frac{W_{g}}{\rho_{g} A_{g}}, \\
U_{l}=\frac{W_{l}}{\rho_{l} A_{l}} \\
U_{g}=\frac{Q_{g}}{A_{g}}, \\
U_{l}=\frac{Q_{l}}{A_{l}}
\end{gathered}
$$

As vezes é necessário usar a fração de vazio volumétrica $\beta$ baseada na vazão volumétrica do escoamento, esta é calculada como:

$$
\beta=\frac{Q_{g}}{Q_{g}+Q_{l}}
$$

A taxa de vazão volumétrica dividida para a área do duto pela qual escoa é conhecida como velocidade superficial $j$, desse jeito:

$$
\begin{gathered}
j=\frac{Q}{A}, \\
j_{g}=\frac{Q_{g}}{A}, \\
j_{l}=\frac{Q_{l}}{A}
\end{gathered}
$$

O conhecimento das velocidades superficiais das fases permite estimar, por meio de mapas, o padrão do escoamento que está atravessando a tubulação. Isto se vê no Capítulo 5 
onde as condições experimentais reproduzidas na seção de testes é localizado no mapa de padrão dos escoamentos proposto por Ulbrich e Mewes (1994).

- Fluido: a VIE ocorre tanto no caso monofásico como no multifásico. A pesquisa dos mecanismos de VIE primeiro foi desenvolvida para escoamento monofásico e depois de vários estudos se começou a estudar o caso de escoamentos multifásicos. Nos aparelhos industriais de troca de calor quase sempre aparece um escoamento bifásico água - vapor, no entanto, por facilidades construtivas na maioria de bancadas experimentais esse escoamento é substituído por um bifásico água - ar. Alguns pesquisadores optaram pelo projeto de bancadas que usem refrigerantes como fluido de trabalho, isso devido à semelhança que apresenta a relação entre propriedades físicas das fases líquido e gás com um escoamento bifásico água - vapor.

- Direção: a direção do escoamento é um parâmetro que é estabelecido no projeto da bancada. As opções são: escoamento vertical em sentido da gravidade ou em contra dela e escoamento horizontal em qualquer dos dois sentidos. É claro que os padrões de escoamento que se apresentam numa bancada com escoamento horizontal não são os mesmos que se apresentam numa bancada com escoamento vertical. Numa bancada com escoamento em direção vertical a distribuição do fluido pode ser pensada simétrica, enquanto que um escoamento horizontal não pode ser pensado como simétrico pela ação da gravidade. Os padrões apresentados em ambos casos são revisados em Collier e Thome (1994).

- Propriedades termodinâmicas: pressão e temperatura.

\subsubsection{Suspensão dos tubos na seção de testes}

Os tubos da bancada experimental estarão expostos ao arrasto e à excitação gerada pelo escoamento. Para conseguir estudar a resposta dinâmica dos tubos é preciso sujeitá-los às condições de excitação e fixá-los à parede da seção de testes de modo que exibam uma resposta mensurável. Nesse ponto surge a questão de qual é o melhor mecanismo para segurar os tubos tal que permita instalar os instrumentos necessários para desenvolver o estudo. Existem algumas configurações possíveis; o extremo de cada tubo pode ser apoiado de forma flexível ou engastado na parede, isto abre três possibilidades para cada tubo. Por exemplo, se um tubo for engastado pelos seus extremos então qualquer deslocamento ou rotação nesses pontos fica restrito. No caso de que só um extremo fosse engastado e o outro ficasse livre então só a rotação do tubo e o deslocamento no engaste ficam restritos, mas o deslocamento no extremo livre é possível. Finalmente, se a suspensão é flexível nos extremos então os deslocamentos são possíveis e a rotação depende da natureza do mecanismo de suspensão.

O tipo de suspensão afeta diretamente aos modos de oscilação dos tubos e suas respectivas frequências naturais. Segundo a informação disponível da bibliografia, os tubos instrumentados engastados nos dois extremos apresentam uma primeira frequência natural sobre os $100 \mathrm{~Hz}$, 
e cabe mencionar que a mesma não é regulável. No caso de tubos em cantilever a primeira frequência natural de vibração é menor do que nos tubos rígidos, ela oscila entre os 50 e $150 \mathrm{~Hz}$, mas também não é regulável. Para o caso dos tubos de suspensão flexível nos dois extremos, a primeira frequência natural de vibração aparece na maioria das vezes antes dos $50 \mathrm{~Hz}$, e dependendo das características do mecanismo na maioria das vezes é um valor que pode ser calibrado com relativa precisão o qual é uma vantagem na hora do teste.

$\mathrm{Na}$ bibliografia se podem encontrar vários tipos de dispositivos de suspensão, os mesmos que foram adaptados segundo as necessidades dos ensaios. Dependendo do escopo do estudo experimental desenvolvido se pode usar diferentes tipos de suspensão para os tubos de uma mesma seção de testes, às vezes isso permite simplificar a construção da bancada. Geralmente nesses casos o que se faz é desprezar a interação hidrodinâmica entre os tubos rígidos e o tubo instrumentado instalado flexivelmente. É importante mencionar que no projeto de uma bancada experimental todas as simplificações devem ser mencionadas e justificadas porque fenômenos dinâmicos podem estar sendo alterados ou desprezados.

Na Figura 3.3 se pode observar um exemplo de sistema de suspensão de tubos numa seção de testes, a qual neste caso é um túnel de vento. Na seção de testes da Fig. 3.3 os tubos são tensados perpendicularmente à direção do escoamento por meio de cordas de aço esticadas. Nos seguintes parágrafos serão revisadas as características das bancadas de testes projetadas em trabalhos anteriores, as mesmas serão descritas em base às características detalhadas. 


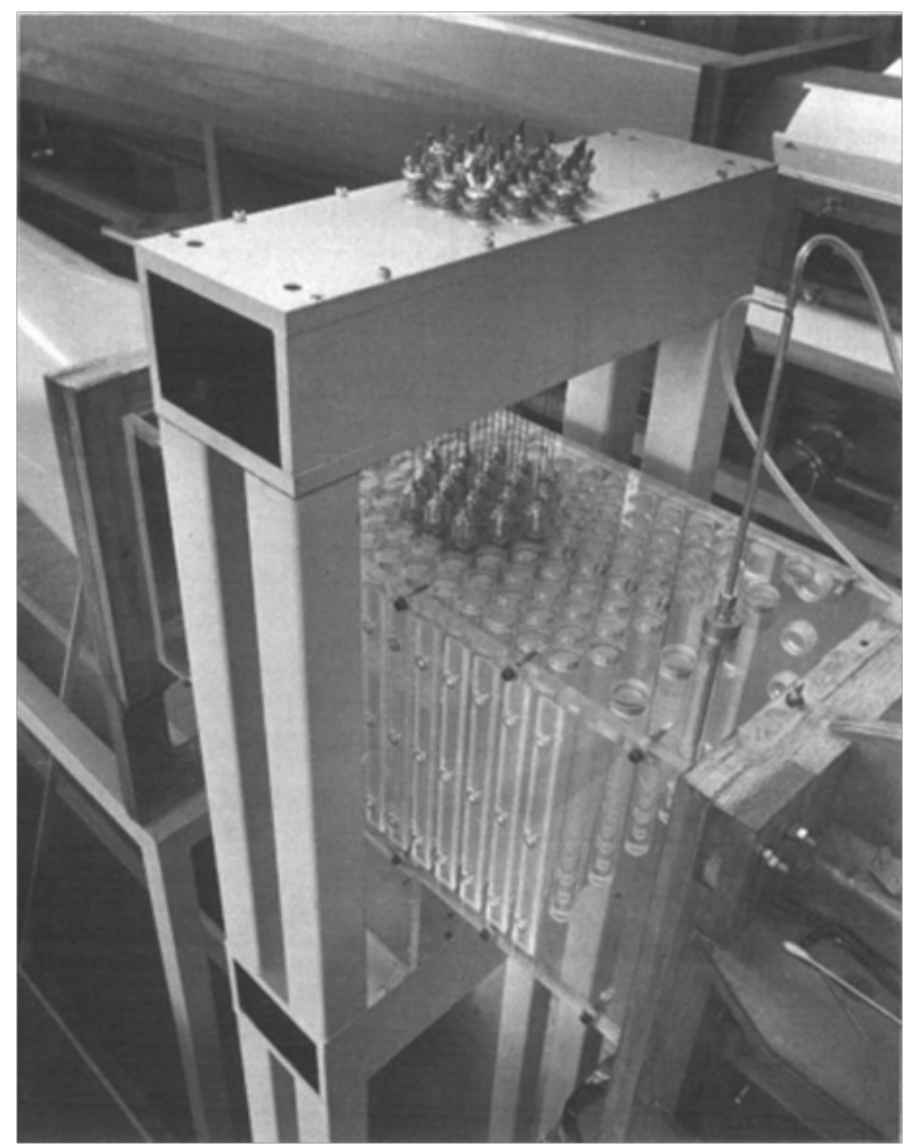

Figura 3.3: Mecanismo de suspensão de uma seção de testes para a análise das vibrações induzidas por escoamentos num túnel de vento. Tomado de Grover e Weaver (1978).

\subsection{Revisão das bancadas experimentais de estudos anteriores}

Para o estudo da VIE tem-se projetado várias bancadas de testes, em cada bancada se usam diferentes métodos para instalar os tubos instrumentados na seção de testes. Embora sejam muitas as bancadas construídas, tem se identificado as estruturas dinâmicas mais comuns usadas para a suspensão dos tubos instrumentados. O uso de diferentes tipos de estruturas dinâmicas depende dos objetivos da pesquisa, espaço disponível na bancada e dos instrumentos que serão usados para medir a resposta dos tubos.

Talvez o modo mais simples de instalar um tubo na seção de testes é engastando ele por um dos seus extremos ou pelos dois. Por exemplo, esses tipos de instalação são usados nos testes reportados em Axisa et al. (1990). Este é um trabalho que apresenta uma recopilação de resultados experimentais para o estudo teórico-experimental da vibração aleatória provocada por escoamento cruzado nas tubulações de um trocador de calor.

Para os testes em escoamento monofásico através de túneis de água e de ar usaram-se bancos de tubos em configurações: normal retangular, normal triangular e triangular paralela. Em Axisa et al. (1990) se usaram dois tipos de bancos: os que têm todos os tubos montados em cantilever e os que têm um único tubo montado em cantilever e o resto são rígidos. Geralmente os instrumentos para medir a resposta dinâmica são instalados nos tubos montados no formato 
mais flexível do banco, nesse caso nos tubos em cantilever. Usaram-se dois tipos de instrumentos: acelerômetros instalados no interior dos tubos e extensômetros colados na superfície do tubo perto do engaste para medir a força do fluido sobre o tubo e indiretamente a sua resposta oscilatória.

Segundo o tabulado em Axisa et al. (1990), nas bancadas usaram-se tubos de 24, 20 e 15 $\mathrm{mm}$ de diâmetro instalados em cantilever cujas primeiras frequências naturais no ar foram de 78,8; 68,6 e $57,8 \mathrm{~Hz}$ respectivamente.

Testes para medir a vibração aleatória causada por escoamento bifásico ar-água e vapor água também foram reportados em Axisa et al. (1990). Os tubos da seção de testes, os quais eram de diâmetro $19 \mathrm{~mm}$ e espessura 1,09 mm, foram montados com dobro engaste em configurações quadrada normal, triangular normal e paralela triangular. A primeira frequência natural daqueles tubos foi medida em $72 \mathrm{~Hz}$. A resposta dinâmica de vários desses tubos foi medida nas direções paralela e transversal ao escoamento por meio de acelerômetros e extensômetros.

Em Pettigrew et al. (2001) também se faz uso de bancadas com tubos montados em cantilever. Neste trabalho se estudam os efeitos da influência da configuração geométrica da bancada nos fenômenos da instabilidade fluido-elástica, vibração aleatória, amortecimento e massa hidrodinâmica em escoamento cruzado bifásico ar-água. Nas seções de testes usaram-se configurações triangular normal e rotacionada, e quadrada normal e rotacionada com razões de passo transversal e diâmetro igual a 1,2; 1,32 e 1,47. Os testes foram desenvolvidos com um único tubo em cantilever rodeado por tubos engastados nos dois extremos. O objetivo dessa simplificação é evitar o efeito de acoplamento hidrodinâmico entre tubos, o qual, segundo como é explicado no artigo, não permite estudar corretamente o amortecimento e a resposta aleatória dos tubos.

Na bancada experimental usada em Pettigrew et al. (2001) instalaram-se de 25 a 30 tubos de aço inoxidável, com diâmetro igual a $12,7 \mathrm{~mm}$ e comprimento igual a $600 \mathrm{~mm}$. As características descritas permitem que o tubo instrumentado em cantilever tenha uma frequência natural de $30 \mathrm{~Hz}$, a qual, segundo os autores, é típica para tubos de trocadores de calor. Os tubos instalados rigidamente apresentaram uma primeira frequência natural de $160 \mathrm{~Hz}$. Em relação à medição da resposta do tubo, esta foi medida na direção paralela e transversal ao escoamento através de dois pares de extensômetros diametralmente opostos, cada par instalado a $90^{\circ}$.

Como se pode ver, nos dois trabalhos detalhados acima se usaram bancadas com tubos rígidos e em cantilever. Nestes bancos se realizaram estudos em diferentes temas ao redor da VIE monofásicos e bifásicos. É importante mencionar que nos artigos até agora citados não se reportaram problemas ocasionados pelo sistema de fixação dos tubos, pelo contrario, o amplo uso deste tipo de bancadas confirma a vantagem na simplicidade da sua construção. No entanto, desde o ponto de vista da versatilidade da bancada, os tubos engastados apresentam a desvantagem de ter frequências naturais fixas, o qual restringe a liberdade de experimentação na seção de testes. Esse problema pode ser resolvido se ao invés de fixar os tubos às paredes da seção de testes se usa uma estrutura dinâmica capaz de segurar o tubo e que, além disso, permita 
sintonizar pelo menos sua primeira frequência natural.

Tem-se proposto algumas técnicas para controlar a frequência natural dos tubos instalados na bancada, uma delas é usar peças de diferentes materiais e seções transversais para a conexão entre os extremos do tubo e as paredes da seção de testes. Um estudo experimental no qual esta técnica é utilizada é Tanaka et al. (2002). Neste artigo se estuda o fenômeno da instabilidade fluido-elástica num banco de tubos de $30 \mathrm{~mm}$ de diâmetro instalados em configuração quadrada normal. Os testes foram rodados com escoamento monofásico vertical de água e ar separadamente. Os tubos foram instalados por meio umas barras adicionais engastadas nos seus extremos, tal como se apresenta na Fig. 3.4. O objetivo de projetar uma seção de testes na qual todos os tubos tenham a mesma flexibilidade é reproduzir os efeitos de acoplamento fluido-dinâmico entre tubos adjacentes. Na realização dos testes usaram-se suportes elásticos de diferentes materiais, entre eles: aço, plástico e acrílico. Por meio da modificação do material das barras se conseguiu modificar a frequência natural e o amortecimento dos tubos. Assim, conseguiram-se estudar os efeitos causados pela dispersão das frequências naturais e do fator de amortecimento dos tubos sobre a velocidade crítica de instabilidade.

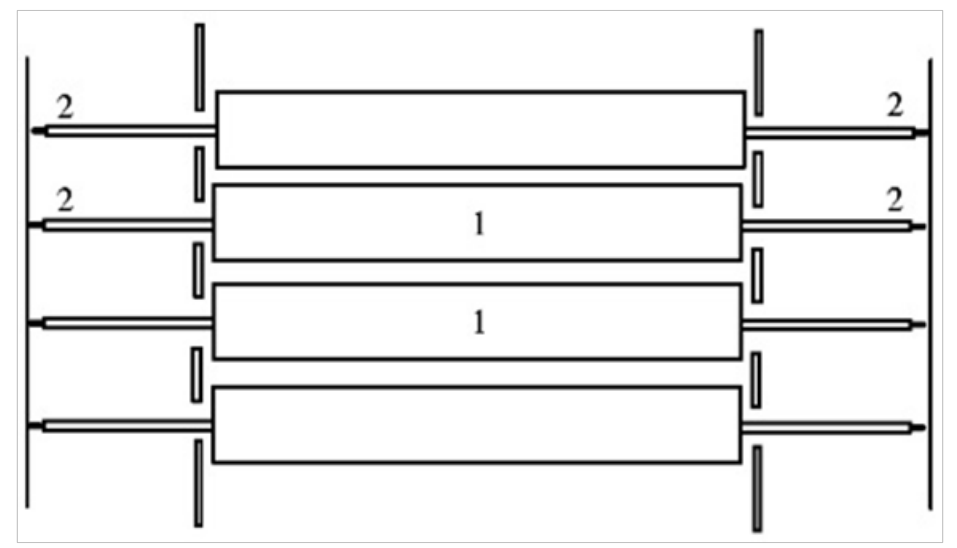

Figura 3.4: Suportes de tubos para testes de vibração. 1) Tubos de aço inoxidável, 2) suportes elásticos. Tomado de Tanaka et al. (2002)

Mureithi et al. (2005) também usaram uma bancada de testes na qual os tubos foram suspendidos por meio de outras peças e desta forma conseguiram alterar a frequência natural do conjunto. $\mathrm{O}$ objetivo deste trabalho foi estudar a instabilidade fluido-elástica numa seção de testes cujos tubos foram projetados para vibrar preferencialmente na direção paralela ao escoamento aplicado dentro de um túnel de vento. Para isso, na seção de testes os tubos foram suspendidos por meio de placas de aço de seção transversal de 1,5 x $15 \mathrm{~mm}$, como se vê na Fig. 3.5 . Uma vez que as placas foram instaladas em cada extremo do tubo, as frequências naturais do conjunto na direção paralela e transversal foram de 18,74 e $188 \mathrm{~Hz}$ respectivamente. O banco de tubos foi montado com tubos de 40,4 mm de diâmetro e $270 \mathrm{~mm}$ de comprimento numa configuração triangular rotacionada com razão de passo transversal e diâmetro igual a 1,37. Realizaram-se testes em bancadas com todos os tubos flexíveis, um único tubo flexível e vários tubos flexíveis em posições aleatórias. 


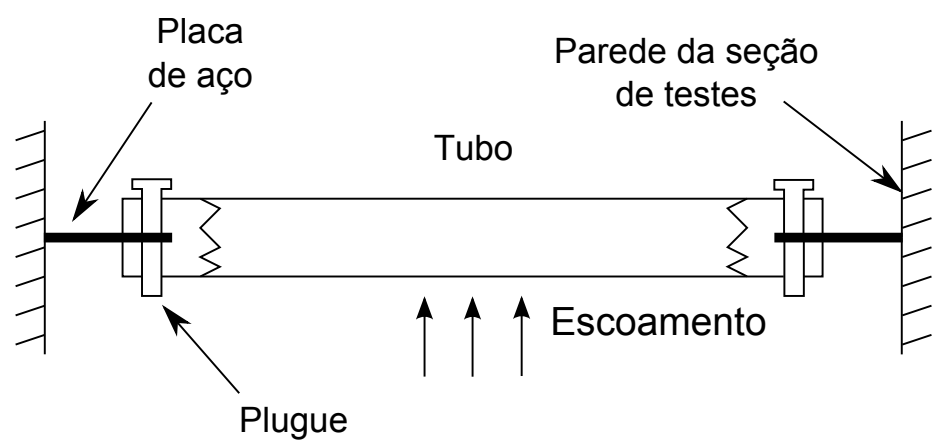

Figura 3.5: Estrutura dinâmica proposta em Mureithi et al. (2005). 1) Tubos de aço inoxidável, 2) suportes elásticos.

Pode-se ver que as seções de testes usadas em Tanaka et al. (2002) e Mureithi et al. (2005) apresentam a vantagem de manipular a frequência natural dos tubos por meio da inclusão de outras peças que alteram a rigidez do conjunto. No entanto, para realizar modificações seria preciso desmontar aquelas peças e trocar por outras de diferente momento de inércia ou material. Para evitar ter que montar e desmontar peças existe a alternativa de usar uma estrutura dinâmica que facilite a calibração da frequência natural do tubo in situ. Alguns trabalhos nos quais este tipo de estrutura dinâmica foi usado são descritos em seguida.

Em Grover e Weaver (1978) se usa uma estrutura dinâmica que permite a calibração da frequência natural dos tubos in situ. Neste trabalho se estudou a resposta oscilatória dos tubos ao desprendimento de vórtices e a sua interação com o fluido. Para isso, se usou uma bancada composta essencialmente por um túnel de vento e um arranjo de tubos instalados transversalmente à direção do escoamento. A tubulação estava composta por tubos leves de alumínio, os quais foram suspendidos na seção de testes com fios de aço de $1 \mathrm{~mm}$ de diâmetro. A tensão nos fios de aço foi regulada a través de um mecanismo composto por um parafuso, uma porca e uma mola. O fio de aço é segurado na cabeça do parafuso, conforme o parafuso sai da porca a mola é comprimida gerando uma força de reação sobre o parafuso, a qual tensa o fio. Esta tensão incrementa com o deslocamento do parafuso.

Segundo a informação proporcionada no artigo, com essa estrutura dinâmica se conseguiu sintonizar a frequência natural dos tubos entre 18 e $40 \mathrm{~Hz}$ com uma variação de $\pm 0,2 \%$. Na Figura 3.3 se pode ver a seção de testes usada neste trabalho, o detalhe da estrutura dinâmica se mostra na Fig. 3.6.

A seção de testes tinha em total 135 tubos, dos quais só 19 foram instrumentados e suspendidos com fios de aço. O restante foi montado rigidamente, mas não foi instrumentado. Para reproduzir as condições desejadas foi necessário inserir um amortecimento maior do que o proporcionado pelo ar do meio, portanto nesta bancada foram projetados e colocados amortecedores de tipo viscoso externamente à seção de testes. Para a medição das vibrações foram usados extensômetros adaptados no fio de aço como se vê na Fig. 3.6.

O tipo de estrutura dinâmica composta por fios de aço tensionados foi usada em mais ban- 


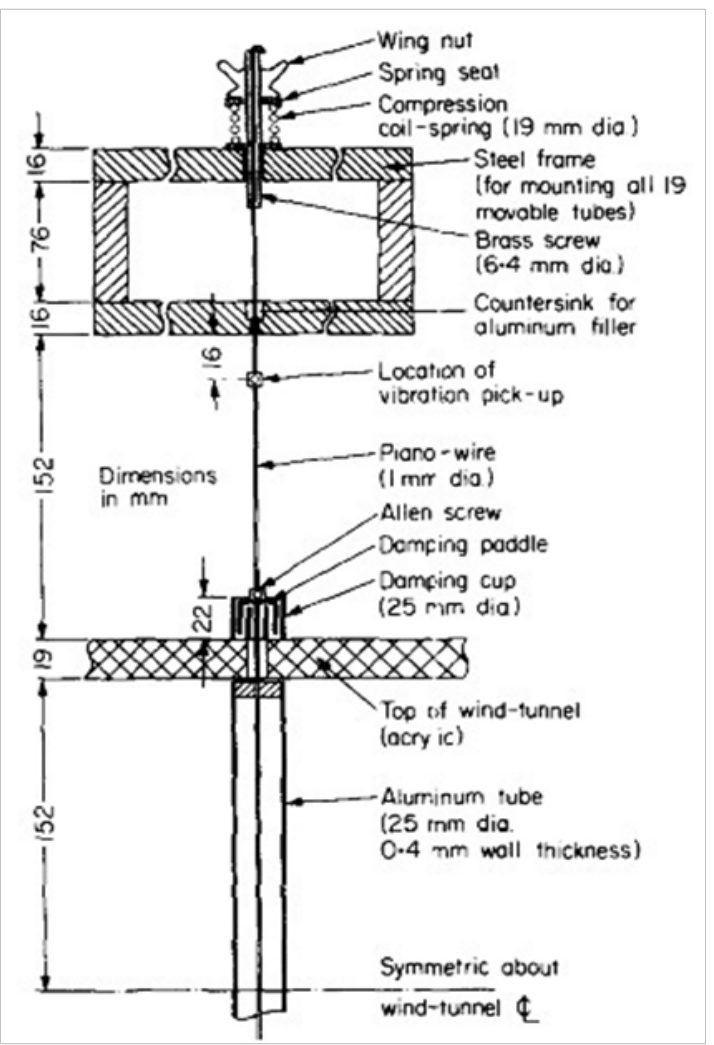

Figura 3.6: Estrutura dinâmica para montar o tubo na seção de testes. Tomado de Grover e Weaver (1978).

cadas experimentais, uma das mais representativas é a apresentada em Price et al. (1987). Neste trabalho se estudou a VIE num banco de tubos em configuração quadrada rotacionada especificamente com razão de passo transversal e diâmetro igual a 2,12. Realizaram-se testes num túnel de água e num túnel de ar para os dois tipos de escoamentos monofásicos. No primeiro conjunto de testes todos os cilindros do banco foram montados rigidamente e no segundo conjunto se usou um arranjo de tubos com um único tubo flexível o qual foi instrumentado. A resposta oscilatória do cilindro foi medida nas direções paralela e transversal ao escoamento.

Para os testes no túnel de vento os cilindros usados foram de $25,4 \mathrm{~mm}$ de diâmetro e dentro deles foram instalados os acelerômetros nas direções mencionadas. O tubo flexível foi montado com uma estrutura dinâmica baseada na tensão dos fios de aço, como se vê na Fig. 3.7. No artigo não se apresentam muitos detalhes sobre o sistema de tensão dos fios, mas se menciona que o rango de frequências de interesse está entre os 0 e $25 \mathrm{~Hz}$ pelo qual se supõe que a estrutura dinâmica deve permitir a calibração da frequência natural nesta faixa de frequências. $O$ cilindro foi instalado de tal forma que preencha a largura da seção de testes para diminuir os efeitos tridimensionais causados pelo fluido nos extremos do cilindro.

Nesta seção de testes também se introduziu amortecimento mecânico aos tubos. Para isso, foram projetados amortecedores viscosos, os quais consistem de um pote pequeno com óleo e um dispositivo tipo pistão colado aos fios. Outra característica importante dessa bancada foi a introdução de um mecanismo para corrigir o deslocamento estático originado pela força de 


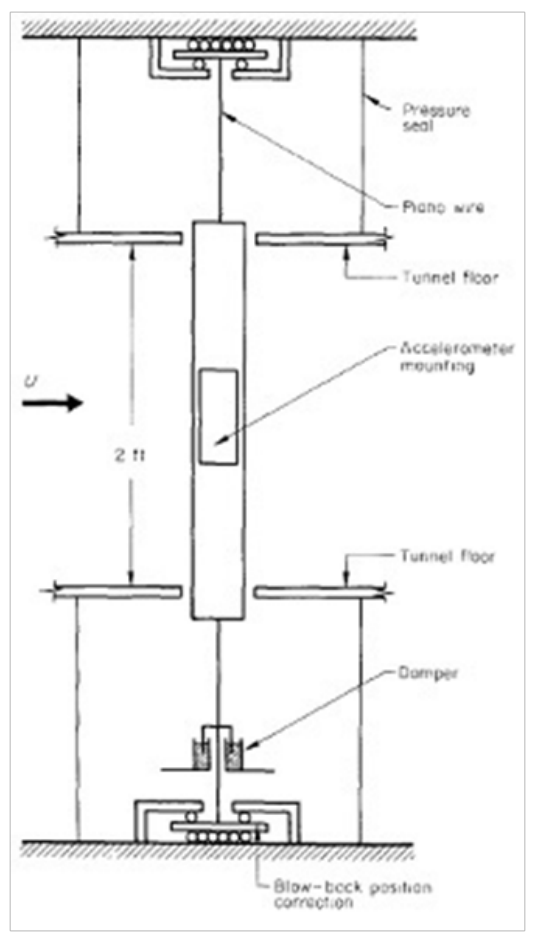

Figura 3.7: Desenho esquemático do cilindro flexível e o seu sistema de montagem no túnel de vento. Tomado de Price et al. (1987).

arrasto do fluido. Esse deslocamento provoca uma deformação inicial da configuração geométrica do banco de cilindros, o qual modifica localmente a razão de passo transversal e diâmetro alterando os resultados que possam ser obtidos.

Por outro lado, para os testes desenvolvidos no túnel de água usaram-se cilindros de 12,7 $\mathrm{mm}$ de diâmetro. $\mathrm{O}$ cilindro flexível foi suspendido num formato diferente respeito ao usado no túnel de vento. A estrutura dinâmica projetada estava composta pelo próprio cilindro rígido conectado a uma barra fina de bronze mais flexível, e esta última montada em cantilever às paredes da seção de testes. O conjunto se pode ver na Fig. 3.8.

O cilindro vibra como um sólido rígido dentro da seção de testes, em quanto que a barra fina em cantilever vibra num ambiente de água estanca, o qual, segundo como é mencionado no artigo, não interfere com o escoamento principal. Nesta estrutura o amortecimento mecânico é introduzido através de uma placa larga ligada à barra fina. A placa vibra junto com a barra no compartimento de água estanca. Devido ao pequeno diâmetro dos cilindros, a resposta oscilatória foi medida com extensômetros colados perto do engaste da barra em cantilever. Finalmente, menciona-se que nessa bancada não foi usado nenhum mecanismo para a correção do deslocamento estático devido a que ele complicava a vedação da seção de testes, no entanto, nos casos que o deslocamento era grande o cilindro flexível foi instalado em posições interiores dentro do banco.

No estudo proposto por Mitra et al. (2009) usou-se também uma estrutura dinâmica baseada em fios de aço tensionados que seguram o tubo na seção de testes. Nesse trabalho se realizaram 


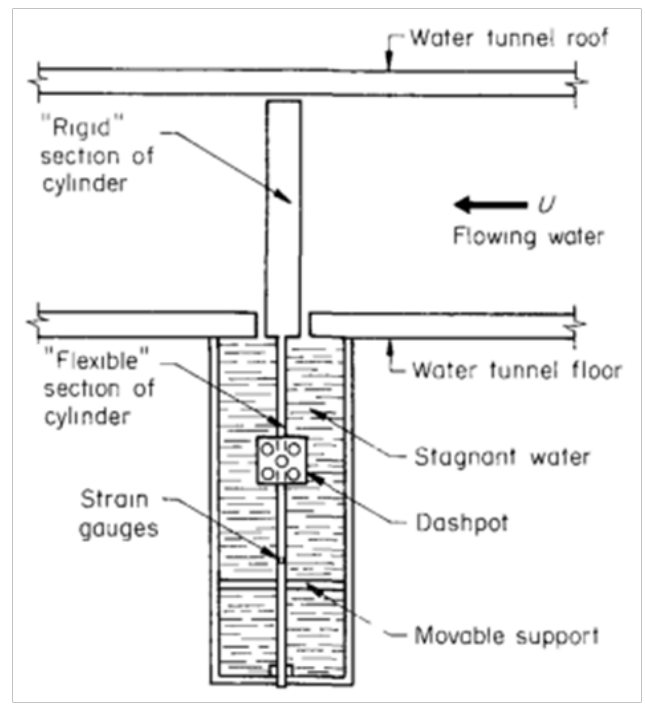

Figura 3.8: Desenho esquemático do cilindro flexível e o seu sistema de montagem no túnel de água. Tomado de Price et al. (1987).

testes para o estudo da instabilidade fluido-elástica em escoamentos bifásicos ar-água e vaporágua. A seção de testes estava composta por dois bancos de tubos em configuração quadrada normal com razão de passo transversal e diâmetro igual a 1,4; um banco foi instalado depois de outro na direção do escoamento. O primeiro foi instalado na sua totalidade com fios de aço tensionados e o segundo foi instalado rigidamente com dobro engaste. $\mathrm{O}$ fio de aço usado para suspender os tubos tinha um diâmetro igual a $0,51 \mathrm{~mm}$. No artigo não se apresentam detalhes sobre o sistema usado para esticar os fios, no entanto, se menciona que por meio do uso dele a variação da frequência natural entre os tubos do banco foi de apenas $\pm 0,3 \mathrm{~Hz}$. A resposta oscilatória do tubo foi medida com extensômetros instalados numa placa, a qual foi soldada ao fio de aço. O formato no qual os fios e a placa com os extensômetros foram instalados se mostra na Fig. 3.9.

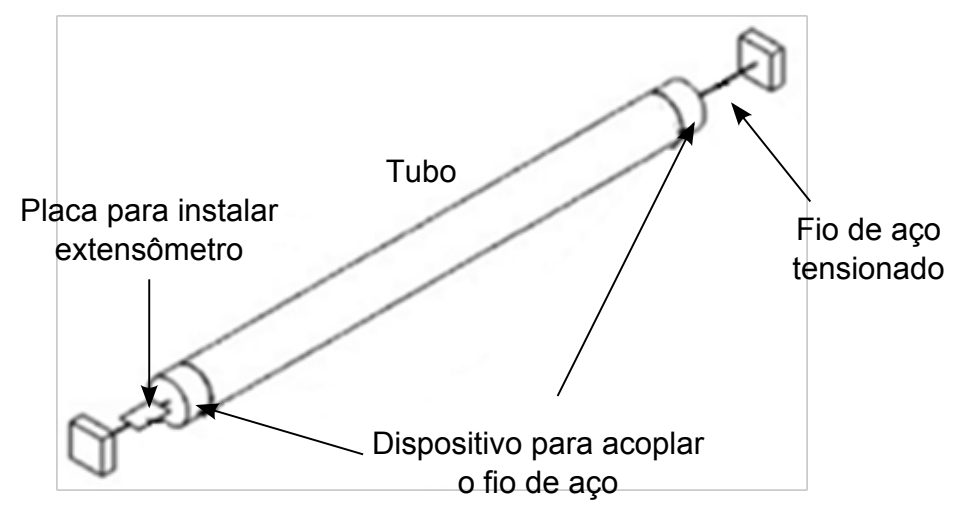

Figura 3.9: Esquema de suspensão do tubo. Tomado de Mitra et al. (2009).

Khalifa et al. (2012) é o artigo mais recente no qual se publicam as características da bancada. Neste estudo se examina o conceito de usar um único tubo flexível num banco de tubos rígidos para predizer a instabilidade fluido-elástica. Para isso, se realizaram testes num túnel 
de vento com dois tipos de bancadas, uma com todos os tubos rígidos e outra com um único tubo flexível rodeado de tubos rígidos. A configuração geométrica usada para os testes foi do tipo triangular paralela porque a resposta dos tubos foi mais estável em comparação com outras configurações testadas. Os tubos de alumínio usados na bancada são de $57 \mathrm{~mm}$ de diâmetro e $305 \mathrm{~mm}$ de comprimento e o arranjo apresenta uma razão de passo transversal e diâmetro igual a 1,54; o qual, segundo o autor, foi escolhido por facilitar a instalação dos instrumentos de medição das características do escoamento.

Na seção de testes dessa bancada os tubos flexíveis foram instalados por meio de fios aço, os quais formam parte de uma estrutura dinâmica que permite sintonizar a frequência natural do tubo com uma precisão de $0,1 \mathrm{~Hz}$. Para realizar os testes a frequência natural dos tubos foi sintonizada em $20 \mathrm{~Hz}$, valor que coincide como range de frequências usadas nas bancadas anteriores. O esquema da estrutura dinâmica usada neste artigo se apresenta na Fig. 3.10. Também foram colocados dispositivos de amortecimento viscoso, estes estavam compostos por uma pá e uma taça. A taça continha o óleo e a pá foi conectada ao fio de aço para se deslocar conjuntamente com ele e amortecer o deslocamento no médio viscoso. O nível de óleo na taça controla a quantidade de amortecimento mecânico inserido na estrutura.

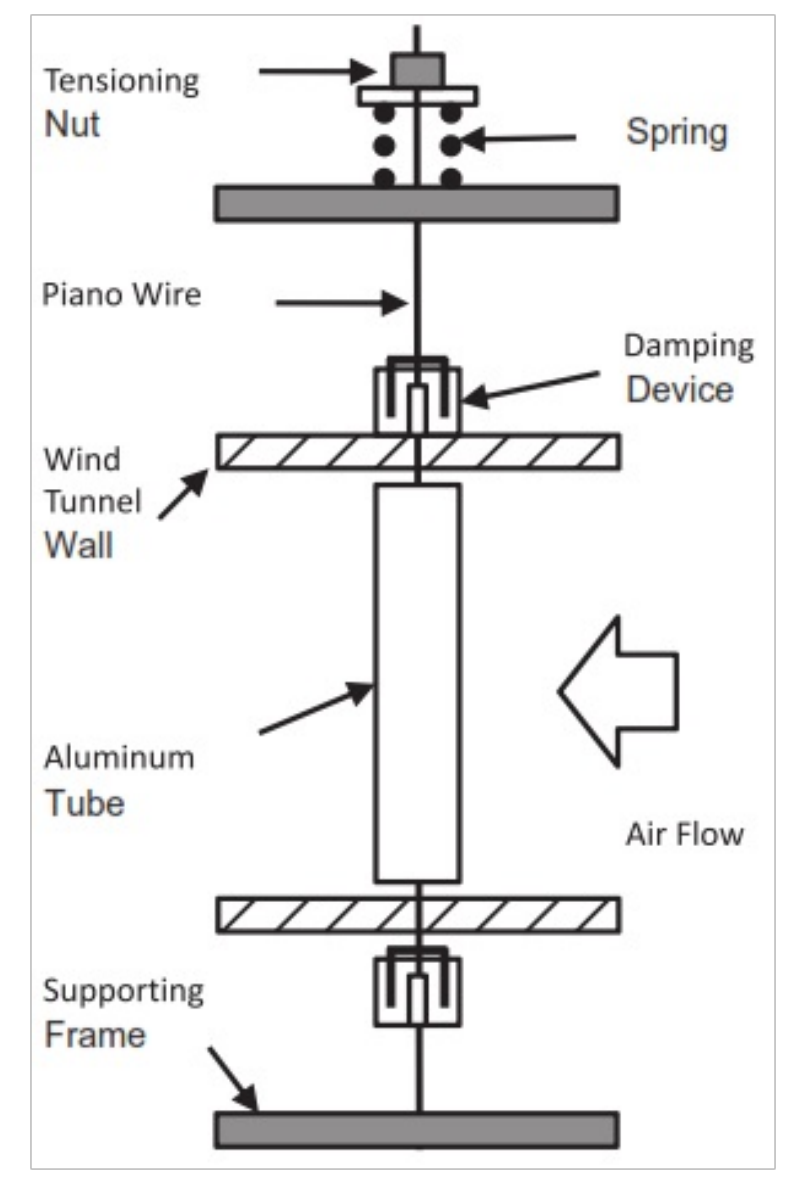

Figura 3.10: Esquema da estrutura dinâmica. Tomado de Khalifa et al. (2012).

Mediu-se a resposta dinâmica dos tubos nas direções paralela e transversal ao escoamento. 
Para isso foram instalados dois acelerômetros uni-axiais em cada tubo flexível, um para cada direção. Além disso, outro acelerômetro uni-axial foi instalado sobre uma estrutura projetada para monitorar o deslocamento transversal de qualquer tubo não instrumentado no arranjo.

Em resumo, têm sido apresentadas duas configurações para a instalação dos tubos instrumentado; elas são a montagem em cantilever e a flexível. A montagem em cantilever apresenta a vantagem de ser simples e não precisar de outras peças. Dependendo das características do tubo, na montagem em cantilever podem ser obtidas frequências naturais em torno dos $100 \mathrm{~Hz}$. Por outro lado está a montagem flexível, a qual na maioria dos casos está composta por uma estrutura dinâmica e o tubo. A estrutura dinâmica consegue regular a frequência natural do tubo por meio da calibração da tensão nos fios de aço, os quais estão acoplados aos extremos do tubo. As vantagens que apresenta a instalação flexível são: sintonização da frequência de ressonância in situ, possibilidade de inclusão de dispositivos de amortecimento e simplicidade do funcionamento. Além disso, usar uma estrutura dinâmica permite evitar o acoplamento hidrodinâmico que ocorre quando vários tubos num fluido oscilam com a mesma frequência. Esta vantagem construtiva pode simplificar o estudo da resposta do tubo. Segundo o revisado na bibliografia, frequências naturais menores do que $40 \mathrm{~Hz}$ podem ser sintonizadas através desse tipo de estrutura dinâmica.

Pelas vantagens descritas, especialmente pela versatilidade do sistema, no presente trabalho se decidiu projetar uma estrutura dinâmica para montar flexivelmente o tubo instrumentado na seção de testes. O tipo de estrutura selecionado é aquele composto por fios de aço tensionados através dos quais é possível a sintonização da primeira frequência natural do tubo.

\subsection{Características da seção de testes da bancada experimental}

A estrutura dinâmica projetada nesse trabalho será instalada numa bancada de testes que além de permitir o estudo da VIE também será usada para o estudo da perda de pressão, fração de vazio e padrões de escoamento durante escoamento cruzado vertical de uma mistura de água e ar que atravessa a um banco de tubos. Em termos gerais, a bancada está composta por um circuito fechado de água ao qual se injeta ar para formar um escoamento bifásico, este escoamento é conduzido por uma seção de testes conformada basicamente por um duto atravessado por um banco de tubos, o qual representa um equipamento de troca de calor. Na Figura 3.11 se apresenta uma ilustração da bancada experimental.

Segundo a informação descrita em Kanizawa (2012), a seção de testes tem as seguintes características:

- Diâmetro dos tubos $d$ igual a $19 \mathrm{~mm}$;

- Espaçamento transversal $s_{1}$ igual a $24 \mathrm{~mm}$;

- Espaçamento longitudinal $s_{2}$ igual a $20,785 \mathrm{~mm}$;

- Comprimento do banco de tubos no sentido axial $L_{t}$ igual a $381 \mathrm{~mm}$; 


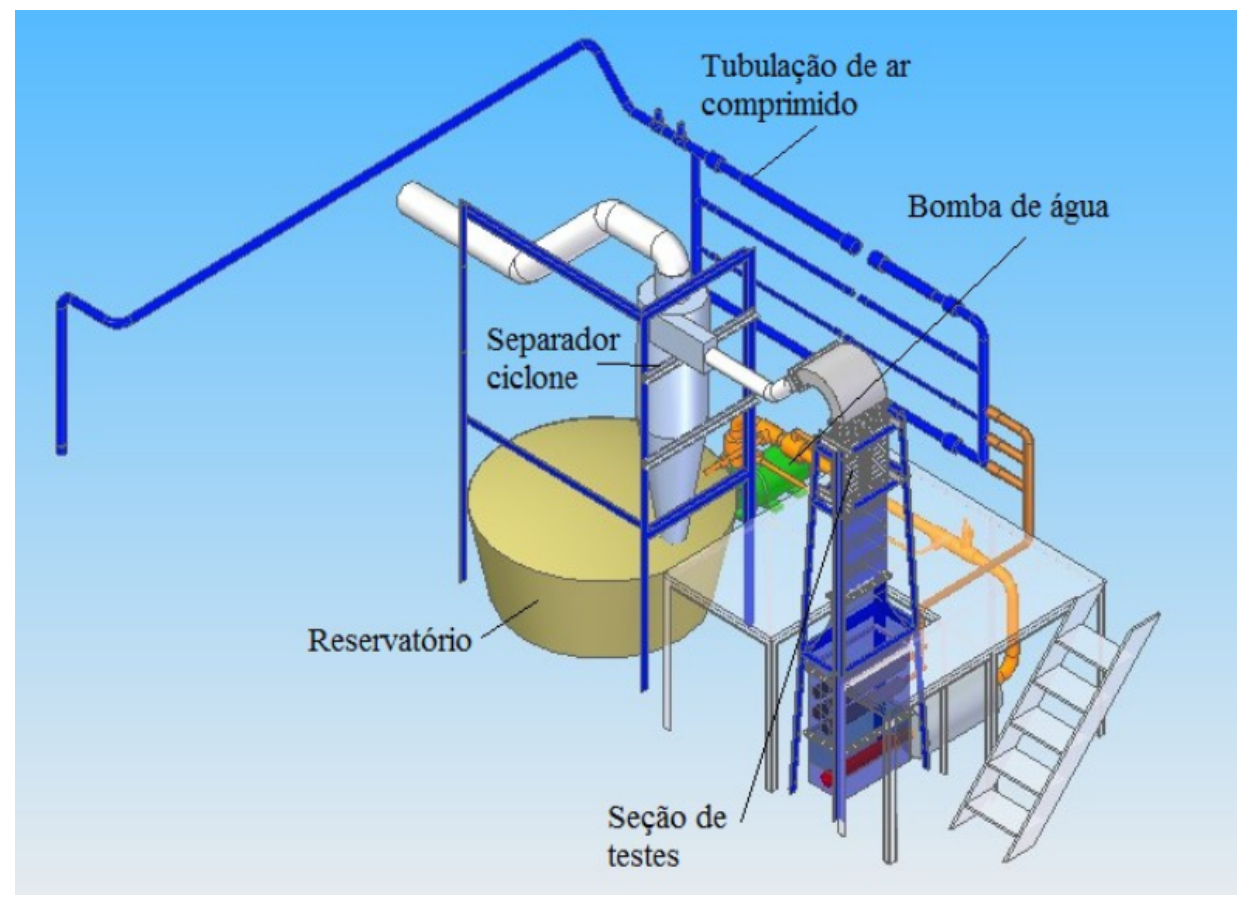

Figura 3.11: Ilustração do circuito principal do aparato experimental. Tomado de Kanizawa (2012)

- Quatro tubos por fileira horizontal;

- Vinte fileiras horizontais;

- Configuração triangular normal com razão $\tau$ igual a 1,26.

A parte interna das paredes laterais da seção de testes foi usinada de acordo com a quantidade e posição dos tubos, e da instrumentação que será intalada neles. Visando a instalação do único tubo flexível da tubulação, no projeto inicial se incluiu um furo passante no centro da décima quinta fileira (ver Fig. 3.11 ). Em Kanizawa (2012) se argumenta que essa região foi escolhida para a instalação de todos os tubos instrumentados devido a que, segundo Kondo e Nakajima (1980), para tubulações com $\tau$ igual a 1,28 o escoamento encontra-se desenvolvido só a partir da décima primeira fileira horizontal.

$\mathrm{Na}$ parte externa das paredes da seção de testes foram usinados furos rosqueados para a fixação de estruturas relacionadas com a instrumentação dos tubos. Na Figura 3.13 se apresenta um detalhe das furações próximas à posição onde o tubo instrumentado com acelerômetros deve ser instalado. Como se pode ver, o furo correspondente ao tubo instrumentado está na metade do largo da parede, este furo tem um diâmetro de $23 \mathrm{~mm}$ pela parte interna e nelefoi feito um rebaixo para ter um diâmetro de $25 \mathrm{~mm}$ na superfície externa da seção de testes. Ao redor, do lado externo da parede, foram usinados 12 furos rosqueados cegos. Destes furos só serão usados os furos rosqueados M6x1 para a instalação da estrutura dinâmica devido a que eles são simétricos com respeito aos eixos vertical e horizontal do furo destinado à instalação do tubo. Além disso, o conjunto de furos M6x1 está mais afastado do furo central do que os outros furos 


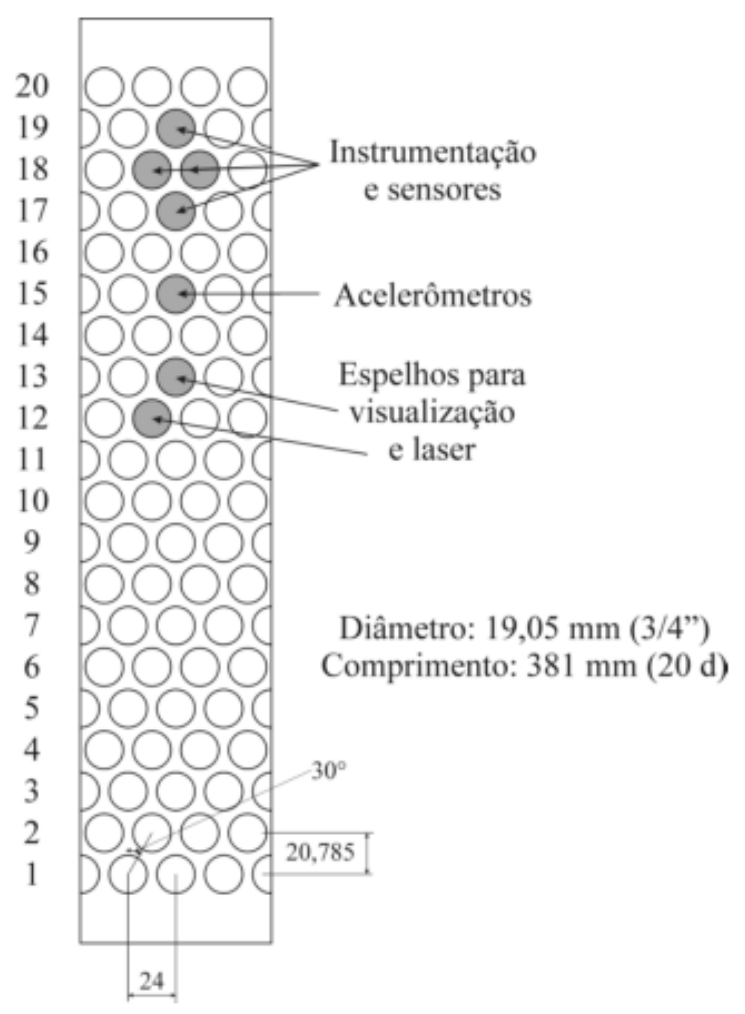

Figura 3.12: Diagrama esquemático da parede do banco de tubos. Tomado de Kanizawa (2012).

que podem ser usados para a instalação da estrutura dinâmica, isto permite uma maior liberdade no projeto das peças.

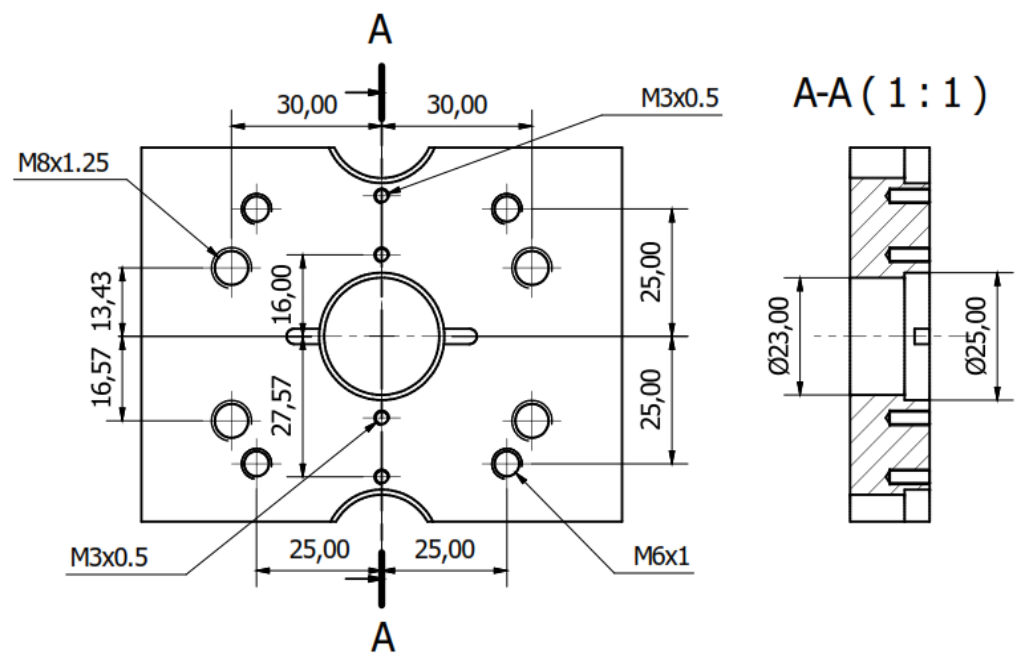

Figura 3.13: Detalhe das furações nas proximidades da posição destinada ao tubo flexível. Tomado de Kanizawa (2012) 


\subsection{Projeto da estrutura dinâmica}

A estrutura dinâmica projetada nesse trabalho deve permitir a sintonização da primeira frequência natural de vibração do tubo instrumentado, a qual deve ser semelhante à apresentada pelos componentes estruturais dos equipamentos reais de troca de calor. Para isso, baseado na revisão bibliográfica e considerando as vantagens desse tipo de configuração, se decidiu projetar um tipo de estrutura na qual o tubo instrumentado é suspendido por fios de aço tensionados.

\subsubsection{Antecedentes}

Como precedente ao projeto da estrutura dinâmica pode-se citar a estrutura construída e testada em Álvarez et al. (2013). Neste estudo o tubo instrumentado foi tensionado por quatro fios de aço de 0,4 mm, dois por cada extremo. Em cada extremo, os dois fios de aço foram tensionados paralelamente ao eixo longitudinal do tubo e equidistantes a seu centro. O objetivo principal desta configuração foi manter o alinhamento dos acelerômetros nas direções paralela e perpendicular à direção que circulará o escoamento na bancada real. Este objetivo foi cumprido, no entanto, a comparação com a modelagem teórica do sistema permitiu observar que nesta estrutura dinâmica o segundo modo de vibração não é bem reproduzido pela modelagem teórica, o qual insere a dificuldade de desconhecer a resposta do tubo num range de frequências acima da primeira frequência natural da estrutura dinâmica. Em Álvarez et al. (2013) concluiu-se que uma das razões pelas quais a segunda frequência natural não é bem reproduzida pode corresponder à linearização das equações diferenciais na modelagem. Por outro lado, no contexto experimental, uma das razões pelas quais resultados teóricos e experimentais não coincidem pode corresponder a que dois dos quatro fios de aço sofrem diferente alongamento do que os outros dois fios no modo rocking de vibração e este fato não é bem reproduzido no modelo teórico.

Pelas razões experimentais e teóricas expostas se descartou o uso de quatro fios para suspender o tubo instrumentado e portanto se decidiu propor o projeto de uma estrutura dinâmica composta por dois fios só, a qual já foi usada em vários estudos experimentais como foi mencionado na revisão bibliográfica. Por tanto, nessa seção se apresenta o projeto das peças que fazem parte desta estrutura dinâmica.

\subsubsection{Porta-acelerômetros}

O objetivo principal deste dispositivo é permitir a instalação de dois microacelerômetros uniaxiais modelo 352A24 da marca PCB Piezotronics ao interior do cada extremo do tubo. Estes acelerômetros servirão para medir a resposta dinâmica do tubo nas direções paralela e transversal ao escoamento. As restrições consideradas para o projeto do porta-acelerômetros são as seguintes:

- O porta-acelerômetros deve funcionar como uma conexão entre o tubo e os fios tensionados, pelo qual entre o tubo e os porta-acelerômetros se deve usar uma junta capaz de 
suportar uma carga de pelo menos $1200 \mathrm{~N}$ (ver dados sobre projeto do subsistema de tensionamento de fios).

- A geometria do porta-acelerômetros deve permitir a entrada e saída dos cabos que conectam os acelerômetros ao sistema de aquisição de dados. De preferência os cabos devem sair por um lado só do tubo para melhorar a organização das conexões.

- Os porta-acelerômetros devem vedar o interior do tubo devido a que os acelerômetros não podem entrar em contato com o líquido.

- Deve-se restringir o deslocamento angular relativo entre o tubo e os porta-acelerômetros para evitar medições erradas da resposta dinâmica do tubo.

- Os porta-acelerômetros devem ajudar ao adequado posicionamento do tubo para evitar mudanças localizadas da razão $\tau$.

- O material usado para construir os porta-acelerômetros deve permitir que as peças sejam leves e, além disso, resistentes à corrosão por estar expostas a um ambiente bifásico água - ar.

Baseado nestas condições se propõe um design como o que aparece na Fig. 3.14. Em geral, os porta-acelerômetros tem o formato de um eixo com seções de diferentes diâmetros. Serão construídas duas peças desse tipo, mas só uma delas será projetada para retirar os cabos dos acelerômetros. Será inserido um porta-acelerômetros em cada extremo do tubo.

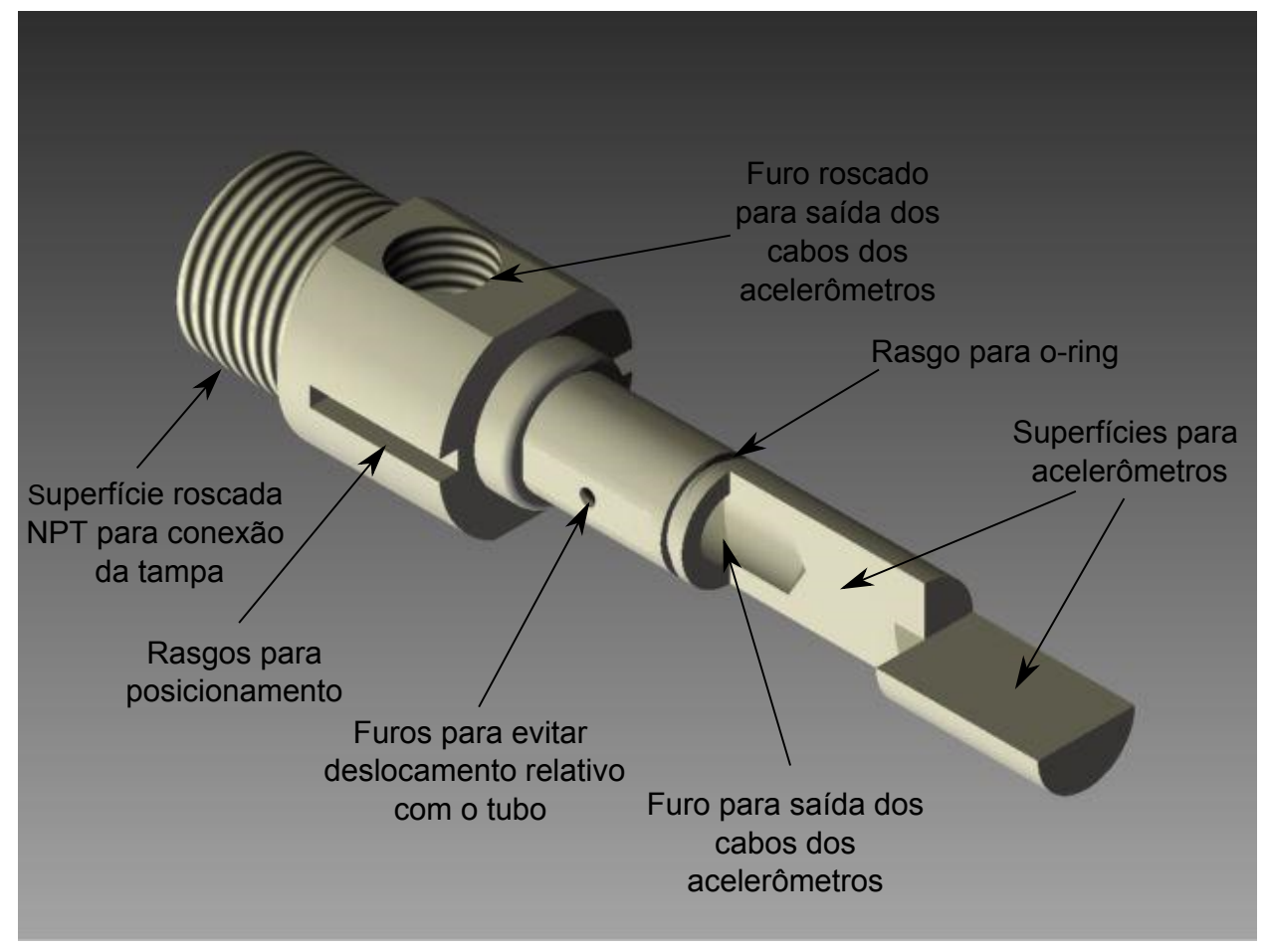

Figura 3.14: Partes do porta-acelerômetros e seu funcionamento. 
Como se pode ver, num dos extremos da peça se projetaram duas superfícies que formam entre elas um ângulo de $90^{\circ}$, essas superfícies servirão para colar os acelerômetros uniaxiais. Para a saída dos cabos dos porta-acelerômetros se projetou um furo que conecta as superfícies planas com o outro extremo da peça. Os cabos serão conduzidos por esse furo até outro orifício perpendicular ao eixo longitudinal da peça, por essa perfuração serão tirados do interior os cabos dos quatro acelerômetros sem entrar em contato com o líquido.

Para segurar o porta-acelerômetros dentro do tubo e evitar o deslocamento relativo entre peças se projetou uma junta por meio de dois parafusos diametralmente opostos. Depois de aplicar o critério de falha de Von Misses a cortante se decidiu que os parafusos sejam do tipo hexagonal M3 passo 0,5 de aço inoxidável. Para a conexão dos parafusos se projetaram dois furos roscados na superfície do porta-acelerômetros e dois furos passantes no tubo, assim os parafusos serão colocados desde a superfície externa do tubo. É importante mencionar que tanto as perfurações no porta-acelerômetros como no tubo devem ser feitas sobre superfícies planas para posteriormente conseguir vedar o interior do tubo.

Na seção de maior diâmetro se projetaram dois rasgos para alinhar o conjunto tubo - portaacelerômetros na bancada de testes através de um par de placas. Nessa mesma seção se encontra o furo roscado que servirá para tirar os cabos dos acelerômetros, neste furo será acoplado uma conexão de tipo pneumática de engate rápido em conjunto com uma mangueira para conduzir os cabos até um ambiente sem líquido. Ao lado desta seção, no extremo do porta-acelerômetro, se decidiu usinar uma superfície roscada NPT macho que servirá para tampar o furo central do porta-acelerômetros e acoplar o tubo aos fios de aço tensionados.

\subsubsection{Tampa do porta-acelerômetros}

A tampa do porta-acelerômetros tem duas funções: a primeira é fechar o furo central do porta-acelerômetros e a segunda é servir como acople entre o conjunto tubo - porta-acelerômetros e os fios de aço. Baseado nessas indicações se projetou uma peça com um furo roscado tipo NPT acorde com a superfície roscada existente no extremo do porta-acelerômetros. As roscas devem ser do tipo NPT para evitar a entrada de líquido ao interior do tubo. A superfície externa dessa seção foi projetada com duas caras paralelas para que seja possível apertar e afrouxar a tampa com as ferramentas.

$\mathrm{Na}$ parte posterior da peça se adicionaram duas placas, as mesmas que permitem conectar uma terceira placa de $5 \mathrm{~mm}$ de espessura com um furo de $2 \mathrm{~mm}$ de diâmetro no meio. O objetivo principal dessa placa é centrar e suportar a carga exercida pelo fio de aço, o qual será enrolado num passador do outro lado da mesma placa. A placa será fixada à peça por meio de 6 parafusos de aço inoxidável M3 passo $0,5 \mathrm{~mm}$; três em cada extremo com o objetivo de distribuir melhor a carga.

Deixou-se espaço entre a placa e a tampa para que conforme a tensão aumente no fio o parafuso possa se acomodar com liberdade mantendo o fio centrado. Na Figura 3.15 se podem ver as partes importantes da peça e na Fig. 3.16 se mostra o conjunto formado pela tampa e o 
porta-acelerômetros.

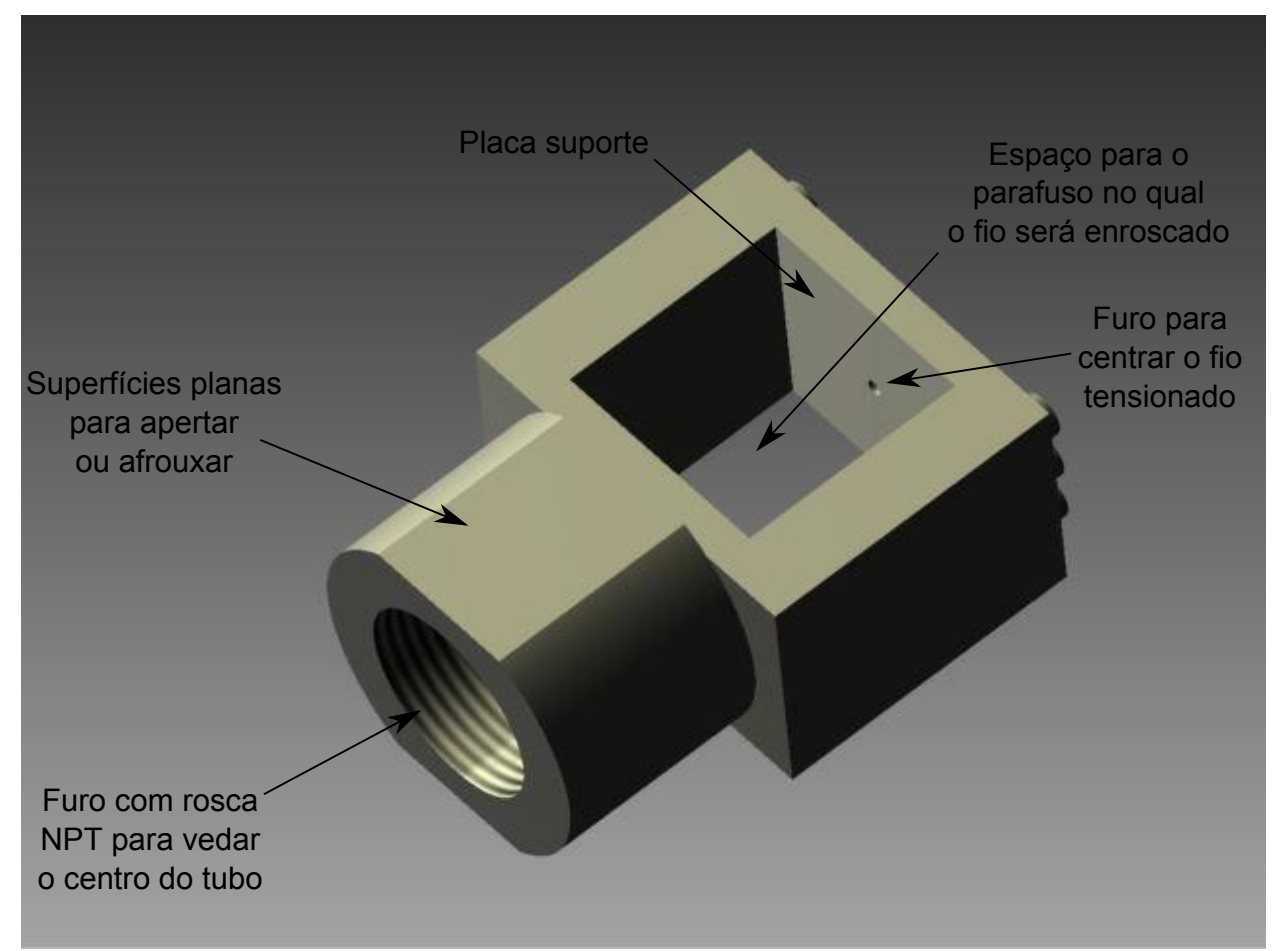

Figura 3.15: Partes da tampa do porta-acelerômetros.

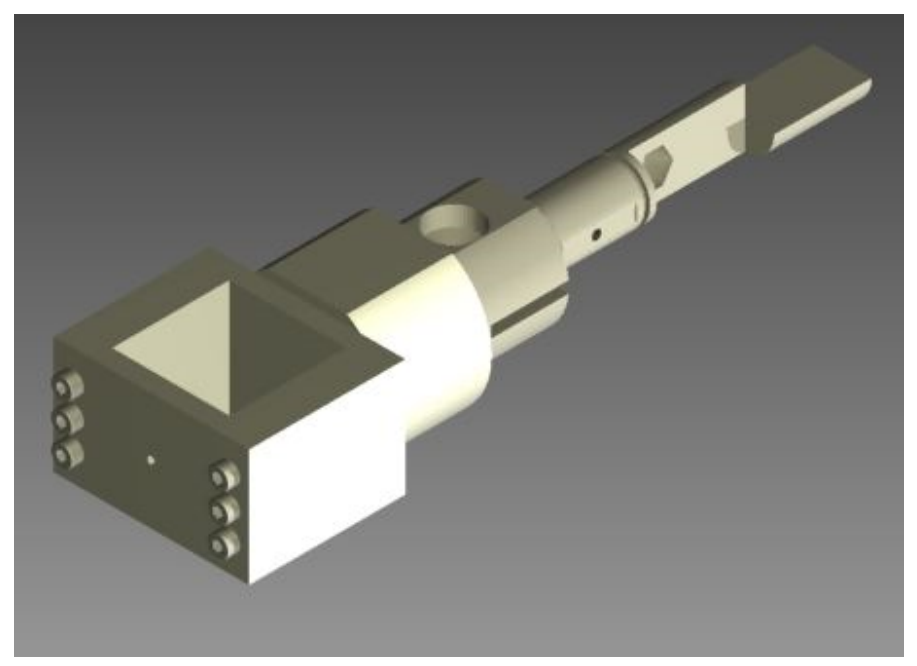

Figura 3.16: Conjunto porta-acelerômetros e tampa.

\subsubsection{Sistema de tensionamento dos fios de aço}

O mecanismo de tensionamento dos fios deve permitir a regulação da primeira frequência natural de vibração do tubo instrumentado, a qual, segundo Blevins (1979), está na faixa entre 10 e $50 \mathrm{~Hz}$ para os componentes estruturais internos dos trocadores de calor reais. Esta informação é confirmada por Pettigrew et al. (2001) quem argumenta que a frequência natural típica de um tubo de trocador de calor é aproximadamente $30 \mathrm{~Hz}$. 
O mecanismo selecionado é simples e está composto por poucas peças. O funcionamento do mecanismo é o seguinte: os fios de aço são tensionados pela força exercida por uma mola, a qual é comprimida gradualmente pelo deslocamento relativo entre um parafuso e uma porca. Para que o fio seja tensionado ele é segurado na tampa do porta-acelerômetros e daí atravessa longitudinalmente o corpo do parafuso regulador até sair do lado da cabeça onde é enrolado e segurado num passador. Desse jeito, quando o parafuso se desloca relativamente à porca a mola é comprimida e a tensão no fio aumenta, no entanto, teoricamente o comprimento dos fios é mantido devido a que é compensado pela deformação da mola. O mecanismo que será projetado nessa seção se apresenta na Fig. 3.17.

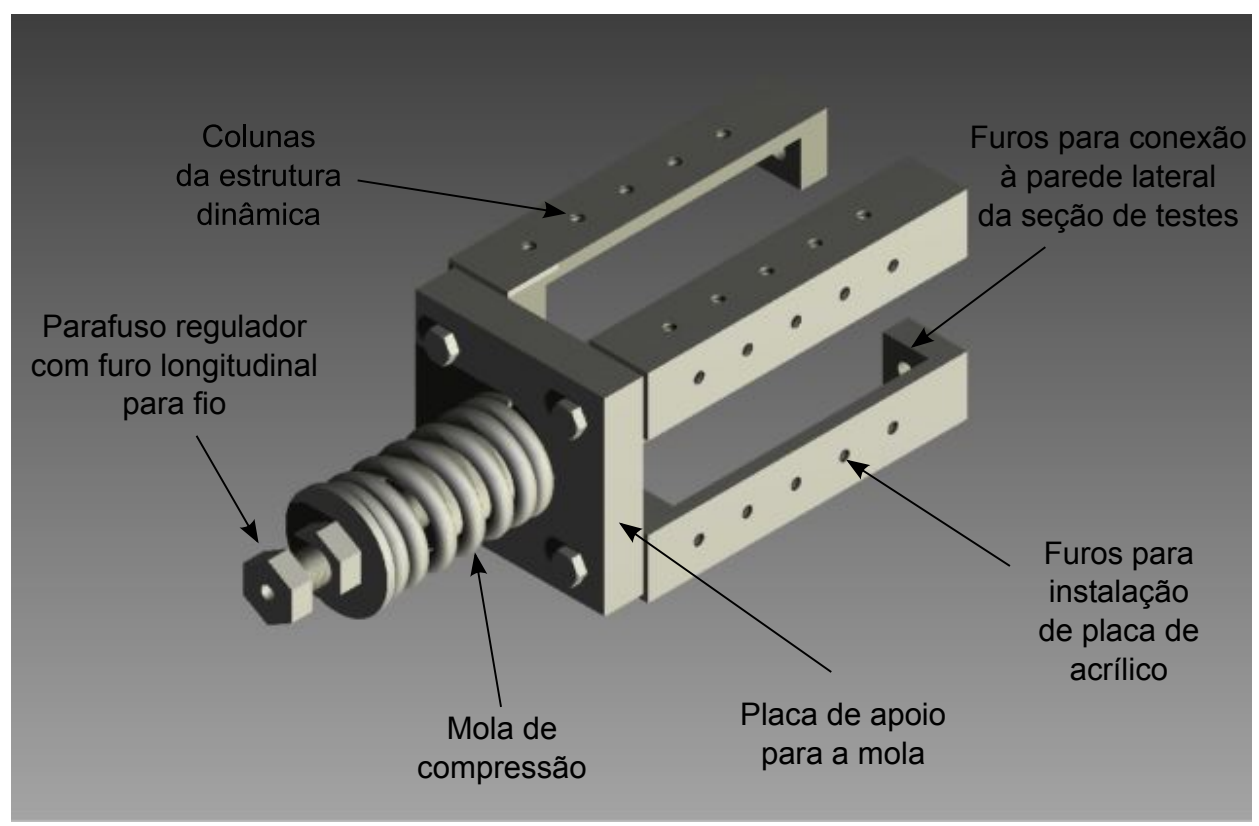

Figura 3.17: Sistema de tensionamento dos fios de aço.

Para dimensionar as partes do mecanismo de tensionamento primeiro se precisa conhecer qual é a força máxima que atua sobre os fios de aço. A força pode ser estimada a partir da equação que define a primeira frequência natural da estrutura dinâmica correspondente ao modo bouncing de vibração. A segunda frequência natural, correspondente ao modo rocking, não é considerada nessa análise devido a que as duas frequências de naturais não podem ser independentemente calibradas, é dizer, depois de que uma frequência de natural é definida então a outra já é fixa. Portanto se decidiu calibrar a primeira frequência natural da estrutura para atingir o range de frequências de interesse. A primeira frequência natural $\omega_{n 1}$ pode ser expressa como:

$$
\omega_{n 1}=\sqrt{\frac{2 T}{m L}}
$$

onde $\omega_{n 1}$ é a primeira frequência de vibração medida em $\mathrm{rad} / \mathrm{s}, \mathrm{m}$ é a massa do sistema que está oscilando, $T$ é a tensão nos fios de aço e $L$ é o comprimento livre dos fios de aço. Se o valor de $m$ for fixo (esse valor só é conhecido depois de ter projetado todas as peças) e estabelecendo 
uma faixa de frequências naturais de interesse entre 10 e $35 \mathrm{~Hz}$ então através da Eq. 3.12 se pode estimar os intervalos de tensão $T$ e comprimento $L$ que permitam gerar esse range de frequências naturais. Para ter uma melhor ideia da relação entre os parâmetros mencionados se pode ver a Fig. 3.18, onde as linhas representam os pares ordenados de $T$ e $L$ necessários para reproducir uma determinada frequência natural. É importante mencionar que essa estimativa não deve ser realizada aisladamente já que ela depende de paramêtros construtivos e geométricos como por exemplo as características mecânicas da mola (dimensionada posteriormente), o deslocamento do parafuso com o qual se planeja tensionar o fio de aço e a massa total do tubo e seus acessórios.

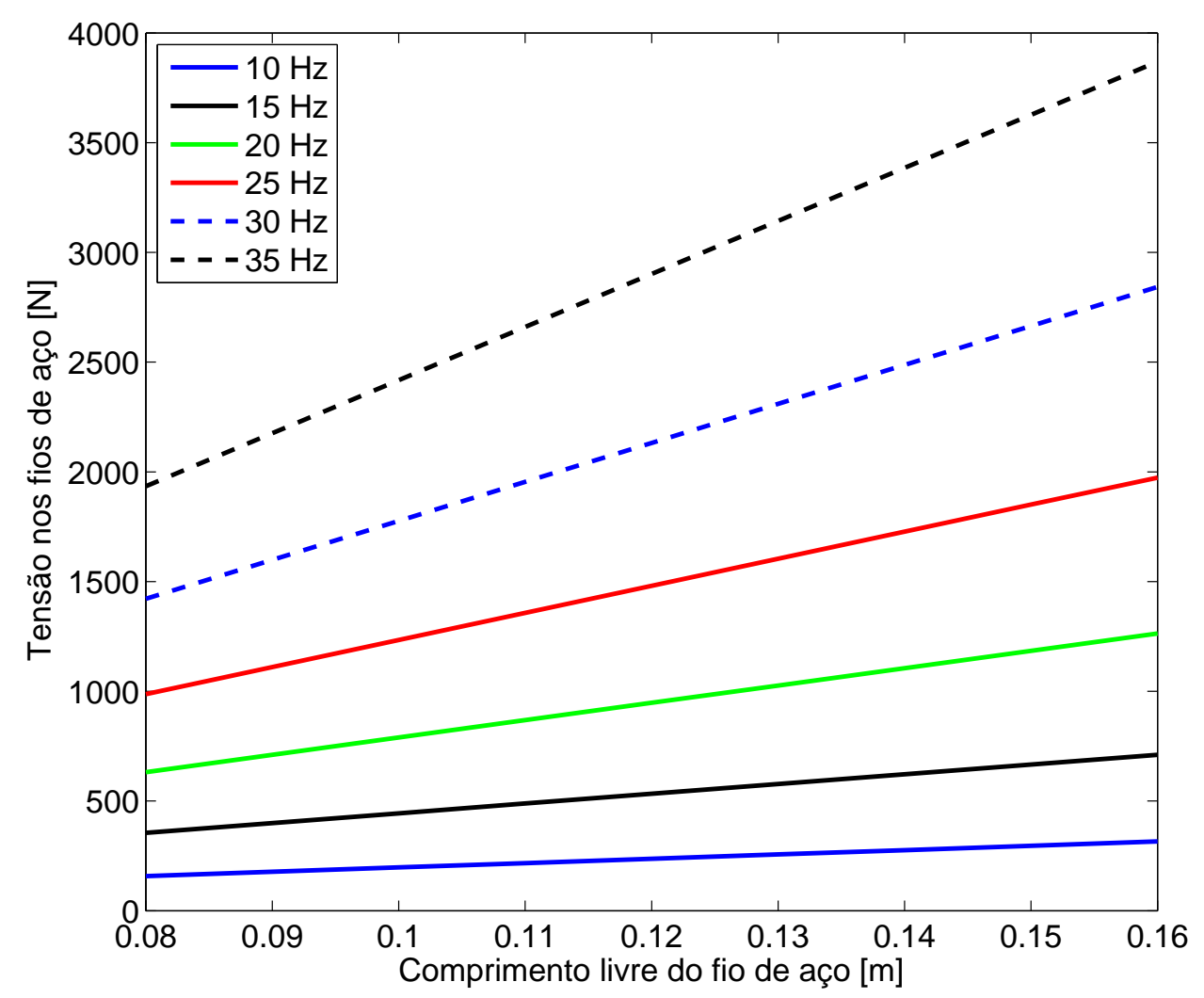

Figura 3.18: Relação entre os parâmetros $L$ e $T$ para diferentes frequências naturais do tubo instrumentado.

Depois desta análise, se determinou que para atingir as frequências naturais da faixa de interesse o comprimento livre do fio deve estar no intervalo de 80 a $160 \mathrm{~mm}$ e a tensão necessária para gerar essa condição está no intervalo de 500 a $1200 \mathrm{~N}$.

Além da força exercida pelos fios de aço, o tubo instalado dentro da seção de testes estará exposto ao arrasto exercido pela componente principal da velocidade $U_{o}$ do escoamento bifásico. $\mathrm{O}$ arrasto contribui com uma componente de força paralela ao escoamento que atua sobre os fios de aço como se vê na Fig. 3.19.

Para dimensionar os fios de aço a força de arrasto exercida pelo escoamento bifásico inicialmente pode ser estimada como a exercida por um escoamento monofásico de água. A força de arrasto pode ser calculada com a expresão apresentada em Zukauskas e Ulinskas (1983): 


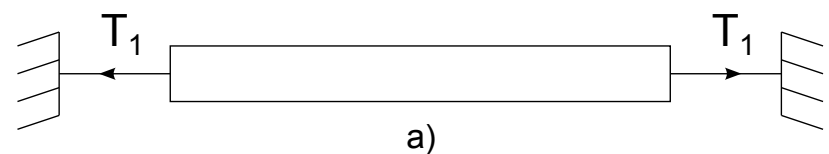

a)

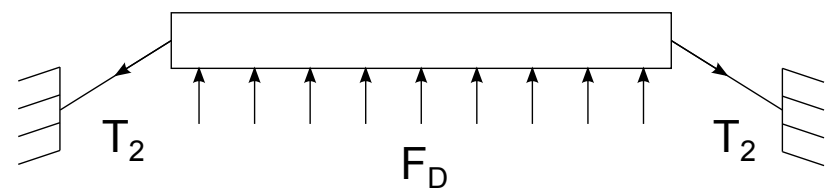

b)

Figura 3.19: Tensões sobre os fios de aço: a) Sem escoamento e b) Sob um escoamento cruzado.

$$
C_{D}=\frac{2 F_{D}}{\rho U^{2} A_{t r}}
$$

Na equação 3.13 o termo $F_{D}$ é a força de arrasto e $A_{t r}$ é a projeção da superfície do tubo sobre o plano perpendicular à direção do escoamento, neste caso igual ao produto entre o comprimento do tubo $H$ e seu diâmetro $d$. O coeficiente de arrasto $C_{D}$ é calculado através de ajuste de curvas (em função do número de $R e$ ) disponíveis na mesma fonte bibliografica.

Se somente se considera um escoamento monofásico de água a uma temperatura de $25^{\circ} \mathrm{C}$ e pressão igual a 4 bar (pressão máxima na seção de testes segundo Kanizawa (2012)) então se obtém uma força de arrasto igual a $9 \mathrm{~N}$, a mesma que comparada à força de tensão dos fios é mínima e por tanto não será considerada no dimensionamento deles.

Consequentemente, sob a suposição de uma tensão máxima nos fios de $1200 \mathrm{~N}$ e com a condição de que o material usado deve ser inoxidável, se propõe usar um fio de aço inoxidável ASTM A302 de 1,2 mm de diâmetro. Por meio dos valores da tabela 10.5 disponível em Budynas e Nisbett (2011) se pode estimar o esforço limite de escoamento do material em $1182 \mathrm{MPa}$, em quanto que o esforço de tração calculado nesse caso é $1061 \mathrm{MPa}$. Embora o esforço solicitado seja menor do que a resistência do material, os dois valores estão muito próximos. Por essa razão a calibração da tensão nos fios deve ser feita com cuidado para evitar a deformação plástica do material, o qual afetaria a resposta dinâmica do tubo.

O parafuso selecionado para regular a compressão da mola é um M12 passo 1,75 mm. Embora a força de $1200 \mathrm{~N}$ é mínima em comparação da resistência de um parafuso M12, o diâmetro foi selecionado devido a que o parafuso deve ser perfurado longitudinalmente para que possa ser atravessado pelo fio. $\mathrm{O}$ diâmetro do furo que atravessa o parafuso é $5 \mathrm{~mm}$.

A mola de compressão da estrutura dinâmica deve ser projetada sob três condições; a primeira é que deve resistir a carga máxima de tensão sobre o tubo instrumentado, a segunda é que a sua constante de rigidez permita ajustar a tensão sobre os fios no intervalo desejado, e a terceira é que as suas dimensões e materiais devem ser compatíveis com a geometria e ambiente da seção de testes. De acordo com as restrições se estabeleceu que a mola de compressão deve ser construída em aço inoxidável ASTM A304 com um diâmetro interno de 25 mm, uma 
constante de rigidez de $70 \mathrm{kN} / \mathrm{m}$ e suportar uma carga máxima de trabalho de $1500 \mathrm{~N}$ com um comprimento de $40 \mathrm{~mm}$ nessa carga. A carga máxima da mola foi superestimada para manter as forças de trabalho numa faixa afastada do limite permissível. Previamente à fabricação, a mola foi modelada num software comercial de CAD, além disso, a viabilidade do projeto foi conferida com o construtor.

O bastidor sobre o qual a mola será comprimida precisa ter um eixo para guiar a sua deformação e garantir o correto funcionamento da estrutura. Para cumprir com esta função se projetou uma placa composta por duas peças conectadas por parafusos. A primeira peça é uma placa retangular de espessura $15 \mathrm{~mm}$ com um furo passante no meio e a segunda é um eixo de diâmetro $25 \mathrm{~mm}$ com um furo longitudinal de $12 \mathrm{~mm}$, esta servirá para guiar a deformação da mola. O eixo será inserido no furo na primeira placa. Para fixar a placa na parede da seção de testes são usadas 4 colunas com seção transversal em formato de $\mathrm{L}$ de espessura $5 \mathrm{~mm}$. As colunas são parafusadas na parede da seção de testes por meio de parafusos de aço inoxidável hegagonal M6 passo $1 \mathrm{~mm}$. Além das columnas, podem ser usados pedaços de placa entre as colunas e a parede da seção de testes para obter o comprimento de fio livre necessário para a montagem do tubo. O material usado para a construção do bastidor é uma liga de alumínio 6351. Este material foi selecionado pela sua resistência à corrosão em água, além disso, a sua rigidez é maior do que o alumínio normal e é mais barato do que o aço inoxidável. Uma ilustração desse subconjunto é apresentada na Fig. 3.20. A espessura dos componentes do sistema é justificada pela necessidade de construir uma estrutura cuja rigidez seja significativamente maior do que a rigidez do tubo instalado na seção de testes.

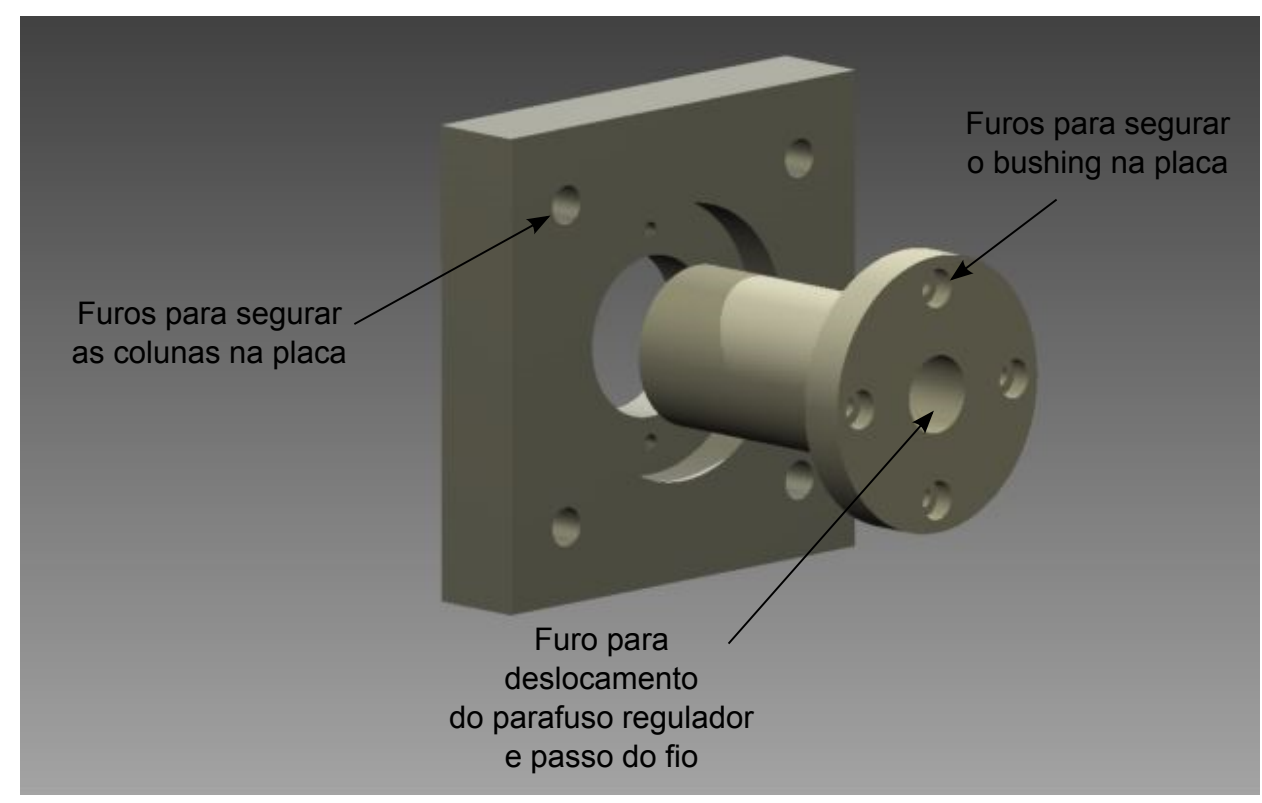

Figura 3.20: Vista posterior do conjunto formado pela placa e o bushing

As quatro colunas serão unidas à placa através de 4 parafusos sextavados M6 passo $1 \mathrm{~mm}$ de aço inoxidável. Decidiu-se usar parafusos sextavados porque nessa parte da estrutura se tem maior liberdade para o uso de ferramentas. 


\subsubsection{Tubo}

O tubo que será montado flexivelmente terá quase as mesmas características que os outros tubos da seção de testes, é dizer, será de aço inoxidável, diâmetro externo igual a $19 \mathrm{~mm}$ e espessura de parede de $2 \mathrm{~mm}$. A única diferença é que o comprimento do tubo instrumentado será $448 \mathrm{~mm}$ e não $381 \mathrm{~mm}$ como os tubos rígidos. O objetivo disso é permitir que seus extremos sejam manipuláveis fora da seção de testes e que a instalação dos instrumentos seja possível. Projetou-se o uso de parafusos para fixar os porta-acelerômetros no tubo. Para isto se realizaram duas perfurações diametralmente opostas a $15 \mathrm{~mm}$ dos extremos do tubo. As perfurações devem estar alinhadas para que as medições dos acelerômetros correspondentes estejam na mesma direção.

Em resumo, uma ilustração da estrutura dinâmica montada num dos extremos da seção de testes se pode ver na Fig. 3.21.

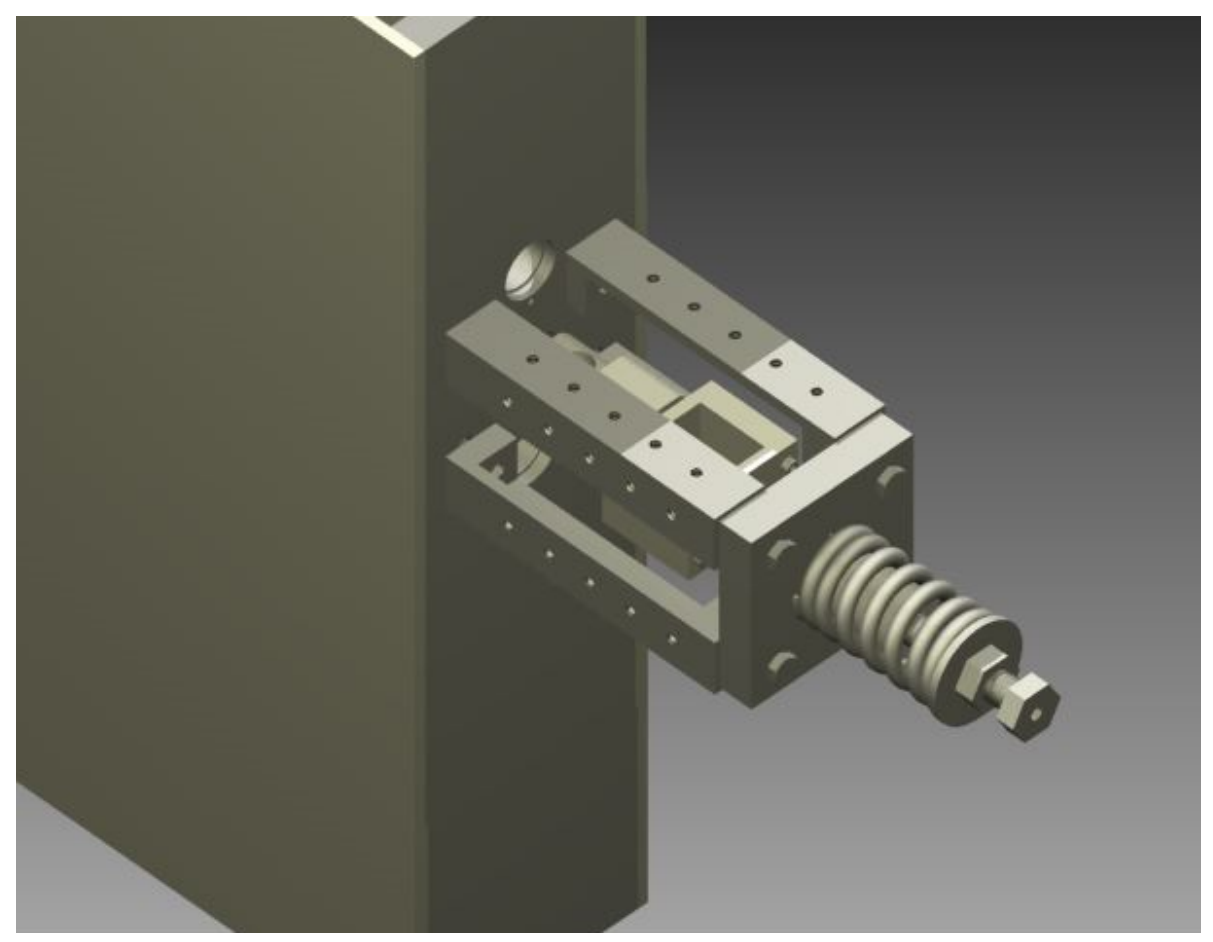

Figura 3.21: Estrutura instalada numa parede da seção de testes.

\subsubsection{Vedação da estrutura dinâmica}

Como se apresentou na seção 3.3, o diametro do furo para a instalação do tubo instrumentado foi projetado para que este último possa vibrar livremente sem bater na parede da seção de testes. No entanto, esta folga permitirá o vazamento do fluido gerando uma perda de pressão na seção de testes. Para solucionar esse problema se propôs fechar o volume ocupado pela estrutura dinâmica com placas de acrílico de modo que o fluido não possa vazar até o ambiente externo. Nas placas de acrílico se adaptaram dispositivos para purgar o fluido acumulado quando seja necessário e, além disso, se instalou o mesmo tipo de plug de purga para permitir a saída do ar 
que possa estar acumulado na parte superior da estrutura formada pelas placas de acrílico. Para tirar os cabos dos acelerômetros da seção de testes se usou uma mangueira pneumática pela qual os fios foram conduzidos internamente, desse jeito se evita que eles entrem em contato com a água. A mangueira pneumática foi instalada através de acoples de engaste rápido compatíveis com as roscas usinadas nos porta-acelerômetros.

\subsubsection{Montagem da estrutura dinâmica}

O tubo instrumentado será instalado na seção de testes por meio de duas estruturas dinâmicas idênticas, as quais seguraram ao tubo pelos seus extremos. Ao mesmo tempo, estas estruturas serão fixadas pelo lado externo das paredes da seção de testes. Devido à configuração da seção de testes e o limitado espaço disponível as duas estruturas dinâmicas tem que ser montadas peça por peça in situ. A ordem sugerida para a instalação das peças no tubo é a seguinte:

1. Colocar os o-rings nos dois porta-acelerômetros.

2. Introduzir o tubo (que será instrumentado) através dos furos destinados para sua instalação nas paredes da seção de testes. $\mathrm{O}$ extremo do tubo pelo qual os fios dos portaacelerômetros serão extraídos será denominado como extremo 1 e o outro extremo do tubo será o extremo 2.

3. Identificar os fios dos acelerômetros.

4. Passar os fios dos quatro acelerômetros através da mangueira pneumática, dos dois acoples pneumáticos de 1/8" e do porta-acelerômetros 1 . Identificar os dois fios dos acelerômetros que serão instalados no ponto 2 e passar eles através do tubo até sair pelo outro extremo.

5. Instalar os acelerômetros nas superfícies do porta-acelerômetros 2 (é o porta-acelerômetros que não tem furos para a saída de fios de instrumentação).

6. Conectar os acelerômetros do ponto 2 .

7. Inserir o porta-acelerômetros 2 no tubo. Usar vaselina para lubrificar se for preciso.

8. Colocar os dois parafusos M3x6 para prender o porta-acelerômetros 2 no tubo.

9. Instalar os acelerômetros sobre as superfícies do porta-acelerômetros 1.

10. Conectar os acelerômetros do ponto 1 .

11. Inserir o porta-acelerômetros 1 no tubo.

12. Colocar os dois parafusos M3x6 para prender o porta-acelerômetros 1 no tubo. 
13. Colocar Teflon nas roscas cônicas dos dois porta-acelerômetros.

14. Colocar e apertar a tampa dos porta-acelerômetros.

Depois, para a instalação da estrutura dinâmica na parte externa da seção de testes o seguinte procedimento é sugerido:

1. Fixar os cilindros de regulação e as colunas da estrutura com os parafusos M6x8.

2. Segurar o fio de aço inoxidável num parafuso M12 hexagonal sem cabeça.

3. Passar o extremo livre do fio pela placa que é fixada na tampa do porta-acelerômetros.

4. Conectar o bushing guia da mola e a placa suporte com parafusos hexagonais M3x12.

5. Instalar a mola de compressão concentricamente ao bushing.

6. Passar o extremo livre do fio pelo furo central do bushing e através do parafuso M12x130. No momento da instalação o parafuso deve ter a sua porca e aroela.

7. Repetir estes $\mathrm{N}$ passos do outro extremo do tubo 


\section{Capítulo 4}

\section{Modelagem da estrutura dinâmica}

A estrutura dinâmica projetada nesse trabalho pode ser entendida como um sistema mecânico que permite a vibração do tubo dentro da seção de testes, portanto é importante modelá-la para compreender os parâmetros que afetam seu comportamento dinâmico. Para o desenvolvimento da modelagem foram usados como referência os trabalhos de Khalifa (2012) e Álvarez et al. (2013), nos quais se modelaram estruturas dinâmicas com um e dois fios (em cada extremo do tubo) respectivamente. Na modelagem os modos considerados são bouncing e rocking, os quais foram observados e verificados na faixa de frequências de interesse (entre 0 e $50 \mathrm{~Hz}$ ) nos testes reportados em Álvarez et al. (2013). Os modos de vibração de corpo contínuo do tubo (modos de viga) não foram considerados por estar afastados desta faixa.

Primeiro, para a modelagem do modo bouncing, se usa como referencia o esquema da Fig. 4.1 onde: $\alpha_{1}$ e $\alpha_{2}$ representam os ângulos formados pelo fio de aço e o eixo horizontal no extremo esquerdo e direito do tubo respectivamente, $H$ é o comprimento total do conjunto formado pelo tubo e os acessórios de instalação (porta-acelerômetros, tampa do portaacelerômetros, etc.), $L$ é o comprimento livre dos fios de aço e $x_{c}$ é deslocamento vertical do centro do tubo. Propõe-se usar as leis de Newton para desenvolver a modelagem, pelo qual se apresenta a somatoria da Eq. 4.1, onde $m$ é a massa total do corpo que se encontra vibrando e $\sum F$ é o somatório das forças que agem sobre ele.

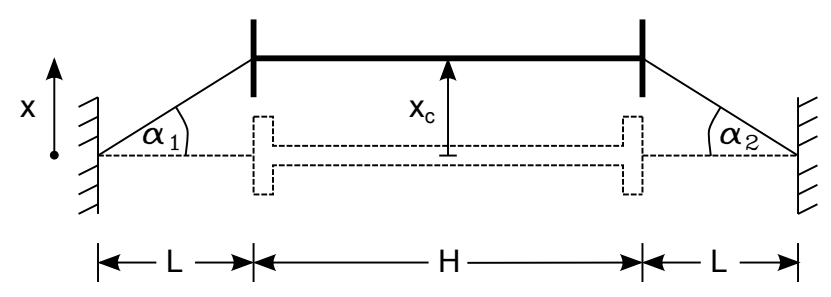

Figura 4.1: Esquema da estrutura dinâmica no modo de vibração bouncing

$$
\sum F=m \ddot{x}_{c}
$$

Neste modo de vibração as únicas forças que atuam sobre o tubo são as tensões exercidas pelos dois fios de aço, as quais podem ser descompostas na direção de deslocamento e depois 
combinadas com a Eq. 4.1. Assume-se que a mesma tensão $T$ atua nos dois fios, como resultado se obtém a Eq. 4.2.

$$
-T \operatorname{sen}\left(\alpha_{1}\right)-T \operatorname{sen}\left(\alpha_{2}\right)=m \ddot{x}_{c}
$$

Pode-se assumir que os ângulos $\alpha_{1}$ e $\alpha_{2}$ são iguais $\left(\alpha_{1}=\alpha_{2}=\alpha\right)$ pela simetria do deslocamento do tubo. Além disso, se esses ângulos forem pequenos então a equação 4.2 pode ser linearizada por meio da Eq. 4.3.

$$
\tan (\alpha)=\operatorname{sen}(\alpha)=\frac{x_{c}}{L}=\alpha
$$

Assim, a expressão que define o deslocamento do tubo no modo bouncing se obtém a partir da combinação das equações 4.2 e 4.3 , cujo resultado é a Eq. 4.4.

$$
m \ddot{x}_{c}+\frac{2 T}{L} x_{c}=0
$$

Para o equacionamento do modo rocking de vibração, se escrevem as forças que atuam sobre o tubo baseado no esquema apresentado na Fig. 4.2, onde $\alpha_{1}$ e $\alpha_{2}$ representam os ângulos formados pelo fio de aço e o eixo horizontal no extremo esquerdo e direito do tubo respectivamente, $\theta$ é o ângulo de giro do tubo e $x_{1}$ e $x_{2}$ representam o deslocamento vertical do extremo e direito do tubo respectivamente.

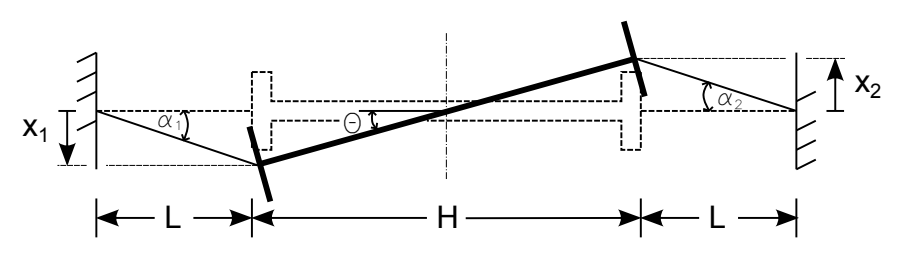

Figura 4.2: Esquema da estrutura dinâmica no modo de vibração bouncing

As forças sobre o tubo, igual do que no modo bouncing, aparecem pela tensão exercida pelos fios. Por facilidade, estas forças são expressas vetorialmente como $\vec{F}_{1}$ e $\vec{F}_{2}$ :

$$
\begin{gathered}
\vec{F}_{1}=-T_{1} \cos \left(\alpha_{1}\right) \widehat{i}+T_{1} \operatorname{sen}\left(\alpha_{1}\right) \widehat{j} \\
\vec{F}_{2}=T_{2} \cos \left(\alpha_{2}\right) \widehat{i}-T_{2} \operatorname{sen}\left(\alpha_{2}\right) \hat{j}
\end{gathered}
$$

Nessa análise, os ângulos $\alpha_{1}$ e $\alpha_{2}$ também podem ser considerados iguais $\left(\alpha_{1}=\alpha_{2}=\alpha\right)$ devido à simetria do deslocamento angular do tubo. $\alpha$ pode ser expresso em função de $\theta$ como se vê na Eq. 4.7.

$$
\tan (\alpha)=\frac{\frac{H}{2} \operatorname{sen}(\theta)}{\frac{H}{2}[1-\cos (\theta)]+L}
$$


Se o deslocamento angular do tubo, $\theta$, for pequeno então o deslocamento dos fios também será pequeno. Por tanto, $\alpha$ pode ser expresso como se vê na Eq. 4.8:

$$
\alpha=\frac{H \theta}{2 L}
$$

Sob a suposição de pequenos valores de $\theta$ e $\alpha$, e supondo que as tensões nos dois fios de aço são iguais $\left(T_{1}=T_{2}=T\right.$ ), então os vetores das forças podem ser linearizados e expressos como:

$$
\begin{gathered}
\vec{F}_{1}=-T \widehat{i}+T \alpha \widehat{j} \\
\vec{F}_{2}=T \widehat{i}-T \alpha \widehat{j}
\end{gathered}
$$

Os braços para o cálculo dos momentos com respeito ao centro de gravidade do tubo estão definidos pelas equações linearizadas 4.11 e 4.12 .

$$
\begin{gathered}
\overrightarrow{r_{1}}=-\frac{H}{2} \widehat{i}-\frac{H}{2} \hat{\theta j} \\
\overrightarrow{r_{2}}=\frac{H}{2} \widehat{i}+\frac{H}{2} \hat{\theta j}
\end{gathered}
$$

Depois de definir os braços e as forças sobre o tubo, se podem calcular os dois momentos com respeito ao centro do tubo a través da fórmula:

$$
\vec{M}=\vec{r} \times \vec{F}
$$

Os dois momentos do sistema são perpendiculares ao plano do papel. A somatória deles deve ser igual à inércia rotacional do sistema:

$$
\sum M=I_{o} \ddot{\theta}
$$

Após algumas operações algébricas se obtém a Eq. 4.15, a qual é a expressão que descreve a oscilação no modo rocking.

$$
I_{o} \ddot{\theta}+\frac{H T}{2 L}(H+2 L) \theta=0
$$

As equações 4.4 e 4.15 representam a translação e rotação do tubo respectivamente e combinadas formam um sistema linear de equações diferenciais expressado em forma matricial na Eq. 4.16 e sintetizado na Eq. 4.17. As variáveis independentes do sistema são $x_{c} \mathrm{e} \theta$.

$$
\left[\begin{array}{cc}
m & 0 \\
0 & I_{0}
\end{array}\right]\left[\begin{array}{c}
\ddot{x}_{c} \\
\ddot{\theta}
\end{array}\right]+\left[\begin{array}{cc}
\frac{2 T}{L} & 0 \\
0 & \frac{H T(H+2 L)}{2 L}
\end{array}\right]\left[\begin{array}{c}
x_{c} \\
\theta
\end{array}\right]=\left[\begin{array}{l}
0 \\
0
\end{array}\right]
$$




$$
[M][\ddot{x}]+[K][x]=0
$$

Do ponto de vista experimental é mais interessante expressar a Eq. 4.16 num sistema de coordenadas alternativo $x^{\prime}$ que esteja expresso em função dos deslocamentos dos extremos do tubo $x_{1}$ e $x_{2}$. Isto pode ser feito, para este sistema de dois graus de liberdade, multiplicando a Eq. 4.17 por uma matriz de transformação baseada na geometria do sistema. Para isso, as equações 4.18 e 4.19 são derivadas do esquema proposto na Fig. 4.3.

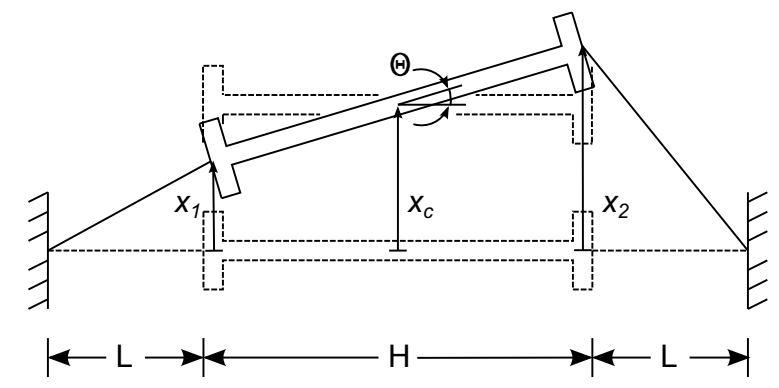

Figura 4.3: Sistema de coordenadas $x_{c}-\theta$ e $x_{1}-x_{2}$

$$
\begin{aligned}
& \theta=\left(\frac{-1}{L}\right) x_{1}+\left(\frac{1}{L}\right) x_{2} \\
& x_{c}=\left(\frac{1}{2}\right) x_{1}+\left(\frac{1}{2}\right) x_{2}
\end{aligned}
$$

A matriz de transformação linear $T_{c}$ está composta pelas equações 4.18 e 4.19 :

$$
T_{c}=\left[\begin{array}{cc}
\frac{1}{2} & \frac{1}{2} \\
-\frac{1}{H} & \frac{1}{H}
\end{array}\right]
$$

A operação para modificar a Eq. 4.17 é descrita na Eq. 4.21 onde $\left[T_{c}\right]^{t}$ é a matriz transposta da matriz $T_{c}$.

$$
\left[T_{c}\right]^{t}[M]\left[T_{c}\right]\left[\ddot{x^{\prime}}\right]+\left[T_{c}\right]^{t}[K]\left[T_{c}\right]\left[x^{\prime}\right]=0
$$

Finalmente, o sistema de equações diferenciais da Eq. 4.16 pode ser expresso como se vê na Eq. 4.22.

$$
\left[\begin{array}{cc}
\frac{m}{4}+\frac{I_{0}}{H^{2}} & \frac{m}{4}-\frac{I_{0}}{H^{2}} \\
\frac{m}{4}-\frac{I_{0}}{H^{2}} & \frac{m}{4}+\frac{I_{0}}{H^{2}}
\end{array}\right]\left[\begin{array}{l}
\ddot{x}_{1} \\
\ddot{x}_{2}
\end{array}\right]+\left[\begin{array}{cc}
\frac{T(H+L)}{H L} & \frac{-T}{H} \\
\frac{-T}{H} & \frac{T(H+L)}{H L}
\end{array}\right]\left[\begin{array}{l}
x_{1} \\
x_{2}
\end{array}\right]=\left[\begin{array}{l}
0 \\
0
\end{array}\right]
$$

Esse sistema de equações diferenciais pode ser usado para descrever o comportamento dinâmico do tubo instrumentado instalado na seção de testes. Após definidos os valores dos parâmetros usados nas matrizes de massa e rigidez, estas são usadas para calcular as frequências 
naturais não amortecidas de vibração e a matriz modal. 


\section{Capítulo 5}

\section{Análise experimental da estrutura dinâmica}

A estrutura dinâmica instalada na seção de testes deve ser calibrada antes que usada para o estudo da resposta dinâmica do tubo sujeito às forças induzidas pelo escoamento. A calibração consiste na identificação e sintonização da primeira frequência de ressonância do tubo, cujo valor é conferido através da medição da Função de Resposta em Frequência (FRF) do tubo em ar. Além disso, o amortecimento em ar é calculado e depois utilizado para a comparação dos resultados experimentais com o modelo teórico desenvolvido no Capítulo 4. A seguir, testes dinâmicos são realizados em diferentes velocidades de escoamento monofásico de água e escoamento bifásico ar - água. Os resultados são analisados em função da velocidade do escoamento entre tubos e a fração de vazio superficial.

\subsection{Procedimento}

Para sintonizar a primeira frequência de ressonância do tubo primeiro é feita uma aproximação da tensão necessária nos fios de aço e do seu comprimento livre de forma que a faixa de frequências desejada possa ser atingida. Embora a força nos fios de aço não seja medida diretamente, uma boa aproximação pode ser obtida usando como dados a deformação de uma das molas da estrutura e a sua constante de rigidez (dado fornecido pelo fabricante). Com estes dados a força de tensão sobre o tubo pode ser calculada. Depois de realizar esta aproximação, o tubo é excitado no extremo 1 (ver Fig.5.1) nas coordenadas $x$ e $y$, estas coordenadas correspondem à direção transversal e paralela ao escoamento, respectivamente. A ponta do stinger é colocada o mais perto possível da posição do microacelerômetro no interior do tubo, de forma que possa ser obtida uma FRF direta com as medições no ponto 1 e uma cruzada com as medições no ponto 2 (ver configuração na Fig.5.2). As FRFs obtidas permitem comprovar a frequência na qual o tubo foi sintonizado. A primeira frequência de ressonância do tubo será calibrada na coordenada $x$ devido ao espaço disponível para a instalação do shaker, já que na coordenada $y$ o espaço é muito restrito. Nesta etapa é feita a sintonia fina da frequencia natural do tubo em ar, ajustando-se a tensão nos cabos de aço. A tensão nos fios é modificada através da compressão das molas da estrutura dinâmica.

Para o estudo da resposta do tubo excitado por um escoamento monofásico de água a seção de testes é vedada por meio da instalação de placas de acrílico, como se vê na Fig.5.3. As pla- 


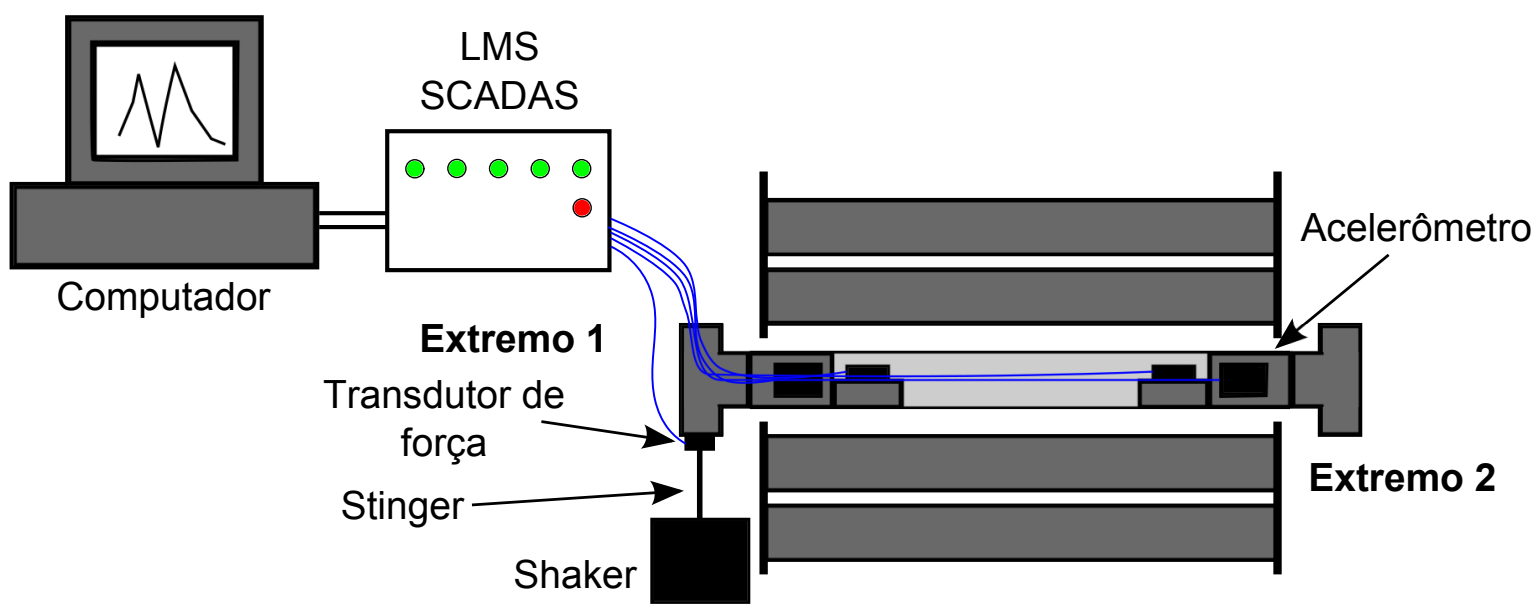

Figura 5.1: Diagrama da configuração para medição da FRF no ar.

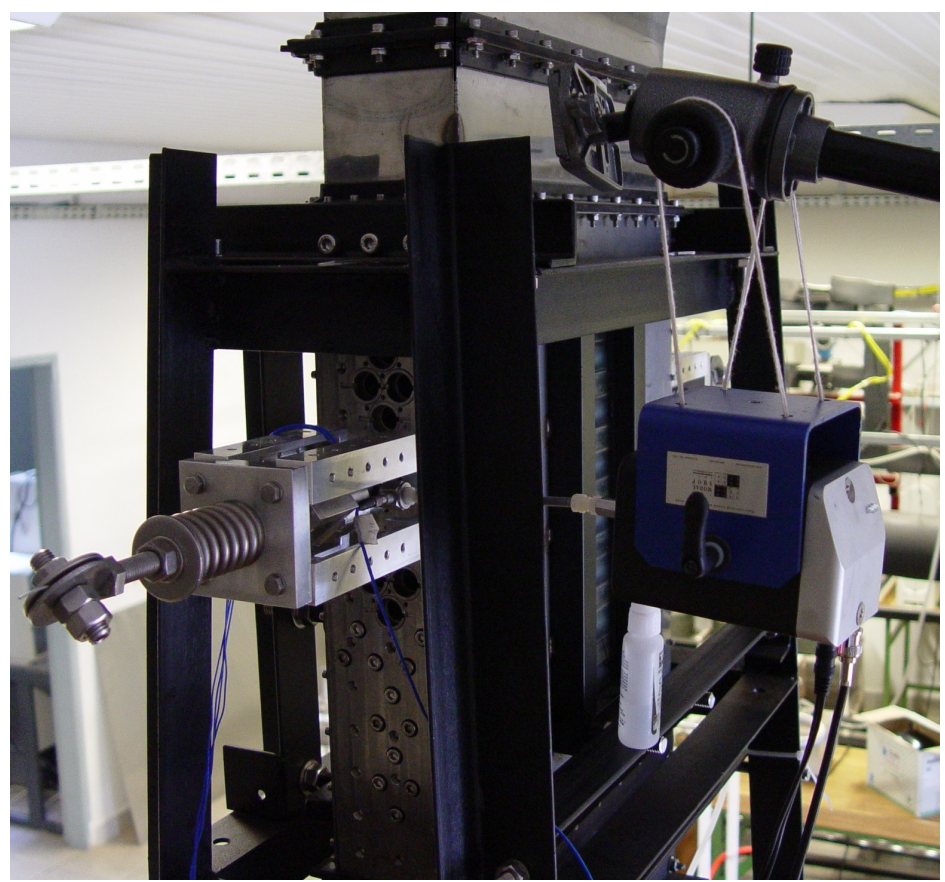

Figura 5.2: Configuração para medição de FRF do tubo montado na seção de testes.

cas de acrílico formam uma caixa ao redor dos extremos do tubo. Devido à presença de água o shaker não pode ser utilizado e o tubo é excitado somente pelo escoamento. A resposta do tubo é medida para diferentes velocidades de escoamento esperando observar diferenças principalmente na amplitude de deslocamento. Para os testes em escoamento bifásico diferentes velocidades superficiales de ar e água são escolhidas, isto permite realizar testes para diferentes frações de vazio. Neste caso a resposta do tubo é analisada em função da velocidade do escoamento e da fração de vazio. 


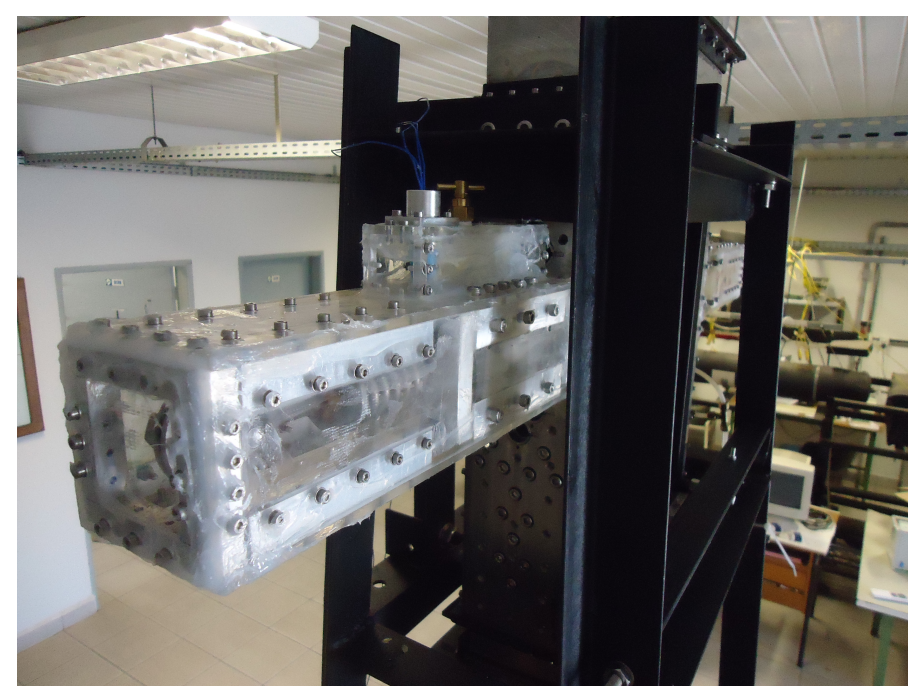

Figura 5.3: Configuração para medição de resposta do tubo a escoamento monofásico de água e escoamento bifásico água-ar.

\subsection{Instrumentação}

Para a medição das FRFs em ar a estrutura dinâmica é excitada com uma força aleatória por meio de um shaker eletrodinâmico modelo K2007E01 da Modal Shop. O stinger é conectado ao shaker, depois a ponta do stinger, equipada com um transdutor de força PCB modelo 208C02, é colada no extremo 1 do tubo instrumentado dependendo da direção a ser excitada. Para medir a resposta dinâmica do tubo são usados os quatro microacelerômetros instalados sobre os porta-acelerômetros no interior do tubo. Os quatro microacelerômetros são da marca PCB Piezotronics modelo 352A24. A configuração dos instrumentos para a medição da FRF na coordenada $x$ pode ser vista na Fig. 5.4. A aquisição de dados é feita por meio do sistema LMS SCADAS Mobile junto com o software LMS Test.Lab.

\subsection{Resultados de testes dinâmicos no ar}

\subsubsection{Medições das Funções de Resposta em Frequência}

A primeira frequência de ressonância do tubo em ambiente ar foi fixada em 15,25 Hz na coordenada $x$ por meio do procedimento descrito anteriormente. $\mathrm{O}$ valor da frequência de ressonância foi escolhido arbitrariamente baixo de forma que o tubo instrumentado seja a estrutura menos rígida dentro da seção de testes, que o comprimento dos fios de aço tensionados seja adequado para a instalação das caixas de acrílico que vedam a seção de testes e que a estrutura dinâmica seja capaz de manter a tensão nos fios de aço pelo tempo que os testes dinâmicos sejam realizados. Em Khushnood et al. (2012) se apresenta uma recopilação das frequências naturais dos tubos instrumentados para o estudo de escoamentos bifásicos, estas frequências vão desde 4 até $175 \mathrm{~Hz}$, no entanto, o formato de instalação do tubo na bancada de testes não é detalhado e portanto uma melhor comparação não pode ser feita com a estrutura dinâmica usada no presente trabalho. 
As FRFs obtidas nas coordenadas $x$ e $y$, nos pontos 1 e 2 , e suas respectivas funções Coerência foram medidas com uma frequência de amostragem de $1024 \mathrm{~Hz}$, com 8192 linhas espectrais e usando 20 médias lineares. As FRFs se apresentam nas figs. 5.4 e 5.5. Vale a pena mencionar que, embora as FRFs na coordenada $y$ tenham sido obtidas, estas não são confiáveis para o cálculo de amortecimento. Isto se deve às dificuldades encontradas na hora de instalar o shaker para excitar esta coordenada. No entanto, as FRFs podem ser usadas para verificar as frequências de ressonância que se apresentam nesta coordenada. As dificuldades na obtenção da FRF na coordenada $y$ podem ser conferidas através da Fig5.5b onde é mostrada a função Coerência entre a força e a aceleração.

Nas figuras 5.4a e 5.5a pode-se notar que na faixa entre 0 e aproximadamente $150 \mathrm{~Hz}$ só aparecem duas ressonâncias bem definidas, as quais correspondem aos modos de vibração de corpo rígido do tubo denominados como bouncing e rocking. Acima desta faixa de frequências aparece um pico de ressonância aproximadamente em $164 \mathrm{~Hz}$ tanto na coordenada $x$ como em $y$. Provavelmente este pico de ressonância corresponde ao primeiro modo de flexão do tubo. No presente trabalho a atenção estará focada sobre os modos de vibração bouncing e rocking e sobre a faixa de frequência na qual eles aparecem. Portanto, um zoom será feito sobre esta parte da FRF para descrever as características da mesma. Assim, nas figuras 5.6 e 5.7 se apresentam as mesmas FRFs e funções Coerência na banda de frequência de 0 até $50 \mathrm{~Hz}$.

a)

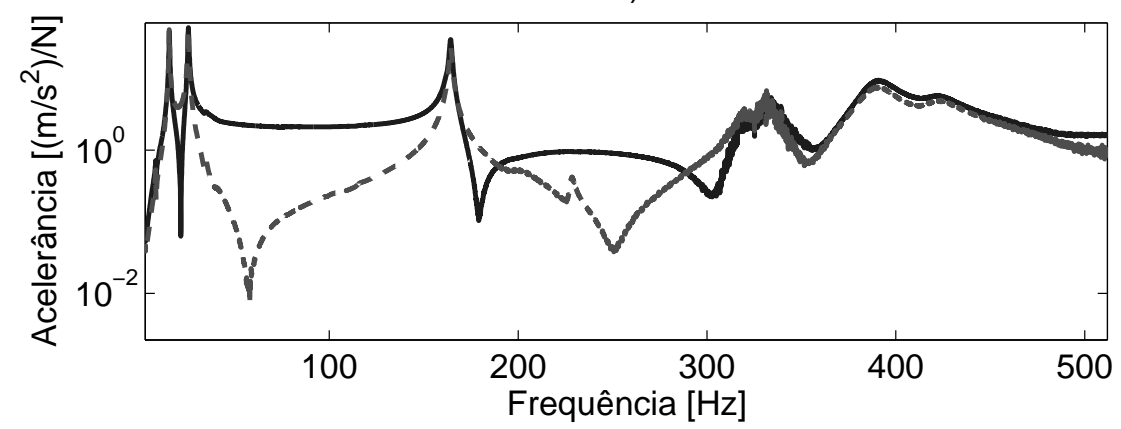

b)

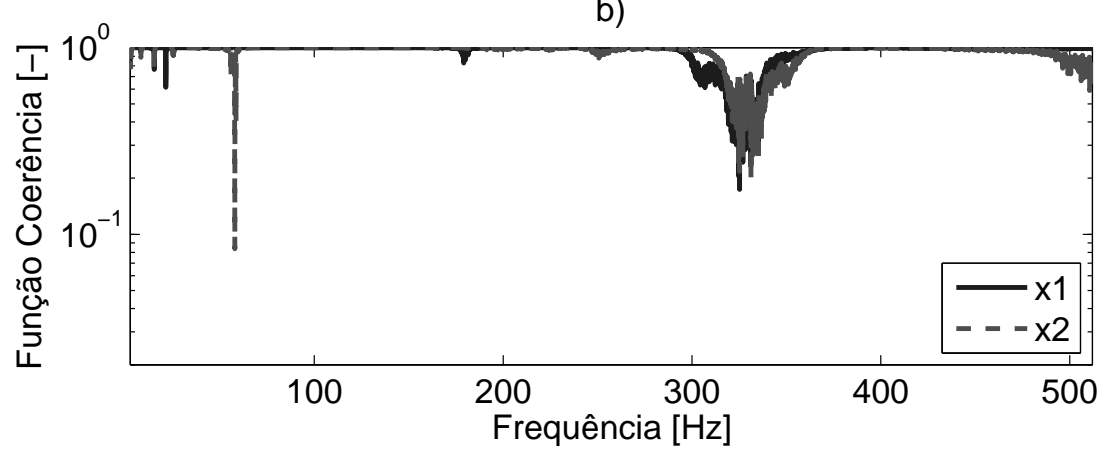

Figura 5.4: a) FRF de acelerância do tubo na direção $x$ e b) Função coerência.

Na Figura 5.6a se pode ver que as FRFs medidas na coordenada $x$, nos pontos 1 e 2, apresentam as mesmas frequências de ressonância, as quais são $15,25 \mathrm{~Hz}$ e $25,38 \mathrm{~Hz}$ para cada modo de vibração e, além disso, os picos das FRFs apresentam amplitudes similares. Como foi 
a)

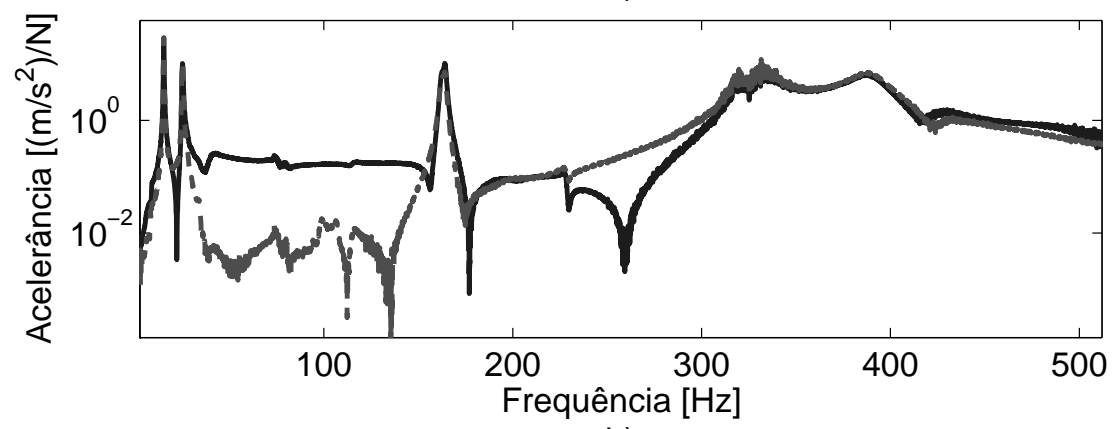

b)

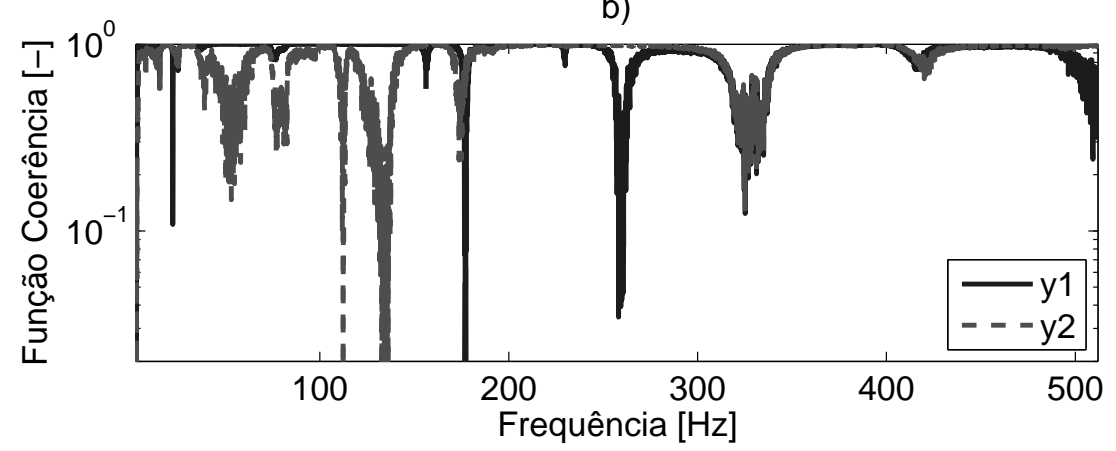

Figura 5.5: a) FRF de acelerância do tubo na direção y e b) Função coerência.

a)

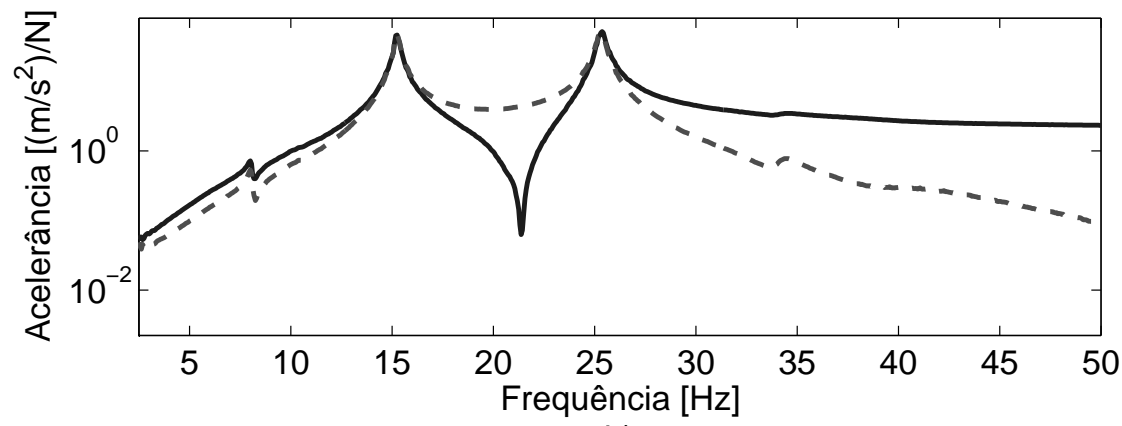

b)

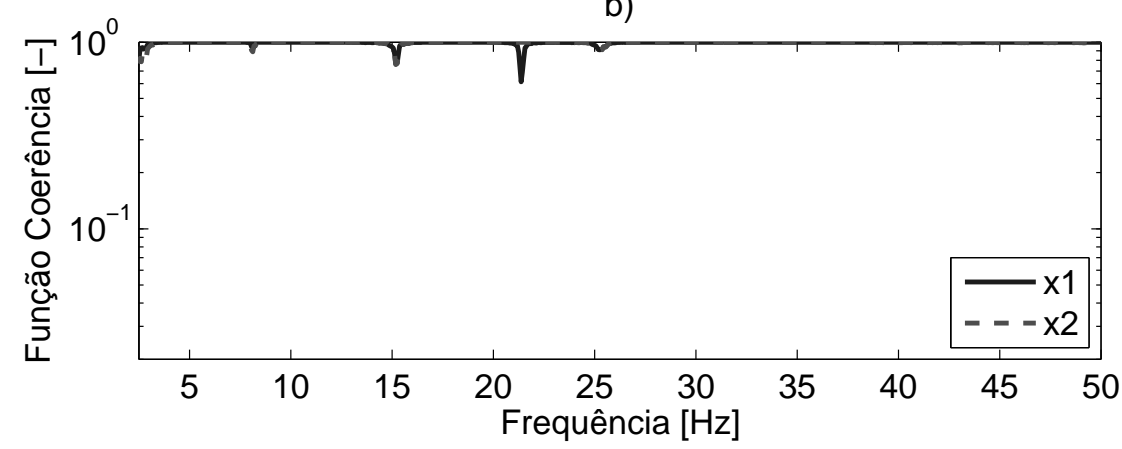

Figura 5.6: a) FRF de acelerância do tubo na direção $x$ e b) Função coerência.

mencionado anteriormente, pode-se ver que na banda de 0 a $50 \mathrm{~Hz}$ só aparecem duas frequências de ressonância. Esta característica também foi destacada em Álvarez et al. (2013) onde usou-se uma estrutura dinâmica com dois fios tensionados em cada extremo. A diferença com 
a)

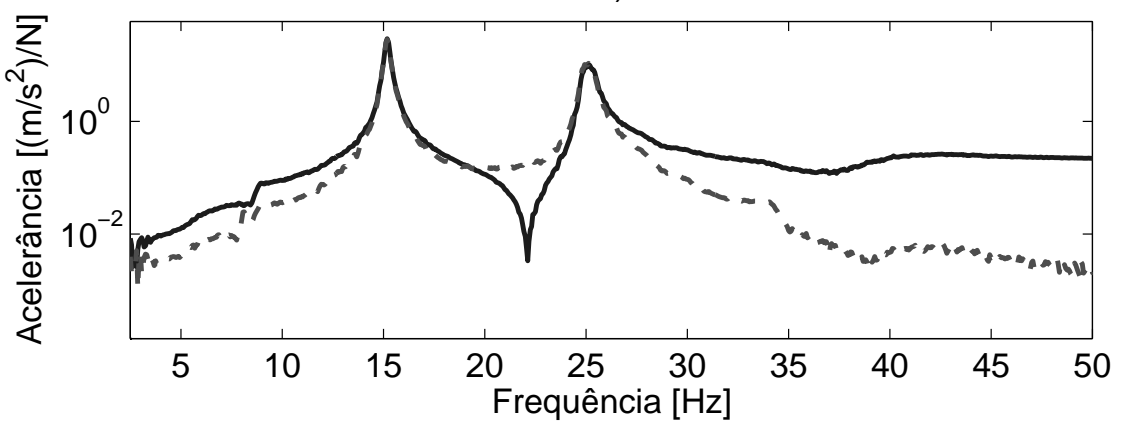

b)

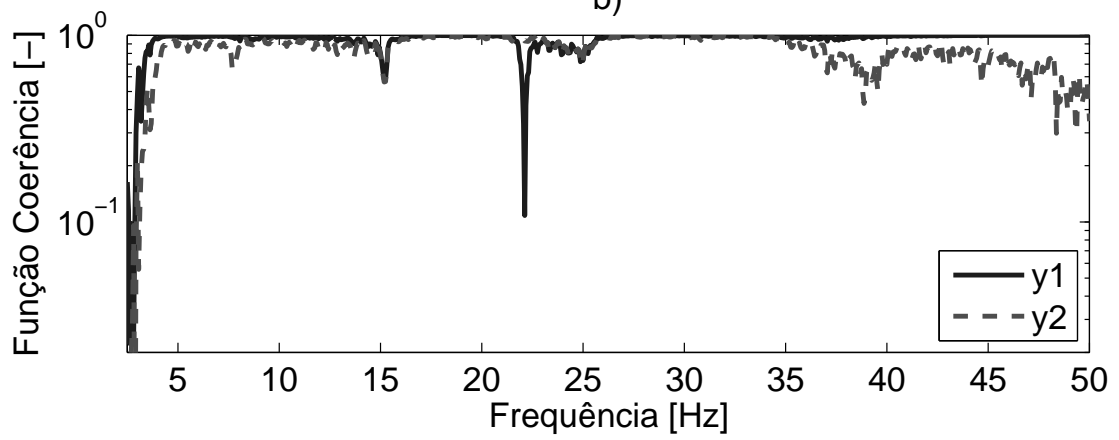

Figura 5.7: a) FRF de acelerância do tubo na direção y e b) Função coerência.

respeito aos resultados obtidos naquele trabalho é que nesse caso a segunda frequência de ressonância não é o dobro da primeira na coordenada $x$, o que pode ser uma consequência de ter incrementado a massa vibratória (tubo mais acessórios), e portanto o momento de inércia da estrutura dinâmica, e ter-se modificado a configuração dos fios tensionados com os quais o tubo é suspendido na seção de testes. É importante mencionar que além dos picos de ressonância esperados outro pico foi registrado na frequência de $8 \mathrm{~Hz}$. Este pico é de pequena amplitude com respeito aos outros dois picos de ressonância (aproximadamente 67 vezes menor do que o primeiro pico), no entanto chama a atenção já que não foi considerado na modelagem. Provavelmente este pequeno pico corresponde a um modo de oscilação torsional do tubo ou uma ressonância da estrutura soporte. Finalmente, na Figura 5.6b se mostram as funções Coerência medidas nos mesmos pontos, pode-se ver que seus valores estão sempre perto de $1 \mathrm{e}$, portanto, pode-se dizer que a resposta dinâmica do tubo se deve à excitação do shaker.

Os mesmos comentários feitos para a Fig. 5.6a podem ser aplicados à Fig. 5.7a, na qual são comparadas as FRFs medidas na coordenada $y$, nos pontos 1 e 2. Estas FRFs apresentam frequências de ressonância em $15,19 \mathrm{~Hz}$ e $25,13 \mathrm{~Hz}$; ou seja, teoricamente as mesmas frequências de ressonância que aparecem na coordenada $x$ aparecem na coordenada $y$. Como foi mencionado antes, os relativos baixos valores de função Coerência que aparecem na Fig. 5.6b se devem à dificuldade prática na hora de excitar o tubo numa coordenada só. 


\subsubsection{Cálculo do amortecimento}

O fator de amortecimento é calculado por meio do método de espaçamento máximo da frequência (Maximum Frequency Spacing), o mesmo que foi primeiro introduzido por Kennedy - Pancu (MAIA; SILVA, 1998). Neste método usa-se um plano de Argand - Gauss para representar a parte imaginária versus a parte real do vetor de receptância mantendo como parâmetro a frequência da força de excitação (CRAIG; KURDILA, 2006). O diagrama resultante é conhecido como FRF de Nyquist, o qual tem um formato de circunferência traçada na parte negativa do eixo imaginário quando se trata de uma receptância de ponto. Segundo Maia e Silva (1998), o método de Kennedy - Pancu é o método que pode resolver com maior precisão as características de dois modos de vibração muito próximos, além disso este método pode ser usado para casos nos quais o amortecimento é relativamente alto.

No modelo de Kennedy - Pancu assume-se um amortecimento histerético que é calculado através do método da largura de meia banda de potência com a expressão:

$$
\eta=\frac{f_{2}-f_{1}}{f_{n}}
$$

onde $\eta$ é conhecido como o fator de perda por amortecimento histerético (damping loss factor). A frequência de ressonância $f_{n}$ pode ser reconhecida na FRF de Nyquist localizando o ponto no qual a razão entre o crescimento do comprimento de arco da circunferência com a variação de frequência é máxima. As frequências $f_{1}$ e $f_{2}$ são os pontos de meia potência, os quais também podem ser reconhecidos da FRF de Nyquist como os pontos extremos diametralmente opostos da circunferência achados ao traçar uma linha paralela ao eixo de valores reais.

Segundo a informação disponível em Maia e Silva (1998), os modelos viscoso e histerético são aproximadamente equivalentes através da relação:

$$
\eta=2 \zeta
$$

onde $\zeta$ é o fator de amortecimento de modelo viscoso.

A FRF de receptância pode ser traçada diretamente no plano complexo. Esta pode ser calculada integrando duas vezes a FRF de acelerância no domínio da frequência. Deve-se lembrar que as unidades da acelerância são $\left[\mathrm{m} / N \mathrm{~s}^{2}\right]$, no entanto, ela também pode ser levada à receptância em $[m / N]$ através da divisão para o quadrado da frequência circular, ou seja, usando a Eq.5.3.

$$
R=-\frac{A}{\omega^{2}}
$$

A FRF de receptância é apresentada no plano complexo na Fig. 5.8. A desvantagem de usar este tipo de formato é que os pontos da FRF perdem a ligação com a informação da frequência. Além disso, se pode ver claramente que a FRF de receptância forma circunferencias distorci- 
das o que complica o reconhecimento da frequência de ressonância e as frequências de média potência.

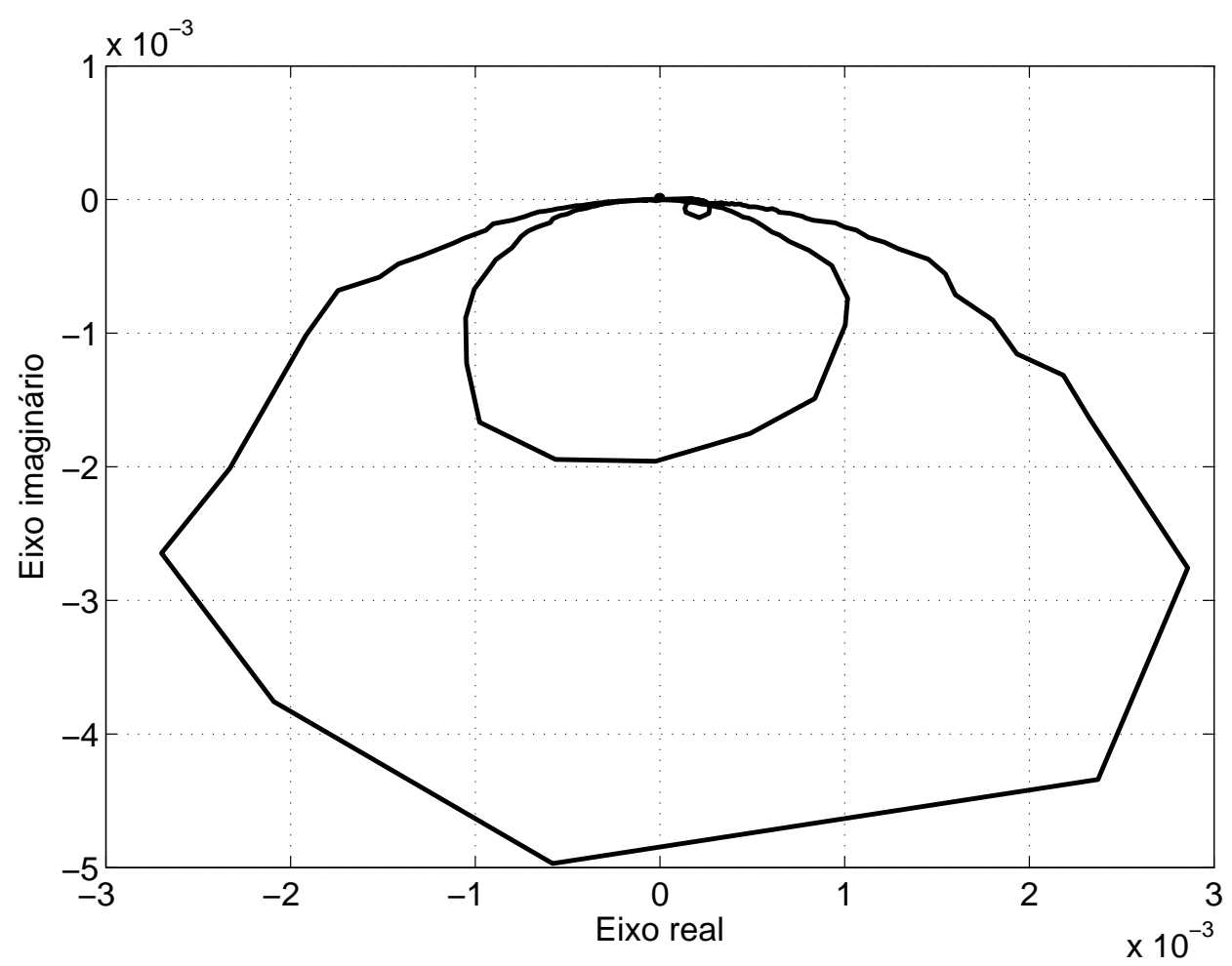

Figura 5.8: Plano complexo ou de Argand da receptância do ponto 1 na coordenada $x$.

Para que o amortecimento possa ser calculado é importante que a FRF de receptância tenha uma geometria o mais definida possível para facilitar o reconhecimento das frequências $f_{1}$, $f_{2}$ e $f_{n}$. Como os dados experimentais não apresentaram esta característica optou-se por usar o Eigensystem Realisation Algorithm (ERA) como passo intermédio à construção da FRF de Nyquist. O ERA é um método que permite a reconstrução das matrizes de estado de um sistema a partir da sua resposta ao impulso no domínio do tempo. O equacionamento completo do método ERA encontra-se desenvolvido em Maia e Silva (1998). Assim, as matrizes de estado foram calculadas através do algoritmo ERA no software Matlab ${ }^{\circledR}$. Os parâmetros de entrada para usar o algoritmo foram selecionados em função das características de amostragem dos resultados experimentais. Os parâmetros selecionados se apresentam na Tab. 5.1. A partir dos dados tratados se pode construir novamente as FRFs de Nyquist, como se vê na Fig. 5.9 para a coordenada $x$ no ponto 1 .

Baseado no procedimento descrito, os valores das frequências de meia potência $f_{1}, f_{2}$ e as frequências de ressonância $f_{n}$ podem ser extraídos da Fig. 5.9. Com esses dados o fator de amortecimento $\zeta$ para os dois modos de vibração na coordenada $x$ podem ser calculados. Estes valores são apresentados na Tab.5.2. 
Tabela 5.1: Parâmetros de entrada para o cálculo das matrizes de estado.

\begin{tabular}{|l|c|l|}
\hline Parâmetro & \multicolumn{1}{|c|}{ Descrição } & Comentário \\
\hline $\begin{array}{l}\text { Resposta do sistema } \\
\text { discretizada no domí- } \\
\text { nio do tempo }\end{array}$ & Vetor & $\begin{array}{l}\text { Calculada através da transfor- } \\
\text { mada inversa de Fourier da } \\
\text { FRF de receptância. }\end{array}$ \\
\hline Ordem do sistema & 4 & $\begin{array}{l}\text { A ordem do vetor de estado } \\
\text { de um sistema N GDL é igual } \\
\text { a 2N como é apresentado em } \\
\text { Maia e Silva (1998). }\end{array}$ \\
\hline $\begin{array}{l}\text { Número de mostras } \\
\text { para montar a matriz de } \\
\text { Hankel }\end{array}$ & $\begin{array}{l}\text { Valor em função da memória } \\
\text { do computador e do tamanho } \\
\text { do vetor da resposta no do- } \\
\text { mínio do tempo composto por } \\
8192 \text { elementos. }\end{array}$ \\
\hline $\begin{array}{l}\text { Intervalo de tempo de } \\
\text { amostragem }\end{array}$ & 4096 & $\begin{array}{l}1024 \text { Hz é a frequência de } \\
\text { amostragem nos testes dinâ- } \\
\text { micos. }\end{array}$ \\
\hline Tipo de saida & 1/1024 & - \\
\hline
\end{tabular}

Tabela 5.2: Pontos de meia potência, frequências de ressonância e fatores de amortecimento.

\begin{tabular}{|c|c|c|c|c|c|c|}
\hline \multirow{2}{*}{ Coordenada } & Modo & $f_{1}$ & $f_{2}$ & $f_{n}$ & $\eta$ & $\zeta$ \\
\cline { 2 - 7 } & $\mathrm{n}$ & $H z$ & $H z$ & $H z$ & - & - \\
\hline \multirow{3}{*}{$x$} & 1 & 15,1 & 15,4 & 15,25 & 0,02 & 0,01 \\
\cline { 2 - 7 } & 2 & 25,1 & 25,6 & 25,38 & 0,02 & 0,01 \\
\hline
\end{tabular}

\subsubsection{Comparação com o modelo teórico}

A estrutura dinâmica projetada no presente trabalho foi modelada teoricamente no Capítulo 4, como resultado se obteve um sistema de duas equações diferenciais lineares de segunda ordem, o qual é apresentado em formato matricial na Eq. 4.22. Os parâmetros usados nesta modelagem são $m, H, I_{0}$ e $L$, seus respectivos valores são apresentados na Tab.5.3.

Tabela 5.3: Valores dos parâmetros da modelagem

\begin{tabular}{|c|c|c|}
\hline Parâmetro & Valor & Unidades \\
\hline$m$ & 0,864 & $\mathrm{~kg}$ \\
\hline$H$ & 0,642 & $\mathrm{~m}$ \\
\hline$I_{0}$ & 0,0422 & $\mathrm{~kg}-\mathrm{m}^{2}$ \\
\hline$T$ & 770 & $\mathrm{~N}$ \\
\hline$L$ & 0,160 & $\mathrm{~m}$ \\
\hline
\end{tabular}




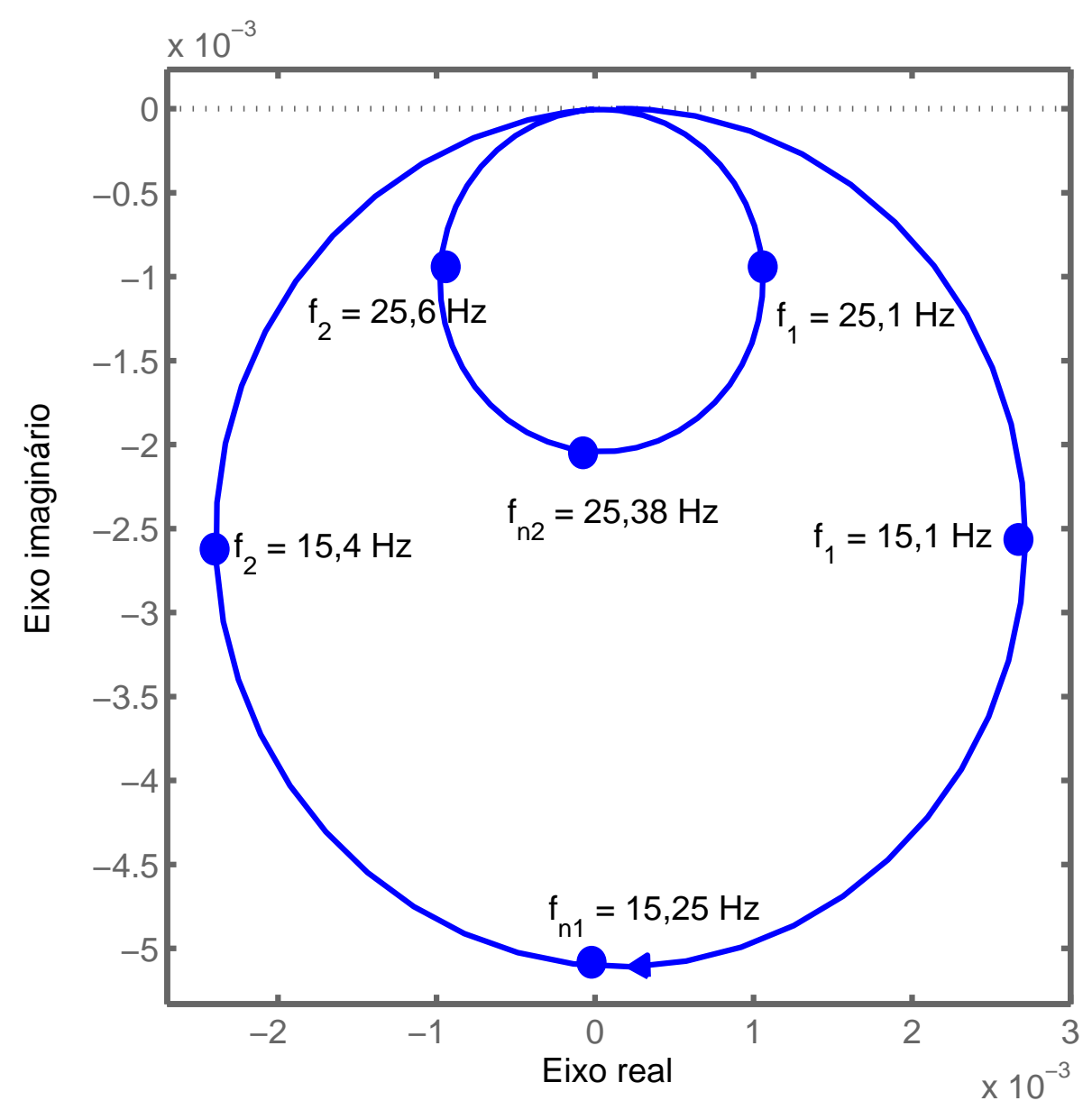

Figura 5.9: FRF de Nyquist para a posição $x_{1}$ manipulada através do ERA.

A massa total do sistema, $m$, representa a soma de todas as massas do sistema que vibrem conjuntamente com o tubo. A massa total está conformada pela massa do tubo, dos portaacelerômetros, suas tampas, os parafusos para segurar os fios e pelas placas de fixação deste parafuso. $\mathrm{O}$ parâmetro $H$ corresponde ao comprimento entre os pontos nos quais o fio de aço é segurado, este comprimento é diferente do comprimento do tubo devido ao espaço ocupado pelos acessórios instalados nos extremos. A inércia do conjunto $I_{0}$ foi calculada com respeito ao centro do tubo. Para o cálculo da inércia do tubo foi necessário incluir o parâmetro $H_{t}$ que representa apenas o comprimento do tubo $(0,448 \mathrm{~m})$. Desse jeito, o momento de inércia do tubo foi calculado com a fórmula disponível em Piersol e Paez (2010):

$$
I_{t 0}=1 / 12 m_{t}\left(3 R_{e}^{2}+3 R_{i}^{2}+H_{t}^{2}\right)
$$

onde $R_{e}$ e $R_{i}$ são os raios externo e interno do tubo respectivamente e $m_{t}$ é a sua massa. Por outro lado, para calcular o momento de inércia dos acessórios respeito ao centro do tubo primeiro foi calculada a inércia de cada um deles com respeito ao seu próprio centro de massa por 
meio do software Autodesk Inventor ${ }^{\circledR}$. Depois, o Teorema dos Eixos Paralelos é usado, este é descrito pela Eq.5.5:

$$
I_{a c 0}=I_{a c}+m_{a c} d_{a c-0}^{2}
$$

onde $I_{a c 0}$ é o momento de inércia de um acessório com respeito ao centro do tubo, $I_{a c}$ é o momento de inércia do acessório com respeito a seu próprio centro de inércia, $m_{a c}$ é a massa do acessório e $d_{a c-0}$ é a distância desde o centro de inércia do acessório até o centro do tubo. Finalmente, os momentos de inércia do tubo e dos acessórios é somada para obter o momento de inércia total $I_{0}$. Nos testes realizados nesse trabalho a vibração é medida nas coordenadas $x 1, y 1, x 2$ e $y 2$ (o número indica o extremo correspondente do tubo), portanto os momentos de inércia $I_{0-y y}$ e $I_{0-z z}$ têm que ser calculados para usar o modelo teórico. Nessa modelagem os momentos de inércia nas duas direções serão considerados iguais $\left(I_{0-y y}=I_{0-z z}\right)$ devido às características geométricas do conjunto formado pelo tubo e os acessórios.

A tensão $T$ nos fios de aço foi calculada por meio da equação da Lei de Hooke apresentada na Eq.5.6:

$$
T=K_{\text {mola }} * \Delta x_{\text {mola }},
$$

a rigidez da mola $K_{m o l a}$ é fornecida pelo construtor $(70 \mathrm{kN} / \mathrm{m})$ e a deformação $\Delta x_{m o l a}$ é medida in-situ no momento em que a frequência de ressonância da estrutura dinâmica é calibrada. Ao mesmo tempo o comprimento livre $L$ do fio de aço também é medido, ele vai desde a cabeça do parafuso regulador até a placa onde é segurado no extremo do tubo.

Uma vez que os elementos das matrizes massa $[\mathrm{M}]$ e rigidez $[\mathrm{K}]$ foram definidos, as frequências naturais não amortecidas e os modos de vibração do sistema podem ser calculados através da resolução do problema de autovalores e autovetores descrito em Maia e Silva (1998) e apresentado na Eq.5.7:

$$
\left[[K]-\omega_{r}^{2}[M]\right]\left\{\psi_{r}\right\}=\{0\}
$$

onde $\psi_{r}$ é o vetor do r-ésimo modo de vibração normalizado pela norma do sistema ( $\mathrm{r}=1,2$ ... N), o qual corresponde a um dos $N$ autovalores do sistema e $\omega_{r}$ é a frequência circular natural não amortecida de vibração do r-ésimo modo. A modelagem da estrutura dinâmica apresenta 2 GDL, portanto $N=2$ e esperam-se 2 modos de vibração e suas frequências naturais não amortecidas respectivas.

Cada modo $\psi_{r}$ contem $N$ elementos, os quais são quantidades reais (positivas e negativas) conhecidas em termos relativos e representam o deslocamento nas coordenadas previamente escolhidas na modelagem. Portanto, a direção do vetor de deslocamento é conhecida, mas não a sua magnitude absoluta (MAIA; SILVA, 1998). Estes autovalores e autovetores são calculados através do software MatLab®, no entanto, os autovetores devem ser reordenados em ordem crescente da sua respectiva frequência natural $\omega_{r}$. Assim, a matriz modal [ $\Psi$ ] é formada como se vê na Eq.5.8:

$$
[\Psi]=\left[\left\{\psi_{1}\right\}\left\{\psi_{2}\right\} \ldots\left\{\psi_{r}\right\}\right]
$$


Os parâmetros modais tais como massa e rigidez modal, $M_{r}$ e $K_{r}$ respectivamente, podem ser calculados com as eqs.5.9 e Eq.5.10:

$$
\begin{gathered}
\left\{\psi_{r}\right\}^{T}[M]\left\{\psi_{r}\right\}=M_{r} \\
\left\{\psi_{r}\right\}^{T}[K]\left\{\psi_{r}\right\}=K_{r}
\end{gathered}
$$

A partir destes parâmetros modais a FRF de receptância $\alpha_{j k}(\omega)$ medida na posição $j$ quando o sistema é excitado na posição $k$ pode ser calculada com a Eq. 5.11:

$$
\alpha_{j k}(\omega)=\frac{\bar{X}_{j}}{F_{k}}=\sum_{r=1}^{N} \frac{{ }_{r} \bar{A}_{j k}}{\omega_{r}^{2}-\omega^{2}+i \eta_{r} \omega_{r}^{2}},
$$

onde $\bar{X}_{j}$ é a resposta do sistema no ponto $j$, a $\eta_{r}$ é o amortecimento modal do modelo histerético, o qual será substituído pelo amortecimento extraído dos resultados experimentais, $\omega$ é a frequência circular e ${ }_{r} \bar{A}_{j k}$ é conhecido como constante modal e está definido pela Eq. 5.12:

$$
{ }_{r} \bar{A}_{j k}=\frac{\psi_{j r} \psi_{k r}}{M_{r}}=\phi_{j r} \phi_{k r}
$$

onde $\phi_{r}$ é a notação para um modo de vibração normalizado pela massa.

Com o equacionamento descrito, tomado de Maia e Silva (1998), a FRF de receptância teórica é construída e comparada com a FRF experimental de ponto direto ( $j=1$ e $k=1$ ) na coordenada $x$. A comparação é apresentada na Fig. 5.10.

Na Figura 5.10 pode-se ver a comparação entre as FRFs de ponto experimental e teórica na coordenada $x$ dentro da faixa de frequências de 0 até $50 \mathrm{~Hz}$. A FRF teórica apresenta seus picos de ressonância nas frequências $15,25 \mathrm{~Hz}$ e $26 \mathrm{~Hz}$. A primeira frequência de ressonância teórica coincide com os resultados experimentais, no entanto, isto não acontece para o segundo pico, o qual é $1.6 \mathrm{~Hz}(6,6 \%)$ maior do que seu valor experimental. Também se pode ver que a amplitude e a agudeza do primeiro pico de ressonância teórico coincide com o valor experimental, o qual indica que o método de estimação do amortecimento usado permite obter uma boa aproximação dos valores reais

As divergências entre o modelo teórico e os resultados experimentais podem ser analisadas através de dois critérios que são: suposições feitas no desenvolvimento da modelagem e os fatores construtivos da estrutura dinâmica. $\mathrm{Na}$ análise da modelagem, provavelmente o ponto mais importante é a linearização das funções trigonométricas das equações diferenciais. Se a oscilação do tubo no modo rocking apresentar um deslocamento angular $\theta$ consideravelmente grande $\left(\theta \geq 30^{\circ}\right)$ então as equações diferenciais linearizadas não conseguirão descrever o deslocamento do tubo. A resposta do tubo no domínio do tempo mostra que as amplitudes máximas de deslocamento são $10^{-5} \mathrm{~m}$ na coordenada $x$, o qual não representa nem um grau de deslocamento 


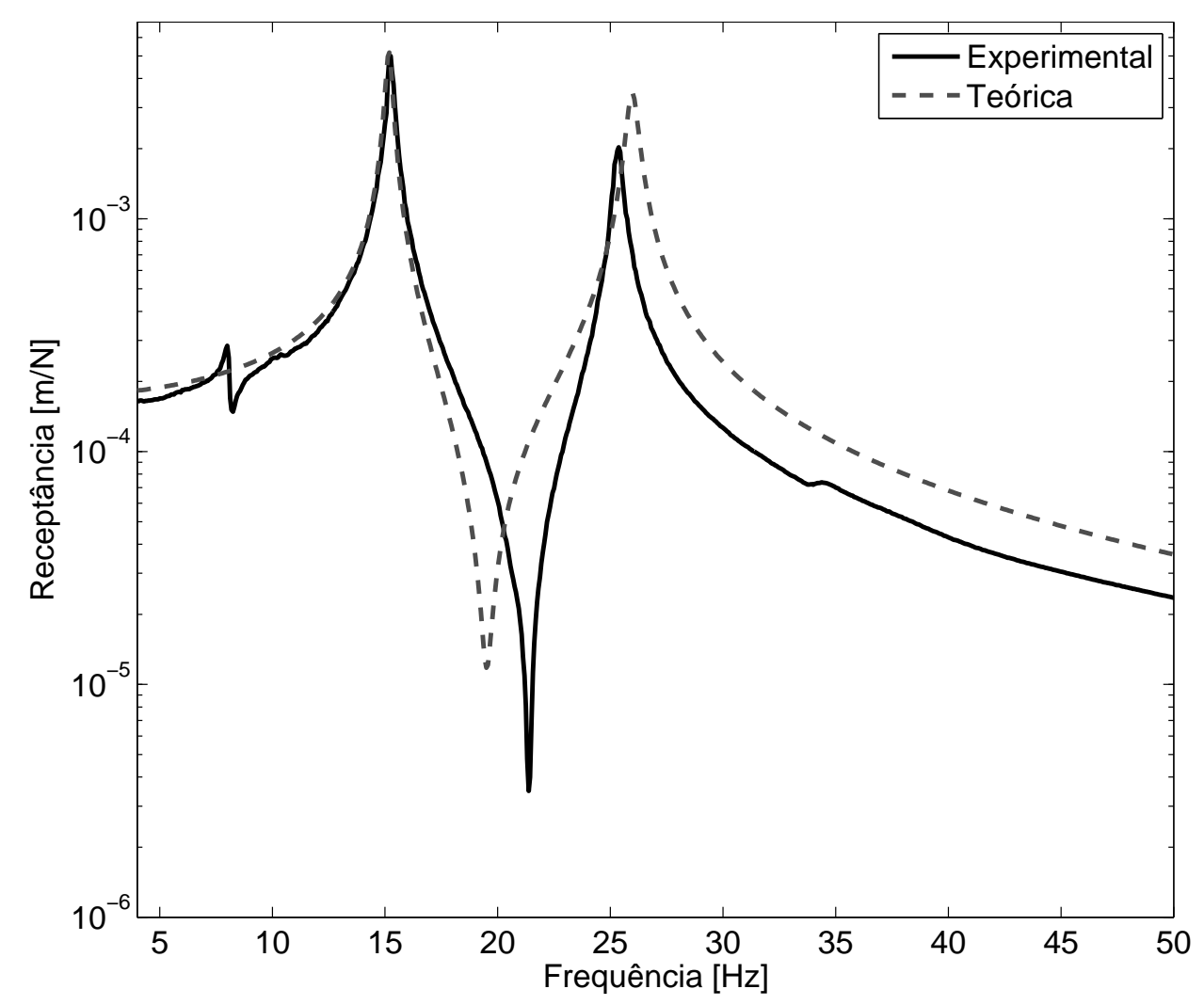

Figura 5.10: FRF de receptância experimental de ponto direto vs. FRF teórica na coordenada $x$.

angular portanto se descarta que o critério de linearização esteja afastando o modelo teórico dos resultados experimentais.

Um fator construtivo - teórico que pode provocar discrepâncias entre o modelo teórico e os resultados experimentais é o momento de inércia do conjunto $I_{0}$. O momento de inércia do tubo foi calculado facilmente, no entanto, há peças que por seu tipo de instalação ou geometria complicam o cálculo do seu momento de inércia. Por exemplo, a tampa do porta-acelerômetros é uma peça com dois planos de simetria e tem que ser ajustada como um parafuso no portaacelerômetros, isto faz que a sua posição angular com respeito ao tubo não seja conhecida com precisão e portanto o cálculo do seu momento de inércia tem que ser aproximado. Além disso, a massa dos parafusos, aroelas e porcas usadas na estrutura dinâmica aportam inércia ao sistema, a qual não é considerada no modelo. Se estes elementos não considerados estiverem relativamente afastados do centro do tubo vão ter maior peso sobre o cálculo do momento de inércia.

Como pode ser visto na Fig.5.10 o pico de ressonância correspondente ao modo rocking difere dos resultados experimentais. Este modo de vibração depende diretamente do momento de inércia, o qual aparentemente não está sendo bem estimado. Na Figura 5.11 se apresenta uma atualização do modelo teórico na qual o momento de inércia foi modificado por um fator de 1,05. Além disso, se pode ver que a amplitude e a agudeza do segundo pico de ressonância não coincide com os valores experimentais, portanto o fator de amortecimento também foi 
atualizado até um valor de 0,015 .

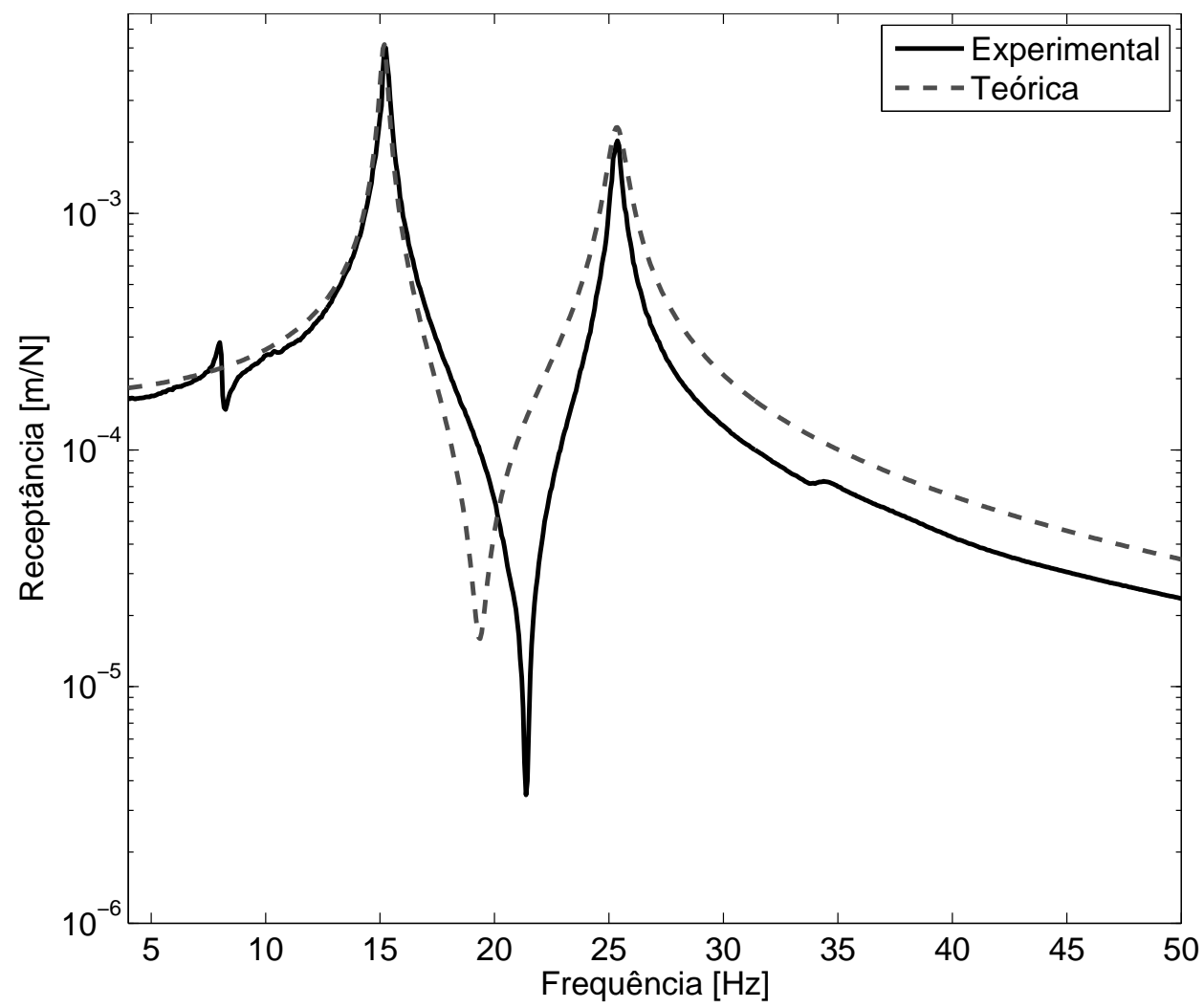

Figura 5.11: FRF de receptância experimental de ponto direto vs. FRF teórica (atualizada) na direção $x$.

\subsection{Resultados de testes dinâmicos em escoamento monofásico de água e escoamento bifásico água - ar}

\subsubsection{Resposta do tubo}

\section{Escoamento monofásico de água}

Nestes testes a única força de excitação foi a exercida pelo escoamento que atravessa o banco de tubos. Na aquisição de dados usou-se uma frequência de amostragem de 819,2 Hz com 8192 linhas espectrais e se calculou a média linear de vinte medições. Primeiro foram realizados ensaios com diferentes velocidades de escoamento monofásico de água. As velocidades utilizadas foram 0,$02 ; 0,10 ; 0,30 ; 0,53$ e $0,70 \mathrm{~m} / \mathrm{s}$, lembrando que por se tratar de um banco de tubos a velocidade usada como referência é a velocidade do escoamento que passa pela menor seção entre os tubos da bancada. Na Figura 5.12 se apresenta a Densidade Espectral (também conhecida pela sigla PSD devido ao seu nome em inglês Power Spectral Density) de aceleração medida no extremo 1 do tubo nas coordenadas $x$ e $y$. Como se pode ver, e tal como é esperado, ao tempo que a velocidade do escoamento de água aumenta o nível de vibração do tubo também aumenta, o qual é válido para as duas coordenadas. Vale a pena notar que a amplitude de deslocamento, velocidade ou aceleração não pode ser analisada através de uma PSD, no entanto 
serve para idealizar uma distribuição da energia de vibração do tubo no espectro de frequência analisado.

a)

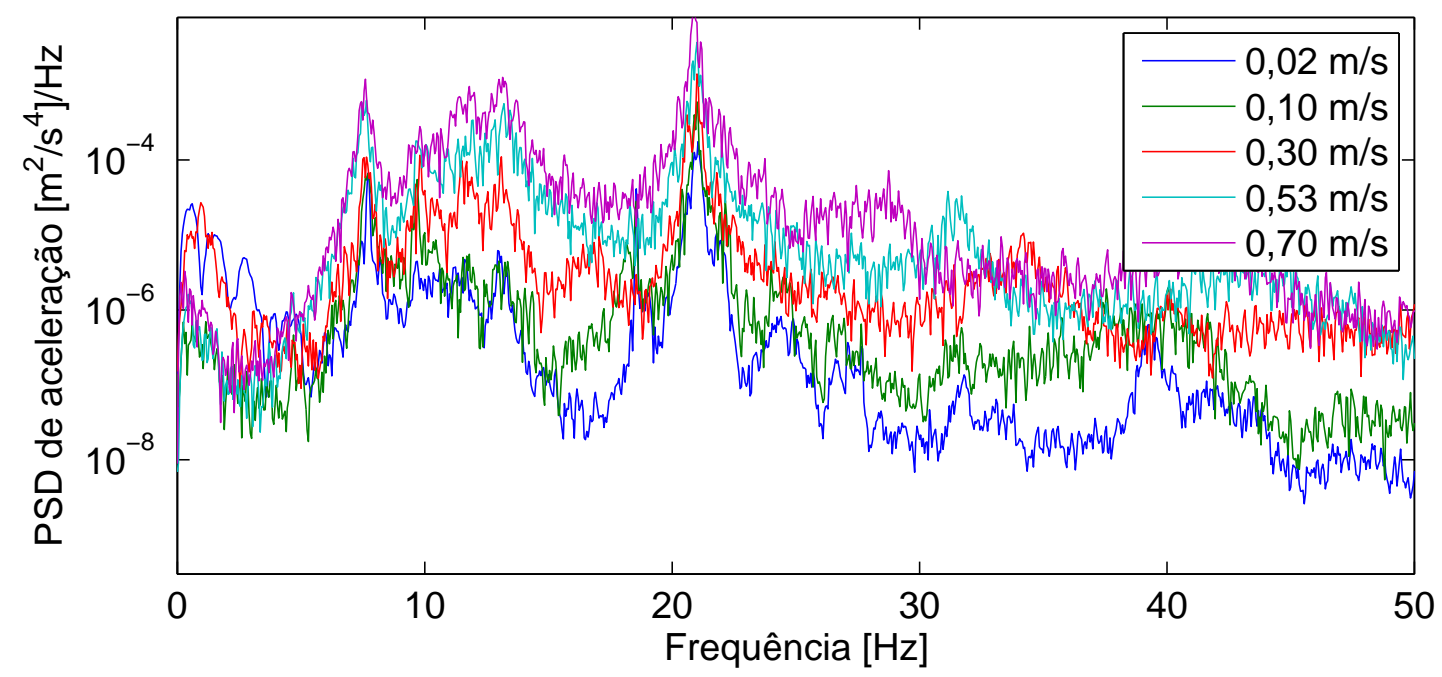

b)

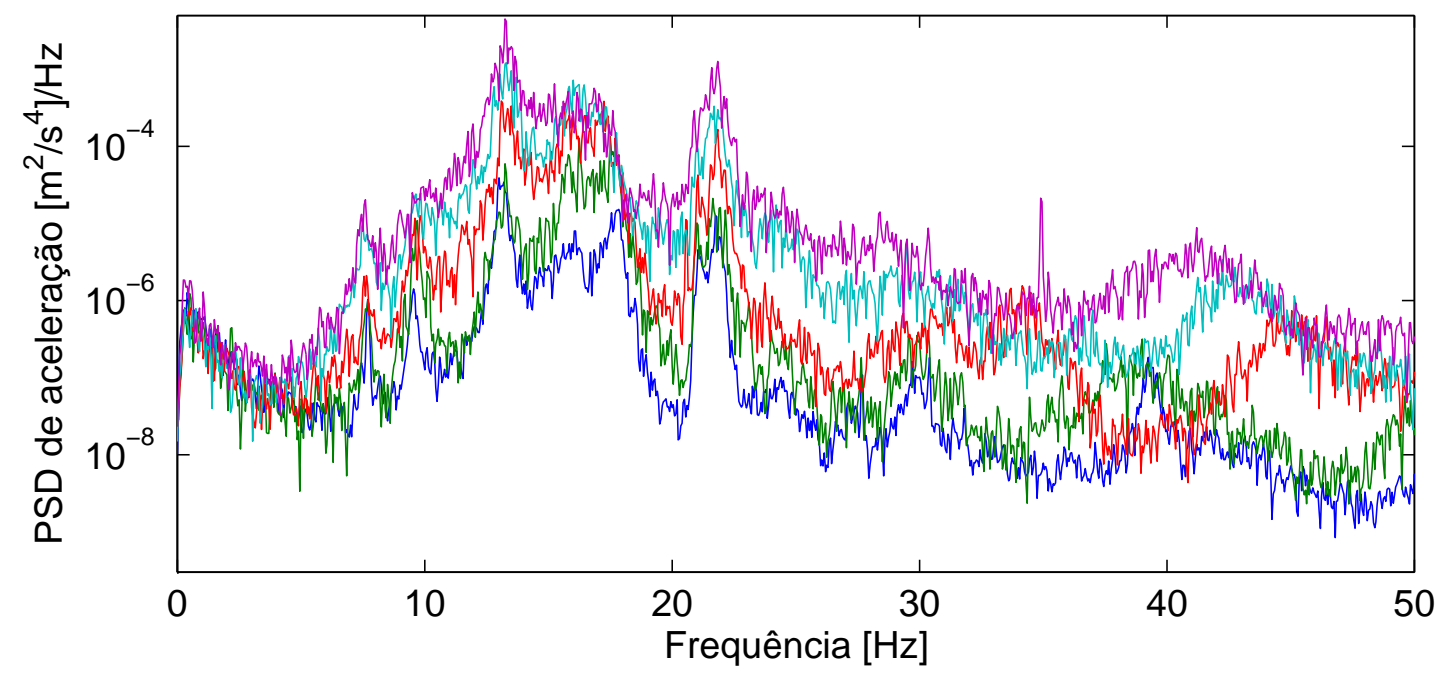

Figura 5.12: PSD de aceleração em escoamento monofásico de água medida no ponto 1. a) Coordenada $x$ e b) coordenada $y$.

Através do software Matlab®é possível suavizar as curvas apresentadas na Fig. 5.12 com o objetivo de reconhecer os picos de ressonância da estrutura dinâmica em escoamento monofásico. O método de médias móveis em 7 valores foi usado, as curvas suavizadas são apresentadas na Fig. 5.13.

$\mathrm{Na}$ Figura 5.13a se pode ver que o escoamento monofásico nas velocidades usadas não excita bem o suficiente ao primeiro modo de vibração do tubo, isto faz que este modo não esteja bem definido na PSD e portanto não seja possível enxergar o valor desta frequência 
a)

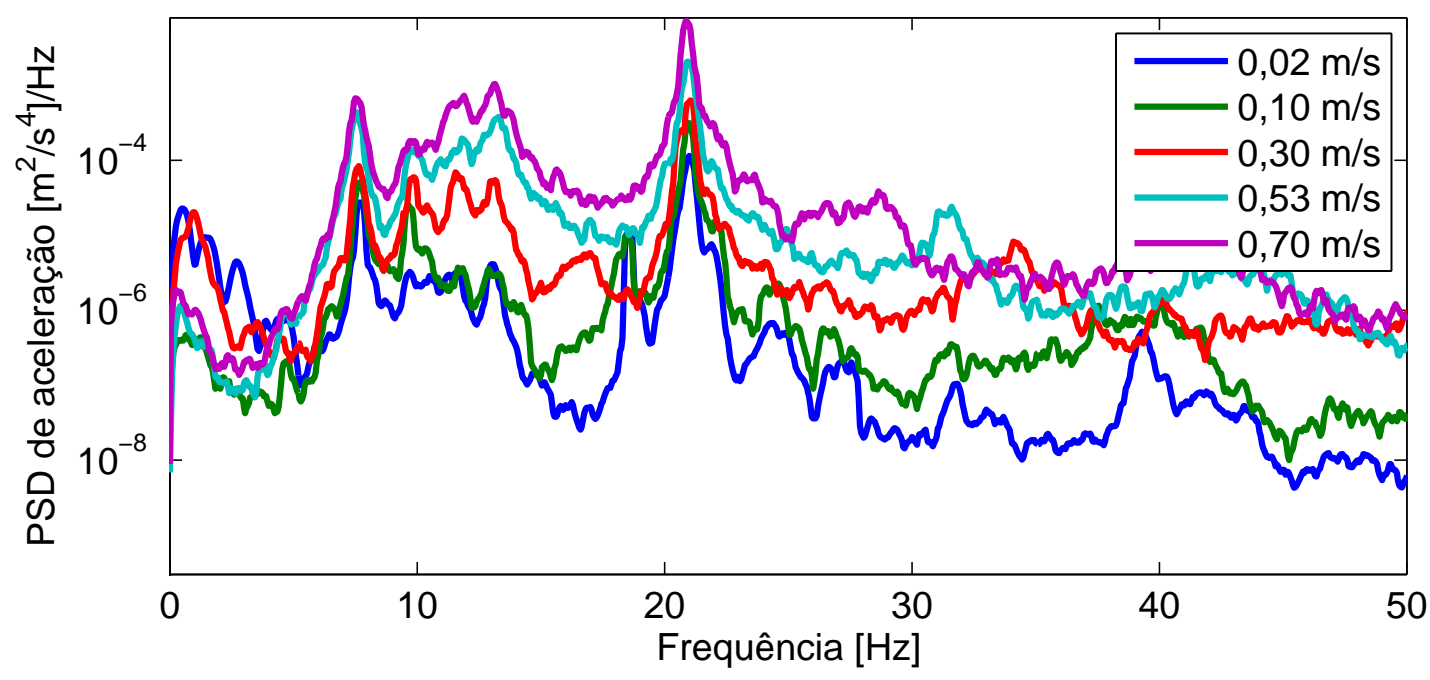

b)

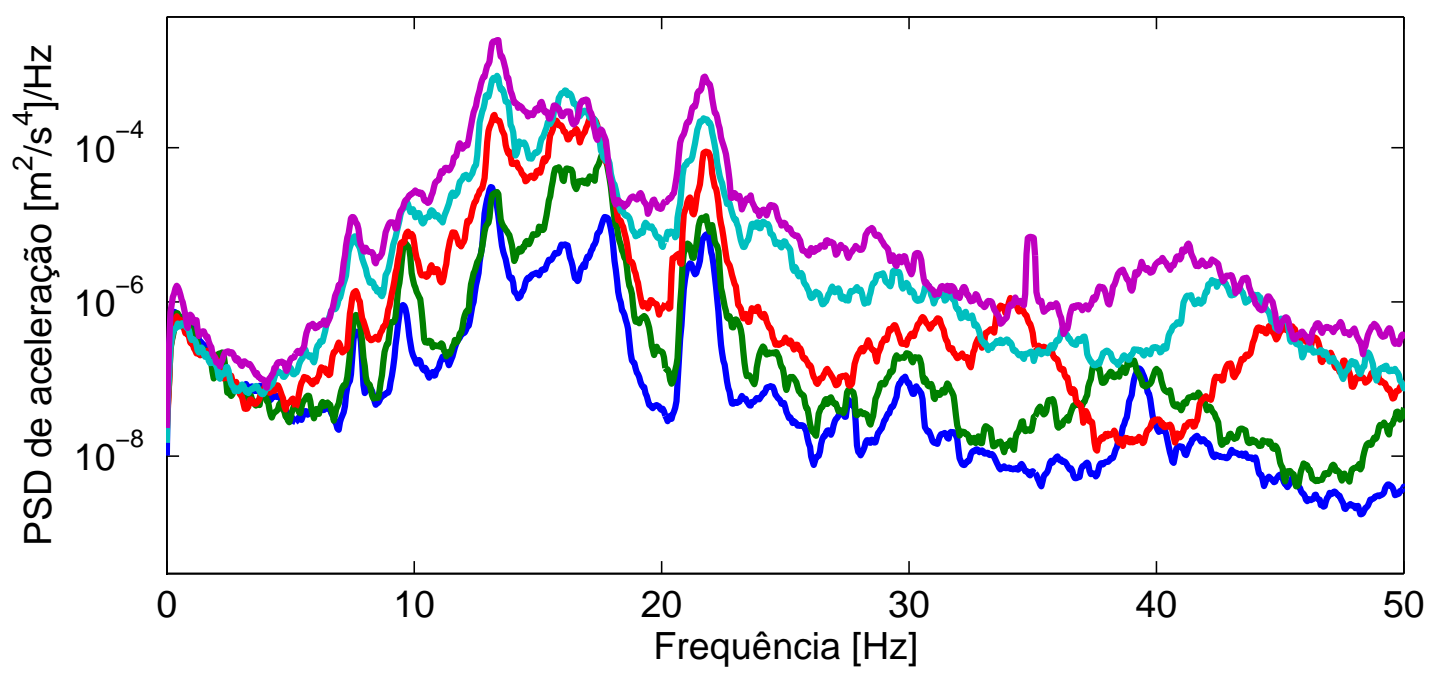

Figura 5.13: PSD suavizada de aceleração em escoamento monofásico de água medida no ponto 1. a) Coordenada $x$ e b) coordenada $y$.

de ressonância na coordenada $x$. Isto difere do que acontece com o segundo modo, o qual é bem excitado e sua frequência de ressonância é aproximadamente $21 \mathrm{~Hz}$. Nos testes não foi observada dependência das frequências de ressonância da estrutura dinâmica com a velocidade do escoamento monofásico.

Como pode-se ver na Fig.5.13a, o pico cujo modo de vibração não foi identificado na medição das FRFs em ambiente ar (ver Fig. 5.6) é excitado chegando a ter uma amplitude maior do que as frequências ao redor do primeiro pico de ressonância nas velocidades baixas de escoamento. No entanto, ao tempo que a velocidade do escoamento é aumentada a amplitude na PSD do primeiro pico de ressonância também cresce equiparando a diferença com o pico do 
modo não reconhecido. O pico do modo de vibração não reconhecido aparece numa frequência aproximada de $7,6 \mathrm{~Hz}$, apresentando um pequeno deslocamento à esquerda com respeito à sua posição na FRF em ambiente ar, onde apareceu na frequência igual a $8 \mathrm{~Hz}$.

Baseado na Figura 5.13b se pode dizer que na coordenada $y$ os dois modos de vibração do tubo são excitados e suas frequências de ressonância são aproximadamente 13,3 Hz e 21,8 Hz. Nesta coordenada, paralela à direção do escoamento, a amplitude do primeiro pico de ressonância é maior do que a amplitude do segundo pico, o qual deve estar relacionado com o arrasto exercido pelo escoamento. Igual do que na coordenada $x$, os testes em escoamento monofásico de água mostram que as frequências de ressonância se deslocaram à esquerda pelo fenômeno de massa adicionada. Além disso, pode-se ver que o modo de vibração não identificado não foi excitado e, portanto, a amplitude da PSD de aceleração nesta frequência é relativamente baixa comparada com o apresentado na coordenada $x$.

\section{Escoamento bifásico}

Os testes em escoamento bifásico foram desenvolvidos injetando um escoamento de ar no escoamento de água de forma que diferentes frações de vazio possam ser obtidas. Os testes foram feitos com frações de vazio desde 0,30 até 0,90 em intervalos de 0,10 . Várias combinações entre as velocidades das fases líquida e gás foram usadas na simulação de cada fração de vazio. O modelo homogêneo foi usado para estimar a relação entre as velocidades superficiais de cada fase para obter a fração de vazio desejada. Neste modelo a velocidade superficial da fase líquida e da fase gás, $j_{l}$ e $j_{g}$ respectivamente, estão relacionadas com a fração de vazio através da expressão:

$$
j_{g}=\left(\frac{\alpha}{1-\alpha}\right) j_{l},
$$

Além disso, a velocidade do escoamento bifásico $U_{2 F}$ é igual à velocidade superficial $j$, a qual está definida como a soma das velocidades superficiais de cada fase, ou seja:

$$
U_{2 F}=j=j_{l}+j_{g}
$$

O padrão de escoamento pode ser previsto através de mapas, os quais estão em função das velocidades superficiais das fases do escoamento. Em Kanizawa (2012) se mostra uma recopilação dos mapas que podem ser usados para o reconhecimento do padrão de escoamento, além disso, foram marcadas as condições experimentais que podem ser alcançadas na bancada na qual a estrutura dinâmica projetada nesse trabalho foi instalada. As combinações de velocidade de líquido e gás consideradas para os testes nesse trabalho foram marcadas no mapa de padrão de escoamentos desenvolvido em Ulbrich e Mewes (1994), apresentado na Fig.5.14. Este mapa foi escolhido por contar com a validação de vários resultados experimentais. Segundo este mapa, a maioria de condições reproduzidas no presente trabalho pertencen ao padrão de escoamento bolhas portanto espera-se que a natureza do carregamento sobre o tubo seja similar na maioria dos testes. 


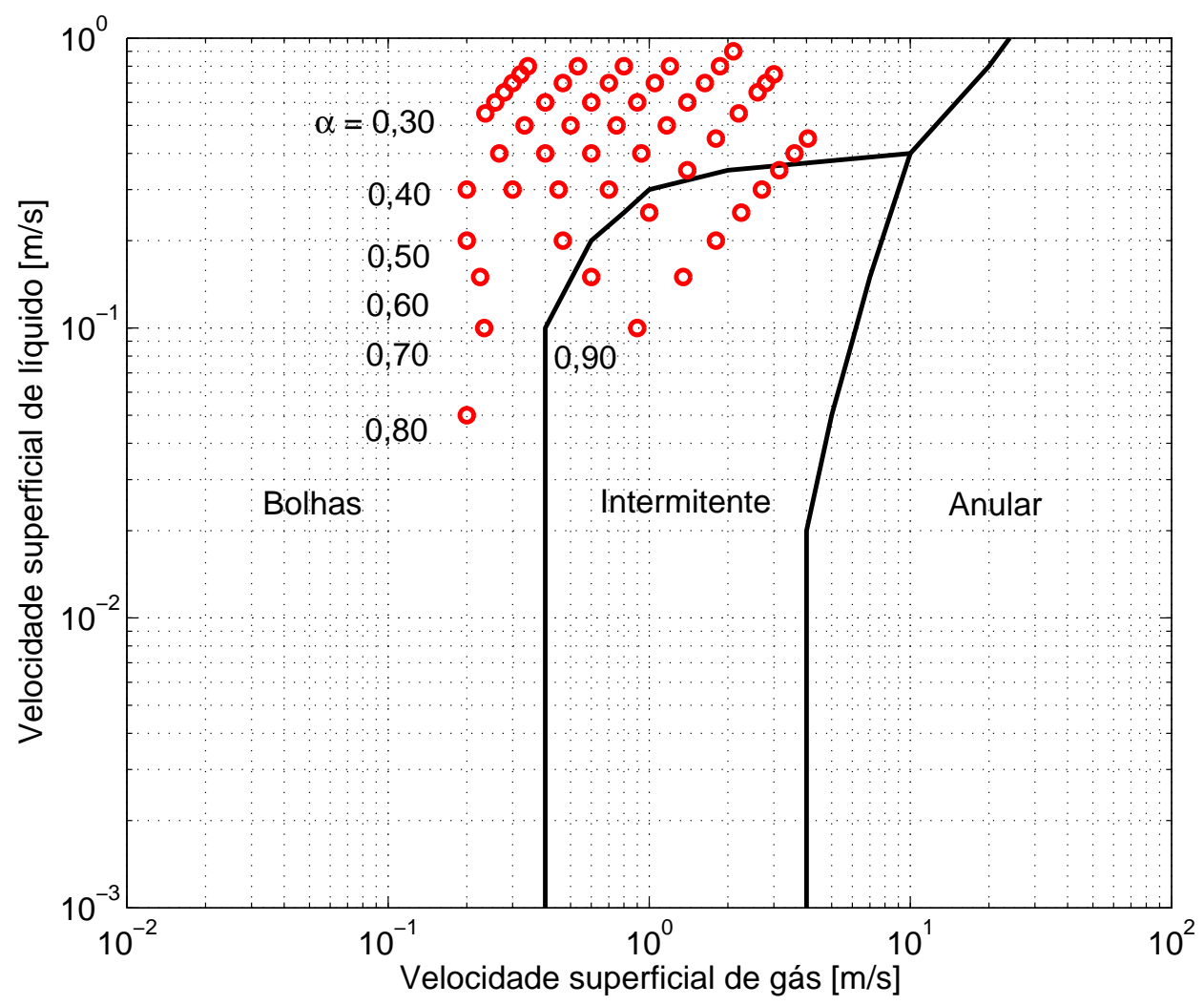

Figura 5.14: Testes realizados no presente trabalho localizados no mapa de padrões de escoamento bifásico proposto por Ulbrich e Mewes (1994).

As PSDs de aceleração para cada fração de vazio são apresentadas na Fig. 5.15 até a Fig. 5.21. Por facilidade na apresentação dos resultados, nas figuras citadas só foram recolhidos dois casos por cada fração de vazio: o de menor e o de maior velocidade de escoamento.

Nas PSDs se pode ver que, ao contrário do que acontece em escoamento monofásico, o escoamento bifásico excita bem aos modos bouncing e rocking do tubo instrumentado. Esta oscilação apareceu nas duas coordenadas sendo mais forte na direção do escoamento. Outra característica geral do sistema que pode ser notada das PSDs é que o pico de ressonância não identificado na coordenada $x$ que aparece na FRF em ambiente ar (ver Fig.5.6) está sendo excitado pelo escoamento bifásico ao igual do que no caso monofásico. Segundo o observado nas figuras, a amplitude do pico cresce com a velocidade do escoamento. Este pico de ressonância não identificado foi registrado na coordenada $x$ em todas as frações de vazio medidas. Embora o pico também tenha aparecido na FRF na coordenada $y$, este não foi bem excitado pelo escoamento bifásico nesta direção. $\mathrm{O}$ aparecimento do pico é indesejável, já que este modo de vibração não foi representado no modelo teórico e complica o estudo da dinâmica do tubo.

Em termos gerais para todas as frações de vazio, pode-se notar que a amplitude da PSD de aceleração na coordenada $y$ é várias vezes maior do que seu equivalente na coordenada $x$ para a mesma velocidade de escoamento. Isto é um sintoma de que a vibração é maior na direção de arrasto do escoamento. Vale a pena notar que a diferença entre as amplitudes da PSD nas coordenadas $x$ e $y$ aumenta conforme a velocidade do escoamento bifásico aumenta para cada 
a)

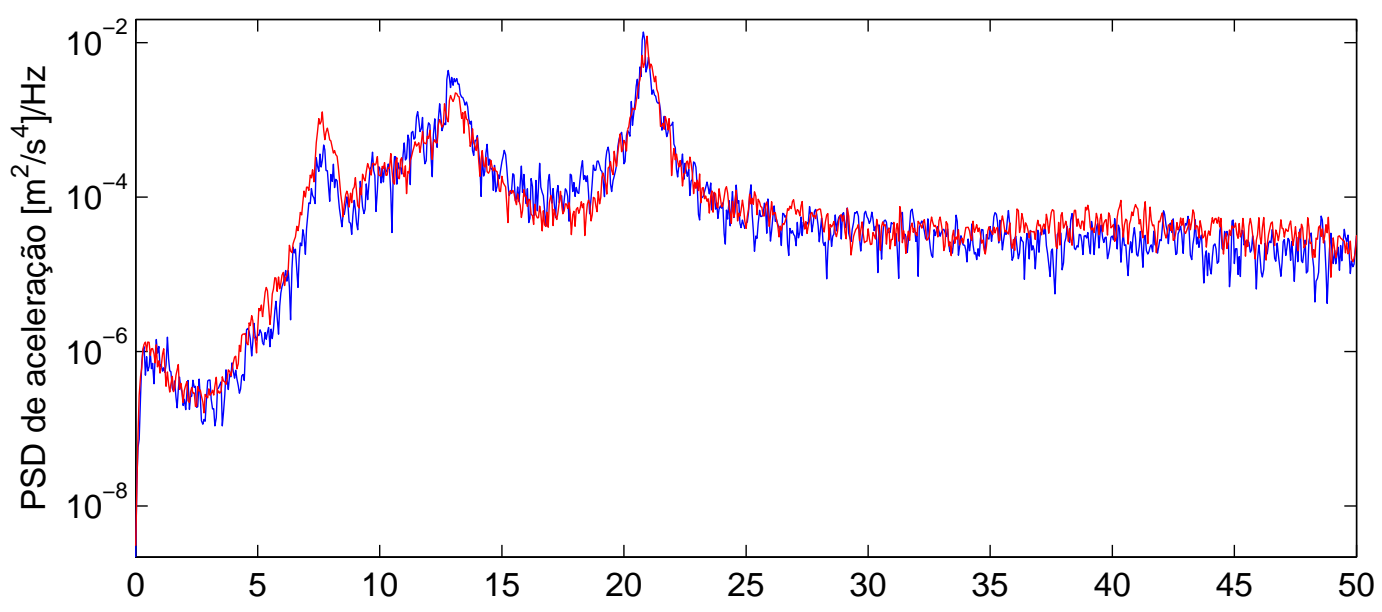

b)

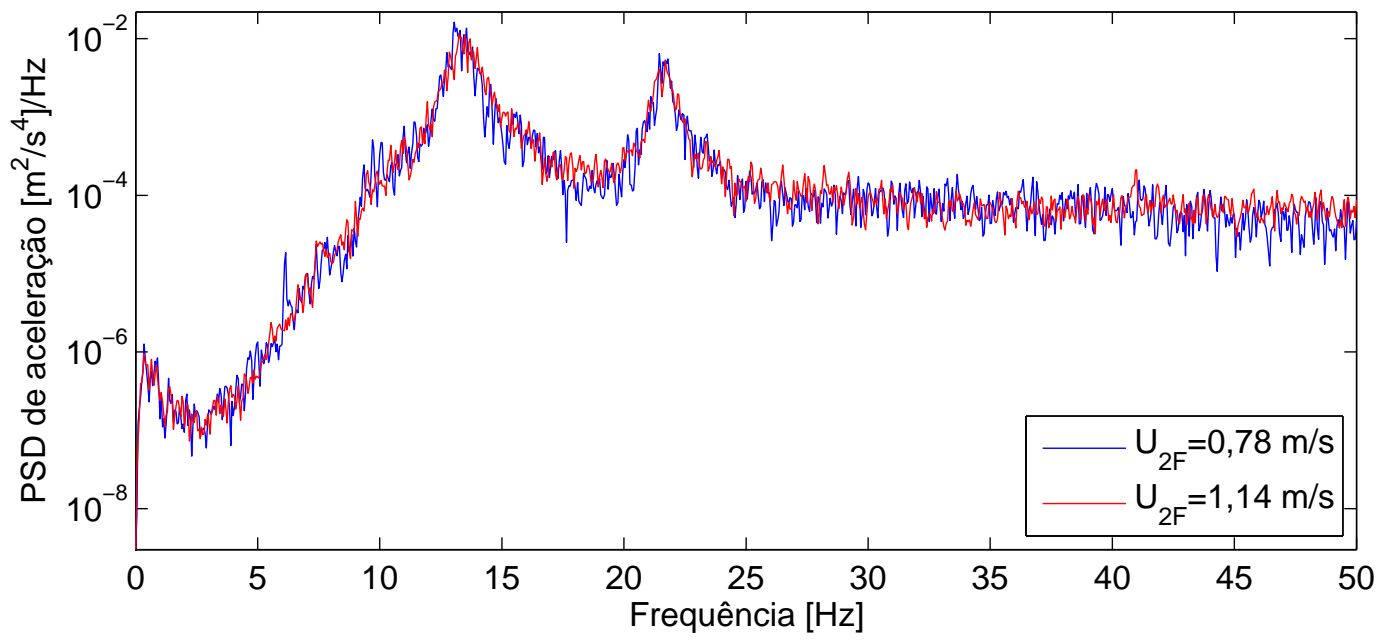

Figura 5.15: PSD de aceleração para escoamento bifásico com fração de vazio de 0,30. Resposta medida no ponto 1 . a) Coordenada $x \mathrm{e} \mathrm{b)} \mathrm{coordenada} y$.

caso de fração de vazio.

As limitações práticas da bancada fazem que para os testes realizados nas frações de vazio de 0,3 e 0,4 a diferença entre a velocidade máxima e a velocidade mínima seja relativamente pequena comparada com os casos de frações de vazio maiores onde a velocidade máxima é o triplo ou quádruplo da velocidade mínima. A pequena diferença entre velocidades extremas faz que as PSDs de aceleração para estes casos estejam muito próximas como se pode ver nas figs. 5.15 e 5.16. Na coordenada $x$ as PSDs estão quase sobrepostas a uma sobre a outra mostrando a pequena variação citada anteriormente, e na coordenada $y$ a PSD de maior velocidade está levemente acima da PSD de velocidade menor, no entanto a diferença é pouca.

As PSDs para uma fração de vazio de 0,5 são apresentadas na Fig. 5.17. Nesta figura decidiu- 
a)

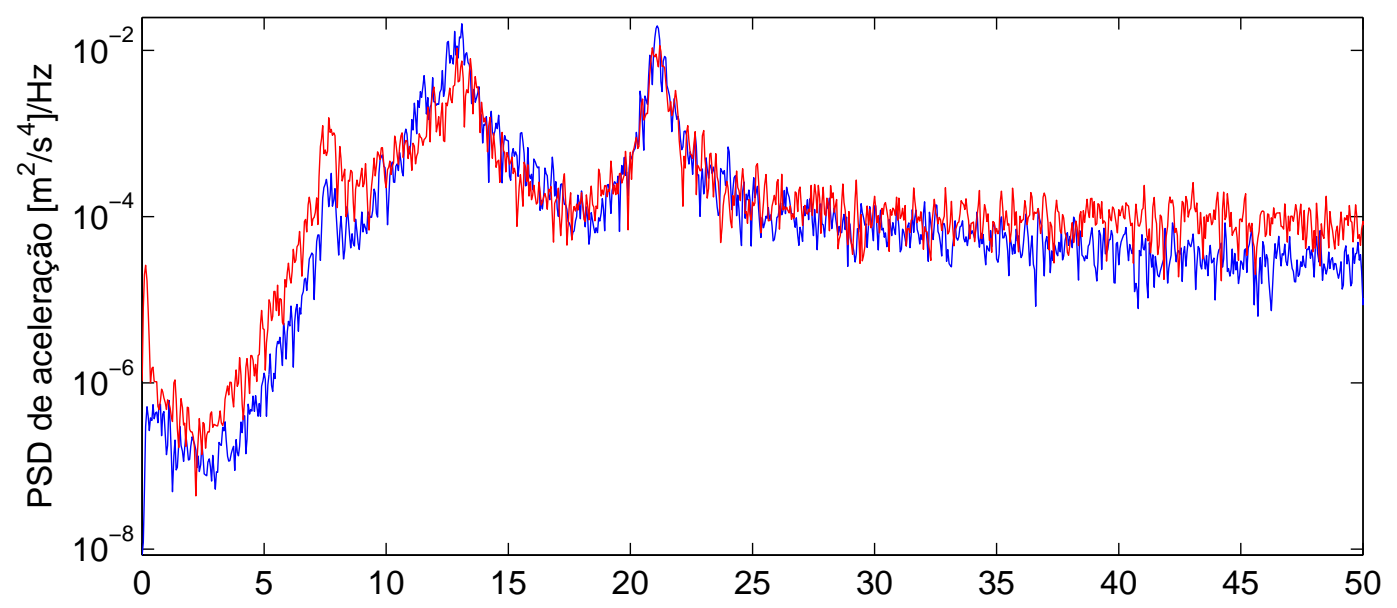

b)

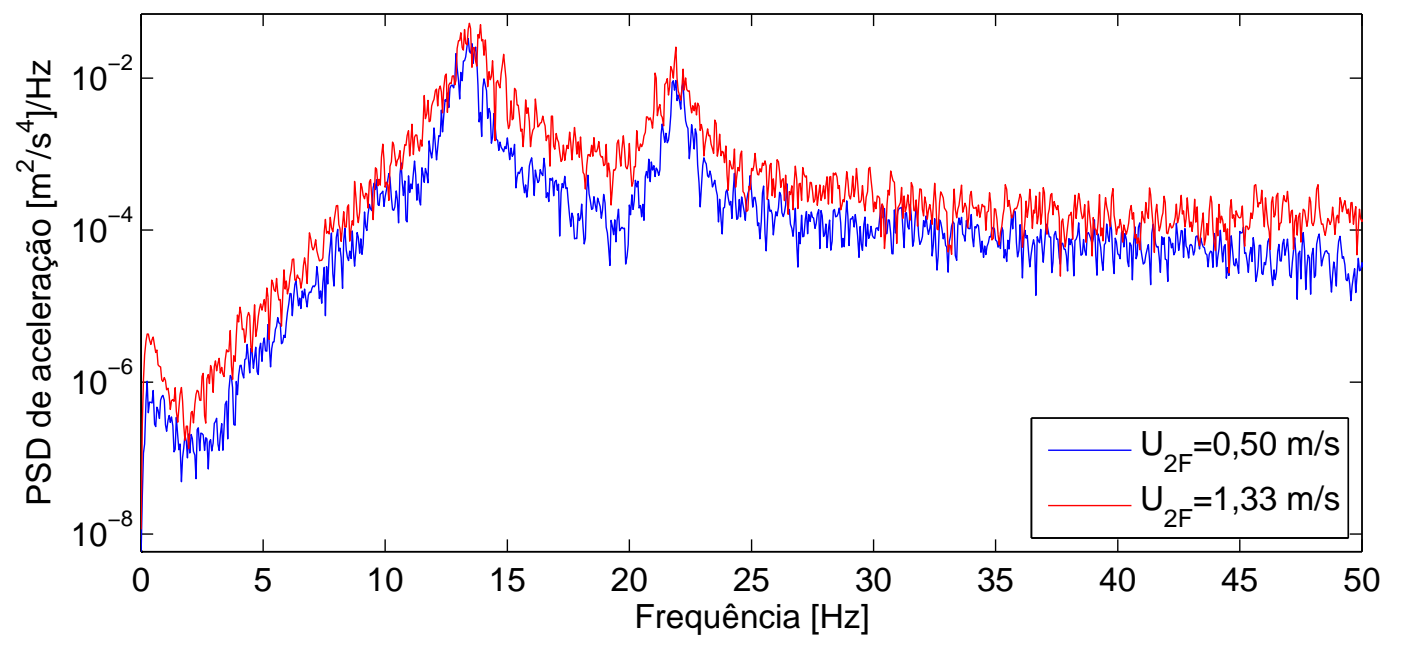

Figura 5.16: PSD de aceleração para escoamento bifásico com fração de vazio de 0,40 . Resposta medida no ponto 1 . a) Coordenada $x$ e b) coordenada $y$.

se incluir as PSDs medidas para um escoamento monofásico de velocidade igual a $0,70 \mathrm{~m} / \mathrm{s}$, desta forma os níveis de vibração induzida por ambos tipos de escoamento podem ser comparados. Como se pode ver, a resposta de aceleração do tubo é maior quando este é excitado por um escoamento bifásico $\left(U_{2 F}=0,40 \mathrm{~m} / \mathrm{s} ; j_{l}=0,2 \mathrm{~m} / \mathrm{s} ; j_{f}=0,2 \mathrm{~m} / \mathrm{s}\right)$ embora sua velocidade seja menor do que o escoamento monofásico $(U=0,70 \mathrm{~m} / \mathrm{s})$. Este resultado ressalta a importância da excitação causada pela variação instantánea de densidade de um escoamento bifásico, o qual provoca a vibração aleatória do tubo. Além disso, pode-se notar que o escoamento bifásico excita o tubo em todo o espectro de frequências analisado melhor do que é excitado pelo escoamento monofásico.

Ao tempo que maiores frações de vazio são usadas nos ensaios, maior é a diferença entre as 
a)

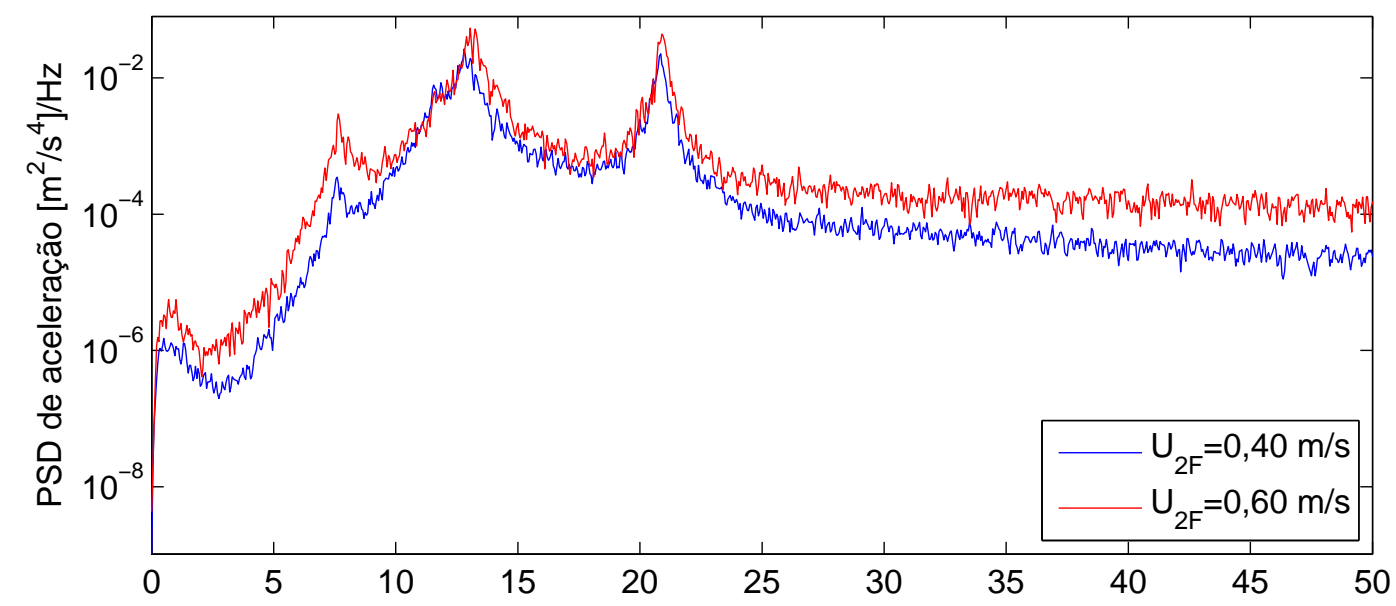

b)

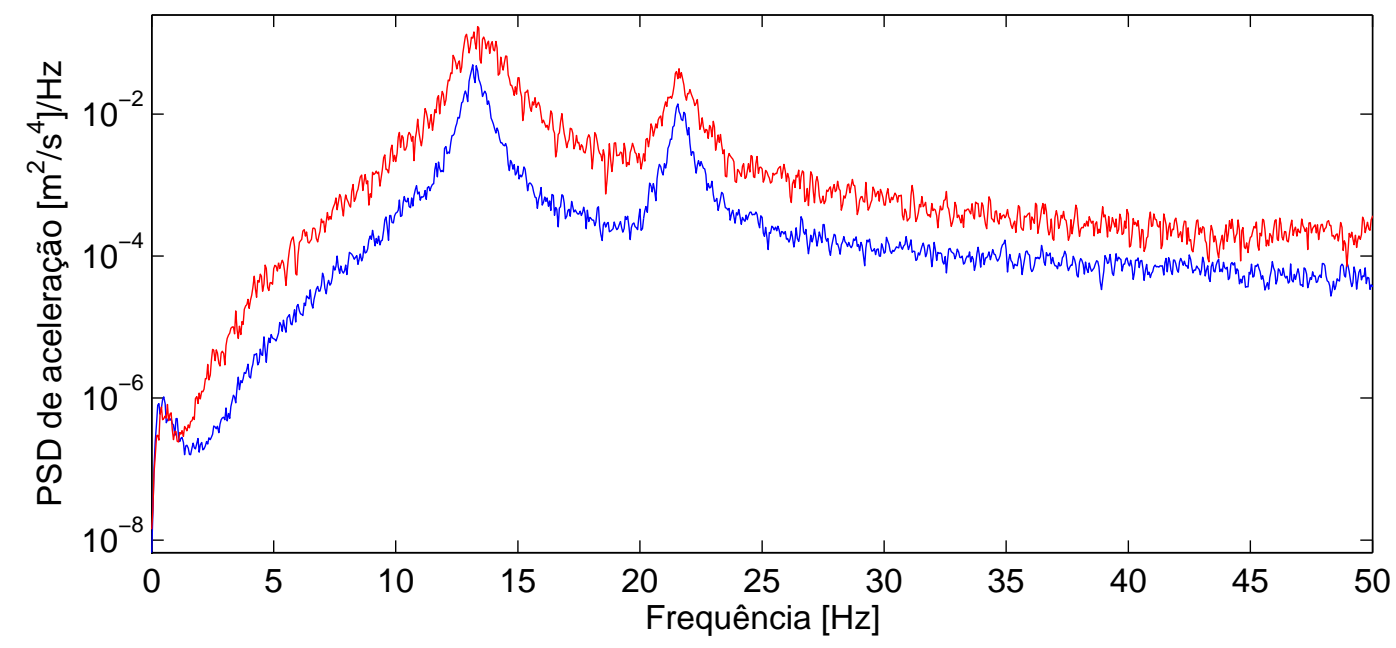

Figura 5.17: PSD de aceleração para escoamento bifásico com fração de vazio de 0,50 . Resposta medida no ponto 1 . a) Coordenada $x$ e b) coordenada $y$.

velocidades máxima e mínima obtidas na seção de testes. Isto pode ser visto nas figuras como o afastamento vertical da PSD de velocidade máxima respeito à PSD de velocidade mínima. Esta diferença é visível a partir da fração de vazio igual a 0,40 na coordenada $y$ e desde a fração de vazio 0,60 na coordenada $x$. Através das figs. 5.18, 5.19, 5.20 e 5.21 pode-se conferir que praticamente o formato da PSD da resposta de aceleração do sistema é mantido para todas as frações de vazio usadas nos testes. Vale a pena mencionar que a partir da fração de vazio igual a 0,60 em diante pode-se notar que as frequências de ressonância correspondentes à velocidade máxima de escoamento em cada fração de vazio se deslocam levemente à direita com respeito às frequências de ressonância obtidas nos testes com velocidade mínima. A explicação a esta leve mudança na frequência de ressonância do tubo deve estar relacionada com a energia cinética 
do fluido. Uma maior velocidade de escoamento carrega ao tubo com uma componente estática maior aumentando a tensão nos fios de aço, o qual termina por modificar a frequência natural do sistema.

a)

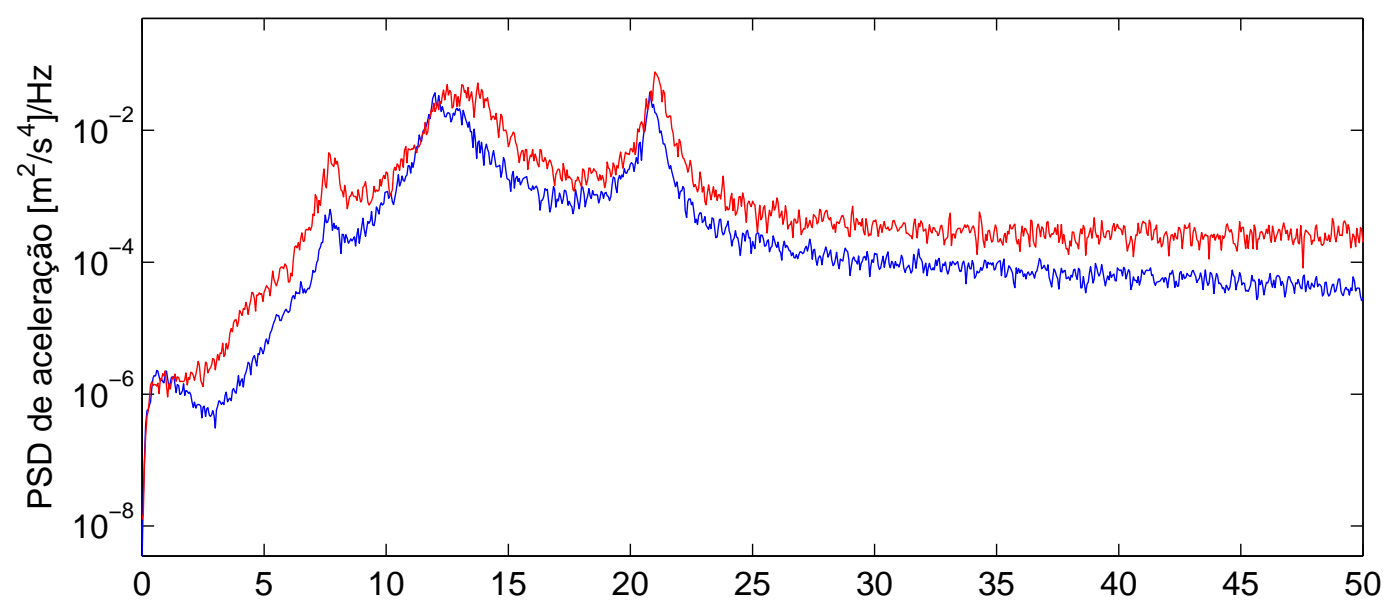

b)

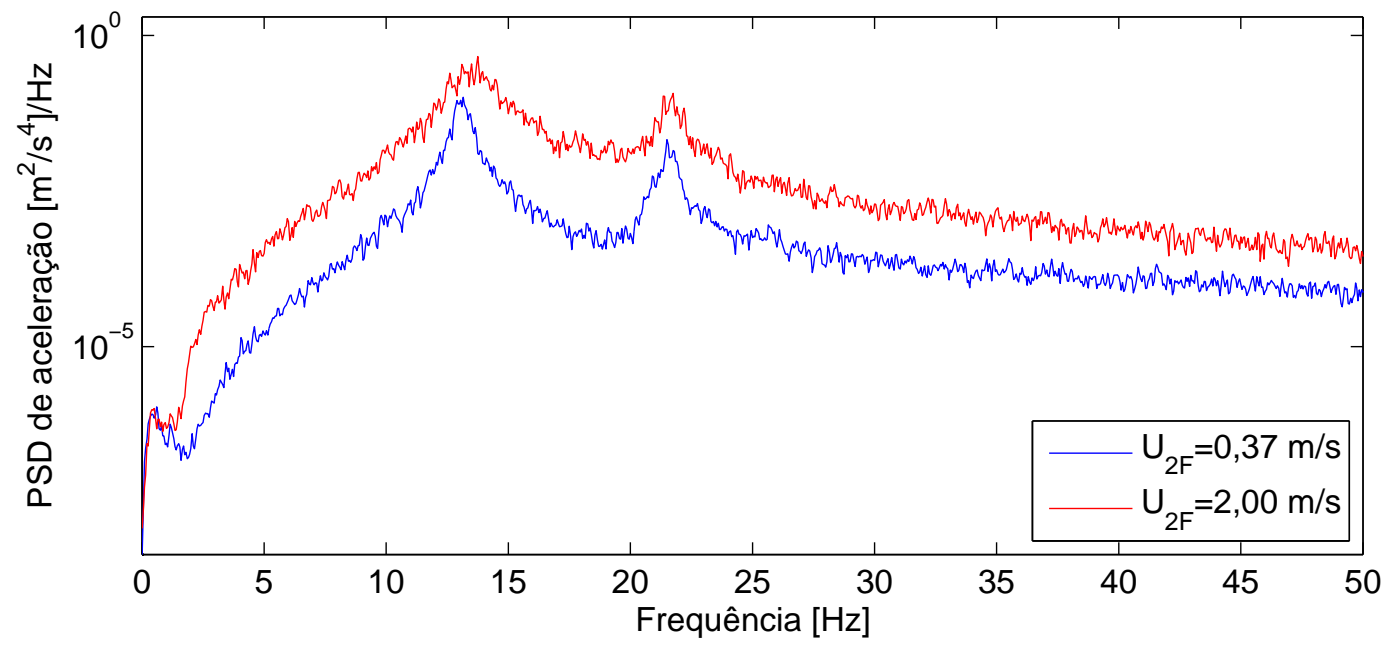

Figura 5.18: PSD de aceleração para escoamento bifásico com fração de vazio de 0,60 . Resposta medida no ponto 1 . a) Coordenada $x$ e b) coordenada $y$.

A influência da fração de vazio sobre as frequências de ressonância da estrutura dinâmica foi revisada através do tratamento das PSDs de aceleração obtidas. Para o reconhecimento das frequências de ressonância no espectro de frequência de 0 até $50 \mathrm{~Hz}$ as PSDs foram suavizadas pelo método exponencial com um fator de 0,9 . Esta ferramenta pode ser selecionada no software TestLab da LMS ${ }^{\circledR}$. Os resultados deste estudo são apresentados na Fig. 5.22, eles mostram que as frequências de ressonância do sistema não dependem da fração da vazio. Aparentemente a velocidade do escoamento provoca uma pequena variação da frequência de ressonância, mas 
a)

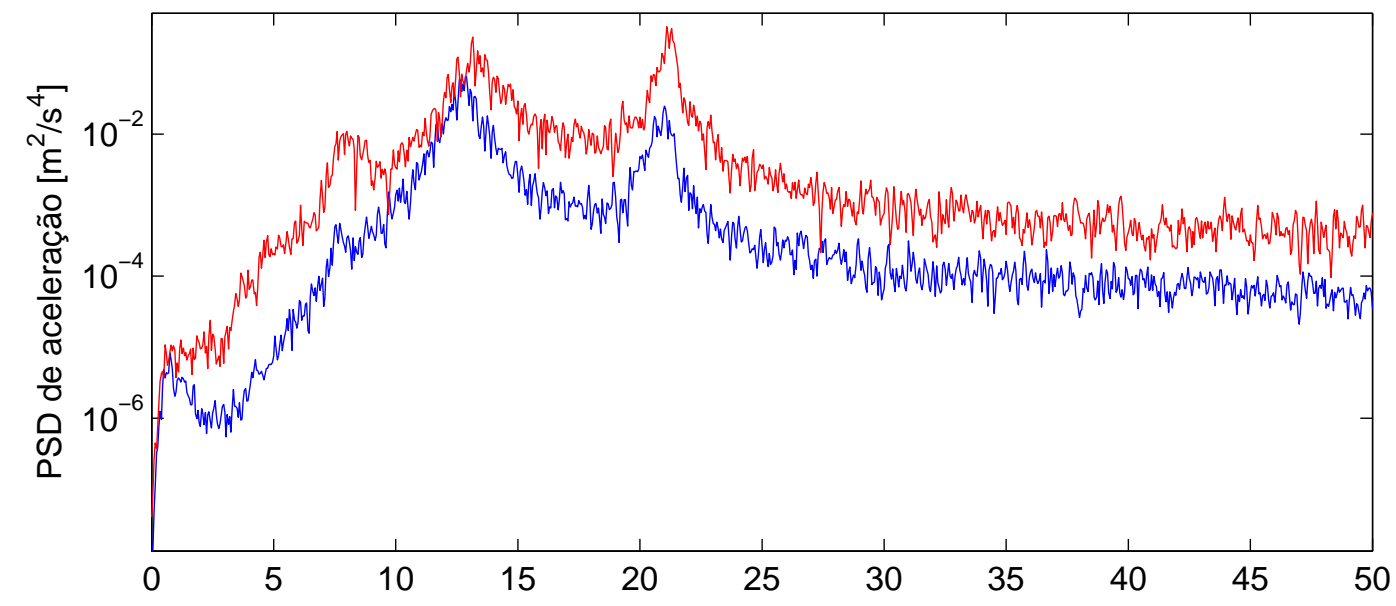

b)

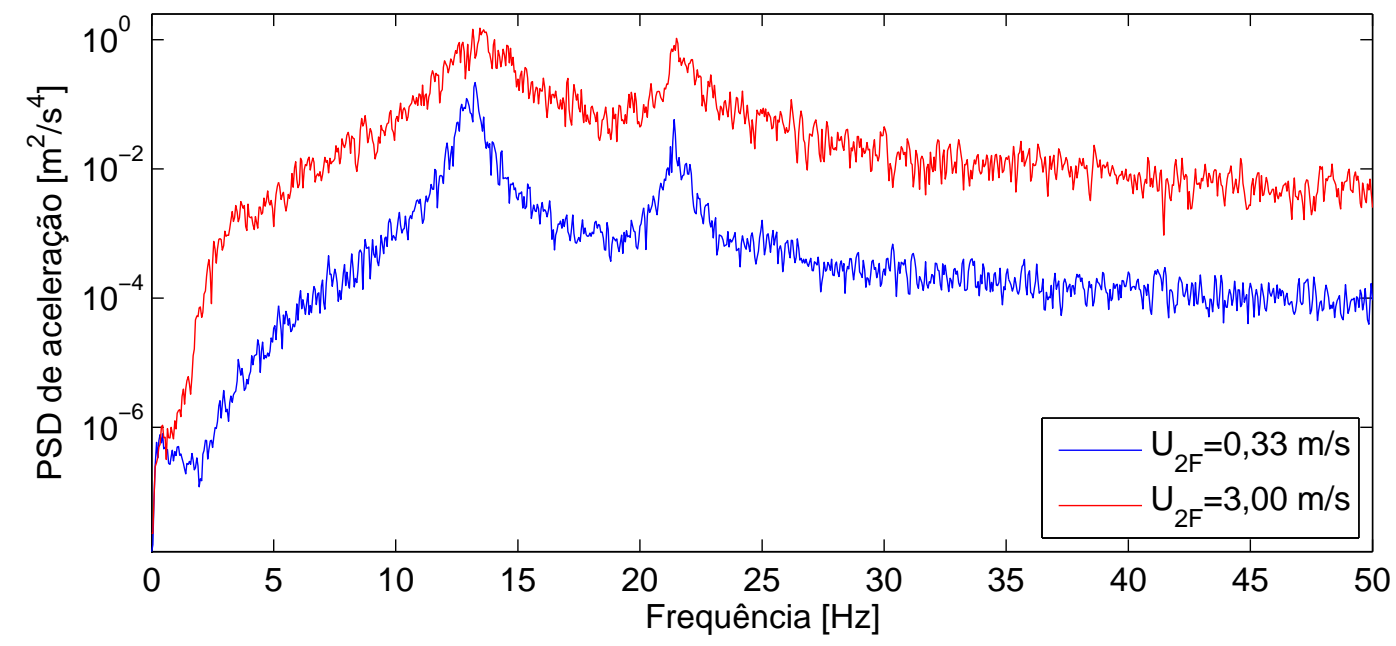

Figura 5.19: PSD de aceleração para escoamento bifásico com fração de vazio de 0,70 . Resposta medida no ponto 1 . a) Coordenada $x$ e b) coordenada $y$.

este fenômeno deve estar relacionado com o arrasto do tubo como foi indicado anteriormente.

Finalmente, se apresenta o valor RMS de aceleração do tubo no largo de banda de frequência de 409,6 Hz para as frações de vazio testadas. Para facilitar a visualzação destes resultados se usaram duas figuras, a primeira reúne os resultados para frações de vazio de 0 até 0,50 e a segunda as frações de vazio desde 0,60 até 0,90 . Como se pode ver na Fig. 5.23 a aceleração RMS está contida até um valor máximo de $0,6 \mathrm{~m} / \mathrm{s}^{2}$. Isto muda para frações de vazio acima de 0,50 onde o maior valor eficaz registrado foi aproximadamente de $4 \mathrm{~m} / \mathrm{s}^{2}$, como se vê na Fig. 5.24. Além disso, usar duas figuras permite analisar o range de velocidades de escoamento usadas para os dois grupos de testes. Este range é mais largo para frações de vazio maiores a 0,60. Devido as limitações práticas da bancada e dos instrumentos os testes não puderam ser 
a)

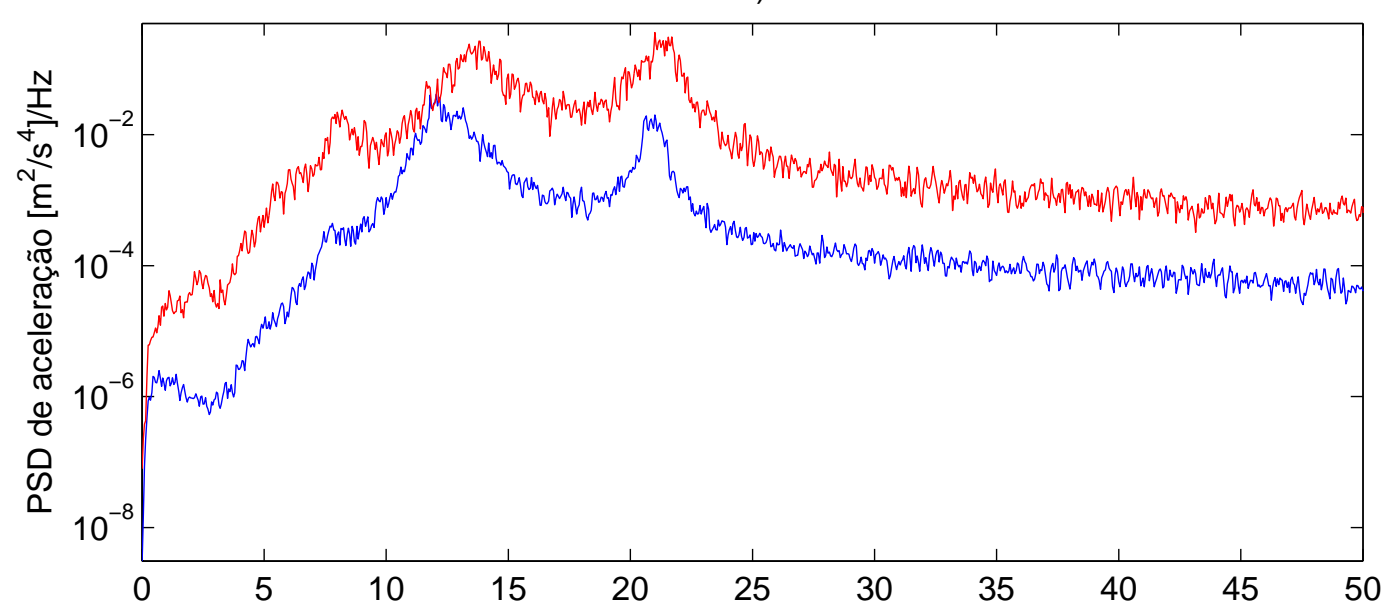

b)

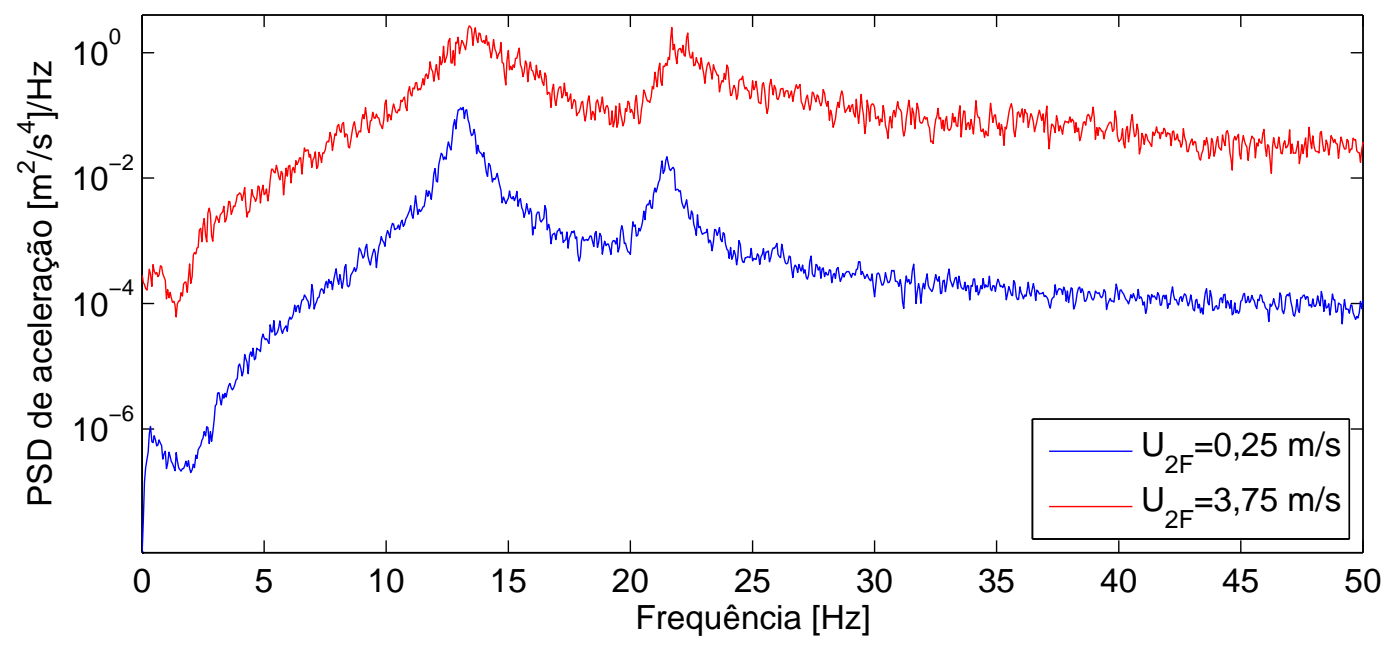

Figura 5.20: PSD de aceleração para escoamento bifásico com fração de vazio de 0,80 . Resposta medida no ponto 1 . a) Coordenada $x$ e b) coordenada $y$.

feitos para todas as frações de vazio num mesmo range de velocidades do escoamento.

Na Figura 5.23 se pode conferir novamente que a excitação induzida por escoamento bifásico é maior do que a induzida por um escoamento monofásico de água. Justamente os resultados para escoamento monofásico $(\alpha=0)$ aparecem na parte inferior da gráfica, embaixo de todos os resultados de escoamento bifásico. Isto vem a confirmar a sensibilidade da estrutura dinâmica à excitação induzida por um escoamento bifásico. Nesta figura se pode ver também que os valores RMS de aceleração para uma fração de vazio de 0,30 são menores do que os apresentados nas outras frações de vazio testadas. No entanto, baseado nos resultados obtidos não se pode afirmar que a resposta de aceleração tem uma relação direta com a fração de vazio. A resposta do tubo obtida na fração de vazio de 0,40 foi maior do que a resposta apresentada 
a)

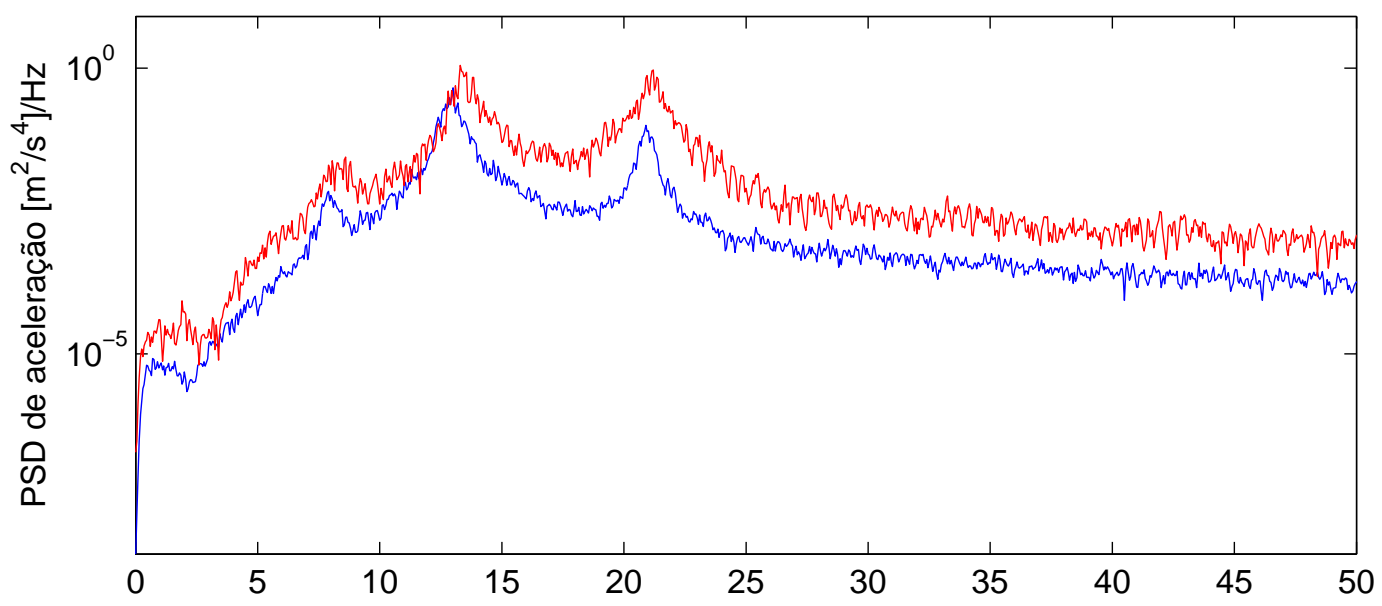

b)

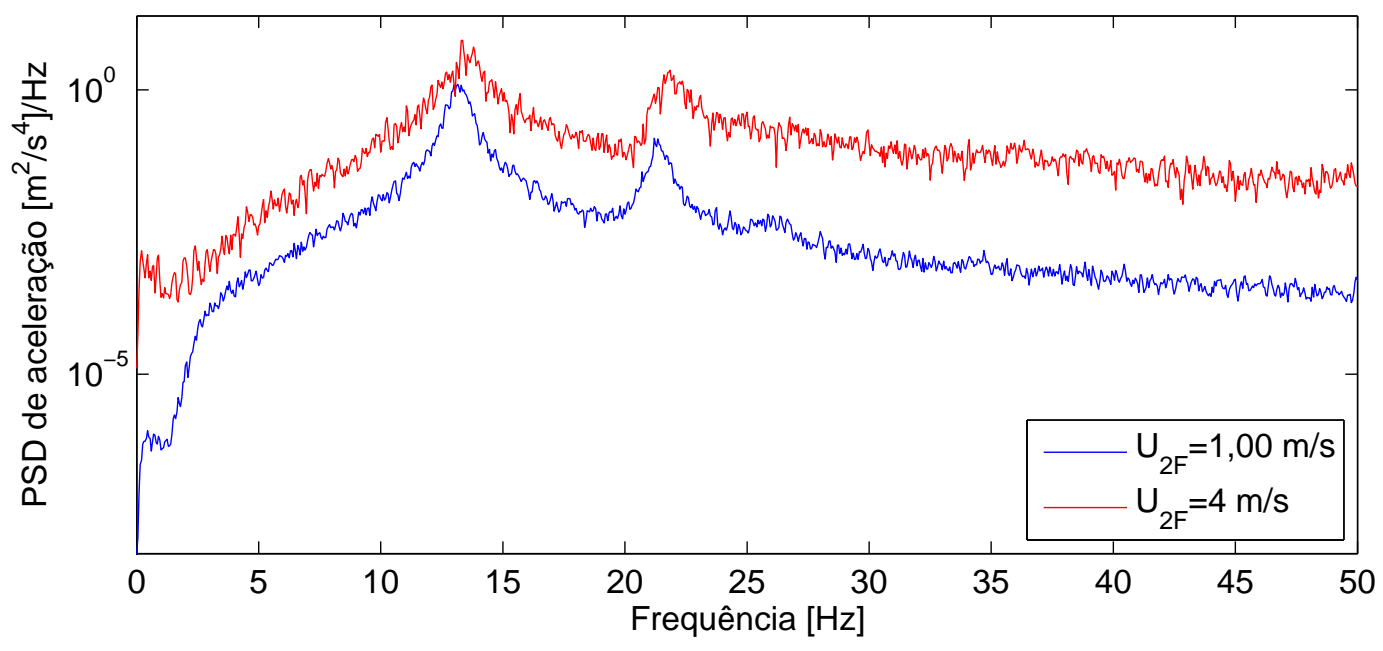

Figura 5.21: PSD de aceleração para escoamento bifásico com fração de vazio de 0,90. Resposta medida no ponto 1 . a) Coordenada $x$ e b) coordenada $y$.

em todas as outras frações de vazio no intervalo de velocidades de escoamento entre 0,6 e 1,33 $\mathrm{m} / \mathrm{s}$. Neste intervalo de velocidades de escoamento os valores RMS de aceleração nas frações de vazio 0,$50 ; 0,60 ; 0,70$ e 0,80 são muito similares e não apresentam um comportamento em particular. Segundo o observado nos testes e conferido nos mapas de padrão de escoamento, baixo as condições mencionadas se obteve um padrão de escoamento de tipo bolhas. Os padrões de escoamento e os resultados experimentais sugerem que o tubo se encontra num mecanismo de vibração aleatória. Os resultados obtidos nesta faixa de velocidades são semelhantes nas coordenadas $x$ e $y$.

Como se pode ver na Fig.5.24, a resposta dinâmica do tubo em frações de vazio de 0,70 e 0,80 é maior a partir de uma velocidade de escoamento aproximadamente de 2,60 m/s. Este 

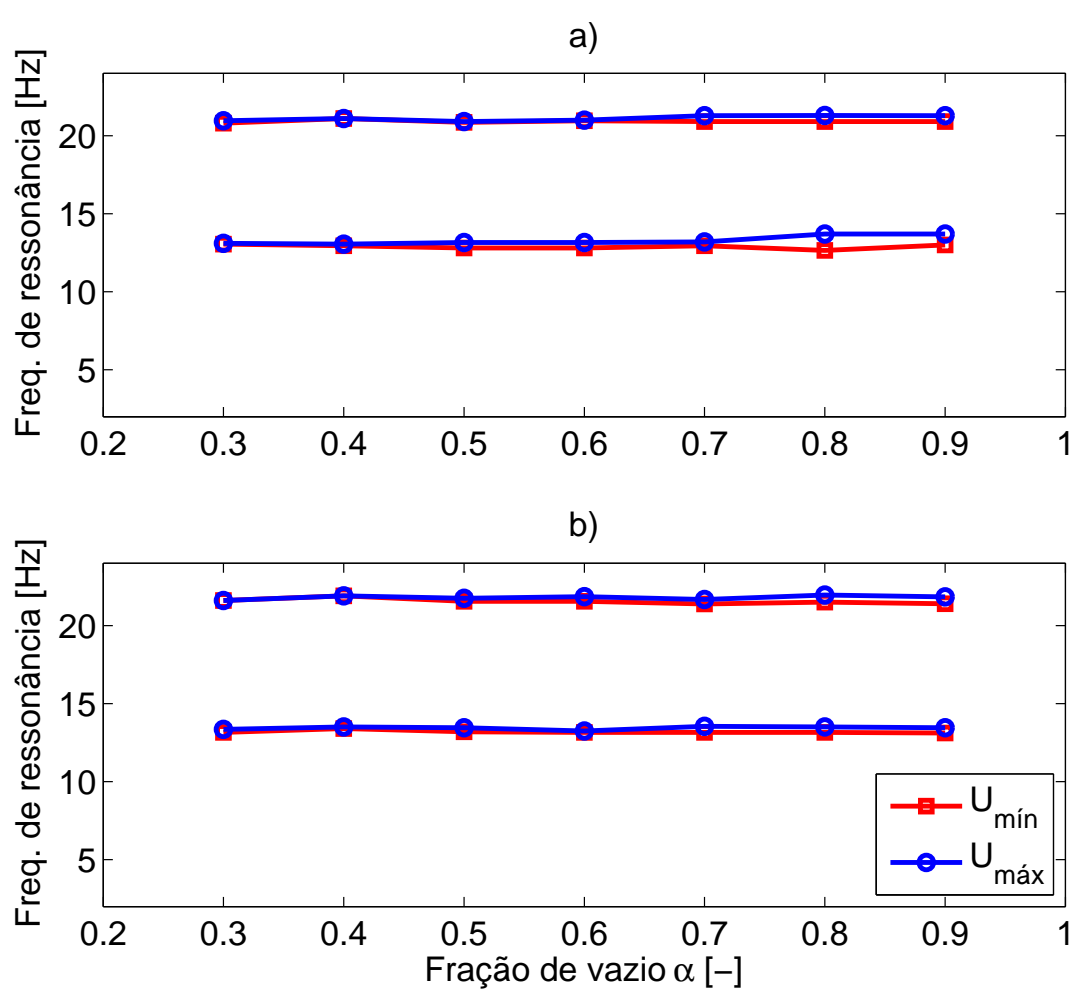

Figura 5.22: Variação da frequência de ressonância com a fração de vazio a) Coordenada $x$ e b) coordenada $y$.

comportamento pode ser identificado como uma mudança na inclinação da curva traçada pelos valores RMS da aceleração versus a velocidade do escoamento. Nos resultados experimentais do presente trabalho esta mudança é mais acentuada na coordenada $y$ do que na coordenada $x$. Para os resultados obtidos na fração de vazio 0,80 o incremento na resposta dinâmica do tubo deve estar relacionada com o padrão de escoamento. O padrão de escoamento registrado visualmente neste caso foi do tipo agitante a partir da velocidade do escoamento igual a $1,75 \mathrm{~m} / \mathrm{s}$ e intermitente a partir de 2,75 m/s. Como se vê na Fig.5.24, o tubo é mais sensível na coordenada $y$ à variação de velocidade de escoamento e portanto à mudança de padrão de escoamento. Isto faz sentido, já que o escoamento agitante e o intermitente estão caracterizados pelo passo intercalado de fases líquida e gás através da tubulação. Vale a pena mencionar que segundo o mapa proposto por Ulbrich e Mewes (1994) os padrões de escoamentos obtidos para a fração de vazio de 0,70 são de tipo bolhas e só uns testes desenvolvidos em fração de vazio igual a 0,80 correspondem a um padrão de escoamento intermitente.

Os resultados obtidos para uma fração de vazio de 0,90 apresentam um comportamento semelhante ao observado para frações de vazio de 0,70 e 0,80 . Na coordenada $x$, a curva para a fração de vazio 0,90 não mostra diferenças respeito às outras frações de vazio dentro do intervalo de velocidades de escoamento entre 1,00 e $3,50 \mathrm{~m} / \mathrm{s}$. A partir deste ponto o valor RMS de aceleração cresce aproximadamente ao dobro do seu valor devido a uma variação de $0,10 \mathrm{~m} / \mathrm{s}$ na velocidade superficial de líquido e $0,90 \mathrm{~m} / \mathrm{s}$ na velocidade superficial de gás. Na coordenada 
a)

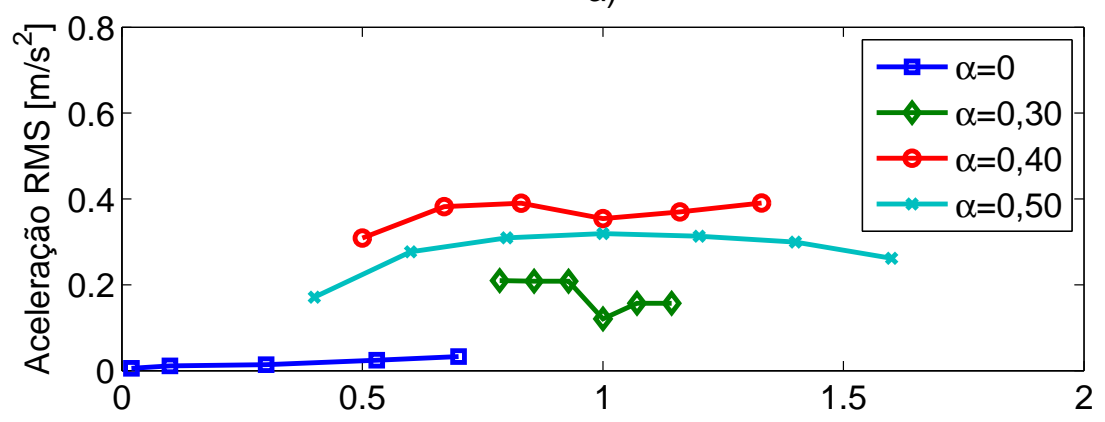

b)

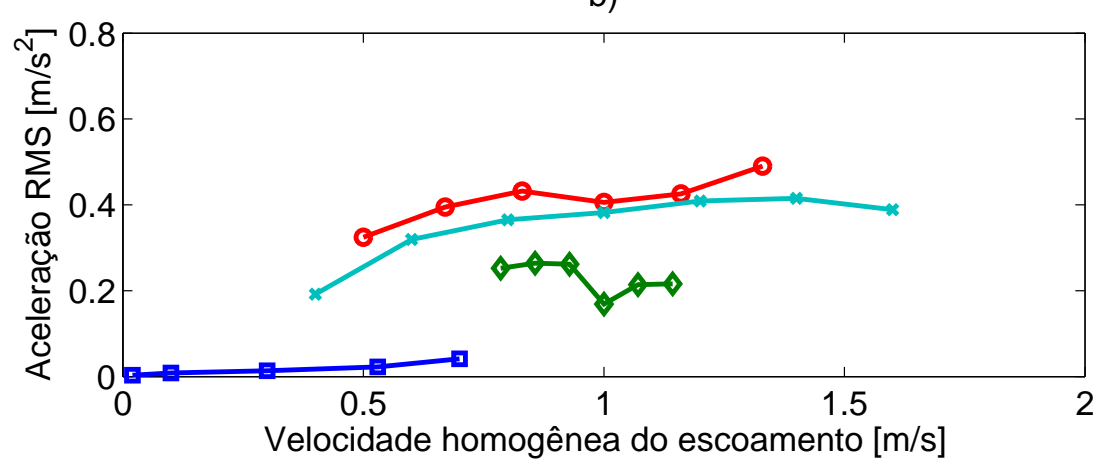

Figura 5.23: Valor RMS da aceleração em função da velocidade homogênea do escoamento para cada fração de vazio. a) Coordenada $x$ e b) coordenada $y$.

$y$ o valor RMS de aceleração aumenta mais rápido com a velocidade do escoamento em comparação ao registrado na coordenada $x$, isto ocorre no intervalo de velocidades de escoamento entre 1 e 3,5 m/s. A partir desta velocidade o valor RMS de aceleração muda de maneira súbita até o triplo do seu valor com a mesma variação das velocidades das fases líquida e gás descrita para a coordenada $x$. Segundo o registrado visualmente nos testes realizados para a fração de vazio de 0,90 , a partir de uma velocidade de escoamento de $2,00 \mathrm{~m} / \mathrm{s}$ o padrão de escoamento é de tipo agitante e na velocidade $3,00 \mathrm{~m} / \mathrm{s}$ muda para um padrão intermitente. Provavelmente este padrão de escoamento está relacionado com o incremento da vibração do tubo.

Desde outro ponto de vista, os altos valores de aceleração para as frações de vazio de 0,80 e 0,90 podem corresponder à presença de instabilidade fluido-elástica na seção de testes. Este fenômeno pode ser reconhecido como um aumento súbito da resposta de deslocamento do tubo em função da velocidade de escoamento, no entanto, esta tendência também pode ser revisada numa representação gráfica da aceleração contra a velocidade do escoamento. Desta forma se evita integrar duas vezes o sinal, o qual amplifica o ruido das medições feitas. A velocidade crítica de instabilidade pode ser estimada do modelo de mecanismo de deslocamento proposto por Connors. Supondo uma frequência natural do tubo em escoamento bifásico igual a $13 \mathrm{~Hz}$, um amortecimento total $\zeta$ de 0,06 (como se vê na seguinte seção), uma constante de instabilidade igual a 4 e um expoente igual a 0,5 (MITRA et al., 2009) se obtem que a velocidade crítica para um escoamento com fração de vazio de 0,80 é igual a $2,3 \mathrm{~m} / \mathrm{s}$ e para um escoamento com fração 
a)

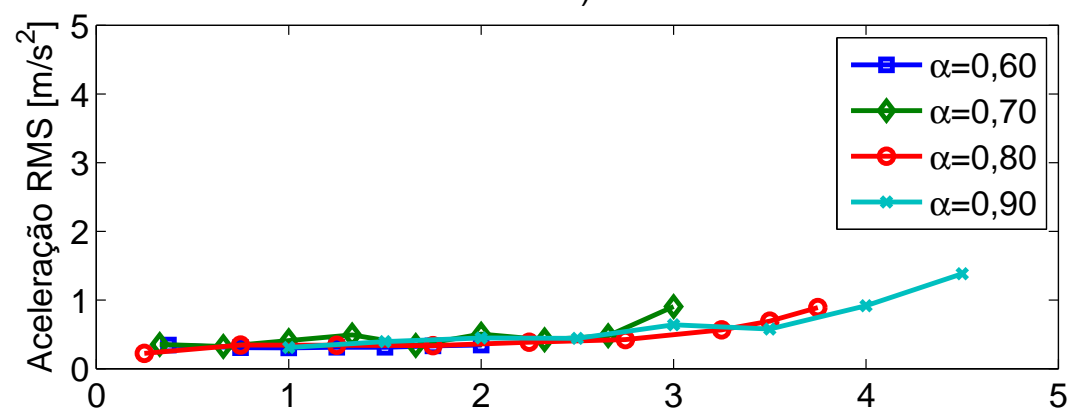

b)

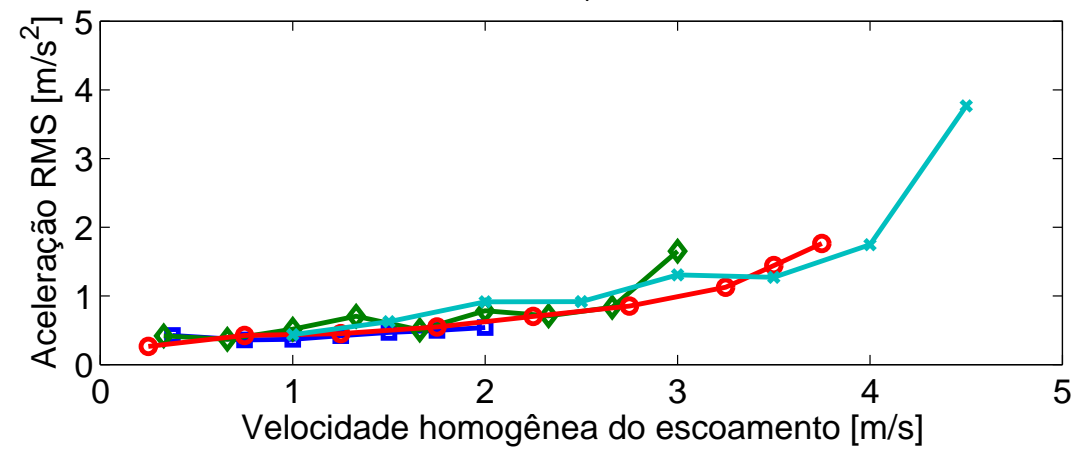

Figura 5.24: Valor RMS da aceleração em função da velocidade homogênea do escoamento para cada fração de vazio. a) Coordenada $x$ e b) coordenada $y$.

de vazio de 0,90 igual a $3,2 \mathrm{~m} / \mathrm{s}$. Como se pode ver na Fig.5.24, os resultados na coordenada $y$ na fração de vazio de 0,80 mostram que a gradiente da curva de aceleração varia levemente a partir da velocidade de escoamento de aproximadamente $3,00 \mathrm{~m} / \mathrm{s}$. Para a fração de vazio de 0,90 a gradiente da curva de aceleração apresenta uma mudança a partir de aproximadamente $3,5 \mathrm{~m} / \mathrm{s}$. Estes valores não confirmam o aparecimento de instabilidade fluido-elástica, portanto, para confirmar a sua presença na seção de testes é necessário uma maior quantidade de pontos experimentais, os quais vão permitir verificar o incremento da gradiente da curva de valores RMS de aceleração em função de velocidade de escoamento. Vale a pena mencionar que embora a instabilidade fluido-elástica seja prevista na seção de testes, este fenômeno depende de outros fatores como, por exemplo, a configuração da bancada de tubos, o acoplamento hidrodinâmico dentro da tubulação, a fila na qual o tubo instrumentado foi instalado e a desintonização dos tubos adjacentes. O efeito destes fatores é ainda confuso como pode-se revisar em Price $e t$ al. (1987), Weaver e Yeung (1983), Lin e Yu (2005), Chung e Chu (2006), entre outros.

A partir das figuras 5.23 e 5.24 se pode ver que na seção de testes usada nesse trabalho não se apresentou vibração induzida por desprendimento de vórtices. Segundo a Figura 2.10, o número de Strouhal correspondente à configuração usada na seção de testes é igual a 0,46 e através da Eq.2.1 se pode estimar a velocidade do escoamento para que a frequência de desprendimento de vórtices seja igual à frequência natural do tubo, esta velocidade é igual a 0,56 m/s. No entanto, não foi observado um mecanismo diferente à vibração aleatória. 
Um detalhe importante da Fig.5.23 que deve ser mencionado é que a quantidade de medições usada para calcular a média durante a aquisição de dados do software TestLab da LMS®é um parâmetro que afeta aos resultados obtidos. Por exemplo, os valores de aceleração para uma fração de vazio de 0,3 mostram dois segmentos de tendência horizontal. A diferença de amplitude RMS entre as duas horizontais se deve a que para cada segmento se usou diferente número de medições para calcular a média. Para os primeiros três pontos usou-se uma média de 6 medições, para o quarto ponto uma média de 18 e para os últimos dois pontos uma média de 11 medições, isto provoca a descontinuidade mostrada na figura. É possível notar que a média de 18 medições é menor do que os outros pontos. Uma maior quantidade de medições permite limpar o ruído próprio do experimento, e portanto este ruído que contribui no cálculo do valor RMS de aceleração é menor.

\subsubsection{Cálculo do amortecimento}

No presente trabalho os fatores de amortecimento para cada fração de vazio foram calculados através da mesma técnica usada em Chung e Chu (2006). Para isto são usadas as PSDs medidas experimentalmente e nos picos de ressonância o amortecimento é calculado através da técnica dos pontos de meia potência. Esta é uma técnica válida para ser usada em FRFs. Para ser usada em PSDs se considera que o escoamento bifásico excita ao tubo como um ruído branco, o qual pela sua definição está distribuído ao longo de todo o espectro de frequência. Esta suposição implica que a PSD terá um formato semelhante a uma FRF, onde as amplitudes nas frequências de ressonância e de meia potência têm a mesma proporção. Como se pode ver nas PSDs das figs.5.15 até 5.21 em comparação com as FRFs apresentadas na figs.5.6 e 5.7 esta é uma suposição razoável.

Para o reconhecimento dos pontos de ressonância e de meia potência foi preciso suavizar as PSDs obtidas. Isto foi feito no software Matlab®através da técnica de média móvel com um espaço de sete pontos. Um exemplo de uma PSD suavizada é mostrado na Fig. 5.25.

Os fatores de amortecimento foram calculados para três velocidades de escoamento diferentes por cada fração de vazio. A média destes valores foi calculada para as coordenadas $x$ e y. Para comparar os resultados com os apresentados em Chung e Chu (2006) e Pettigrew et al. (1989) se calculou a média entre os fatores de amortecimento das duas coordenadas. Os resultados são apresentados contra a fração de vazio na Fig.5.26.

Como pode-se ver, os fatores de amortecimento calculados no presente trabalho são maiores do que os obtidos nos trabalhos desenvolvidos por Chung e Chu (2006) e Pettigrew et al. (1989) e, além disso, não apresentam uma tendência definida. Na Figura 5.26 se pode ver que o amortecimento gerado por um escoamento monofásico é menor do que o gerado por um escoamento bifásico. Isto concorda com os resultados obtidos pelas pesquisas usadas como referência nesta análise. Em todo caso, o fator de amortecimento no escoamento monofásico de água continua sendo alto com respeito aos estudos anteriores.

As FRFs medidas em ambiente ar serviram para determinar que o amortecimento do tubo 
a)

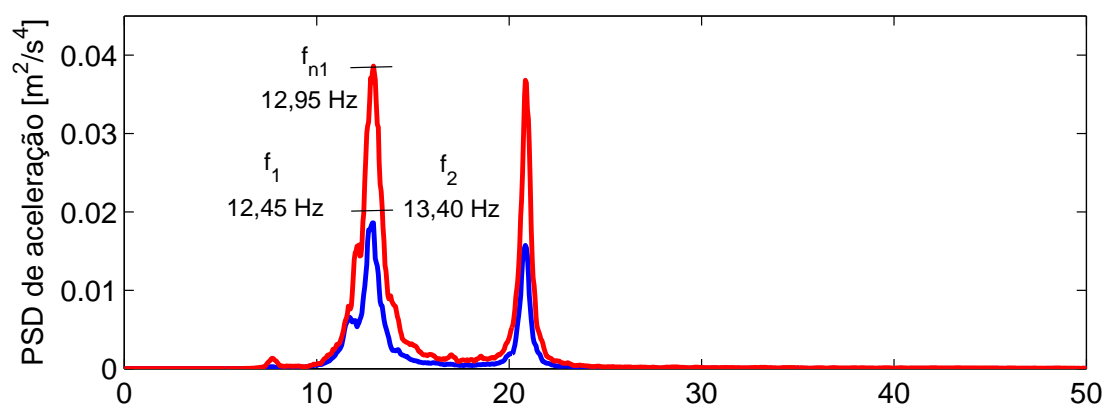

b)

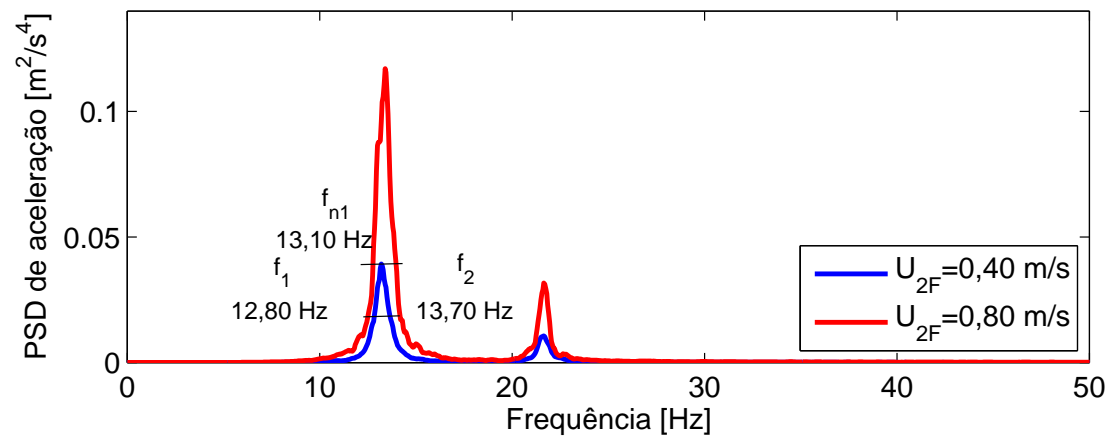

Figura 5.25: Exemplo de PSD suavizada a) Coordenada $x$ e b) Coordenada $y$.

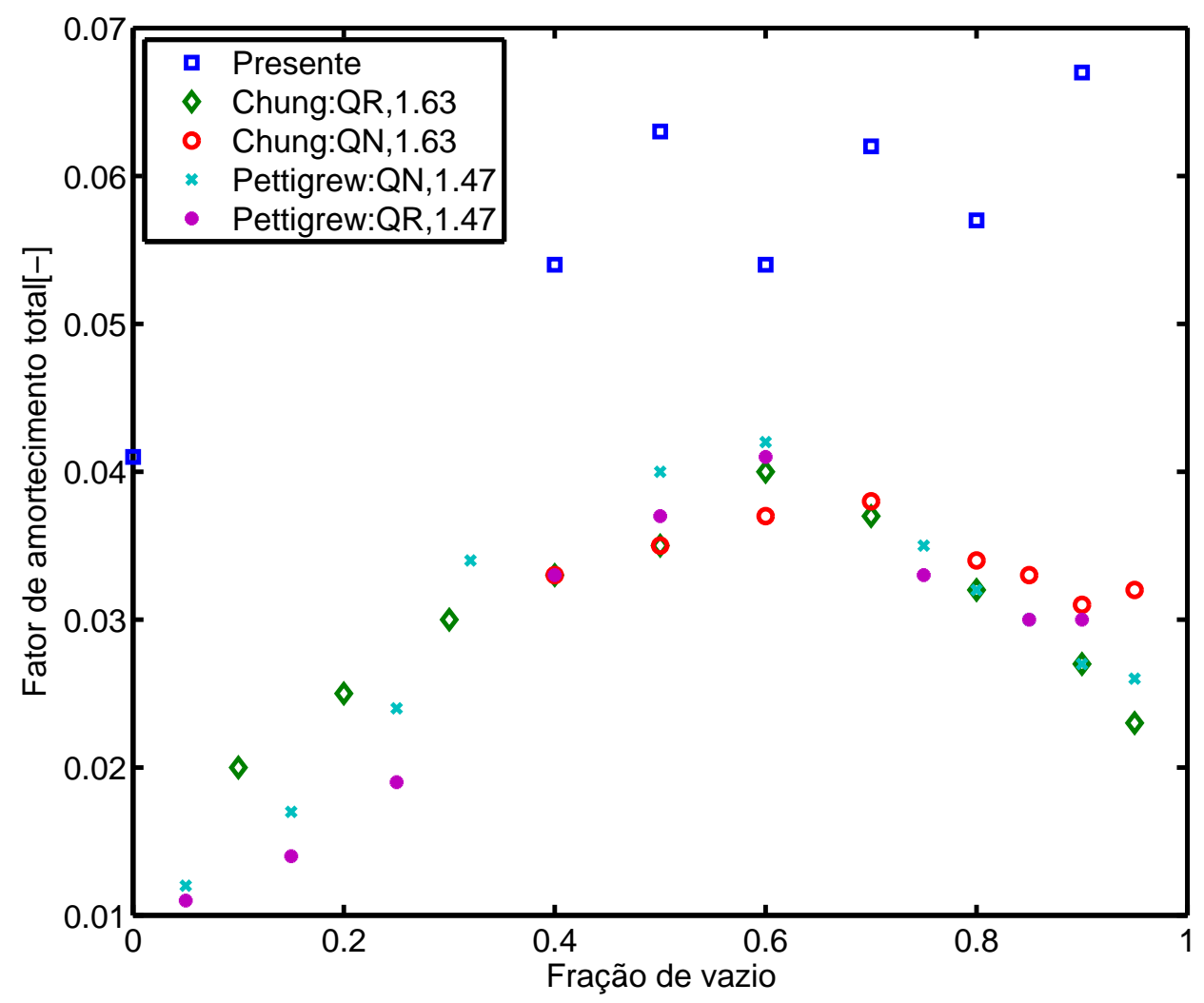

Figura 5.26: Fator de amortecimento total médio em escoamento bifásico. Resultados comparados com os trabalhos Chung e Chu (2006) e Pettigrew et al. (1989) 
nestas condições é menor e igual a 0,01. Para realizar estes testes a estrutura de vedação da seção de testes ainda não foi instalada. Isto aponta a que o alto fator de amortecimento se deve à configuração da estrutura dinâmica projetada. Acredita-se que o problema é gerado pela mangueira que é instalada na hora de realizar os testes em escoamento monofásico e bifásico. A mangueira de silicone amortece o deslocamento do tubo nas duas coordenadas, no entanto, seu uso foi necessário para evitar que os acelerômetros entrem em contato com a água. 


\section{Capítulo 6}

\section{Conclusões e sugestões para trabalhos futuros}

Nesse capítulo se apresentam as conclusões obtidas ao longo da realização do presente trabalho. As características da FRF experimental em ambiente ar são discutidas e comparadas com a modelagem teórica desenvolvida. As PSDs de aceleração do tubo são comparadas para as velocidades limites de uma mesma fração de vazio e entre frações de vazio. O método de cálculo de amortecimento em ar e em escoamento monofásico de água e bifásico água-ar é comentado. São listados os detalhes que precisam ser melhorados no projeto da estrutura dinâmica. Finalmente uma série de atividades futuras é listada, com elas o presente trabalho pode ser continuado.

\subsection{Conclusões}

- As vibrações induzidas por escoamentos estão entre os problemas dinâmicos mais importantes no projeto e uso de trocadores de calor de tipo carcaça e tubos. Existem diferentes tipos de mecanismos de VIE, os quais têm sido definidos ao longo do desenvolvimento desta linha de pesquisa. Os mais importantes mecanismos de VIE são: desprendimento de vórtices, vibração aleatória e instabilidade fluido - elástica. Destes três a instabilidade fluido-elástica é o problema mais grave já que pode provocar a falha de um trocador de calor em poucas horas.

- Uma estrutura dinâmica para o estudo da vibração induzida por escoamentos bifásicos foi projetada e construída no presente trabalho. Pelas vantagens descritas escolheu-se um sistema no qual a primeira frequência de ressonância pode ser regulada através da tensão nos fios de aço que suspendem o tubo instrumentado na seção de testes.

- A comparação entre o modelo teórico e os resultados experimentais em ambiente ar permitiu confirmar que o modelo teórico desenvolvido no presente trabalho representa bem a estrutura dinâmica construída na faixa de frequências de $0 \mathrm{~Hz}$ até $150 \mathrm{~Hz}$ onde aparecem os modos de vibração considerados na modelagem: bouncing e rocking. No entanto, a instalação da estrutura dinâmica deve ser aperfeiçoada para evitar o aparecimento de picos de ressonância não desejados. 
- O método de Keneddy - Pancu combinado com o uso do algoritmo ERA foi usado para calcular o fator de amortecimento experimental do tubo num ambiente de ar. A comparação entre o modelo teórico e os resultados experimentais demonstram que o fator de amortecimento estimado representa bem o que ocorre na prática.

- Baseado na diferença entre o nível de vibração medido em escoamento de água e o medido em escoamento bifásico, pode-se dizer que a estrutura dinâmica é sensível ao tipo de escoamento com o qual esta sendo excitada. O escoamento bifásico excita o tubo mais do que o escoamento monofásico e esta excitação está distribuída ao longo de toda a faixa de frequências analisada.

- A resposta dinâmica do tubo não apresenta uma relação direta com a fração de vazio. Na faixa de velocidades entre $0,6 \mathrm{~m} / \mathrm{s}$ e $1,33 \mathrm{~m} / \mathrm{s}$ os resultados indicam que um escoamento com fração de vazio de 0,40 excita mais ao tubo do que as frações de vazio maiores, com exceção da fração de vazio igual a 0,90. Este comportamento, aparentemente correspondente a um mecanismo de vibração aleatória, deve estar relacionado com o padrão de escoamento bolhas que se apresenta nesta faixa de velocidades.

- Não se achou uma relação entre a frequência de ressonância do tubo e a fração de vazio, embora se conheça que a frequencia de ressonância deve estar perto da medida no ar conforme a fração de vazio vai se aproximando a 1. Estudos anteriores reportam variação da frequência de ressonância com a velocidade do escoamento, no entanto na bancada usada neste estudo não se consiguiu obter todas as frações de vazio dentro de um mesmo range de velocidades e, portanto, uma comparação objetiva não pôde ser feita.

- A quantidade de medições usada para calcular a resposta de aceleração no domínio do tempo é um fator que afeta diretamente sobre o cálculo do seu valor RMS. Uma baixa quantidade de médias (menos de 10) não consegue limpar o ruído próprio da medição. Além disso, os resultados obtidos para diferentes quantidades de médias dificilmente podem ser comparados ou podem levar em conclusões erradas.

- O método de meia potência foi usado para o cálculo do amortecimento em escoamento monofásico de água e escoamento bifásico água - ar. Os resultados obtidos não seguem a tendência reportada por outros pesquisadores, no entanto, o método não pode ser descartado porque os resultados também são afetados por outros fatores, como por exemplo, a quantidade de medições feita com a qual a média da PSD é calculada além das dificuldades construtivas.

- Não se apresentou excitação por desprendimento de vórtices na seção de testes.

- A resposta do tubo para frações de vazio de 0,80 e 0,90 aumenta subitamente para as velocidades máximas usadas nestes testes. Este tipo de resposta poderia estar relacionado 
com o mecanismo de instabilidade fluido-elástica. O critério de Connors foi usado para estimar a entrada ao regime instável, no entanto como resultado se obtiveram velocidades diferentes às que o aumento da vibração do tubo ocorreu. Se precisam testes com maior velocidade de escoamento para conferir esta tendência.

- A estrutura dinâmica projetada no presente trabalho pode ser usada para o estudo da vibração induzida por escoamentos bifásicos pois, segundo os resultados obtidos ela é sensível ao tipo de escoamento usado e à fração de vazio utilizada. No entanto, a mangueira de silicone usada aumenta de forma significativa o amortecimento da estrutura, dessa forma é necessário que o projeto do método de extração dos fios seja refeito. $\mathrm{O}$ alto amortecimento faz que velocidades de escoamento maiores sejam necessárias para alcançar níveis de instabilidade, atrapalha o estudo da relação entre o amortecimento e a fração de vazio, ou até pode que esteja ocultando outros mecanismos de VIEs como a excitação gerada pelo desprendimento de vórtices.

\subsection{Sugestões para trabalhos futuros}

- A estrutura de acrílico usada para a vedação da seção de testes deve ser aperfeiçoada. Isto permitirá que o estudo das VIE bifásicos seja acompanhado do estudo da perda de pressão ao longo da tubulação. Isto inclui a melhora do método de extrair os fios dos acelerômetros do interior do tubo para evitar o alto amortecimento que a mangueira usada atualmente introduz na estrutura dinâmica.

- Adicionar os modos de vibração de corpo contínuo à modelagem desenvolvida no presente trabalho. Isto permitirá ter um modelo teórico mais completo da estrutura dinâmica.

- Projetar e realizar testes para o estudo de mecanismos de VIEs como vibração aleatória, vibração por desprendimento de vórtices e instabilidade fluido-elástica. Conjuntamente com a execução da parte experimental devem-se validar os resultados obtidos por outros pesquisadores e comparar com os modelos teóricos adequados.

- Estudar a resposta vibratória do tubo instrumentado baixo diferentes escoamentos bifásicos caracterizados pela sua fração de vazio e seu tipo de padrão. Repetir o cálculo do amortecimento usando um número maior de medições e validar a tendência achada nos trabalhos anteriores.

- Estudar a natureza e características da força induzida por escoamentos bifásicos. Esta abordagem pode ser feita através das técnicas de Análise Modal Operacional (Operational Modal Analysis - OMA). Além disso, relacionar os resultados obtidos com parâmetros do escoamento como: fração de vazio, velocidade e tipo de padrão de escoamento. Depois de caracterizada a força, reproduzir a resposta experimental do tubo com a modelagem teórica e comparar resultados. 


\section{Referências Bibliográficas}

AXISA, F.; ANTUNES, J.; B., V. Random excitation of heat exchanger tubes by cross flow. In: 1988 Symposium on Flow-Induced Vibration and Noise. [S.1.: s.n.], 1988.

AXISA, F.; ANTUNES, J.; VILLARD, B. Random excitation of heat exchanger tubes by cross-flows. Journal of Fluids and Structures, v. 4, p. 321 - 341, 1990.

BALSA, T. F. Potential flow interactions in an array of cylinders in cross-flow. Journal of Sound and Vibration, v. 96, p. 263-267, 1977.

BARNETT, K. M.; CERMAK, J. E. Turbulence Induced Changes in Vortex Shedding from a Circular Cylinder. [S.1.], 1974.

BEARMAN, P. W.; GRAHAM, J. M. R.; OBASAJU, E. D. A model equation for the transverse forces on cylinders in oscillatory flows. Applied Ocean Research, v. 6, p. 166-172, 1984.

BEARMAN, P. W.; HALL, P. F. Dynamic response of circular cylinders in oscillatory flow. In: International Conference on Flow Induced Vibrations. [S.1.: s.n.], 1987.

BLEVINS, R.; GILBERT, R.; VILLARD, B. Experiments on vibration of heat exchanger tube arrays in cross flow. In: Transactions of the 6th International Conference on Structural Mechanics in Reactor Technology (SMIRT), Paper B6/9. [S.1.: s.n.], 1981.

BLEVINS, R. D. Flow-induced vibration in nuclear reactors: a review. Progress in Nuclear Energy, v. 4, p. 25 - 49, 1979.

BLEVINS, R. D. Discussion of 'guidelines for the instability flow velocity of tube arrays in cross flow'. Journal of Sound and Vibration, v. 97, p. 641-644, 1984a.

BLEVINS, R. D. Formulas for Natural Frequency and Mode Shape. [S.1.]: Malabar, 1984b.

BLEVINS, R. D. Flow-Induced Vibration. [S.1.]: Kreiger Publishing Company, 1990.

BUDYNAS, R. G.; NISBETT, J. K. Shigley's Mechanical Engineering Design. [S.1.]:

Raghothaman Srinivasan, 2011.

CENGEL, Y. Heat transfer: A practical approach. [S.1.]: Elizabeth A. Jones, 2003.

CHEN, S. S. A general theory for duynamic instability of tube arrays in cross-flow. Journal of Fluids and Structures, v. 1, p. 35 - 53, 1987.

CHEN, S. S.; JENDRZEJCZYK, J. A.; LIN, W. H. Experiments on Fluid Elastic Instability in Tube Banks Subject to Liquid Cross Flow. [S.1.], 1978.

CHU, I. C. et al. The effect of the flow regime transition on the fluid-elastic instability. Trans. KPVP, v. 1, p. 1, 2005. 
CHUNG, H.; CHU, I. Fluid-elastic instability of rotated square tube array in an air-water two-phase cross-flow. Nuclear Engineering and Technology, v. 38, p. 69-80, 2006.

COLlIER, J. G.; THOME, J. R. Convective Boiling and Condensation. [S.1.]: Oxford University Press, 1994.

CONNORS, H. Fluid-elastic vibration of heat exchanger tube arrays. ASME Journal of Mechanical Design, v. 100, p. 347 - 353, 1978.

CONNORS, H. J. Fluidelastic vibration of tube arrays excited by cross flow. In: Symposium on Flow Induced Vibration in Heat Exchangers ASME Winter Annual Meeting. [S.l.: s.n.], 1970.

CRAIG, R.; KURDILA, A. Fundamentals of Structural Dynamics. [S.1.]: John Wiley \& Sons, Inc., 2006.

FAGE, A.; WARSAP, J. H. The Effects of Turbulence and Durface Rougness on Drag of a Cyircular Cylinder. [S.1.], 1929.

FEENSTRA, P.; WEAVER, D. S.; NAKAMURA, T. Vortex shedding and fluidelastic instability in a normal square tube array excited by two-phase cross-flow. Journal of Fluids and Structures, v. 17, p. 793, 2003.

FITZHUGH, J. S. Flow induced vibration in heat exchangers. In: Proceedings of UKAEA/NPL International Symposium on Vibration Problems in Industry. [S.1.: s.n.], 1973.

GARTSHORE, I. S. Some effects of upstream turbulence on the unsteady lift forces imposed on prismatic two dimensional bodies. Journal of Fluids Engineering, v. 94, p. 87 - 94, 1984.

GRAHAM, J. M. R. Transverse forces on cylinders in random seas. In: International Conference on Flow Induced Vibrations. [S.1.: s.n.], 1987.

GRIFFIN, O. M.; RAMBERG, S. E. The vortex street wakes of vibrating cylinders. Journal of Fluid Mechanics, v. 66, p. 553 - 576, 1974.

GROVER, L. K.; WEAVER, D. S. Cross-flow induced vibrations in a tube bank - vortex shedding. Journal of Sound and Vibration, v. 59, p. 263 - 276, 1978.

HARA, F. Unsteady fluid dynamic forces acting on a single row of cylinders vibrating in a cross flow. Journal of Fluids and Structures, v. 3, p. 97-113, 1989.

KANEKO, S. et al. Flow-Induced Vibrations: Classifications and Lessons from Practical Experiences. [S.1.]: Elsevier, 2008.

KANIZAWA, F. T. Estudo teórico e experimental sobre padrões de escoamento, fração de vazio e perda de pressão durante escoamento bifásico água - ar cruzado ascendente externo a banco de tubos. Descrição da bancada experimental. 2012.

KHALIFA, A. Fluidelastic Instability in Heat Exchanger Tube Arrays. Tese (Doutorado) McMaster University, 2012.

KHALIFA, A.; WEAVER, D.; ZIADA, S. A single flexible tube in rigid array as a model for fluidelastic instability. Journal of Fluids and Structures, v. 34, p. 14 - 32, 2012.

KHUSHNOOD, S. et al. Nuclear Power Plants. [S.1.]: InTech, 2012. 
KHUSHNOOD, S. et al. A review of heat exchanger tube bundle vibrations in two-phase cross-flow. Nuclear Engineering and Design, v. 230, p. 233 - 251, 2004.

KOOPMAN, G. H. The vortex wakes of vibrating cylinders at low reynolds numbers. Journal of Fluid Mechanics, v. 28, p. 501 - 512, 1967.

LEVER, J. H.; WEAVER, D. S. A theoretical model for fluid elastic instability heat exchanger tube bundles. Journal of Pressure Vessel Techonology, v. 104, p. 147-158, 1982.

LIENHARD, J. H. Synopsis of Lift, Drag and Vortex Frequency Data for Rigid Circular Cylinders. [S.1.], 1966.

LIN, T.-k.; YU, M.-h. An experimental study in the cross-flow vibration of a flexible cylinder in cylinder arrays. Experimental Thermal and Fluid Science, v. 29, p. 523 - 536, 2005.

ÁLVAREZ, R. et al. Design and analysis of a dynamic structure for the study of multiphase flow induced vibration. In: 22nd International Congress of Mechanical Engineering (COBEM). [S.1.: s.n.], 2013.

MAIA, N.; SILVA, J. Theoretical and Experimental Modal Analysis. [S.1.]: Research Studies Press LTD., 1998.

MITRA, D.; DHIR, V. K.; CATTON, I. Fluid-elastic instability in tube arrays subjected to air water and steam-water cross-flow. Journal of Fluids and Structures, v. 25, p. 1213 - 1235, 2009.

MUREITHI, N. W. et al. Fluidelastic instability tests on an array of tubes preferentially flexible in the flow direction. Journal of Fluid and Structures, v. 21, p. 75 - 87, 2005.

NAKAMURA, T. et al. Study on the vibrational characteristics of a tube array caused by two-phase flow. part i: Random vibration. Journal of Fluids and Structures, v. 9, p. 519 - 538, 1995.

NAKAMURA, T. et al. Study on the vibrational characteristics of a tube array caused by two-phase flow. part ii: Fluidelastic vibration. Journal of Fluids and Structures, v. 9, p. 539 $562,1995$.

NAKAMURA, T.; HIROTA, K.; TOMOMATSU, K. Some problems on the estimation of flow-induced vibration of a tube array subjected to two-phase flow. In: Proceedings of FIV-2000. [S.1.: s.n.], 2000.

NAKAMURA, T.; MUREITHI, M.; CHEN, S. Fluid-elastic instability threshold for tube arrays in two-phase flow: a model incorporating temporal fluid force correction along the tube axis. In: Proceeding of ASME Winter Annual Meeting, A.D. [S.1.: s.n.], 1997.

NOGHREHKAR, G. R.; KAWAJI, M.; CHAN, A. M. C. Investigation of two-phase flow regimes in tube bundles under cross-flow conditions. International Journal of Multiphase Flow, v. 25, p. $857-874,1999$.

OBASAJU, E. D.; BEARMAN, P. W.; GRAHAM, J. M. A study of forces circulation and vortex patterns around a circular cylinder in oscillating flow. Journal of Fluid Mechanics, v. 196, p. 467-494, 1988. 
OLINGER, D. J.; SREENIVASAN, K. R. Nonlinear dynamics of the wake of an oscillating cylinder. Physical Review Letters, v. 60, p. 797 - 800, 1988.

PAIDOUSSIS, M. P.; MAVRIPLIS, D.; PRICE, S. J. A potential flow theory for the dynamics of cylinder arrays in cross flow. Journal of Fluid Mechanics, v. 146, p. 227-252, 1984.

PETTIGREW, M. et al. Vibration behavior of rotated triangular tube bundles in two-phase cross flow. ASME Journal of Pressure Vessel Technology, v. 124, p. 144-153, 2002.

PETTIGREW, M. et al. Vibration of tube bundles in two-phase cross-flow: Part 2: Fluid-elastic instability. ASME Journal of Pressure Vessel Technology, v. 111, p. 478 - 487, 1989.

PETTIGREW, M.; TROMP, J. H.; MASTORAKOS, J. Vibration of tube bundles in two-phase cross-flow. ASME Journal of Pressure Vessel Technology, v. 107, p. 335 - 343, 1985.

PETTIGREW, M. J. et al. Flow-induced vibration and related technologies in nuclear components. Nuclear Engineering and Design, v. 131, p. 81 - 100, 1991.

PETTIGREW, M. J.; TAYLOR, C.; KIM, B. Vibration of tube bundles in two-phase cross-flow: Part 1 - hydrodynamic mass and damping. ASME Journal of Pressure Vessel Technology, v. 111, p. $466,1989$.

PETTIGREW, M. J.; TAYLOR, C. E. Fluidelastic instability of heat exchanger tube bundles: Review and design recommendations. ASME Journal of Pressure Vessel Technology, v. 113, p. 242-256, 1991.

PETTIGREW, M. J.; TAYLOR, C. E. Vibration analysis of shell-and-tube heat exchangers: an overview - part 1: flow, damping, fluidelastic instability. Journal of Fluids and Structures, v. 18, p. $469-483,2003$.

PETTIGREW, M. J.; TAYLOR, C. E.; KIM, B. S. The effects of bundle geometry on heat exchanger tube vibration in two-phase cross flow. Journal of Pressure Vessel Technology, v. 123 , p. $414-420,2001$.

PIERSOL, A.; PAEZ, T. Harris' Shock and Vibration Handbook. [S.1.]: McGrawHill, 2010.

PRICE, S. J. et al. The flow-induced vibration of a single flexible cylinder in a rotated square array of rigid cylinders with pitch-to-diameter ratio of 2.12. Journal of Fluids and Structures, v. 1 , p. $359-378,1987$.

PRICE, S. J.; PAIDOUSSIS, M. P. A single flexible cylinder analysis for the fluidelastic instability of an array of flexible cylinders in cross-flow. Journal of Fluids Engineering, v. 108, p. 193-199, 1986.

PRICE, S. J.; VALERIO, N. R. A nonlinear investigation of cylinder arrays in cross flow. American Society of Mechanical Engineers, v. 154, p. 1-10, 1989.

ROBERTS, B. W. Low Frequency, Aerolastic Vibrations in a Cascade of Cylinders. Dissertação (Mestrado) — Institution of Mechanical Engineers, 1966.

SASAKAWA, T.; SERIKAWA, A.; KAWARA, Z. Fluid-elastic vibration in two-phase cross flow. Experimental Thermal and Fluid Sience, v. 29, p. 403 - 413, 2005. 
SKOP, R. A.; GRIFFIN, O. M.; RAMBERG, S. E. Strumming predictions for the seacon ii experimental mooring. In: Offshore Technology Conference. [S.1.: s.n.], 1977.

SOPER, B. M. H. The effect of tube layout on the fluid elastic instability of tube bundles in cross flow. Journal of Heat Transfer, v. 105, p. 744-750, 1983.

STANSBY, P. K. The locking-on of vortex shedding due to cross stream vibration of circular cylinders in uniform and shear flows. Journal of Fluid Mechanics, v. 74, p. 641 - 665, 1976.

TANAKA, H.; TAKAHARA, S. Fluid elastic vibration of tube array in cross flow. Journal of Sound and Vibration, v. 77, p. 19-37, 1981.

TANAKA, H.; TANAKA, K.; SHIMIZU, F. Fluidelastic analysis of tube bundle vibration in cross-flow. Journal of Fluid and Structures, v. 16, p. 93 - 112, 2002.

TAYLOR, C. E. et al. Vibration of tube bundles in two-phase freon cross-flow: Part 3 turbulence - induced excitation. ASME Journal of Pressure Vessel Technology, v. 111, p. 488, 1989.

TOEBES, G. H. The unsteady flow and wake near an oscillating cylinder. ASME Journal of Basic Engineering, v. 91, p. 493 - 502, 1969.

TORUM, A.; ANAND, N. M. Free span vibrations of submarine pipelines in steady flows-effect of free-stream turbulence on mean drag coefficients. Journal of Energy Resources Technology, v. 107, p. $415-420,1985$.

ULBRICH, R.; MEWES, D. Vertical, upward gas-liquid two-phase flow across a tube bundle. International Journal Of Multiphase Flow, v. 20, p. 249 - 272, 1994.

VANDIVER, J. K. Drag coefficients of long-flexible cylinders. In: Offshore Technology Conference. [S.1.: s.n.], 1983.

WEAVER, D.; YEUNG, H. Approach flow direction effects on the cross flow induced vibrations of a square array of tubes. Journal of Sound and Vibration, v. 87, p. 469-482, 1983.

WEAVER, D. S.; EL-KASHLAN, M. The effects of damping and mass ratio on the stability of a tube bank. Journal of Sound and Vibration, v. 76, p. 283-294, 1981.

ZUKAUSKAS, A.; ULINSKAS, R. Single - Phase Fluid Flow: Banks of Plain and Finned Tubes. [S.1.]: Washington Hemisphere Publishing, 1983. 